OAK RIDGE

NATIONAL

LABORATORY

LocknEED matrit7

\section{Strength and Fatigue of NT551 Silicon Nitride and NT551 Diesel Exhaust Valves}

February 2000

M. J. Andrews

A. A. Wereszczak

T.P. Kirkland

K. Breder 

Strength and Fatigue of NT551 Silicon Nitride and NT551 Diesel Exhaust Valves

M. J. Andrews, ${ }^{1,2}$ A. A. Wereszczak, ${ }^{2,3}$ T. P. Kirkland, ${ }^{4}$ and K. Breder ${ }^{4,5}$ Mechanical Characterization and Analysis Group

High Temperature Materials Laboratory

Oak Ridge National Laboratory

Oak Ridge, TN 37831-6069

\author{
Prepared for the \\ Advanced Automotive Technologies and the \\ Heavy Vehicle Propulsion System Materials Programs \\ Office of Transportation Technologies \\ Assistant Secretary for Energy Efficiency and Renewable Energy \\ U.S. Department of Energy \\ EE0702000 and EE0701000
}

Prepared by the

OAK RIDGE NATIONAL LABORATORY

Oak Ridge, Tennessee 37831-6285

managed by

LOCKHEED MARTIN ENERGY RESEARCH CORP.

for the

U.S. DEPARTMENT OF ENERGY

under contract DE-AC05-96OR22464

1 Now with U.S. Department of Energy, Albuquerque Operations, Albuquerque, NM.

2 Principal investigator.

3 Author for correspondence (wereszczakaa@oml.gov).

4 Contributing investigator.

5 Now with Norton Company, Worcester, MA. 


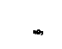




\section{Executive Summary}

The inert strength and fatigue performance of a diesel engine exhaust valve made from silicon nitride $\left(\mathrm{Si}_{3} \mathrm{~N}_{4}\right)$ ceramic were assessed. The $\mathrm{Si}_{3} \mathrm{~N}_{4}$ characterized in this study was manufactured by Saint Gobain / Norton Industrial Ceramics and was designated as NT551. The evaluation was performed utilizing a probabilistic life prediction algorithm that combined censored test specimen strength data with a Weibull distribution function and the stress field of the ceramic valve obtained from finite element analysis. The major assumptions of the life prediction algorithm are that the bulk ceramic material is isotropic and homogeneous and that the strength-limiting flaws are uniformly distributed.

The results from mechanical testing indicated that NT551 was not a homogeneous ceramic and that its strength was a function of temperature, loading rate, and machining orientation.

Fractographic analysis identified four different failure modes; 2 were identified as inhomogeneities that were located throughout the bulk of NT551 and were due to processing operations. The fractographic analysis concluded that the strength degradation of NT551 observed from the temperature and loading rate test parameters was due to a change of state that occurred in its secondary phase.

Pristine and engine-tested valves made from NT551 were loaded to failure and the inert strengths were obtained. Fractographic analysis of the valves identified the same four failure mechanisms as found with the test specimens.

The fatigue performance and the inert strength of the $\mathrm{Si}_{3} \mathrm{~N}_{4}$ valves were assessed from censored and uncensored test specimen strength data, respectively. The inert strength failure probability predictions were compared to the inert strength of the $\mathrm{Si}_{3} \mathrm{~N}_{4}$ valves. 
The inert strength failure probability predictions were more conservative than the strength of the valves. The lack of correlation between predicted and actual valve strength was due to the nonuniform distribution of inhomogeneities present in NT551. For the same reasons, the predicted and actual fatigue performance did not correlate well.

The results of this study should not be considered a limitation of the life prediction algorithm but emphasize the requirement that ceramics be homogeneous and strength-limiting flaws uniformly distributed as a prerequisite for accurate life prediction and reliability analyses. 


\section{TABLE OF CONTENTS}

Page

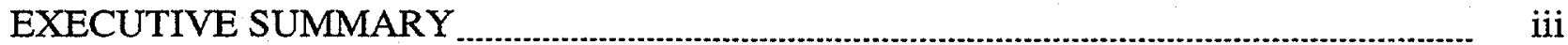

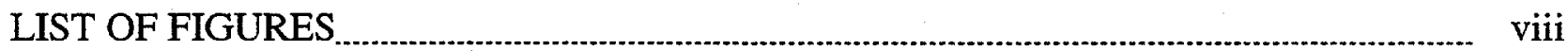

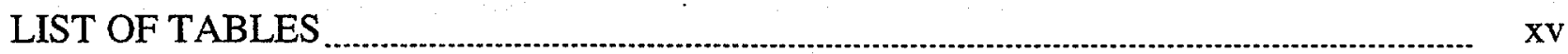

NOMENCLATURE

1. INTRODUCTION

2. BACKGROUND

2.1 Ceramic Materials for Internal Combustion Engine Components........................... 5

2.2 Fracture Mechanics Failure Criteria and Life Prediction Algorithms........................ 9

2.3 Results and Limitations of Previous Life Prediction Studies .................................... 13

3. OBJECTIVES OF THIS RESEARCH

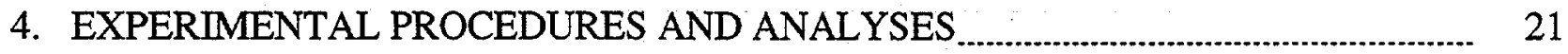

4.1 Description, Material Properties, and Preparation of NT551 Silicon Nitride _............ 21

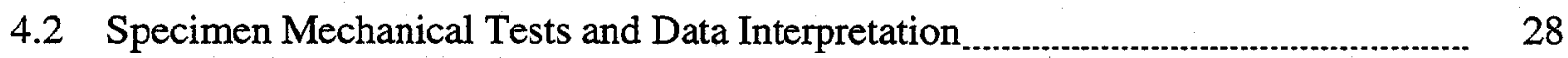

4.2.1 Strength Testing Procedures and Facilities

4.2.2 Fatigue Testing Procedures and Facilities ............................................. $\quad 32$

4.2.3 Fractographic Facilities and Censoring Procedures ................................... $\quad 35$

4.2.4 Statistical Analysis Procedures

4.3 Valve Mechanical Tests and Data Interpretation _................................................. 42

4.3.1 Strength Testing Procedures and Facilities _............................................. $\quad 42$

4.3.2Fractographic and Censoring Procedures .............................................. 45

4.4 Supplemental Testing and Analyses ................................................................... 45

4.4.1 Finite Element Modeling

4.4.2 Fracture Toughness

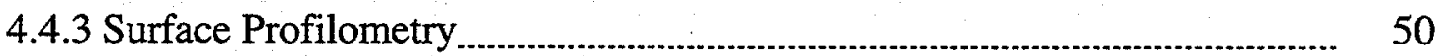


5. RESULTS _ 51

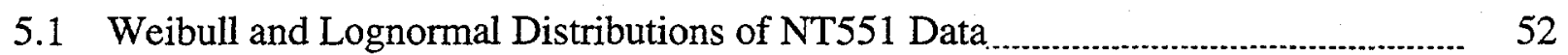

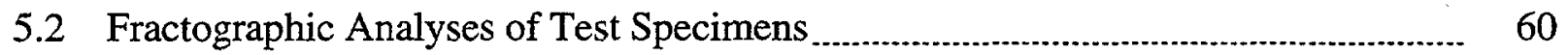

5.2.1 Overview of NT551 Specimen Flaw Populations _................................. $\quad 60$

5.2.2 Fractography of Test Specimens................................................................ 65

5.2.2.1 Surface-Induced Failure from Machining Damage (SUR1-MD, SUR2-MD) .................................................... 65

5.2.2.2 Volume-Induced Failure from Compositional Inhomogeneity

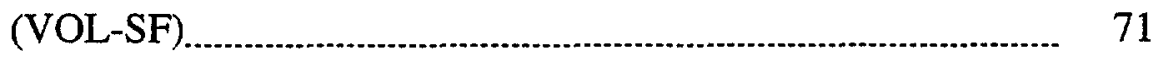

5.2.2.3 Volume-Induced Failure from Agglomerates (VOL-AGG)_..... 73

5.2.2.4 Unknown Failure Types $\ldots$

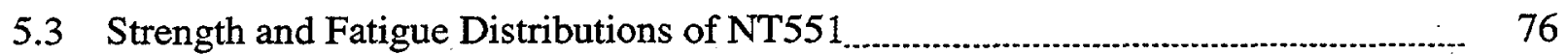

5.3.1 Transversely Machined ASTM C 1161-B Flexure Bars _._....................... $\quad 76$

5.3.1.1 Uncensored Weibull Distributions ....................................... 76

5.3.1.2 Weibull Distributions with Censored Strength Data................. 82

5.3.2 Longitudinally Machined ASTM C 1161-B Flexure Bars__......................... 95

5.3.2.1 Uncensored Weibull Distributions ......................................... 95

5.3.2.2 Weibull Distributions with Censored Strength Data.................. 96

5.3.3 Machining Orientation and Strength for ASTM C 1161-B Flexure

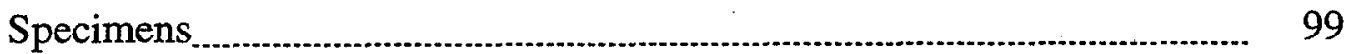

5.3.4 Cylindrical Flexure Specimens

5.3.5 Modified ORNL Tension Specimens

5.3.5.1 Uncensored Weibull Distributions .............................................. 106

5.3.5.2 Weibull Distributions with Censored Strength Data_............. 106

5.3.6 Dynamic Fatigue Test Results

5.4 Supporting Tests and Analyses

5.4.1 Finite Element Modeling of Diesel Exhaust Valve

5.4.2 Finite Element Analysis of a Cylinder in Four-Point Flexure _.................. 115

5.4.3 Fracture Toughness and Other Material Properties ................................. 117

5.4.4 Surface Profilometry ................................................................. 120

5.5 Measured and Predicted Strength Distributions of NT551 Valves _........................ 124

5.5.1 Fractography of S149 Diesel Exhaust Valves..................................... 124

5.5.2 Inert Strength of As-Received Valves .............................................. 130

5.5.3 Retained Strength of Engine-Tested Valves

5.5.4 Predicted Inert Strength Distributions

5.5.5 Predicted Fatigue Performance of S149 Valves _ 138 


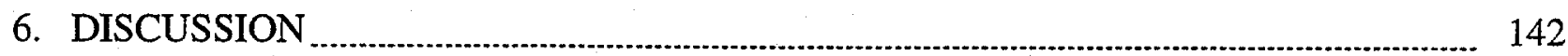

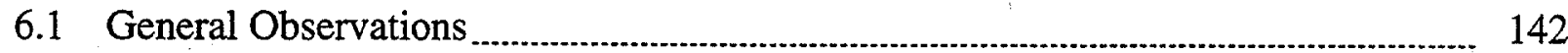

6.2 Material Properties of NT551 .................................................................... 144

6.3 Fractography of NT551

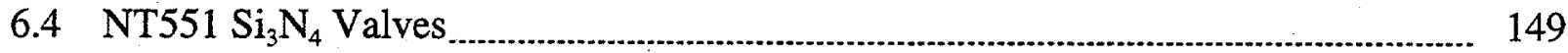

6.5 Life Prediction and Fatigue Performance of NT551 $\mathrm{Si}_{3} \mathrm{~N}_{4}$ Valves _.................... 150

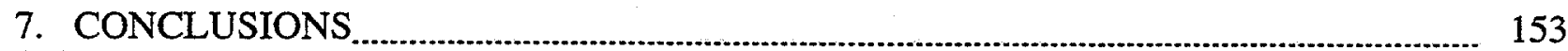

8. SUGGESTIONS FOR FUTURE WORK

REFERENCES

APPENDIX A

APPENDIX B 


\section{LIST OF FIGURES}

Figure $\quad$ Page

4.1 NT551 microstructure.

4.2 NT551 material in the as-received state before machining......................... 24

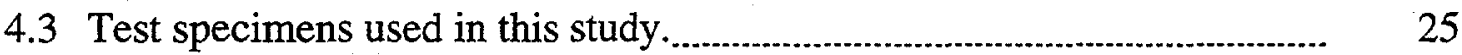

4.4 Centerless machining schematic used for cylindrical flexure specimens... $\quad 26$

4.5 Polished end of a ASTM C 1161-B flexure bar after machining showing dark reaction layer region and material inhomogeneities.

4.6 Cross-sectional view of NT551 cylindrical stock showing dark reaction layer.

4.7 Transversely machined valve fillet radius region showing white snowflake-like areas.

4.8 Flexure Test System at ORNL High Temperature Materials Laboratory...

4.9 Four-point flexure fixture made of $\alpha-S i C$ with ASTM C 1161-B flexure specimen mounted.

4.10 (a) Characteristic patterns found from brittle failure. The strength limiting flaw was located at or very near the surface. (b) Actual fracture surface of ASTM C 1161-B flexure bar 29-25-7.

4.11 Flow chart of life prediction algorithm used in this study.

4.12 Hydraulic test facility for testing NT551 valves.

4.13 Installing valve with elastomeric seal into high pressure hydraulic chamber.

4.14 Chevron v notch dimensions.

4.15 Examples of stable and unstable crack growth from chevron v notch load displacement data.

5.1 ASTM C 1161-B flexure data as a Weibull distribution.

5.2 ASTM C 1161-B flexure data as a log normal distribution.

5.3 Cylindrical flexure data as a Weibull distribution.

5.4 Cylindrical flexure data as a lognormal distribution.

5.5 ASTM C 1161-B flexure data as a Weibull distribution probabilityprobability plot.

5.6 ASTM C 1161-B flexure data as a lognormal distribution probabilityprobability plot. 
5.7 Cylindrical flexure data as a Weibull distribution probability-probability plot.

5.8 Cylindrical flexure data as a lognormal distribution probabilityprobability plot.

5.9 Weibull density function using ASTM C 1161-B flexure data.

5.10 Lognormal density function using ASTM C1161-B flexure data.

5.11 Weibull density function using cylindrical flexure data.

5.12 Lognormal density function using cylindrical flexure data.

5.13 Optical micrograph of ASTM C 1161-B polished flexure bar showing regions of snowflakes.

5.14 Representative NT551 microstructure (polished and plasma etched).

5.15 NT551 microstructure within snowflake region. Arrows point to locations in the secondary phase where preferential polishing had occurred.

5.16 Elemental mapping of VOL-SF region. Images (a) and (b) are overall views while (c) through (h) present aluminum, yttrium, neodymium, nitrogen, oxygen, and silicon, respectively.

5.17 ASTM C 1161-B flexure specimen fracture and corresponding tensile surfaces. Failure from machining damage (SUR1-MD). $\sigma_{\mathrm{f}}=509 \mathrm{MPa}$...

5.18. Detail of Figure 5.17 showing the remains of the machining groove where failure initiated.

5.19 ASTM C 1161-B flexure specimen fracture and corresponding tensile surfaces. Failure from machining damage (SUR1-MD). $\sigma_{\mathrm{f}}=489 \mathrm{MPa}$..

5.20 Detail of Figure 5.19 showing the remains of the machining groove where failure initiated.

5.21 Fracture and corresponding tensile surfaces from FF-29 cylindrical specimen. Failure from machining damage (SUR2-MD). $\sigma_{\mathrm{f}}=633 \mathrm{MPa}$.

5.22 Detail of Figure 5.21 showing the machining groove where failure initiated.

5.23 Fracture and corresponding tensile surfaces for SF-17 cylindrical specimen. Failure from machining damage (SUR2-MD). $\sigma_{\mathrm{f}}=496 \mathrm{MPa}$.

5.24 Detail of Figure 5.23 cylindrical specimen fracture surface. Failure from machining damage (SUR2-MD).

5.25 Detail of cylindrical specimen failure surface showing evidence of microcracking below machined surface. $\sigma_{\mathrm{f}}=500 \mathrm{MPa}$. 
5.26 ASTM C 1161-B transversely machined flexure specimen fracture and corresponding tensile surfaces. Failure due to white snowflake regions (VOL-SF). $\sigma_{\mathrm{f}}=647 \mathrm{MPa}$.

5.27 ASTM C 1161-B longitudinally machined flexure specimen fracture and corresponding tensile surfaces. Failure due to white snowflake regions (VOL-SF). $\sigma_{\mathrm{f}}=1128 \mathrm{MPa}$.

5.28 ASTM C 1161-B longitudinally machined flexure specimen fracture and corresponding tensile surfaces. Specimen failure from an agglomerate (VOL-AGG). $\sigma_{\mathrm{f}}=773 \mathrm{MPa}$.

5.29 Detail of an agglomerate failure origin from a modified ORNL tension specimen (VOL-AGG). $\sigma_{\mathrm{f}}=714 \mathrm{MPa}$.

5.30 Unknown failure from an ASTM C 1161-B specimen. $\sigma_{\mathrm{f}}=224 \mathrm{MPa}$...... 75

5.31 Unknown failure type from ASTM C 1161-B flexure specimen. $\sigma_{\mathrm{f}}=527 \mathrm{MPa}$.

5.32 Temperature and load rate dependence of the Weibull modulus from ASTM C 1161-B transversely machined flexure specimens with 95\% confidence bounds indicated.

5.33 Temperature and load rate dependence of the Weibull characteristic strength from ASTM C 1161-B transversely machined flexure specimens with $95 \%$ confidence bounds indicated.

5.34 Load rate dependence of NT551 at $20^{\circ} \mathrm{C}$ from ASTM C 1161-B flexure bars.

5.35 Load rate dependence of NT551 at $700^{\circ} \mathrm{C}$ from ASTM C 1161-B flexure bars.

5.36 Load rate dependence of NT551 at $850^{\circ} \mathrm{C}$ from ASTM C 1161-B flexure bars.

5.37 Temperature dependence of NT551 at $36 \mathrm{~N} / \mathrm{s}$ load rate for ASTM C 1161-B flexure bars.

5.38 Temperature dependence of NT551 at $0.36 \mathrm{~N} / \mathrm{s}$ load rate for ASTM C 1161-B flexure bars.

5.39 Temperature dependence of NT551 at $0.0036 \mathrm{~N} / \mathrm{s}$ load rate for ASTM C 1161-B flexure bars.

5.40 Uncensored Weibull distribution for ASTM C 1161-B flexure specimens at $20^{\circ} \mathrm{C}$ and $36 \mathrm{~N} / \mathrm{s}$ load rate.

5.41 Uncensored Weibull distribution for ASTM C 1161-B flexure specimens at $20^{\circ} \mathrm{C}$ and $0.36 \mathrm{~N} / \mathrm{s}$ load rate. 
5.42 Uncensored Weibull distribution for ASTM C 1161-B flexure specimens at $20^{\circ} \mathrm{C}$ and $0.0036 \mathrm{~N} / \mathrm{s}$ load rate.

5.43 Uncensored Weibull distribution for ASTM C 1161-B flexure specimens tested at $700^{\circ} \mathrm{C}$ and $36 \mathrm{~N} / \mathrm{s}$ load rate.

5.44 Uncensored Weibull distribution for ASTM C 1161-B flexure specimens at $700^{\circ} \mathrm{C}$ and $0.36 \mathrm{~N} / \mathrm{s}$ load rate.

5.45 Uncensored Weibull distribution for ASTM C 1161-B flexure specimens at $700^{\circ} \mathrm{C}$ and $0.0036 \mathrm{~N} / \mathrm{s}$ load rate.

5.46 Uncensored Weibull distribution for ASTM C 1161-B flexure specimens at $850^{\circ} \mathrm{C}$ and $36 \mathrm{~N} / \mathrm{s}$ load rate.

5.47 Uncensored Weibull distribution for ASTM C 1161-B flexure specimens at $850^{\circ} \mathrm{C}$ and $0.36 \mathrm{~N} / \mathrm{s}$ load rate.

5.48 Uncensored Weibull distribution for ASTM C 1161-B flexure specimens at $850^{\circ} \mathrm{C}$ and $0.0036 \mathrm{~N} / \mathrm{s} \mathrm{load}$ rate.

5.49 Temperature dependence for ASTM C 1161-B longitudinally ground flexure bars at $36 \mathrm{~N} / \mathrm{s}$ load rate.

5.50 Uncensored Weibull distribution for ASTM C 1161-B flexure specimens longitudinally machined and tested at $20^{\circ} \mathrm{C}$ and $36 \mathrm{~N} / \mathrm{s}$ load rate.

5.51 Uncensored Weibull distribution for ASTM C 1161-B flexure specimens longitudinally machined and tested at $850^{\circ} \mathrm{C}$ and $36 \mathrm{~N} / \mathrm{s}$ load rate.

5.52 Strength as a function of machining orientation for ASTM C 1161-B flexure bars tested at $20^{\circ} \mathrm{C}$ and $36 \mathrm{~N} / \mathrm{s}$.

5.53 Strength as a function of machining orientation for ASTM C 1161-B flexure bars tested at $850^{\circ} \mathrm{C}$ and $36 \mathrm{~N} / \mathrm{s}$.

5.54 Strength dependence on load rate of cylindrical flexure specimens tested at $20^{\circ} \mathrm{C}$.

5.55 Uncensored Weibull distribution for cylindrical flexure specimens tested at $20^{\circ} \mathrm{C}$ and $14.67 \mathrm{~N} / \mathrm{s}$ load rate.

5.56 Uncensored Weibull distribution for cylindrical flexure specimens tested at $20^{\circ} \mathrm{C}$ and $0.1467 \mathrm{~N} / \mathrm{s}$ load rate.

5.57 Uncensored Weibull distribution for cylindrical flexure specimens tested at $20^{\circ} \mathrm{C}$ and $0.001467 \mathrm{~N} / \mathrm{s}$ load rate.

5.58 Strength dependence on load rate of modified ORNL tension specimens tested at $20^{\circ} \mathrm{C}$.

5.59 Uncensored Weibull distribution for modified tension specimens tested at $20^{\circ} \mathrm{C}$ and $288.6 \mathrm{~N} / \mathrm{s}$ load rate. 
5.60 Uncensored Weibull distribution for modified tension specimens tested at $20^{\circ} \mathrm{C}$ and $2.886 \mathrm{~N} / \mathrm{s}$ load rate.

5.61 Uncensored Weibull distribution for modified tension specimens tested at $20^{\circ} \mathrm{C}$ and $0.02886 \mathrm{~N} / \mathrm{s}$ load rate.

5.62 Summary of the slow crack growth parameter $\mathrm{N}$ with $95 \%$ confidence bounds for three different test specimens and at three test temperatures..

5.63 Slow crack growth regression analysis of ASTM C 1161-B flexure specimens tested at 20,700 , and $850^{\circ} \mathrm{C}$. Values in parenthesis are the $95 \%$ confidence bounds.

5.64 Slow crack growth regression analysis for the modified ORNL tension specimens tested at $20^{\circ} \mathrm{C}$. Values in parenthesis are $95 \%$ confidence bounds.

5.65 Slow crack growth regression analysis for cylindrical flexure specimens tested at $20^{\circ} \mathrm{C}$. Values in parenthesis are $95 \%$ confidence bounds.

5.66 Finite element model of S149 valve using two-dimensional axisymmetric elements. A combustion pressure of $16 \mathrm{MPa}$ is applied to the model. Values in legend are MPa.

5.67 Finite element model of a cylinder in four-point flexure. Stress units are $\mathrm{MPa}$.

5.68 Chevron v-notch fracture surfaces.

5.69 Chevron v-notch tip showing the presence of NT551 material inhomogeneities.

5.70 Surface profilometry of selected test specimens and valves.

5.71 Surface finish from a modified ORNL tension specimen.

5.72 Surface finish from an ASTM C 1161-B transversely machined flexure bar.

5.73 Surface finish from a cylindrical flexure bar.

5.74 Surface finish from a transversely machined valve in the fillet radius region.

5.75 Fillet radius region of a valve taken to failure.

5.76 Fracture mirror and tensile surface of a longitudinally machined valve.

Failure from VOL-SF. $\sigma_{\mathrm{f}}=1013 \mathrm{MPa}$.

5.77 Fracture mirror and tensile surface of a longitudinally machined valve.

Failure from VOL-SF. $\sigma_{\mathrm{f}}=1128 \mathrm{MPa}$.

5.78 Fracture surface and tensile side of a transversely machined valve.

Failure from SUR2-MD. $\sigma_{\mathrm{f}}=668 \mathrm{MPa}$. 
5.79 Fracture surface and tensile surface of a transversely machined valve.

Failure from SUR2-MD. $\sigma_{\mathrm{f}}=623 \mathrm{MPa}$.

5.80 Fracture origin and tensile surface of a transversely machined valve.

Failure from VOL-AGG. $\sigma_{\mathrm{f}}=634 \mathrm{MPa}$.

5.81 Fracture surface of a longitudinally machined valve. Failure from VOL-AGG. $\sigma_{\mathrm{f}}=685 \mathrm{MPa}$.

5.82 Fracture mirror of a longitudinally machined valve that was engine tested for 1000 hours. Arrow points to the fracture origin that is a volume flaw. $\sigma_{\mathrm{f}}=753 \mathrm{MPa}$.

5.83 Fracture surface of a longitudinally machined engine-tested valve $(1000 \mathrm{hr})$. Arrow points to the fracture origin that is a volume flaw. Failure from VOL-SF. $\sigma_{\mathrm{f}}=765 \mathrm{MPa}$.

5.84 Inert strength Weibull distribution of S149 as-received transversely machined valves tested at $20^{\circ} \mathrm{C}$.

5.85 Inert strength Weibull distribution of S149 as-received longitudinally machined valves tested at $20^{\circ} \mathrm{C}$.

5.86 Retained strength Weibull distribution of S149 transversely machined 1000 hour engine tested valves.

5.87 Retained strength Weibull distribution of S149 longitudinally machined 166 hour engine tested valves.

5.88 Inert strength failure probability prediction of S149 valves using ASTM C 1161-B transversely machined flexure specimens.

5.89 Inert strength failure probability prediction of $\$ 149$ valves using ASTM C 1161-B longitudinally machined flexure specimens.

5.90 Inert strength failure probability prediction of S149 valves using cylindrical flexure data.

5.91 Inert strength failure probability prediction of S149 valves using modified ORNL tension data.

5.92 Predicted static fatigue performance of transversely machined S149 valves from ASTM C 1161-B transversely machined flexure specimens tested at $20^{\circ} \mathrm{C}$.

5.93 Predicted static fatigue performance of transversely machined S149 valves from ASTM C 1161-B transversely machined flexure specimens tested at $850^{\circ} \mathrm{C}$.

5.94 Predicted static fatigue performance of transversely machined S149 valves based on cylindrical flexure data generated at $20^{\circ} \mathrm{C}$. 
5.95 Predicted static fatigue performance of transversely machined S149 valves based on modified ORNL tension data generated at $20^{\circ} \mathrm{C}$.

B.1 Energy dispersive spectroscopy of NT551 $\mathrm{Si}_{3} \mathrm{~N}_{4}$.

B.2 Energy dispersive spectroscopy identifying $\mathrm{Al}_{2} \mathrm{O}_{3}, \mathrm{Nd}_{2} \mathrm{O}_{3}$, and $\mathrm{Y}_{2} \mathrm{O}_{3}$ compounds as the secondary phase in NT551. This spectrograph was taken from a "non-snowflake" region where no strength-limiting failure mechanisms were identified.

B.3 Energy dispersive spectroscopy identifying $\mathrm{SiO}_{2}$ as the secondary phase found in NT551. This spectrograph was taken from a "snowflake" region and was identified as strength-limiting failure mechanism. 


\section{LIST OF TABLES}

\section{Table}

Page

2.1 Select material properties of three ceramic materials [Wills, 1988]............. 6

4.1 Materials properties of NT551 provided by SGNIC [Pujari, 1998].............. 25

4.2 Number and type of specimens for inert strength tests of NT551.............. 32

4.3 Test specimen loading rate $(\mathrm{N} / \mathrm{s})$ and corresponding stressing rate 35 $(\mathrm{MPa} / \mathrm{s})$.

4.4 Number and type of specimens for constant stress rate testing.

4.5 Material properties of NT551, valve seat inserts, and load pins (cylindrical in four-point flexure) used for finite element analysis.

5.1 Comparison of three NT551 vintages all tested at $36 \mathrm{~N} / \mathrm{s}$ loading rate and at 20 and $850^{\circ} \mathrm{C}$.

5.2 Number of specimens of each failure type for ASTM C 1161-B transversely machined specimens tested at $20^{\circ} \mathrm{C}$

5.3 Number of specimens of each failure type for ASTM C 1161-B transversely machined specimens tested at $700^{\circ} \mathrm{C}$.

5.4 Number of specimens of each failure type for ASTM C 1161-B transversely machined specimens tested at $850^{\circ} \mathrm{C}$.

5.5 ASTM C 1161-B transversely machined flexure bars at $20^{\circ} \mathrm{C}$ and $36 \mathrm{~N} / \mathrm{s}$. Values in parenthesis are $95 \%$ confidence bounds. Failure distributions are assumed concurrent.

5.6 ASTM C 1161-B transversely machined flexure bars at $20^{\circ} \mathrm{C}$ and $36 \mathrm{~N} / \mathrm{s}$. Values in parenthesis are $95 \%$ confidence bounds. Failure distributions are assumed exclusive.

5.7 ASTM C 1161-B transversely machined flexure bars at $20^{\circ} \mathrm{C}$ and $0.36 \mathrm{~N} / \mathrm{s}$. Values in parenthesis are $95 \%$ confidence bounds.

5.8 ASTM C 1161-B transversely machined flexure bars at $20^{\circ} \mathrm{C}$ and $0.0036 \mathrm{~N} / \mathrm{s}$. Values in parenthesis are $95 \%$ confidence bounds.

5.9 ASTM C $1161-\mathrm{B}$ transversely machined flexure bars at $700^{\circ} \mathrm{C}$ and 36 $\mathrm{N} / \mathrm{s}$. Values in parenthesis are $95 \%$ confidence bounds.

5.10 ASTM C 1161-B transversely machined flexure bars at $700^{\circ} \mathrm{C}$ and $0.36 \mathrm{~N} / \mathrm{s}$. Values in parenthesis are $95 \%$ confidence bounds.

5.11 ASTM C 1161-B transversely machined flexure bars at $700^{\circ} \mathrm{C}$ and $0.0036 \mathrm{~N} / \mathrm{s}$. Values in parenthesis are $95 \%$ confidence bounds. 
5.12 ASTM C 1161-B transversely machined flexure bars at $850^{\circ} \mathrm{C}$ and 36

$\mathrm{N} / \mathrm{s}$. Values in parenthesis are $95 \%$ confidence bounds.

5.13 ASTM C 1161-B transversely machined flexure bars at $850^{\circ} \mathrm{C}$ and $0.36 \mathrm{~N} / \mathrm{s}$. Values in parenthesis are $95 \%$ confidence bounds.

5.14 ASTM C 1161-B transversely machined flexure bars at $850^{\circ} \mathrm{C}$ and $0.0036 \mathrm{~N} / \mathrm{s}$. Values in parenthesis are $95 \%$ confidence bounds.

5.15 Power failure dependence on ASTM C 1161-B transversely machined flexure bars tested at $850^{\circ} \mathrm{C}$ and at $0.0036 \mathrm{~N} / \mathrm{s}$. Values in parenthesis are $95 \%$ confidence bounds.

5.16 ASTM C $1161-\mathrm{B}$ specimens longitudinally machined and tested at $20^{\circ} \mathrm{C}$ and $850^{\circ} \mathrm{C}$. Number of specimens for each flaw type shown.

5.17 ASTM C $1161-B$ longitudinally machined bars at $20^{\circ} \mathrm{C}$ and $36 \mathrm{~N} / \mathrm{s}$. Values in parenthesis are $95 \%$ confidence bounds.

5.18 ASTM C 1161-B longitudinally machined bars at $850^{\circ} \mathrm{C}$ and $36 \mathrm{~N} / \mathrm{s}$. Values in parenthesis are $95 \%$ confidence bounds.

5.19 Cylindrical transversely machined flexure bars tested at $20^{\circ} \mathrm{C}$. Values in parenthesis are $95 \%$ confidence bounds.

5.20 Fractographic results for cylindrical four-point flexure specimen tested at $20^{\circ} \mathrm{C}$. Number of specimens for each flaw shown.

5.21 Cylindrical transversely machined flexure bars tested at $20^{\circ} \mathrm{C}$ and $14.67 \mathrm{~N} / \mathrm{s}$. Values in parenthesis are $95 \%$ confidence bounds.

5.22 Cylindrical transversely machined flexure bars tested at $20^{\circ} \mathrm{C}$ and $0.1467 \mathrm{~N} / \mathrm{s}$. Values in parenthesis are $95 \%$ confidence bounds.

5.23 Cylindrical transversely machined flexure bars tested at $20^{\circ} \mathrm{C}$ and $0.001467 \mathrm{~N} / \mathrm{s}$. Values in parenthesis are $95 \%$ confidence bounds. 105

5.24 Modified ORNL transversely machined tension specimens tested at $20^{\circ} \mathrm{C}$. Values in parenthesis are $95 \%$ confidence bounds.

5.25 Fractographic results for the modified ORNL tension specimens tested at $20^{\circ} \mathrm{C}$. Number of specimens for each flaw shown.

5.26 Modified ORNL transversely machined tension specimens tested at $20^{\circ} \mathrm{C}$ and $288.6 \mathrm{~N} / \mathrm{s}$. Values in parenthesis are $95 \%$ confidence bounds.

5.27 Modified ORNL transversely machined tension specimens tested at $20^{\circ} \mathrm{C}$ and $2.886 \mathrm{~N} / \mathrm{s}$. Values in parenthesis are $95 \%$ confidence bounds.

109

5.28 Modified ORNL transversely machined tension specimens tested at $20^{\circ} \mathrm{C}$ and $0.02886 \mathrm{~N} / \mathrm{s}$. Values in parenthesis are $95 \%$ confidence bounds. 
5.29 ASTM C PS 70 (1998) chevron v notch fracture toughness results at 20, 700 , and $850^{\circ} \mathrm{C}$. Tests conducted in air using a cross-head displacement of $5 \mu \mathrm{m} /$ minute.

5.30 NT551 material properties determined in this study and material properties provided by SGNIC.

5.31 Summary of as-received S149 diesel exhaust valve fractography. Number of valves for each flaw type shown.

5.32 Summary of engine-tested S149 diesel exhaust valve fractography. Number of valves for each flaw type shown. 


\section{NOMENCLATURE}

$A$

ASE

ASTM

$B$

BSE

C

CARES / LIFE

CERAMIC

CRADA

DDC

DOE

E

EDS

EDX

EIA

ERICA

F

FE

$H$

HIP

$I_{V, A, C}$

IC

$K_{I}$

$K_{I C}$.

$L$

LVDT

$M R$

$N$

NT551

ORNL

$P, P_{\max }$

PIA

PSZ

$\mathrm{R}_{\mathrm{a}}$

$S$

SEM
Slow crack growth curve fit parameter

AlliedSignal Engines, Inc.

American Society of Testing and Materials

Width, mm

Backscatter Electron

Shetty's empirical constant

Ceramic Analysis and Reliability Evaluation of Structures

AlliedSignal life prediction computer program

Cooperative Research and Development Agreement

Detroit Diesel Corp.

Department of Energy

Young's Modulus, MPa

Energy Dispersive Spectroscopy

Energy Dispersive X-Ray spectroscopy

Energy Information Agency

AlliedSignal life prediction computer program

Probability of failure function

Finite Element

Cumulative hazard rate function

Hot Isostatic Pressing

Multiaxial and stress gradient factor

Internal Combustion (engine)

Stress intensity factor, MPa $\sqrt{m}$

Mode I fracture toughness, MPa $\sqrt{m}$

Load span, mm, likelihood function

Linear Variable Differential Transducer

Median Rank

Slow crack growth curve fit parameter

Silicon Nitride manufactured by Saint Gobain Norton Industrial Ceramics

Oak Ridge National Laboratory

Force, N

Principle of Independent Action

Partially Stabilized Zirconia

Average surface roughness, $\mu \mathrm{m}$

Probability of survival function

Scanning Electron Microscope 


\begin{tabular}{|c|c|}
\hline SGNIC & Saint Gobain Norton Industrial Ceramics \\
\hline SiAlON & Specific formulation of silicon nitride containing $\mathrm{Si}, \mathrm{Al}, \mathrm{O}$, and $\mathrm{N}$ \\
\hline SUR1-MD & Strength-limiting extrinsic flaw due to machining damage \\
\hline SUR2-MD & Strength-limiting extrinsic flaw due to machining damage \\
\hline$T$ & Random variable (e.g. strength) \\
\hline UNK & Unknown failure type \\
\hline$V$ & Volume, $\mathrm{mm}^{3}$ \\
\hline VOL-AGG & Strength-limiting intrinsic flaw due to an agglomerate \\
\hline VOL-SF & Strength-limiting intrinsic flaw due to compositional inhomogeneity \\
\hline$W$ & Width, mm \\
\hline$Y$ & Fracture mechanics geometric factor \\
\hline$Y^{*}$ & Bluhm's geometry factor for fracture mechanics \\
\hline$a$ & crack length, mm, m \\
\hline $\begin{array}{l}a_{1}, a_{11}, a_{12}, a_{0} \\
b\end{array}$ & $\begin{array}{l}\text { Chevron } \mathrm{v} \text { notch dimensions, } \mathrm{mm} \\
\text { width, } \mathrm{mm}\end{array}$ \\
\hline$f$ & Probability density function \\
\hline$h$ & Hazard or failure rate function \\
\hline$h$ & height, mm \\
\hline$k$ & Load factor (same as multiaxial and stress gradient factor, I) \\
\hline$l_{l}, l_{2}$ & Inner and outer load span dimensions, $\mathrm{mm}$ \\
\hline$m$ & Weibull shape parameter (modulus) \\
\hline$m_{a}$ & Degrees of freedom \\
\hline$p$ & Probability of failure at a specific stress level \\
\hline$r$ & Radius, $\mathrm{mm}$ \\
\hline $\mathrm{rpm}$ & Revolutions per minute \\
\hline rst & ANSYSTM binary stress results file extension \\
\hline$t$ & Specific value of random variable, $T$ \\
\hline$t_{f}$ & Time to failure, seconds \\
\hline$x_{i}$ & Failure stress, $\mathrm{MPa}$ \\
\hline$\Phi$ & Normal distribution function \\
\hline$\alpha$ & $\begin{array}{l}\text { Alpha material composition, failure probability } \\
\text { confidence region }\end{array}$ \\
\hline$\theta$ & $\begin{array}{l}\text { Polar coordinate integration variable, } \\
\text { standard deviation }\end{array}$ \\
\hline$\mu$ & Mean or average value \\
\hline$v$ & Poisson's ratio \\
\hline$\sigma_{i}$ & Inert strength, $\mathrm{MPa}$ \\
\hline$\sigma_{f}$ & Failure strength, MPa \\
\hline
\end{tabular}




$\begin{array}{ll}\sigma_{E} & \text { Equivalent strength, } \mathrm{MPa} \\ \sigma_{\max } & \text { Maximum stress, } \mathrm{MPa} \\ \sigma_{N} & \text { Normal stress, } \mathrm{MPa} \\ \sigma_{O V} & \text { Weibull scale parameter, volume, } \mathrm{MPa} \mathrm{mm} \\ \sigma_{O \mathrm{~A}} & \text { Weibull scale parameter, surface, } \mathrm{MPa} \mathrm{mm} \\ \sigma_{O C} & \text { Weibull scale parameter, edge, } \mathrm{MPa} \mathrm{mm} \\ \sigma_{\theta} & \text { Weibull characteristic strength, } \mathrm{MPa} \\ \sigma_{\tau} & \text { Shear stress, } \mathrm{MPa}\end{array}$




\section{INTRODUCTION}

The content of this report is excerpted from Mark Andrew's Ph.D. Thesis (Andrews, 1999), which was funded by a DOE/OTT High Temperature Materials Laboratory Graduate Fellowship. It involves the characterization of NT551 and valves fabricated with it. Greater detail of the described issues may be found in that reference or through communications with Andrew Wereszczak (wereszczakaa@ornl.gov).

The motivations behind using silicon nitride $\left(\mathrm{Si}_{3} \mathrm{~N}_{4}\right)$ as an exhaust valve for a diesel engine are presented in this section. There are several economic factors that have encouraged the design and implementation of ceramic components for internal combustion (IC) engines. The reasons for selecting the diesel engine valve for this study are also presented.

The Energy Information Administration (EIA, 1998) within the U.S. Department of Energy (DOE) has reported in its publication, Annual Energy Review, 1998 (1998) that American consumption of petroleum products has increased over the last 15 years and has become more dependent on foreign oil imports. The Annual Energy Review, 1998 (1998) publication estimated that the total net import of petroleum products from foreign lands as a percentage of consumption in the United States was 51\%. To put this into perspective, during the oil crises of 1973 and 1978, the total net import as a percentage of U.S. consumption was 35 and $46 \%$, respectively. The EIA using its National Energy Modeling System projects that by the year 2020, the US petroleum consumption met by net imports might rise as high as $71 \%$.

The Annual Energy Review, 1998 (1998) publication states that usage of petroleum products for transportation purposes (e.g. gasoline, diesel, and aviation fuels) constitutes approximately $62 \%$ of the total U.S. petroleum consumption. The so-called greenhouse gases (carbon dioxide, methane, and nitrous oxide) resulting from the combustion of petroleum products are considered to have an adverse effect on human health and the environment. The Annual Energy Review, 1998 estimates that approximately 5.5 billion tons of carbon dioxide was emitted in 1977, an increase of $1.5 \%$ from the previous year, and $20 \%$ higher than emitted in 1985 . In the transportation energy sector, the release of carbon dioxide and other greenhouse gases principally comes from the consumption of gasoline and diesel fuel for motor vehicles and jet fuels for aviation travel. The Annual Energy Review, 1998 projects that by the year 2020, the carbon dioxide emissions could reach 7.3 billion metric tons, an increase of approximately 33\% over the 1997 emission level. It is anticipated that due to these emission increases, the U.S. Environmental Protection Agency will respond with more stringent motor vehicle emission standards. 
In 1982 a survey funded by the DOE and conducted by Johnson et al. from the Argonne National Laboratory (ANL) concluded that the implementation of advanced ceramic materials in the automotive industry would substantially increase the economic growth in the United States. The "ceramic fever" that ensued in the mid 1980's was abated when the ceramic performance expectations from this survey were not achieved.

In 1988 the DOE through ANL contracted Larsen and Vyas to update the 1982 survey. This study refined its objectives and focused on estimating future projections of the ceramic marketplace and timing in order for government and industry to make more informed decisions in the development of engineered ceramic technologies.

Ceramic experts worldwide were interviewed on the current and future ceramic market size, benefits of developing and using this technology, the restrictions that exist for implementation, and global competitiveness.

In the 1988 survey it was forecasted that by $1993,1 \%$ of the market share would include ceramic valves for heavy-duty diesel engines and by $1995,1 \%$ of the market share would include ceramic valves for light-duty gasoline engines. The common technology barriers mentioned from the survey were that ceramics have unproved reliability and durability, inadequate and undeveloped nondestructive evaluation methods, and limited knowledge base for developing a ceramic design methodology for structural applications.

The automobile manufacturers in the 1988 survey stated that a major barrier to the development of ceramics for engine applications was that the current requirement of conducting inspections for every ceramic component would be unacceptable from a manufacturing cost standpoint. Alternative statistical methodologies would have to be developed and employed.

The respondents of the 1988 survey indicated that the success of ceramics for IC engines would come from a market pull driven by consumers rather than from a market push by industry. Engine manufacturers and ultimately consumers must be convinced that ceramic components would greatly enhance the vehicle's performance and reliability and thus be worth the additional expense. Otherwise, the deciding factor for vehicle options would be cost. The automobile market demand is a function of the selling price of the vehicle, and that is directly related to manufacturing costs. Lowering manufacturing cost and demonstrating higher vehicle reliability from ceramic engine components would create the needed consumer market pull for the ceramic industry.

Another survey entitled An Assessment of the Benefits of Ceramics in Automotive and Truck Engines (1993) was funded by the DOE through the Oak Ridge National Laboratory (ORNL) and conducted by the Automotive Consulting Group Inc. (ACG). The ACG survey had similar objectives as the previously conducted 1988 survey by ANL. The survey interviewed ceramic experts, engineers, and executives in only the United States, assessing the potential market of 
advanced ceramic materials in the automotive field. The objective of the ACG study was to identify the benefits and barriers of ceramics for use in gasoline and diesel engines, which engine components are the best candidates for structural ceramics, and what impact the marketplace might have when ceramic manufacturing costs are reduced. This information would assist the ceramic technology community in making prudent research and development decisions and setting realistic short and long term program goals.

The 1993 ACG survey stated that a significant portion of the country's economy derives from the U.S. automotive industry. Increased government regulation in the form of higher air quality standards have brought about the development of new technologies to meet the regulatory demand. The future of the automotive field will undoubtedly continue to address these regulations and rely on additional technologies, such as ceramics, being developed and implemented.

Because of the large volume produced each year, light-duty powered vehicles are essentially designed for one-time-use with little emphasis for engine rebuilding. Replacing the engine at the end of its service life is more economical than rebuilding the engine. The primary criteria for implementing ceramics in light-duty engines are achieving low cost and high reliability for ceramic components.

Heavy-duty engines are designed for rebuilding due to the small production output and large capital investment. Excessive wear and corrosion of metal components require diesel engines to be serviced several times over their expected lifetimes. In this case, rebuilding the diesel engine is more economical than replacement. Alternate materials having better corrosion and wear resistance are sought for the heavy-duty engine components. Note that the primary criteria for implementing ceramic components in heavy-duty engines differs from that of the light-duty engine manufacturers.

The potential diesel engine components identified by the respondents of the 1993 ACG survey were the cam roller follower, intake and exhaust valves, turbocharger rotor, exhaust port liner, and piston. The response from the survey indicated that $\mathrm{Si}_{3} \mathrm{~N}_{4}$ was the material of choice for four of the five ceramic components listed above.

The top five benefits identified from the 1993 ACG survey by using ceramics for diesel engine components were excellent wear resistance, favorable thermal properties, improved emissions, high resistance to corrosion, and greater fuel efficiency. The top five barriers identified from the 1993 ACG survey for designing ceramic components for diesel engines were high manufacturing costs, manufacturability of ceramics in the industry, limited supply of ceramic vendors, inherent brittleness of ceramics, and the ability to produce reliable, quality products. 
Another assessment of previously taken 1988 survey data was made in 1995 (Vyas et al., 1995). An multi-generation adoption-and-substitution economic model defined by Norman and Bass (1987), and later modified by Speece and McLachlan (1992), was used to estimate the energy savings and the reduction of emissions from the implementation of ceramic components in gasoline and diesel engines. The Vyas et al. 1995 study made the following conclusions:

1) The cost of ceramic components is the largest deterrent for their implementation into the automotive industry as engine components.

2) The ceramic technologies will assist diesel engine manufacturers to meet upcoming stringent emission standards.

3) The projected savings after 10 years from the introduction of ceramic engine components would be $\$ 292$ million.

4) Approximately 526 trillion Btu of energy would be saved annually during the 20th year after introduction of ceramic engine components in the marketplace.

5) The Gross Domestic Product would increase by $\$ 10-17$ billion within 25 years of introduction of ceramic engine components in the marketplace.

The Vyas et al. study determined that the ceramic valve would contribute the largest benefit in the forms of fuel efficiency and reduced emissions when compared to the other ceramic engine components in the study.

The manufacturers of commercial diesel engines such as Detroit Diesel Corp. (DDC), Cummins Inc., and Caterpillar Inc. have been conducting research in order to reduce the frequent maintenance services presently required for diesel engines. Valve wear and corrosion and subsequent valve seat insert guttering is a major problem that is typically solved by frequently rebuilding the diesel engine. The current metal valves and seat inserts have been known to require maintenance after running for just 300 hours. Significant savings in the form of fewer maintenance rebuilds would be realized if a more wear and corrosion resistant valve and seat insert system for diesel engines were available. Many ceramic materials are known to have excellent corrosion and wear resistance but have not been thoroughly researched for use in load bearing applications for diesel and gasoline engines.

The DOE through the ORNL funded a collaboration between DDC and Saint Gobain Norton Industrial Ceramics (SGNIC) for the purpose of designing and testing ceramic valves in diesel engines. A second separate study funded by the DOE involved the ORNL and AlliedSignal Engines Inc. (ASE) in Phoenix AZ. In this study, ORNL generated the mechanical properties of 
the $\mathrm{Si}_{3} \mathrm{~N}_{4}$ manufactured by SGNIC, and made life predictions using ASE's life prediction computer codes that were under development.

These studies were essentially market driven by manufacturers and consumers of large diesel engines that were seeking a reduction of operational maintenance costs. The S149 series diesel engine manufactured by DDC was chosen for testing ceramic valves in order to address the corrosion and wear problems attributed to high maintenance costs. The S149 diesel series is a two-cycle engine having up to 16 cylinders and 64 exhaust valves and capable of producing 1.6 MW of power.

\section{BACKGROUND}

Presented in this section are the results of several $\mathrm{Si}_{3} \mathrm{~N}_{4}$ studies that demonstrate the desirable material properties and its potential in the automotive industry. Ceramics use a probabilistic design methodology and a probabilistic approach to estimate the service life of a component. The objectives for using these approaches are presented. A description of the life prediction algorithm used in this study is presented along with the assumptions and limitations of the algorithm. Lastly, published studies in the life prediction of ceramic components similar to this dissertation are presented.

\subsection{Ceramic Materials for Internal Combustion Engine Components}

An overview of the future of ceramic components for IC engines by Huber and Heinrich (1987) makes the following conclusions. It is likely that the future of ceramics, such as $\mathrm{Si}_{3} \mathrm{~N}_{4}$, will essentially become components of an IC engine. Ceramics have several material properties that make them attractive alternatives for currently used metal engine components. Table 2.1 taken from a study by Wills (1988) shows some of the material properties of three monolithic ceramics; $\mathrm{Si}_{3} \mathrm{~N}_{4}$, silicon carbide ( $\mathrm{SiC}$ ), and partially-stabilized zirconia (PSZ).

Ceramics for structural applications typically have high strength and stability above $1000^{\circ} \mathrm{C}$ and are extremely corrosion and wear resistant as reported by McEntire et al. (1993). Having the ability to operate IC engines at higher temperatures results in better fuel economy and lower emissions (Richerson, 1982; Wills, 1988, Rodgers et al., 1990; and Hamminger and Heinrich, 1993). In addition, ceramics have a relatively low coefficient of thermal expansion and low thermal conductivity, and are less dense than metals (Richerson, 1982; Ashby and Jones, 1986; and Watchman, 1996). 
Table 2.1. Select material properties of three ceramic materials [Wills, 1988].

\begin{tabular}{|c|r|r|r|r|r|}
\hline Ceramic & $\begin{array}{c}\text { Density } \\
\left(\mathrm{g} / \mathrm{cm}^{3}\right)\end{array}$ & $\begin{array}{c}\text { Elastic } \\
\text { Modulus } \\
(\mathrm{GPa})\end{array}$ & $\begin{array}{c}\text { Flexure } \\
\text { Strength } \\
(\mathrm{MPa})\end{array}$ & $\begin{array}{c}\text { Fracture } \\
\text { Toughness } \\
(\mathrm{MPa} \sqrt{\mathrm{m}})\end{array}$ & $\begin{array}{c}\text { Thermal } \\
\text { Expansion } \\
\left(\mathrm{ppm} /{ }^{\circ} \mathrm{C}\right)\end{array}$ \\
\hline $\mathrm{SiC}$ & 3.1 & 410 & 600 & 3 & 4.3 \\
\hline $\mathrm{Si}_{3} \mathrm{~N}_{4}$ & 3.2 & 310 & 800 & 5 & 3.0 \\
\hline $\mathrm{PSZ}$ & 5.8 & 200 & 138 & $6-15$ & 10 \\
\hline
\end{tabular}

The attributes of having a material with a low coefficient of thermal expansion is in maintaining very close tolerances over a wide range of temperatures. A material that has a low thermal conductivity can be an attribute since it restricts the flow of heat energy and keeps unintended nearby regions from getting too hot.

Kamo (1991) stated that $\mathrm{Si}_{3} \mathrm{~N}_{4}$ is being considered for use as valve train components. The less dense, lighter valve train offers reduced inertia effects and inherently provides good tribological properties. The lighter valve train assembly would allow higher engine speeds, whereas metal valve train systems have restricted IC engine speeds.

Another analytical study into the benefits of using ceramic valves for IC engines was conducted by Rodgers et al. (1990). A 2.8 liter overhead valve V- 6 engine was the model from which the results of the study are based. The findings of the analytical study include the following: a $20 \%$ increase in the engine speed, a $30 \%$ reduction in the maximum valve train forces, and a $30 \%$ reduction in the valve train friction. These improvements could be channeled into better fuel economy, higher engine speeds, or additional torque at low speeds by up to $5 \%$. Their study also indicated that the ceramic valve had the greatest impact on performance when compared to other ceramic valve train components.

Kabat et al. (1988) examined $\mathrm{Si}_{3} \mathrm{~N}_{4}$ and PSZ as candidate materials for diesel valves. Extensive finite element modeling of the valve in steady-state and transient thermo-mechanical load conditions were performed. The analytical study concluded that PSZ exceeded its failure strength when finite element boundary conditions representing a severe thermal shutdown were imposed on the valve model. Under the same severe thermal shutdown conditions, the $\mathrm{Si}_{3} \mathrm{~N}_{4}$ did not exceed its failure strength. The finite element model representing the $\mathrm{Si}_{3} \mathrm{~N}_{4}$ did not exceed its failure strength during any of the steady-state or transient thermal-mechanical load conditions. 
Wills (1988) conducted an analytical study examining three structural ceramics as candidates for engine valves (see Table 2.1). The ceramics chosen for the study were $\mathrm{Si}_{3} \mathrm{~N}_{4}, \mathrm{SiC}$, and PSZ. PSZ was initially chosen for the study due to its relatively low thermal conductivity. The reported thermal conductivity of $\mathrm{PSZ}, \mathrm{Si}_{3} \mathrm{~N}_{4}$, and $\mathrm{SiC}$ were $2 \mathrm{~W} / \mathrm{mK}, 31 \mathrm{~W} / \mathrm{mK}$, and $83 \mathrm{~W} / \mathrm{mK}$, respectively. However, the PSZ was removed from the study since Asnani and Kuonen (1986) found that because of its low strength, PSZ had inadequate thermal shock resistance during transient engine shutdown (see Table 2.1).

Wills's criteria for selecting a ceramic material for engine valves was based on the stress. fields from finite element analysis. The selected material would have the lowest stresses from thermalmechanical boundary conditions in both steady-state and transient conditions.

Wills found through finite element modeling that the $\mathrm{SiC}$ exhibited lower stresses than the $\mathrm{Si}_{3} \mathrm{~N}_{4}$, in the steady-state and the transient state thermal load conditions. However, combining the thermal loads with mechanical loads resulted in the $\mathrm{Si}_{3} \mathrm{~N}_{4}$ having a lower stress field than the $\mathrm{SiC}$. Wills explained this phenomena by pointing out that the $\mathrm{Si}_{3} \mathrm{~N}_{4}$ has a lower elastic modulus than the SiC. An additional benefit in choosing the $\mathrm{Si}_{3} \mathrm{~N}_{4}$ is that it has a higher fracture toughness than $\mathrm{SiC}$.

Valves were made from $\mathrm{Si}_{3} \mathrm{~N}_{4}$ and durability tests were conducted in the 1988 Wills study using a dynamometer with a light-duty gasoline engine and light and heavy-duty diesel engines. A 1987 Oldsmobile Cutlass Ciera automobile with a gasoline engine was equipped with $\mathrm{Si}_{3} \mathrm{~N}_{4}$ valves and field tested accumulating over 20,000 miles without failure in a variety of weather conditions.

The following conclusions were made by the 1988 Wills study. The potential advantages to using $\mathrm{Si}_{3} \mathrm{~N}_{4}$ valves in engines are reduced valve and seat insert wear, improved (lighter) valve train dynamics, increased engine output, and reduced friction from lower valve spring loads.

McEntire et al. (1993) stated that the greatest benefit in using ceramic valves in diesel engines would be greater resistance to wear and corrosion. Tests conducted under a joint venture with TRW and SGNIC indicated that $\mathrm{Si}_{3} \mathrm{~N}_{4}$ was very wear and corrosion resistant in a diesel engine combustion environment. In one test scenario, valves made from $\mathrm{Si}_{3} \mathrm{~N}_{4}$ were installed in a diesel engine and tested for over 100 hours. Measurements after 100 hours showed very little, or no, wear on the $\mathrm{Si}_{3} \mathrm{~N}_{4}$ valves.

In conjunction with Dow Corp., McEntire et al. installed $\mathrm{Si}_{3} \mathrm{~N}_{4}$ valves in a Caterpillar 3304 sixcylinder diesel engine. A mixture of methylene chloride and diesel fuel was combusted in the engine. The diesel engines that had metallic valves began failing after 50 hours of running while the engines with ceramic valves ran for more than 700 hours without any sign of wear or corrosion. McEntire et al. also reported that valve train wear was reduced by up to $80 \%$ with the use of $\mathrm{Si}_{3} \mathrm{~N}_{4}$ valves. 
Updike and Nagle (1988) examined the wear characteristics between metal and ceramic engine components. They tested combinations of metal valves with ceramic seat inserts installed in gasoline and diesel engines. The study concluded that the combination of SiAlON (a specific composition of $\mathrm{Si}_{3} \mathrm{~N}_{4}$ ) seat inserts and metal valves significantly reduced wear in the seat / valve face region and also in the valve guide.

Research was conducted by Hoechst CeramTec in cooperation with Hoechst research center on $\mathrm{Si}_{3} \mathrm{~N}_{4}$ valves for a Daimler Benz 300 E24 engine (Hamminger and Heinrich, 1993). Different designs were pursued for the valves; one design was for the intake valve while the other design was for the exhaust valve. Each design had a different design criteria with the exhaust valve having more stringent requirements for strength at elevated temperatures.

The exhaust valves were required to have strength greater than $900 \mathrm{MPa}$, a Weibull modulus greater than 25 , and a slow crack growth exponent parameter, $\mathrm{N}$, greater than 50 . Less stringent requirements were listed for the intake valves.

Their study concluded the following: a 30\% reduction of hydrocarbons, a $20 \%$ reduction in carbon dioxide, and an $80 \%$ reduction in $\mathrm{NO}_{\mathrm{x}}$ byproducts were observed by introducing ceramic valves to the Daimler Benz 300 E24 engine. They also reported a reduction in the fuel consumption between 3 and $4 \%$.

Pattimore et al. (1994) addressed the issues of cost reduction by mass production of $\mathrm{Si}_{3} \mathrm{~N}_{4}$ valves. Their proposal was based on existing ceramic production equipment that has already been proven for mass manufacturing. The proposed machining of $\mathrm{Si}_{3} \mathrm{~N}_{4}$ valves would be conducted using a centerless grinding operation and completed within one minute. A patented proof test procedure is included as a means to check all parts produced before shipment. Their proposal was based on making 12 million valves per year, with the intent of ramping up to that production level over several years, as demanded by the market.

Linder et al. (1998) proposed a large-scale production method using non-destructive evaluation for $\mathrm{Si}_{3} \mathrm{~N}_{4}$ by employing ultrasonic test methods. The system would be able to detect surface defects as small as $90 \mu \mathrm{m}$ and would easily capture defects in the 100-200 $\mu \mathrm{m}$ range. Their system would scan the critical regions of the valve; fillet radius region, valve seat and valve stem under 60 seconds.

To put this 100-200 $\mu \mathrm{m}$ size defect into perspective, one can estimate the corresponding range of failure stresses by using theories from fracture mechanics. Assuming a fracture toughness of $6 \mathrm{MPa} V_{\mathrm{m}}$ and a semicircular surface crack geometry, the range of failure stresses for defects in the 100-200 $\mu \mathrm{m}$ size would be approximately between 350 and $475 \mathrm{MPa}$. 


\subsection{Fracture Mechanics Failure Criteria and Life Prediction Algorithms}

The availability of a dependable ceramic design methodology and database would significantly increase the use of ceramic materials for structural applications (see Section 2.1). The brittle nature of ceramics necessitates a probabilistic design approach in order to successfully utilize the desirable mechanical properties.

Ceramic materials inherently have a large number of randomly oriented microscopic defects or flaws that limit their strength. These defects vary in size and shape and are a result of material processing operations. Fracture is initiated in a ceramic component when a certain stress level is reached at a material defect having the most favorable size and orientation for failure. The stress at failure is known as the critical stress, and the material defect where failure initiated from is known as the critical or strength-limiting flaw. The strength-limiting flaw is assumed stable up to the critical stress level and then becomes unstable when the critical stress is reached or exceeded, resulting in a catastrophic failure.

The observed variation in ceramic strength data can be modeled using a probabilistic approach. Probabilistic methods are able to account for data variability and uncertainty by allowing failure strength to be a random variable. The wide range of strength-limiting flaws is described with a statistical distribution function. Some of the more widely used distribution functions are the Gaussian or Normal distribution, the Weibull distribution, and the lognormal distribution.

Design methodologies regardless of material type are generally based on strength properties generated from test specimens that are usually different in geometry and smaller in size than the design component. It has long been observed that the strength of a ceramic component is dependent on its size. Due to physical size, a large ceramic component includes a greater quantity of defects than a smaller-sized ceramic component. The greater quantity of defects found in a larger component results in a wider distribution of strength-limiting flaws, some that will initiate at failure loads less than the observed failure loads of a smaller component. Thus a desirable requisite for a ceramic design methodology would include a factor to scale strength to physical size. This strength-to-size scaling characteristic distinguishes ceramics from other materials. For example, the strength of many ductile materials is known to be independent of the physical size, and therefore a strength-to-size scaling mechanism is not utilized. The design of a ceramic component based on smaller-sized test specimens will be non-conservative if the strength-to-size scaling effect were not included in the design process.

The design of components made from ductile materials has been very successful when using the deterministic methodology. The deterministic approach defines failure when a parameter, such as stress, has reached or exceeded a specified limit. Some of the more widely used parameters that 
define failure are the normal stress, shear stress, strain, and distortion energy (elastically stored energy). A disadvantage in applying the deterministic approach for the design of ceramic components is that large factors of safety must be included to assure a high degree of reliability (Nemeth et al., 1993).

Probabilistic methods as applied to the design of ceramic components provide a means to account for variation in the strength data. In addition, probabilistic methods have the ability to model competing or concurrent flaw distributions. The Weibull two-parameter distribution function is widely used to represent the probability of failure for ceramic materials, and models the failure behavior of ceramics very well (Richerson, 1982; Crowder et al., 1991, Tucker and Johnson, 1993; Watchman, 1996). The Weibull function consists of an exponential function that has as its argument, failure strength data normalized by a scale parameter, that is then raised to a given power by the second Weibull parameter. The Weibull scale parameter provides a means to scale strength to physical size while the second parameter, the Weibull modulus, describes the width of the distribution function, which is a measure of the variance in the strength data.

The accuracy of use of a probabilistic method is sensitive to the quantity of failure data used in the analysis. Studies by Tennery et al. (1993), indicate that estimating Weibull parameters from 30 data points (or more) has been shown as a useful quantity in reducing the estimator error. If there are concurrent failure mechanisms active, an ideal situation would be to have 30 data points for each failure mechanism. However, obtaining 30 data points for each failure mechanism may not be a cost effective measure since it can involve conducting considerably more than 30 failure tests.

The Weibull distribution assumes that failure in a ceramic material is caused by an independent and mutually exclusive event. This means that material defects do not interact with each other but act independently. Thus every material defect has its own "failure probability" and each is assumed to have an equally probable chance of inducing failure. The total probability of failure for a component can be described as the product of the "failure probability" of all the defects. These assumptions describe well the inherent material processing flaws of ceramic materials; defects that vary in size and shape and that are randomly oriented.

The Weibull distribution is often referred to as the "weakest link theory", in that failure of a ceramic component is defined when a single defect or "link" has failed. This failure criterion describes well the catastrophic failure observed in ceramic components and is a considered conservative approach to design when utilized properly (Crowder et al., 1991).

A failure criterion defines the safe limits of the design component under combined stresses. The more widely used failure criteria are based on the fundamentals of fracture mechanics that are utilized within a Weibull distribution function. Batdorf and Crose (1974) introduced a failure criterion for a multiaxial stress state where flaws are assumed crack-like defects, randomly 
oriented, and uniformly distributed in the material bulk. Initially the Batdorf and Crose failure criterion was based on the normal stresses acting at crack-like defects. A revised criterion developed later by Batdorf and Heinisch (1978) included normal stresses as well as shear stresses that act parallel to the crack plane.

Another failure criterion using a different approach was developed by Evans (1977) shortly before the Batdorf and Heinisch criterion (1978) was published. The Evans criterion assumed that the material had an elemental strength that could be characterized by the inherent flaw population(s).

Boulet (1988) stated in his assessment of ceramic failure predictions that no one failure criterion has been found to be clearly superior to another. The size of defects relative to the ceramic microstructure is known to play a role in the resistance to crack propagation. The failure criteria reviewed by Boulet (1988) found that for polycrystalline ceramics, the assumed crack geometry was a very simplistic model when compared to the observed crack geometry.

The degree of shear sensitivity is the primary difference between many of the failure criteria used in ceramic probability analysis. The normal stress criterion excludes shear stresses while a criterion presented by Shetty (1987), known as the strain energy release rate, includes an empirical shear stress parameter.

The Shetty strain energy release rate criterion requires conducting additional failure tests to assess the shear sensitivity factor of the material. As reported by Nemeth et al. (1993), different values used for the Shetty shear sensitivity factor essentially convert the Shetty strain energy release rate criterion to other failure criteria. The Shetty criterion is equivalent to the following failure criterion when the shear sensitivity factor is fixed at specific values; the maximum strain energy release rate by Ichikawa (1991), the maximum tangential stress by Erdogan and Sih (1963), and the maximum strain energy release rate with collinear crack extension by Hellen and Blackburn (1975). Due to this versatility, the strain energy release rate criterion is commonly used in ceramic failure analysis.

Many ceramics are known to exhibit time dependent failure, better recognized as slow crack growth behavior or environmentally assisted fatigue. The rate of crack propagation is typically represented using a power-law formulation (Wiederhorn, 1974). The slow crack growth model assumes that no crack coalescence occurs and that the initial weakest flaw in a component grows to the final weakest flaw, inducing failure. Boulet (1988) points out that slow crack growth behavior is a difficult process to model since it may be comprised of more than one failure mechanism. For example, environment factors such as moisture are known to contribute to slow crack growth. The power-law model represents the complex slow crack growth process for all concurrent failure mechanisms as if it were a single active failure mechanism. 
Life prediction algorithms combine experimental strength data with a Weibull distribution function and finite element analysis to estimate the failure probability or reliability of a ceramic component. In addition to the previously presented constraints, the following were additional assumptions made in deriving the life prediction algorithms:

1) The material process operations are mature and produce ceramics that have consistent and repeatable material properties.

2) The bulk material is homogeneous and isotropic on a macroscopic scale.

3) The flaw population(s) are non-interacting and uniformly distributed.

4) The test specimens are identical to the design component with regard to surface finish, material composition, and flaw population(s).

5) The Weibull two-parameter distribution describes well the experimental strength data.

6) The finite element analyses represent well the stress fields of the design component using relevant service boundary conditions.

An ideal method for obtaining the complete stress field of a design component is by using the finite element method. As presented by Powers et al. (1992), by using the Gaussian integration points, each finite element can be subdivided into smaller elements. The subelements can be made arbitrarily small such that the stresses acting on each element are assumed constant. A finite element postprocessor as found within NASA's Ceramic Analysis and Reliability Evaluation of Structures (CARES / LIFE, Nemeth et al., 1993), or the ASE's ERICA (Cuccio et al., 1995) life prediction computer programs determines the failure probability of each subelement The product of all of the subelement's failure probabilities is the component's probability of failure.

The finite element analysis is a method that approximates the thermo-mechanical behavior of the design component under combined stresses. Errors associated with finite element analysis are often related to the coarseness of the mesh; the coarser the mesh the greater the discretization error. Studies by Smart (1990) indicate that the most sensitive parameter in finite elements with regard to life prediction is the number of Gauss points used for integration. Smart studied a series of finite element models that had different mesh densities. He concluded that when using 4 Gauss integration points, the discretization error with a medium and a fine meshed model were minimal. Smart also concluded that 4 Gauss points appeared invariant to changes in the Weibull modulus. Using a higher number of Gauss points increased the computational time and did not significantly modify the life prediction estimation. 


\subsection{Results and Limitations of Previous Life Prediction Studies}

Ceramic designers have chosen $\mathrm{Si}_{3} \mathrm{~N}_{4}$ for numerous structural applications that involved high temperatures and / or hazardous environments. An important constituent in the design of ceramic components is estimating the service life of the component. There are a limited number of publications in the literature examining the life prediction of ceramic components. Since the operating temperatures of the $\mathrm{Si}_{3} \mathrm{~N}_{4}$ exhaust valve in this study $\left(850^{\circ} \mathrm{C}\right)$ are well below the oxidation / creep regime, only examples of inert or fast fracture strength and slow crack growth (fatigue) life prediction studies are presented.

Studies published in the open literature involving fast fracture life prediction are more numerous than those estimating the fatigue life of a ceramic component. Examples of fast fracture life prediction include the work by Kabat et al. (1988), Salem et al. (1991), Tsuruzono et al. (1992), Jadaan et al. (1993), Corum et al. (1996), and Wereszczak et al. (1997, 1998). Ceramic components in these studies were analyzed using commercially available finite element software. Steady-state and transient thermo-mechanical boundary conditions relative to the service environment of each ceramic component were analyzed. The finite element model that produced the largest (credible) stresses in the component was then used for the life prediction analysis.

Kabat et al. (1988) examined $\mathrm{Si}_{3} \mathrm{~N}_{4}$ intake and exhaust valves for use in a diesel engine. The study did not utilize a life prediction computer software such as NASA CARES / LIFE. Rather, the ceramic valve was first extensively modeled using finite element methods. The failure probability of the valve was estimated using the Weibull statistics once the finite element analysis identified the model(s) producing the highest stresses. The failure probability of the valve was determined by first calculating the probability of failure from each finite element. The failure criteria used in these analyses was Weibull's principle of independent action (PIA) criterion, and the assumed failure mode was from volume-induced flaws. The study states that the individual failure probabilities were "summed up" to arrive at the valve's fast fracture reliability. This is believed to be an incorrect statement. By definition, it is the product and not sum of the individual failure probabilities that results in the component's failure probability (Crowder et al., 1991). The conclusions from the failure probability analyses were that the $\mathrm{Si}_{3} \mathrm{~N}_{4}$ valve would have a very low probability of failure under fast fracture conditions.

The second phase of the study by Kabat et al., consisted of testing the $\mathrm{Si}_{3} \mathrm{~N}_{4}$ valves in an uncooled, one-cylinder, direct-injected diesel engine and comparing the failure probability prediction to the experimental results. The valves were subjected to transient startups and shutdowns and steady-state operating conditions at several engine speeds and under different engine loads. After 26 hours of engine testing, the valves were removed and inspected with a 
fluorescent dye penetrant. No signs of wear or distress were identified on the valves, the valve seat inserts, and the valve guides during the inspection. The study concluded that the $\mathrm{Si}_{3} \mathrm{~N}_{4}$ valves had potential in the automotive market and that further studies were warranted to address long term cyclic behavior and the effects of manufacturing variability. This study was unique in that it did not generate any $\mathrm{Si}_{3} \mathrm{~N}_{4}$ test specimen strength data and that no fractographic analysis was performed since there were no valve failures reported. Subsequent studies have shown that using the PIA failure criterion has produced non-conservative failure probability predictions (Batdorf, 1977). The dye penetrant inspection method was unable to detect any surface defects because of its sensitivity to surface roughness and its limited detection range. High strength ceramic materials typically fail from flaws in the 10-20 $\mu \mathrm{m}$ range while the dye penetrant inspection method can only detect flaws greater than $50 \mu \mathrm{m}$, according to the Nondestructive Testing Handbook (1982).

In the study by Salem et al. (1991), a gas turbine combustion chamber made from $\mathrm{Si}_{3} \mathrm{~N}_{4}$ was analyzed. Standard sized flexure bars were cut and machined from combustion chamber components and tested at 25,1000 , and $1371^{\circ} \mathrm{C}$. The $\mathrm{Si}_{3} \mathrm{~N}_{4}$ exhibited a significant change in the mode of failure from surface-induced to volume-induced when the temperature increased from 1000 to $1371^{\circ} \mathrm{C}$. At $25^{\circ} \mathrm{C}$, there were 26 surface-induced failures and 3 volume-induced failures reported while at $1000^{\circ} \mathrm{C}$, there were 26 surface-induced failures and one volume-induced failure reported. At $1371^{\circ} \mathrm{C}$, there were 29 surface-induced failures and 21 volume-induced failures. The small number of volume-induced failures at 25 and $1000^{\circ} \mathrm{C}$ resulted in an insufficient statistical characterization of this failure mode at these temperatures. Salem et al. attributed this failure change to a healing of surface-connected flaws between 1000 and $1371^{\circ} \mathrm{C}$.

The probability of failure for the $\mathrm{Si}_{3} \mathrm{~N}_{4}$ combustion chamber was estimated using the NASA CARES / LIFE computer program in the Salem et al. study. The CARES / LIFE program offers several failure criteria to select and for this study, seven different criteria were chosen for comparison. The failure probability for volume and surface-induced modes of failure were estimated by combining the censored specimen strength data with the stress field from finite element modeling. In all failure criteria cases, a very low probability of failure was estimated, indicating that the combustion chamber would safely operate for short time periods under the assumed loading conditions. The study concluded that fractographic analysis played an important role for life prediction. Since the flexure bars did not exploit volume-induced flaws at 25 and $1000^{\circ} \mathrm{C}$, it was suggested that in future studies, tension specimens be included along with flexure specimens.

One limitation of this study was that no combustion chamber strength data and subsequent fractographic analysis were available to compare with the life predictions made using test specimen flexure bar strength data. Fractographic analysis of failed combustion chamber components could 
be compared to the flexure test specimens to validate the mode(s) of failure. This failure data would be particularly useful since the study observed a change in the mode of failure between 1000 and $1371^{\circ} \mathrm{C}$ for the flexure test specimens.

The failure probability predictions of a gas turbine wheel made from $\mathrm{Si}_{3} \mathrm{~N}_{4}$ were investigated by Tsuruzono et al. (1992) using CARES / LIFE computer software. Fast fracture predictions were made based on flexure bar strength data that were machined from the as-molded turbine wheel component. Three surface conditions were analyzed; as-molded, longitudinal and transverse grinding orientations on flexure bars. Specifications were not provided about the surface roughness of each surface condition. The failure probability predictions from test specimen flexure data tested at room temperature were then compared to cold spin test strength data.

Shetty's empirical failure criterion was utilized for the analysis and multiaxial fracture tests were conducted to determine the shear sensitivity factor. The multiaxial tests found the shear sensitivity factor to be very close to unity. Finite element modeling of the turbine wheel was made at the design speed of 76,000 rpm and no thermal loading was considered in the analysis.

The life prediction based on flexure bar strength data was more conservative than actual spin disk strength data. The closest correlation between prediction and experimental data came from the longitudinally machined specimens. The transversely machined and as-molded flexure specimens gave nearly the same failure probability prediction. Fractographic analysis of the test specimens was not presented in this study, an important omission and a limitation often found in life prediction studies. A special photographic system captured the spin disks at the moment of failure, and it was assumed from this observation that all of the spin disk failures were surface-induced.

Studies by Jadaan et al. (1993), investigated life prediction for a SiC heat exchanger. Test specimens (C-ring and O-ring) were cut and machined directly from the $\mathrm{SiC}$ heat exchanger component. Fast fracture and slow crack growth tests were conducted on the test specimens at 25 , 1200 , and $1300^{\circ} \mathrm{C}$. The inert or fast fracture strength of 14 heat exchangers were measured; 10 at $25^{\circ} \mathrm{C}$ and 4 at $1300^{\circ} \mathrm{C}$ using a special tube burst test facility. Fractography of test specimens and the heat exchangers indicated that the dominant mode of failure was a volume-induced failure, and subsequent life prediction analyses were based on this observation.

Failure probability predictions using CARES / LIFE were made based on the C-ring test specimen strength data tested at $25^{\circ} \mathrm{C}$. This fast fracture prediction was then compared to actual heat exchanger strength data from tests conducted at $25^{\circ} \mathrm{C}$. At certain stress levels, the failure probability prediction was found to be less conservative than actual strength data. In addition, the failure probability prediction and the heat exchanger strength data appeared to have different Weibull moduli. 
Strength data from C-ring and O-ring tests were pooled together, and a failure probability prediction was made and was also compared to the heat exchanger strength data. A better correlation was found with the heat exchanger strength data when compared to the prediction based on the pooled data than with the prediction based on just the $\mathrm{C}$-ring test data. However, at certain stress levels this pooled failure probability prediction was less conservative than the heat exchanger strength data.

A time dependent failure analysis was presented based on slow crack growth tests conducted at $1300^{\circ} \mathrm{C}$ and compared with the heat exchanger's fast fracture data at the same temperature. The heat exchanger strength data, consisting of only 4 data points, correlated closely with the inert strength failure probability prediction, but also appeared to have a steeper Weibull modulus than the time dependent failure analyses.

The fractographic analysis of the heat exchangers was a limiting feature of this study since it was not reported. The non-conservative failure probability prediction might be explained from a fractographic analysis of the failed heat exchangers. In addition, it is difficult to compare fatigue life predictions to 4 experimental data points, as was presented for the fatigue life of the heat exchanger. The apparent difference in the Weibull moduli of the fatigue prediction and the fatigue data could be attributed to another active failure mechanism not identified in the study. As summarized by Boulet (1988), the model used for time dependent failure does not explicitly include parameters for other mechanisms of failure, such as environmental effects, that may be concurrent with mechanical loading.

A study by Corum et al. (1996) examined design parameters of a $\mathrm{Si}_{3} \mathrm{~N}_{4}$ exhaust valve and estimated the fast fracture and fatigue performance under laboratory conditions. Two design methodologies were used to estimate the inert strength of the valves; a deterministic approach where average strength values were used, and a probabilistic approach using the NASA CARES / LIFE computer programs. Fatigue performance was estimated using only a deterministic approach.

Censored inert strength data from four-point flexure tests conducted at $25^{\circ} \mathrm{C}$ were provided by the $\mathrm{Si}_{3} \mathrm{~N}_{4}$ vendor. The flexure bars were longitudinally machined relative to the maximum tensile loading and had a reported surface roughness of $4.1 \mu \mathrm{m}$.

The inert strength of $7 \mathrm{Si}_{3} \mathrm{~N}_{4}$ valves was measured at room temperature using a test apparatus that applied a hydraulic pressure on the valve face. Cyclic tests on 4 valves were conducted at room temperature using the same hydraulic test facility. There were no valve failures from cyclic loading; the cyclic pressure was three times the measured combustion pressure, and the valves accumulated more than $10^{7}$ cycles before the tests were terminated. 
It was assumed in the life prediction analyses that surface-induced flaws would be the dominant mode of failure for the valves, and life predictions were made based on surface failure data. The finite element model used for life prediction incorporated thermo-mechanical loads while the inert strength of the valves was determined at room temperature.

The non-linear sliding effects of the valve and valve seat insert were taken into account when using the deterministic life prediction. The deterministic life prediction of the valves was more conservative than the actual valve strength data. The probabilistic life prediction made using CARES / LIFE was found to be more conservative than the deterministic life prediction. Fractographic analysis indicated that volume-induced failures were the dominant mode of valve failure. This was contrary to the previously assumed surface-induced failures upon which the failure probability predictions were based. The CARES / LIFE program offers several failure criteria for life prediction, and it was not known which failure criterion was used for the probabilistic life prediction in this study.

Since no fatigue data was generated in this study, the deterministic approach examined the fatigue performance of the valves from two data points from another fatigue data study. Two different cycles-to-failure versus strength curves were calculated. One curve was based on extrapolating the combustion pressure prediction to a static failure prediction, and another curve was based on a nonlinear pressure versus maximum stress prediction. The study concludes that the fatigue data correlated more closely to the extrapolation prediction when compared to the nonlinear prediction.

The limitations of this study are the following. As mentioned in the report, strength data provided by the vendor were found to be contradictory and inconsistent and thus the life predictions based on these data are questionable. Probabilistic methodology and fractographic analyses were underutilized by the investigators since a life prediction for one failure mode (surface) was presented and compared to failure data from different failure mode (volume). The boundary conditions of the finite element model included thermal loading while the boundary conditions of the valve strength data had no thermal loading. This comparison assumed that the $\mathrm{Si}_{3} \mathrm{~N}_{4}$ had negligible strength degradation at elevated temperatures which may be an invalid assumption, since the vendor-supplied data was found to be questionable. The fatigue life predictions are also questionable since they are based on two data points not generated in this study.

A four year study conducted by Cuccio et al. (1995), made life predictions based upon several different test specimens using the CERAMIC and ERICA computer codes. Three different confirmatory components (spin disk, tension-torsion, and notched-tensile) were loaded to failure and compared to the failure probability predictions based on the specimen strength data. 
Censored specimen test data were pooled for the fast fracture and slow crack growth life prediction exercises. Fast fracture tests were conducted at room temperature and $1200^{\circ} \mathrm{C}$, while slow crack growth tests were conducted only at $1200^{\circ} \mathrm{C}$. Shetty's failure criterion was used in the life prediction exercises and the shear sensitivity factor was experimentally determined as 2.07 .

Good agreement was found with the tension-torsion component for surface-induced failures and with spin disks for volume-induced failures. Poor agreement was found for surface failures between the life predictions based on test specimen data and the inert strength of the notched tensile and spin disk components. In addition, the slow crack growth fatigue predictions did not correlate well with the inert strength measurements of the confirmatory components.

The study concluded that the surface of machined ceramics is not well understood. The surfaces of the test specimens and the confirmatory components were somehow different even though the reported surface roughness measurements of each were equivalent. The flaw populations identified from the test specimens did not seem to match the flaw populations of the confirmatory components, as required for life prediction analysis. The study recommended that additional analysis of the ceramic surface systems be investigated. The study also recommended that tensile specimens be included in a test program with flexure specimens in order to exploit volume-induced failures. One limitation of this study was in the choice of confirmatory ceramic components. The components were essentially academically based and did not directly correlate to an actual ceramic component.

Wereszczak et al. (1997), examined the fast fracture life prediction of a $\mathrm{Si}_{3} \mathrm{~N}_{4}$ exhaust valve for use in a diesel engine. Four censored test specimen strength data sets (tensile and flexure), where each set had between 7-14 test specimens, were used as input into ASE's CERAMIC and ERICA life prediction computer codes. Fractographic analysis of the 7 valves loaded to failure indicated that the dominant mode of failure was volume-induced. Subsequent life prediction analyses were based on volume-induced failures. All test specimen and valve strength tests were conducted at $20^{\circ} \mathrm{C}$.

Fast fracture predictions based on volume-induced failures from test specimen strength data were made and compared to actual valve strength data. Within a $95 \%$ confidence bounds, very good agreement was found with the life predictions and the valve strength data in three of the four data sets. One data set having the smallest number of test specimens showed a slightly less conservative prediction than valve strength data, but the data still remained within the $95 \%$ confidence bounds. In another analysis by Wereszczak et al. (1998), the fast fracture data from different test specimens were pooled together and a fast fracture failure probability prediction was estimated for the valve. Within a 95\% confidence level, the failure probability prediction based on pooled data agreed very well with the valve strength data. One limitation of these studies was the 
small number of test specimen data points used for the life prediction estimate. Numerical studies by Tennery et al. (1993), have shown the benefit of having at least 30 data points for each failure mode when estimating the Weibull parameters.

Past life prediction studies have, or provide, the following limitations and insights:

1) Fractographic analyses of test specimens and design components for life prediction are often times omitted or assumed, and not very comprehensive. This is understandable since fractography is usually a time consuming process and to determine the mechanism(s) of failure from fracture surfaces is not a trivial matter. As ceramic materials increase in strength, their strength-limiting flaws become smaller in size and thus more difficult to identify. However, valuable information is gained and utilized in life algorithms by completing a comprehensive fractographic analysis.

2) The life prediction of a design component should be compared to actual design component strength data in order to validate the life prediction results and the assumptions of the life prediction algorithm.

3) A fundamental understanding of Weibull statistics and fracture mechanic failure criteria is essential for accurate employment of any life prediction algorithm. The limitations and assumptions that are the basis of the life prediction algorithms must also be understood.

4) There are significant benefits for including more than one test specimen geometry in a life prediction assessment. These include a more representative database of failure mechanism(s) for use as input into the life prediction computer programs.

5) Fatigue behavior of ceramics is not well understood since the phenomenon is difficult to model mathematically and it is laborious to obtain good fatigue data.

6) Ceramic surface systems are not well understood and future studies should be focused on obtaining a better understanding of the strength-controlling parameters.

\section{OBJECTIVES OF THE RESEARCH}

There are two primary objectives of this research. The first was to assess NT551, a $\mathrm{Si}_{3} \mathrm{~N}_{4}$ manufactured by SGNIC, for use as a ceramic exhaust valve in a diesel engine. The evaluation would be based on utilizing a life prediction algorithm specially developed for structural and failure estimation with brittle materials and components made from them. The utilized probabilistic-based algorithm combines the Weibull distribution function with theories from fracture mechanics and finite element modeling to estimate the service life of a ceramic design component. 
The second objective of this research was to validate the life prediction algorithm for use in evaluating ceramic materials in structural applications. This was done by comparing the underlying assumptions of the life prediction algorithm with the observed fracture behavior of NT551. The life prediction algorithm used in this study consisted of two recently developed computer programs by ASE. Their use has primarily been internal to ASE; an intended outcome of the present research was to objectively assess its execution and capabilities.

In order to meet the first objective of this study, the generation of a NT551 strength database was required. The strength database portrayed the inert strength and fatigue performance of NT551 through the examination of the following test parameters: machining orientation, temperature, loading rate, and test specimen geometry. For validating the test specimen-based life prediction, the inert strength of NT551-made exhaust valves was measured and compared to the prediction.

Fractographic analyses on test specimens and valves were completed in order to identify (censor) the strength-limiting mode(s) of failure. A finite element model was developed for the ceramic valve with representative boundary conditions and used as input into the life prediction algorithm. Test specimen strength data and valve strength data were analyzed from the estimated censored and uncensored Weibull distribution parameters computed by the life prediction computer program.

The ASE life prediction algorithm combined the test specimen censored strength data with the stress distribution of the finite element model to make a prediction of the inert strength of the $\mathrm{Si}_{3} \mathrm{~N}_{4}$ ceramic exhaust valve. The fatigue performance of the $\mathrm{Si}_{3} \mathrm{~N}_{4}$ ceramic exhaust valve was also predicted using test specimen strength data as input into the life prediction computer programs.

The inert strength life prediction estimates were compared with the actual valve strength data, and the utility of NT551 for use as an exhaust valve in a diesel engine was assessed. The underlying assumptions used in the life prediction algorithm were compared to the fracture behavior of NT551, in order to validate the algorithm's utility for predicting the mechanical behavior of ceramic materials. 


\section{EXPERIMENTAL PROCEDURES AND ANALYSES}

This chapter describes four topics. A description of the NT551 $\mathrm{Si}_{3} \mathrm{~N}_{4}$ examined in this study is presented first. The mechanical tests of the NT551 and their data analyses are then described. The mechanical testing of diesel engine valves made from NT551 and their analyses then follows. Lastly, supplemental analysis procedures are presented.

\subsection{Description, Material Properties, and Preparation of NT551 Silicon Nitride}

The ceramic material characterized in this study was a silicon nitride $\left(\mathrm{Si}_{3} \mathrm{~N}_{4}\right)$ manufactured by SGNIC, and was designated as NT551. The material features a bimodal grain size and shape microstructure. The grains are a mixture of hexagonally shaped long cylinders and smaller equiaxed grains. The long cylindrical shaped grains have an approximate diameter between 0.5 and $1.0 \mu \mathrm{m}$ and an aspect ratio from five to 20 . The average diameter for the equiaxed grains was approximately in the range of 0.25 to $1 \mu \mathrm{m}$. Figure 4.1 illustrates the microstructure of NT551.

NT551 $\mathrm{Si}_{3} \mathrm{~N}_{4}$ was fabricated by gas pressure sintering at temperatures above $1600^{\circ} \mathrm{C}$. Prior to this step, $\mathrm{Si}_{3} \mathrm{~N}_{4}$ powder was mixed with $\mathrm{Al}_{2} \mathrm{O}_{3}, \mathrm{Y}_{2} \mathrm{O}_{3}$, and $\mathrm{Nd}_{2} \mathrm{O}_{3}$ which served as liquid sintering aids during processing. The liquid phase wets the $\mathrm{Si}_{3} \mathrm{~N}_{4}$ grains, bonds them, and acts to minimize porosity. The volume of the component will typically shrink as a result of the sintering process.

After sintering, the fabricated components and billets were subjected to hot isostatic pressing (HIP) for further densification. In this process, temperature and pressure are applied simultaneously.

Pristine and engine-tested NT551 valves were received for this study having two different machining orientations; transverse and longitudinal relative to the valve's axis of symmetry. The NT551 material received for machining test specimens came in two shapes and sizes; there were 31 tiles or billets that were nominally $60 \times 60 \times 8 \mathrm{~mm}$ in size and 106 cylindrical valve stems having a diameter and length of approximately 11 and $130 \mathrm{~mm}$, respectively. Figure 4.2 shows the NT551 material in the as-received state before machining into test specimens. Table 4.1 lists some of the mechanical properties of NT551 provided by SGNIC (Pujari, 1998).

The received valves were machined by two outside ceramic machine shops; SGNIC's World Grinding Technology Center (WGTC) and Chand Kare Technical Ceramics (both located in Worchester, MA). The longitudinally machined valves were machined by Chand Kare Technical Ceramics while the transversely machined valves were machined by the WGTC. The specified surface finish for the valves was $20 \mu \mathrm{m}$ for the valve seat, stem, and keeper groove (part of the mechanical fastener for the springat the end of the valve stem), and $40 \mu \mathrm{m}$ for the remainder of the 
valve's surfaces (Allain, 1998). The engine-tested valves received for testing were previously installed and tested in an S149 diesel engine at DDC.

The machining of NT551 stock material into test specimens was completed using in-house facilities. There were three test specimens made for the study (see Figure 4.3): a rectangular crosssection four-point flexure bar; a cylindrical cross-section four-point flexure bar; and a cylindrical tension specimen. The rectangular flexure bar is a conventional test specimen commonly used in ceramic mechanical testing programs that follows the ASTM C 1161-B standard (1998). The cylindrical flexure bar was introduced to the study to model bending loads applied to the valve stem from potential misalignment of the valve to the seat insert and valve guide. In addition, the cylindrical specimens introduced the centerless machining process as a test parameter.

The last examined test specimen was a tensile specimen designed by the ORNL technical staff. It is referred to as a "modified ORNL tension specimen" because it was a smaller sized version of a standard tensile specimen published in the ASTM C 1273 standard (1998). Tension specimens were included in the study due largely in part to their greater potential to exploit any existing volume-induced flaws.

The ASTM C 1161-B rectangular cross-section four-point flexure specimens were machined from the square tiles. The $4 \mathrm{~mm}$ dimension of the flexure bar was aligned parallel with the $8 \mathrm{~mm}$ dimension of the tile. This allowed a minimal removal of material from the billet and a yield of 15 to 20 test specimens per billet. The flexure bars having dimensions of $3 \times 4 \times 50 \mathrm{~mm}$ were machined using conventionally practiced machining procedures as found in the ASTM C 1161 standard (1998). The final grinding was completed using a 320 diamond grit wheel. The edges of the flexure bars were longitudinally chamfered to reduce the likelihood of corner-induced failures. The tensile side of each ASTM C 1161-B flexure bar was machined in either of two directions in order to examine strength as a function of machining orientation. A majority of the flexure bars was machined transverse to the maximum tensile axis in bending while the remainder were machined longitudinal or parallel to the maximum tensile axis.

Longitudinally machined flexure specimens tend to produce the maximum strength limit of the material, while transversely machined specimens tend to yield the material's lower strength limit.

The cylindrical flexure specimens were machined from the $11 \mathrm{~mm}$ diameter valve stem stock using a 320 diamond grit wheel. The cylindrical specimens were machined using a centerless machining process, which is illustrated in Figure 4.4. A regulator wheel rotates the stock material at low speeds while a high speed grinding wheel rotating in the opposite direction removes material from the stock. The stock material is translated along its axis of rotation between the regulator and grinding wheels. The machining direction on the specimen surface was transverse to the tensile axis in bending. The centerless machining process used to make the cylindrical specimens was 
being considered early in the project as the process to machine the ceramic valves. It was introduced into SGNIC's valve program since it was a lower cost alternative to conventional machining methods for this axisymmetric component geometry.

The modified ORNL tension specimens were machined from the $11 \mathrm{~mm}$ diameter valve stem stock using a cylindrical machining process with a 320 diamond grit wheel. Both ends of the stock material were mounted in a high speed lathe. The diamond grit wheel rotating in the opposite direction removes material from the stock. The tension specimen geometry had a gage diameter of $3.5 \mathrm{~mm}$, a gage length of $30 \mathrm{~mm}$, and a resulting gage volume of $288.6 \mathrm{~mm}^{3}$. The final machining direction was transverse to the uniaxially applied load.

After machining, all test specimens were ultrasonically cleaned in acetone for approximately 15 minutes to remove any residual machining fluids. Then the specimens were heated to approximately $300^{\circ} \mathrm{C}$ to burn off grinding fluid remnants which the acetone may not have removed. The geometry of the specimens was measured using a micrometer and vernier calipers, and then weighed on a Mettler 360 gram capacity scale (Model AJ100, Mettler Instrument Corp., Highstown, NJ). Density calculations were made from ten randomly chosen ASTM C 1161-B flexure specimens.

After specimen preparation, nearly all of the ASTM C1161-B flexure specimens showed a dark reaction layer region running along the length with respect to their $3 \mathrm{~mm}$ dimension. This inhomogeneous region varied in thickness but was approximately 0.5 to $1.0 \mathrm{~mm}$ in depth. It contained randomly distributed small black specks and white snowflake-like shapes as shown in Figure 4.5. The location of the dark reaction layer region on the specimens corresponds to the outer-perimeter-volume of the tiles during the HIP'ing stage of their fabrication.

Shown in Figure 4.6 is a cross-sectional view of the cylindrical valve stock. Notice about the perimeter the same dark reaction layer region found on the ASTM C 1161-B flexure specimens. The $5 \mathrm{~mm}$ final diameter of the cylindrical flexure and the $3.5 \mathrm{~mm}$ gage diameter of the tension specimens were small enough that nearly all of this reaction layer was removed by machining.

This reaction layer region was not unique to NT551. Studies by Bright et al. (1996) reported a thick reaction layer observed after batch processing of NT451, a SiAlON manufactured by SGNIC. Bright, et al. report that additional stock was included on components manufactured using NT451 in order that the reaction layer region could be removed by machining.

The valves did not exhibit the same dark reaction layer region as frequently as the ASTM C 1161-B flexure bars, but did very often show white snowflake-like regions, as shown in Figure 4.7. The image is a detail of a transversely machined valve in the fillet radius region. There is a darker toned region closer to the valve stem (in the middle bottom portion of photo) and a lighter 
toned region directly above. It is not certain whether this is a reaction layer from HIP'ing or possibly due to machining techniques used in this region.

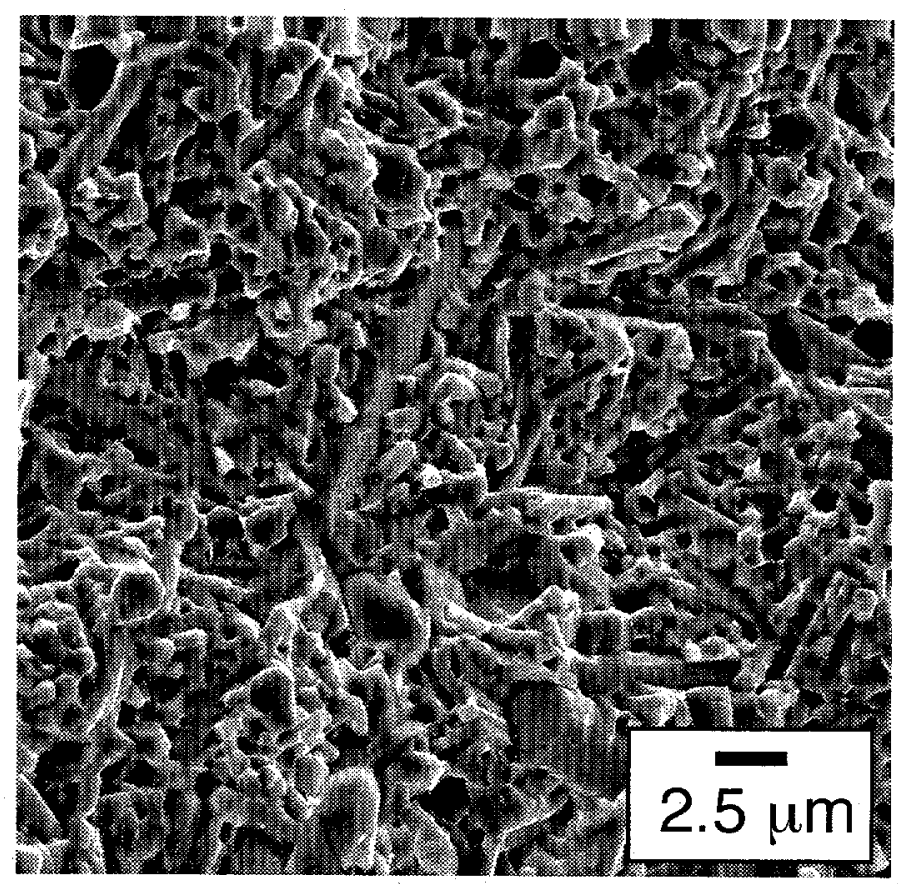

Figure 4.1. NT551 microstructure.

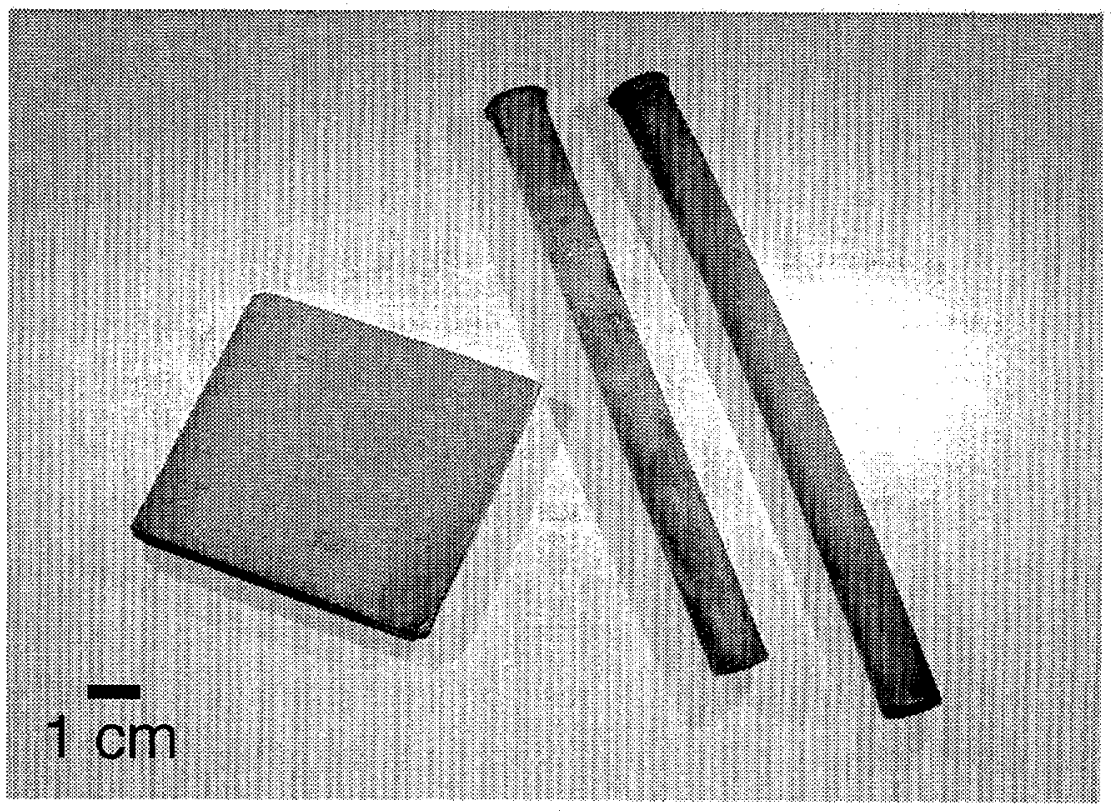

Figure 4.2. NT551 material in the as-received state before machining. 
Table 4.1: Material properties of NT551 provided by SGNIC [Pujari, 1998].

\begin{tabular}{|l|c|c|}
\hline Mechanical Property & Value & Method \\
\hline Density $\left(\mathrm{g} / \mathrm{cm}^{3}\right)$ & $3.285-3.290$ & unknown \\
\hline Elastic Modulus at $22^{\circ} \mathrm{C}(\mathrm{GPa})$ & $302-310$ & unknown \\
\hline Poisson's Ratio at $22^{\circ} \mathrm{C}$ & $0.275-0.280$ & unknown \\
\hline Porosity & $<20 \mu \mathrm{m}$ & unknown \\
\hline Flexure Strength at $22^{\circ} \mathrm{C}(\mathrm{MPa})$ & 966 & 4-point bend \\
\hline Weibull Modulus at $22^{\circ} \mathrm{C}$ & $20-30$ & 4-point bend \\
\hline Flexure Strength at $850^{\circ} \mathrm{C}(\mathrm{MPa})$ & 932 & 4-point bend \\
\hline Weibull Modulus at $850^{\circ} \mathrm{C}$ & $>20$ & 4-point bend \\
\hline Fracture Toughness $(\mathrm{MPa} \sqrt{\mathrm{m}})$ & 7.0 & indentation \\
\hline
\end{tabular}

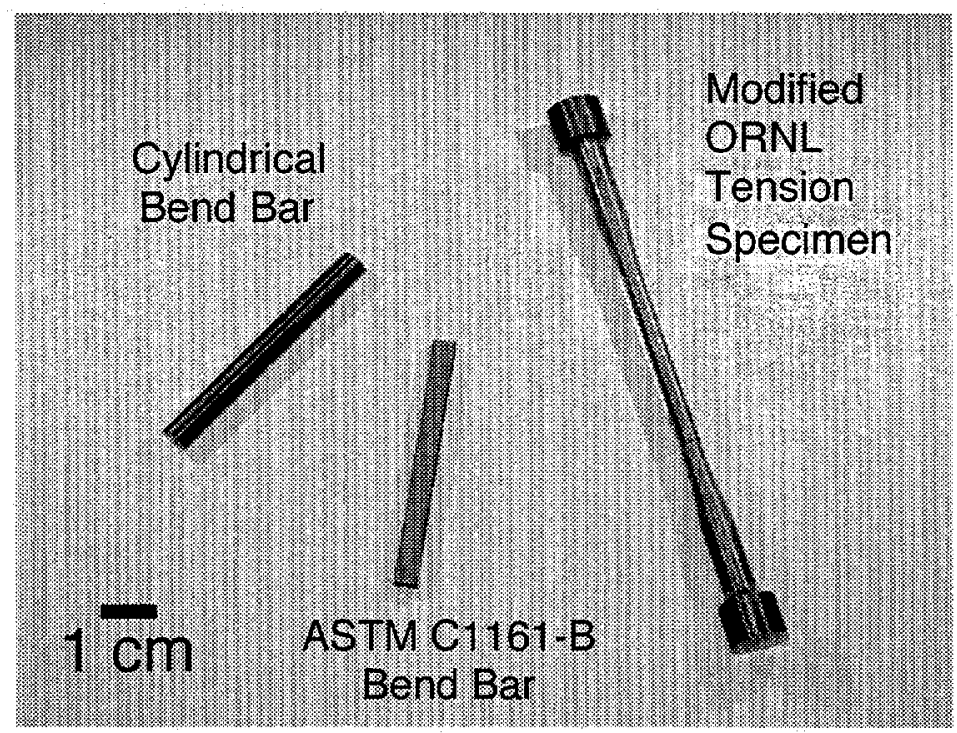

Figure 4.3. Test specimens used in this study. 


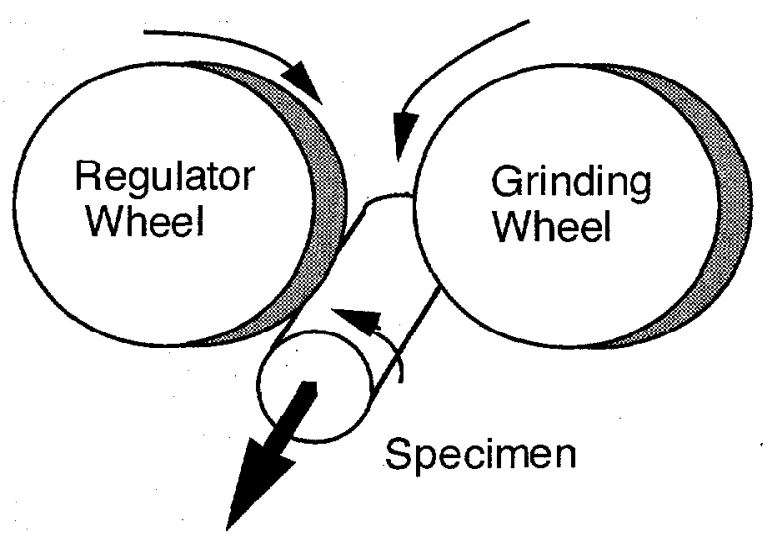

Figure 4.4. Centerless machining schematic used for cylindrical flexure specimens.

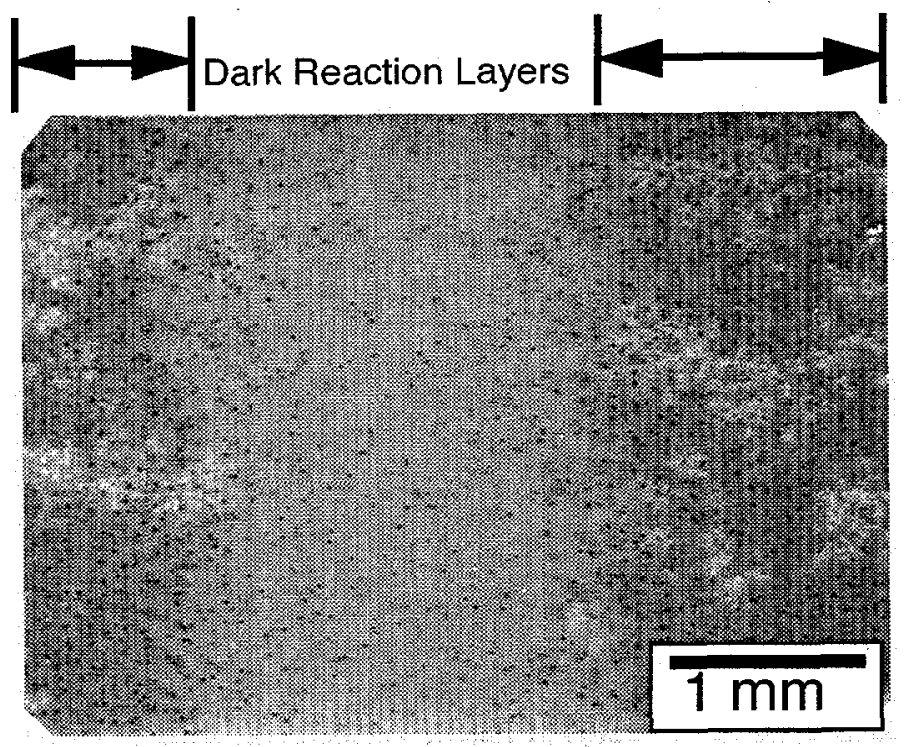

Figure 4.5. Polished end of a ASTM C 1161-B flexure bar after machining showing dark reaction layer region and material inhomogeneities. 


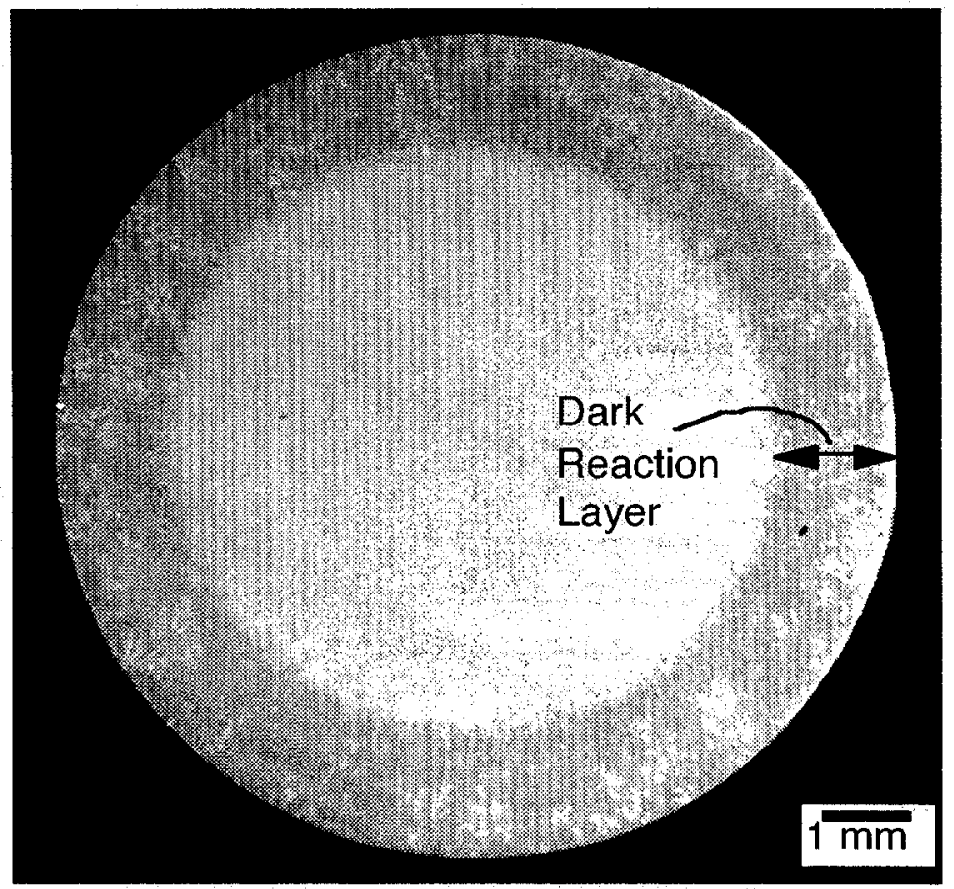

Figure 4.6. Cross-sectional view of NT551 cylindrical stock showing dark reaction layer.

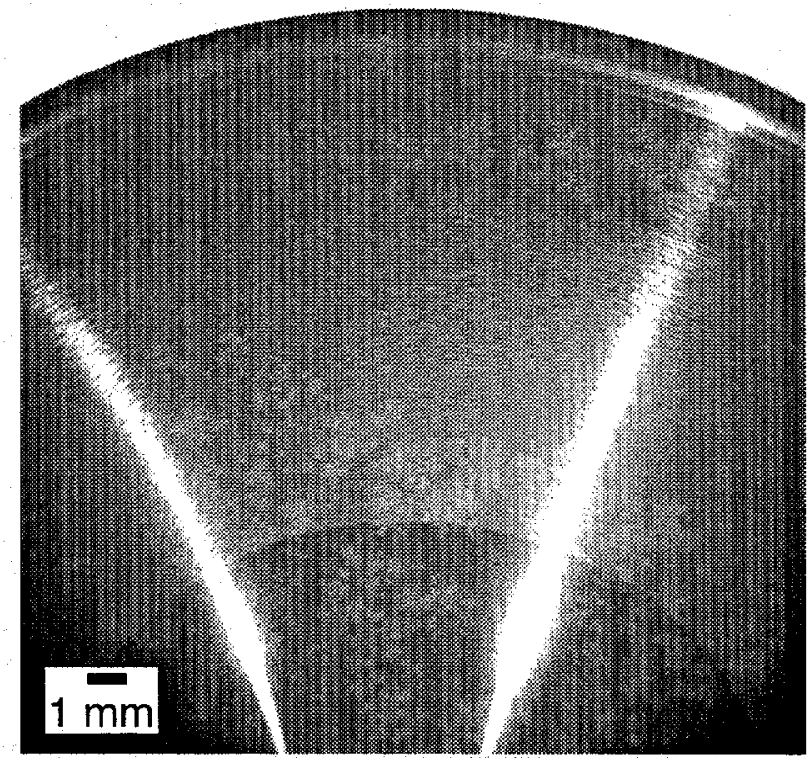

Figure 4.7. Transversely machined valve fillet radius region showing white snowflake-like areas. 


\subsection{Specimen Mechanical Tests and Data Interpretation}

\subsubsection{Strength Testing Procedures and Facilities}

There were two different test facilities used to determine the NT551 inert strength of the three different test specimens. The test facility used most often was the Flexure Test System, an inhouse test machine designed by the ORNL technical staff. There were nine Flexure Test Systems available, each having the ability to test three flexure specimens simultaneously. Figure 4.8 shows one of the Flexure Test Systems. Each system included a CM furnace (Rapid Temp Furnace, Model 870121, Bloomfield, NJ) permitting testing up to $1600^{\circ} \mathrm{C}$, and a Keithley closed loop control and data acquisition software (Soft500, Cleveland, $\mathrm{OH}$ ) on a PC computer controlled and monitored the temperature and load rates. The software featured programmable load-time waveforms that controlled the rate of loading and the number of load cycles to apply.

The loads were generated using a pneumatically-driven air cylinder in which hydraulic fluid was the working medium. A semiarticulating four-point flexure fixture was placed inside the $\mathrm{CM}$ furnace between two opposed and concentrically aligned $\alpha-\mathrm{SiC}$ rods. The top rod applied the load from the air cylinder while the bottom rod was attached to a load cell. Displacement was measured using a linear variable displacement transducer (LVDT).

In the (quarter point) four-point flexure configuration, the specimen is symmetrically loaded at two locations that are situated one quarter of the overall span, away from the outer support points. The four-point flexure inner and outer load spans were 20 and $40 \mathrm{~mm}$, respectively. The flexure fixtures for the ASTM C 1161-B specimens were made from $\alpha$-SiC and used $\alpha$-SiC load bearing pins, see Figure 4.9. The flexure fixtures for the cylinder specimens were made from steel and used steel load bearing pins. The material properties for the steel fixture and load pins were in accordance with the ASTM C 1161 standard (1998).

The four-point flexure fixture used for the cylindrical specimens was modified by increasing the loading pin diameter by 1.5 times the height (diameter in this case) of the specimen as recommended by the ASTM C 1161 standard (1998). The locations of the inner and outer load pins were repositioned to keep the same 20 and $40 \mathrm{~mm}$ inner and outer load spans, respectively. The test procedures for the ASTM C 1161-B flexure bars were adopted for the cylindrical flexure specimens since no standard presently exists for this geometry. The Flexure Test Systems tested the ASTM C 1161-B and cylindrical flexure specimens for determining the inert strength of NT551. 
The modified ORNL tension specimens were loaded to failure using a different test facility. Electromechanical tensile test machines which had a closed loop control system (Model 1380, Instron, Canton, MA) provided the mechanical loading on the specimens. Specimen grips were attached to the load frame in a series of hydraulic couplers. The couplers were tensile-loadactivated and designed to minimize bending loads on the specimen. Between the couplers and specimen were oxygen free copper collets. With accurate specimen and collet machining and a properly activated hydraulic couplers, bending loads was estimated at less than $5 \%$ (Jenkins et al., 1991).

Inert strength measurements are made by the rapid application of a load, which minimizes the likelihood of any possible time-dependent strength-decreasing phenomena such as slow crack growth or stress corrosion cracking occurring. The ASTM standards (ASTM C 1161, C 1273, 1998) recommend a stressing rate of at least $29 \mathrm{MPa} / \mathrm{s}$ for flexure testing and a stressing rate greater than $35 \mathrm{MPa} / \mathrm{s}$ for tension testing. In this study, the inert strength load rate was $30 \mathrm{MPa} / \mathrm{s}$ for flexure and tension tests. A summary of the inert strength tests conducted for this study are presented in Table 4.2 .

The following procedure was used when conducting a four-point flexure test. A similar procedure was used for the tension specimens.

1) Check to see if flexure test stations requires load cell calibration and calibrate if needed.

2) Program load waveform function with data acquisition software for each station (one time requirement).

3) Mark specimen's compressive side with either a marker pen $\left(20^{\circ} \mathrm{C}\right.$ tests $)$ or a diamond scribe $\left(700\right.$ and $850^{\circ} \mathrm{C}$ tests) in order to reassemble each specimen after the test.

4) Position the specimen in the $\alpha$-SiC fixture and place inside the furnace the lower $\alpha$ SiC push rod.

5) Preload the specimen to $20 \mathrm{~N}$.

6) Repeat steps 4 and 5 until the test system is full.

7) If the specimens are to be tested at an elevated temperature, turn on furnace. Adjust LVDT on each station to read $500 \mu \mathrm{m}$.

8) Thermal equilibrium is reached when the $\alpha$-SiC load rods no longer require LVDT adjustments. Begin test after equilibrium is reached. 
9) For high temperature tests, the furnace will automatically shut off after the tests are complete. Remove fractured specimens from furnace when it has returned to ambient temperature.

10) Check the load-displacement data on the computer to determine the failure load and record it for each specimen.

For the ASTM C 1161-B specimens, the failure stress $\left(\sigma_{f}\right)$ in MPa derived from classical beam theory is

$$
\sigma_{f}=\frac{3 P\left(I_{2}-I_{1}\right)}{2 b h^{2}}
$$

where $\mathrm{P}$ is the failure load in Newtons, 12 and 11 are the outer and inner load spans in $\mathrm{mm}$, respectively, $b$ is the width in $\mathrm{mm}$, and $\mathrm{h}$ is the height in $\mathrm{mm}$. The cylindrical flexure specimen failure stress was also derived from classical beam theory by exchanging the moment of inertia term for a beam having a rectangular cross-section with a beam having a circular cross-section;

$$
\sigma_{f}=\frac{P\left(I_{2}-I_{1}\right)}{\pi r^{3}}
$$

where all other parameters are defined by Eq. 4.1 and $\mathrm{r}$ is the radius in $\mathrm{mm}$ of the cylinder. For the modified ORNL tension specimen, the following equation from the ASTM C 1239 standard (1998) was used to determine the stress at failure:

$$
\sigma_{f}=\frac{P}{\pi r^{2}}
$$

where $\mathrm{r}$ is the radius in $\mathrm{mm}$ and $\mathrm{P}$ is defined from Eq. 4.1 . 


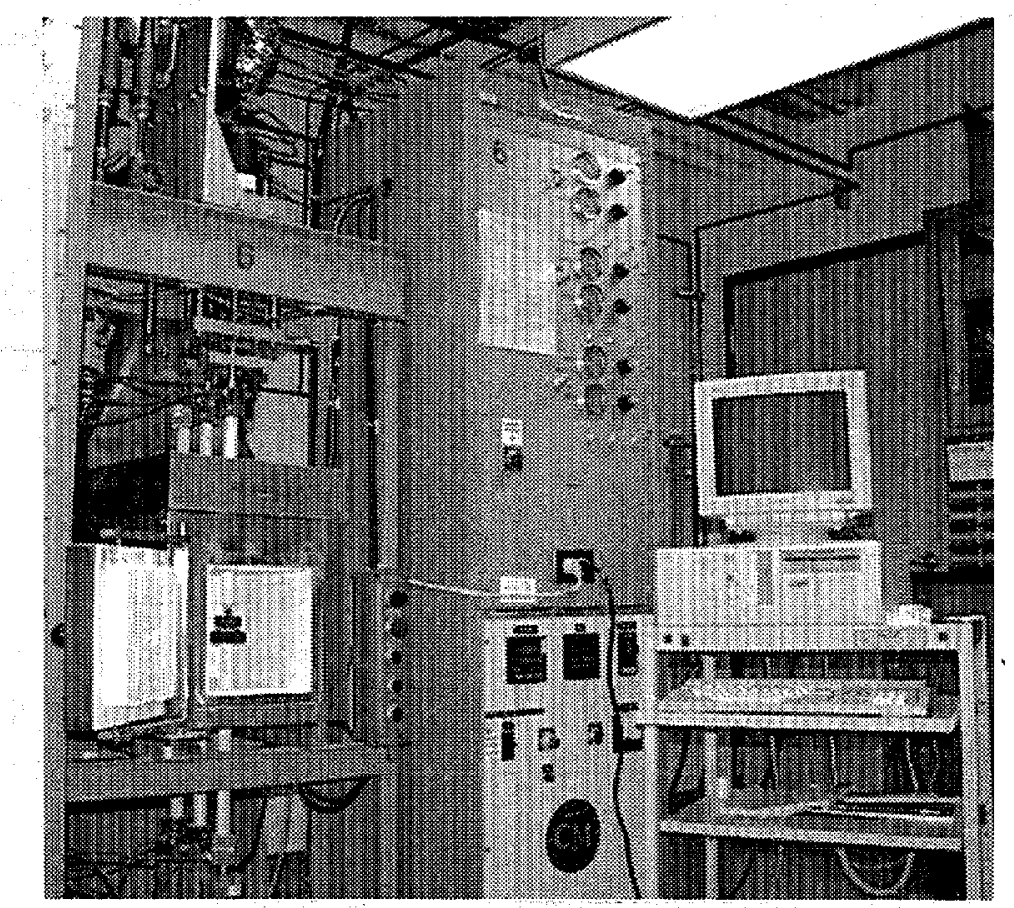

Figure 4.8. Flexure Test System at ORNL High Temperature Materials Laboratory.

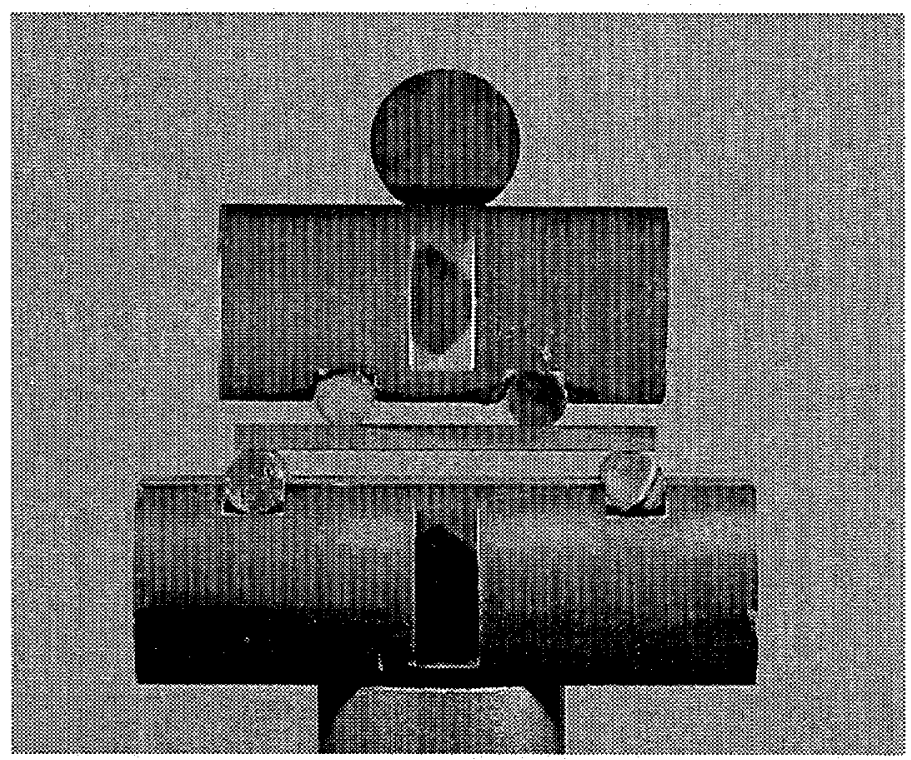

Figure 4.9. Four-point flexure fixture made of $\alpha$-SiC with ASTM C 1161-B flexure specimen mounted. 
Table 4.2. Number and type of specimens for inert strength test of NT551.

\begin{tabular}{|c|c|c|c|c|}
\hline $\begin{array}{l}\text { Temp } \\
\left({ }^{\circ} \mathrm{C}\right)\end{array}$ & $\begin{array}{l}\text { ASTM Flexure } \\
\text { Transverse }\end{array}$ & $\begin{array}{l}\text { ASTM Flexure } \\
\text { Longitudinal }\end{array}$ & $\begin{array}{l}\text { Cylinder in } \\
\text { Flexure }\end{array}$ & $\begin{array}{l}\text { Modified ORNL } \\
\text { Tension }\end{array}$ \\
\hline 20 & 30 & 30 & 30 & 15 \\
\hline 700 & 15 & --- & $-\cdots$ & $\cdots$ \\
\hline 850 & 30 & 30 & -- & - \\
\hline
\end{tabular}

\subsubsection{Fatigue Testing Procedures and Facilities}

The fatigue properties of NT551 were determined using the recently adopted ASTM C 1368 standard (1998). In this standard, the susceptibility of a ceramic material to slow crack growth behavior was determined using constant stress rate flexure tests. The flexure strength is determined as a function of the applied stress rate in a given environment at $20^{\circ} \mathrm{C}$. The basis of the test method is to examine any strength degradation when the applied stress rate is reduced. Combining data from these tests with the previously completed inert strength results provides a means to assess slow crack growth behavior of the NT551.

Three test specimen geometries were subjected to 0.3 and $0.003 \mathrm{MPa} / \mathrm{s}$ stressing rates in order to examine NT551's susceptibility to the slow crack growth phenomena. The test geometries utilized in the dynamic fatigue study were the ASTM C 1161-B transversely machined specimens, the cylindrical four-point flexure specimens, and the modified ORNL tension specimens. At $20^{\circ} \mathrm{C}$ and for each load rate, there were approximately 30 specimens tested in flexure and 15 specimens tested in tension.

To study the effects temperature has on the slow crack growth phenomena, additional ASTM $\mathrm{C} 1161$ - B flexure specimens were loaded to failure at 700 and $850^{\circ} \mathrm{C}$. Fifteen specimens were tested at stressing rates of 0.3 and $0.003 \mathrm{MPa} / \mathrm{s}$ for the $700^{\circ} \mathrm{C}$ temperature while 30 and 40 specimens were used at the $850^{\circ} \mathrm{C}$ temperature for the same stressing rates, respectively.

The ASTM C 1368 standard (1998) uses the term "stressing rate" whereas other sections of the dissertation use the term "loading rate". A stressing rate is dependent upon the geometry of the test specimen while a loading rate is independent of any specimen geometry. Presented in Table 4.3 are the loading rates and corresponding converted stressing rates for each of the specimens in this study. 
The same test facilities used to determine the inert strength of NT551 (described in Sections 4.1 and 4.2) were also used to assess NT551's slow crack growth susceptibility. A summary of the constant stress rate flexure tests performed for this study is presented in Table 4.4.

For many ceramics and glasses the slow crack growth rate can be approximated by the empirical power-law relationship as presented in the ASTM C 1368 standard (1998):

$$
\frac{d a}{d t}=A\left[\frac{K_{1}}{K_{1 C}}\right]^{N}
$$

where daldt is the slow crack growth rate in $\mathrm{m} / \mathrm{s}, A$ and $N$ are slow crack growth curve fit parameters, $K_{I}$ is the Mode I stress intensity factor in MPa $\sqrt{\mathrm{m}}$, and $K_{I C}$ is the fracture toughness under Mode I luading in MPa $\sqrt{m}$.

For a uniformly-applied stress, the stress intensity factor can be expressed as:

$$
K_{I}=Y \sigma \sqrt{a}
$$

where $\sigma$ is the remote applied stress in MPa, $Y$ is geometry factor related to flaw shape and orientation with respect to direction of applied loading, and $a$ is the crack length in $\mathrm{m}$.

For these tests, the flexure strength was calculated using the same equations presented in 4.2.1. Manipulating Eqs. 4.4 and 4.5 results in a relationship between the inert strength $\left(\sigma_{i}\right)$ and fracture strength $\left(\sigma_{f}\right)$ for slow crack growth:

$$
\sigma_{f}^{N-2}=\sigma_{i}^{N-2}-\frac{1}{B} \int_{0}^{t}[\sigma(t)]^{N} d t
$$

where:

$$
B=\frac{2 K_{I C}^{2}}{A Y^{2}(N-2)}
$$

The inert strength $\left(\sigma_{i}\right)$ is the fracture strength in an inert environment where no subcritical crack growth or any other strength degradation effect occurs prior to fracture, and is the strength 
value measured in tests described in Section 4.2. For a constant stress-rate, $\sigma(t)=\dot{\sigma} t$ and when integrated, $\mathrm{Eq} .4 .6$ becomes:

$$
\sigma_{f}^{N+1}=B(N+1) \sigma_{i}^{N-2} \dot{\sigma}
$$

It is implicitly assumed when deriving Eq. 4.7 that $\left(\sigma_{f} / \sigma_{i}\right)^{N-2}<1$ since $N>=5$ for most ceramics and $\sigma_{f}<\sigma_{i}$. Taking the logarithm of both sides of Eq. 4.7 yields:

$$
\log \sigma_{f}=\frac{1}{N+1} \log [\dot{\sigma}]+\log D
$$

where

$$
\log D=\frac{1}{N+1} \log \left[B(N+1) \sigma_{i}^{N-2}\right]
$$

The slow crack growth parameters $D$ and $N$ can be determined by a linear regression analysis when $\sigma_{f}$ is graphed as a function of $\dot{\sigma}$ on log-log plots. For a given material, strength-limiting flaw type, and test environment, the ASTM 1368 standard (1998) states that the parameter $N$ is a constant regardless of specimen size, while the parameter $D$ is a of function inert strength and therefore depends on specimen size. If a material is susceptible to slow crack growth then the strength will decrease when the stressing rate decreases; the severity of slow crack growth is represented by the $N$ value.

There are several assumptions in the derivation of Eq. 4.8. The power-law equation approximates well the crack growth behavior as a function of the stress intensity factor. The material selected for testing displays no rising R-curve behavior, is isotropic, homogeneous, and has the same moduli of elasticity in tension and compression. The material responds to loading in a linear elastic manner and flexure strength is based on classical beam theory.

Fatigue plots presented in Chapter 5 use a variation of Eq. 4.7. Knowing that $\dot{\sigma}=\sigma_{f} / t_{f}$, and by substituting this expression in Eq. 4.7 , the time to failure can be calculated according to

$$
t_{f}=B \sigma_{i}^{N-2} \sigma_{f}^{-N}
$$


Table 4.3. Test specimen loading rate $(\mathrm{N} / \mathrm{s})$ and corresponding stressing rate $(\mathrm{MPa} / \mathrm{s})$.

\begin{tabular}{|l|l|l|}
\hline $\begin{array}{l}\text { ASTM C 1161-B } \\
\text { Flexure }\end{array}$ & Cylindrical Flexure & Modified ORNL Tension \\
\hline $36 \mathrm{~N} / \mathrm{s}=30 \mathrm{MPa} / \mathrm{s}$ & $14.67 \mathrm{~N} / \mathrm{s}=30 \mathrm{MPa} / \mathrm{s}$ & $288 \mathrm{~N} / \mathrm{s}=30 \mathrm{MPa} / \mathrm{s}$ \\
\hline $0.36 \mathrm{~N} / \mathrm{s}=$ & $0.1467 \mathrm{~N} / \mathrm{s}=$ & $2.88 \mathrm{~N} / \mathrm{s}=$ \\
$0.30 \mathrm{MPa} / \mathrm{s}$ & $0.30 \mathrm{MPa} / \mathrm{s}$ & $0.30 \mathrm{MPa} / \mathrm{s}$ \\
\hline $0.0036 \mathrm{~N} / \mathrm{s}=$ & $0.00146 \mathrm{~N} / \mathrm{s}=$ & $0.0288 \mathrm{~N} / \mathrm{s}=$ \\
$0.0030 \mathrm{MPa} / \mathrm{s}$ & $0.0030 \mathrm{MPa} / \mathrm{s}$ & $0.0030 \mathrm{MPa} / \mathrm{s}$ \\
\hline
\end{tabular}

Table 4.4. Number and type of specimens for constant stress rate testing.

\begin{tabular}{|c|c|c|c|}
\hline Temp / Stressing Rate & $\begin{array}{l}\text { ASTM Flexure } \\
\text { Transverse }\end{array}$ & $\begin{array}{l}\text { Cylinder in } \\
\text { Flexure }\end{array}$ & $\begin{array}{l}\text { Modified ORNL } \\
\text { Tension }\end{array}$ \\
\hline $20^{\circ} \mathrm{C} / 0.30 \mathrm{MPa} / \mathrm{s}$ & 30 & 30 & 15 \\
\hline $20^{\circ} \mathrm{C} / 0.003 \mathrm{MPa} / \mathrm{s}$ & 30 & 30 & 15 \\
\hline $700^{\circ} \mathrm{C} / 0.30 \mathrm{MPa} / \mathrm{s}$ & 15 & $-\cdots$ & --- \\
\hline $700^{\circ} \mathrm{C} / 0.003 \mathrm{MPa} / \mathrm{s}$ & 15 & $-\cdots$ & $\cdots$ \\
\hline $850^{\circ} \mathrm{C} / 0.30 \mathrm{MPa} / \mathrm{s}$ & 30 & $-\cdots$ & $\cdots$ \\
\hline $850^{\circ} \mathrm{C} / 0.003 \mathrm{MPa} / \mathrm{s}$ & 30 & $-\cdots$ & \\
\hline
\end{tabular}

\subsubsection{Fractographic Facilities and Censoring Procedures}

A brittle material is one that adheres to Hooke's law up to the point of fracture. Materials which are brittle commence fracture at a single location. The fracture origin normally consists of some irregularity that acts as a stress concentrator from an applied load. The goal of fractographic analysis is to characterize the strength limiting failure origins by identity, location, and size. The application of the failure identification to the strength data is referred to as censoring the strength data.

There are two types of flaws found in ceramic materials. The first type, intrinsic flaws, are inherent to the material. These flaws, such as agglomerates or inclusions are typically distributed throughout the volume of the material. By cutting or machining, it is possible that the intrinsic flaw could be located on the surface. The second type of flaw found in ceramic materials is called extrinsic. These flaws are a result of post-fabrication activities, such as machining and are located on or just below the surface of the material. 
The ASTM has developed a standard (ASTM C 1322, 1998) practice for the characterization of fracture origins in ceramic materials. This document was referred to extensively during this study to systematically characterize failure origins.

Figure 4.10 (a) illustrates schematically the fracture characteristics found as a result of brittle failure and Figure 4.10 (b) shows an example from a failed NT551 flexure bar. Surrounding the failure origin is the mirror, a region that is relatively smooth in appearance. The transition from the mirror to a much rougher hackle region is a relatively small area known as the mist. The hackle lines beyond the mist region point back toward the fracture origin. When failure is initiated, the accelerating crack travels radially outward in usually a single plane which creates the smooth mirror rcgion. The mist region represents the region where the crack encounters one of the following events; reaches a critical speed, intersects an inclusion or is acted upon by a change in the stress field. In doing so, the crack deviates from the original fracture plane creating "river patterns" (Richerson, 1982). The hackle region represents further amplification of the events that began in the mist region.

All test specimens were examined with an Olympus optical stereo microscope (Model SZH10, Lake Success, NY) which had a $7 \mathrm{X}$ to $70 \mathrm{X}$ magnification range. Several digital images were made using a Polaroid digital microscope camera (Model DMC 1, Cambridge, MA) that was connected to an Apple computer.

The location, the type of failure, and a sketch of the failure origin were recorded for every test specimen on an in-house developed fractographic document. After optical examinations, a smaller set of test specimens was selected for viewing with the scanning electron microscope (SEM, Model S4100, Hitachi Corp., San Jose, CA). These specimens were chosen either as representative examples of identified failure mechanisms or for additional analysis since the failure mechanism was unidentified.

The specimens for SEM were cut using a diamond saw blade and then ultrasonically cleaned in acetone for approximately 15 minutes. After cleaning, the specimens were mounted on a metal staging button, carbon coated, (Model 11428, Structure Probe Inc., West Chester, PA) and then viewed with the SEM.

An Apple computer connected to the SEM having Adobe Photoshop software (Version 2.5.1) installed, allowed for the capturing of digital images of the fracture surfaces from secondary electron imaging. To help identify elements on the fracture surface, an energy dispersive x-ray spectroscopy (EDS) system was used on the SEM. The EDS system used the Desk Top Spectrum Analyzer (DTS $\Lambda$, V2.0.1) software that was developed by the National Institute of Standards and Technology in Gaithersburg MD. The software produces a graphical plot of the elemental peaks detected. 
To capture images of the elements identified through spectroscopy, an energy dispersive x-ray spectrum imaging technique (EDX) was used on the SEM. This technique produced elemental mappings or images that indicated the presence and spatial distribution of a single element. This technique used a Phillips SEM (Model XL30 / FEG, Eindhoven, The Netherlands) equipped with an Oxford energy dispersive x-ray detector (North America; Concord, MA) and an EMiSpec integrated acquisition system (Tempe, AZ).

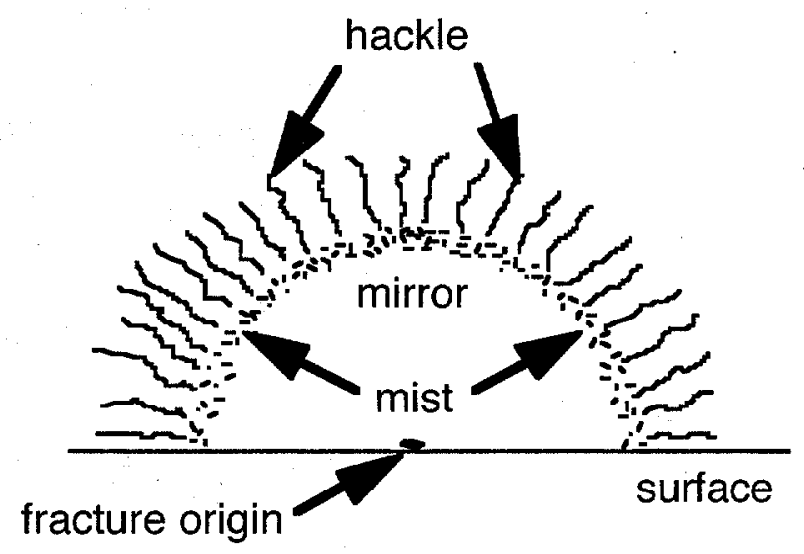

(a)

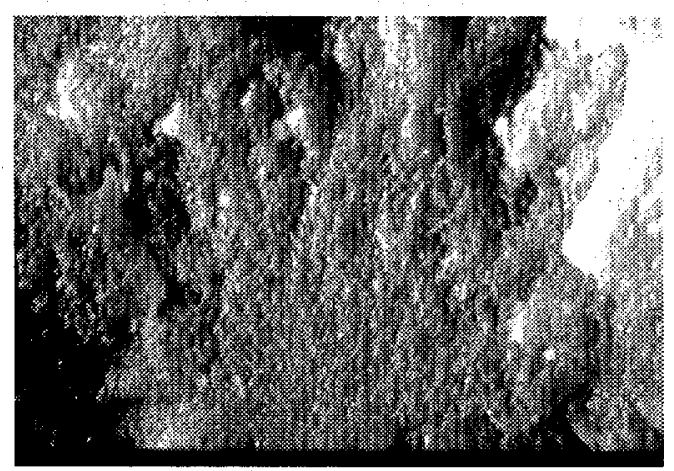

(b)

Figure 4.10 (a) Characteristic patterns found from brittle failure. The strength limiting flaw was located at or very near the surface (b) Actual fracture surface of ASTM C 1161-B flexure bar 29$25-7$

\subsubsection{Statistical Analysis Procedures}

The statistical procedures used in this dissertation are based on the definition of reliability. Reliability is defined as the probability that an item will perform a required function without failure under stated conditions for a specified period of time (Crowder et al., 1991). The definition of reliability requires three components; a definition of failure, a description of the operating environment, and a designated period of time for operation.

Reliability studies use the following fundamental concepts which are independent of any specified distribution function (e.g. Weibull or Gaussian). Assume that $\mathrm{T}$ is a continuous random 
variable, such as failure strength, and define $F(t)$ as the cumulative distribution function of T. The failure probability of $T$ when it is less than $t$ is

$$
F(t)=P_{f}(T<t)
$$

The survivor function, which is the reciprocal of the failure probability is

$$
S(t)=1-F(t)=P_{f}(T \geq t)
$$

The density function is the derivative of the cumulative distributive function, which can be expressed in terms of either the cumulative distribution function or the survivor function;

$$
f(t)=\frac{d F(t)}{d t}=-\frac{d S(t)}{d t}
$$

The hazard or failure rate function is given as

$$
h(t)=\frac{f(t)}{S(t)}
$$

and the cumulative hazard function is the integral of the hazard rate function;

$$
H(t)=\int_{0}^{t} h(u) d u .
$$

Notice that

$$
H(t)=-\ln S(t)
$$

and that the survivor function in Eq. 4.15 can be expressed as

$$
S(t)=\exp [-H(t)]
$$


The presented functional relationships for $F, \tilde{f}, S, h$, and $H$ are mathematically equivalent expressions for $\mathrm{T}$ such that given any one of these functions, the previous four expressions may be determined (Crowder, et al., 1991).

Reliability of a system can be categorized as a series system, a parallel system, or a combination of the two (coherent systems). A series system defines failure when any one component fails and is often referred to as the weakest-link theory, analogous to a "chain" made of several "links". The reliability of a series system is only as high as its weakest component.

A parallel system is comprised of components that are used in a redundant fashion. If one component fails, it does not necessarily mean that the system has failed. A parallel system has failed when a specific number of components that comprise a critical path for operation fail.

The reliability of a series system is determined by the product of the reliability of each component. In a parallel system, the reliability is determined as the product of each component's probability of failure which is then subtracted from unity. The more conservative series system approach is most often used when modeling the mechanical behavior of ceramic materials, and was the approach chosen for this study.

The failure of ceramic materials is almost always presented using probabilistic methods. The brittle nature of ceramics results in a wide variability of strength from what appear to be "identical" specimens. In addition, ceramic materials show a strength dependence on physical size; large ceramic specimens fail at lower stresses than small ceramic specimens. Probabilistic methods are typically not used when designing for other materials, such as metals, since they do not show a wide variance in failure strengths, and the strength is essentially a constant value, independent of size.

In 1939, Waloddi Weibull introduced his probabilistic models for uniaxial and multiaxial stress states. He based his models on the notion that material strength could be treated as a random variable. By applying the weakest-link theory, in which a structure has failed when its weakest link has been exceeded, the strength of a structure can be described as a function of size. Since its introduction, the Weibull distribution has modeled the failure of brittle materials very successfully (Cuccio et al., 1995).

Life prediction algorithms, such as used in this study, employ the Weibull two-parameter distribution function to model failure strengths. The probability that a test specimen would fail under an applied load is given as follows: 


$$
P_{f}=1-\exp \left[-\left(\frac{\sigma}{\sigma_{\theta}}\right)^{m}\right]
$$

where $P_{f}$ is the failure probability, $\sigma$ is the failure strength of test specimens in $\mathrm{MPa}, \sigma_{\theta}$ is the characteristic strength of the test specimens in $\mathrm{MPa}$, and $m$ is the Weibull shape parameter (or modulus). The Weibull characteristic strength is the stress level at which 63.2 percent of the test specimens have failed. The characteristic strength is dependent on the test specimen and will change in value when a different specimen size and/or geometry is tested.

An alternative and perhaps more useful expression for the failure probability from volume flaws is given as

$$
P_{f}=1-\exp \left[-\int_{V}\left(\frac{\sigma}{\sigma_{0}}\right)^{m} d V\right]
$$

in which the volume integration is carried out over the region of interest. By changing the integration to the area or edge of interest, Eq. 4.18 can also express the probability of failure for surface and edge failures, respectively. The characteristic strength term $\sigma_{\theta}$ from Eq. 4.17, is replaced with Weibull scale parameter, $\sigma_{0}$ in Eq. 4.18. The scale parameter is the characteristic strength of a unit sized specimen. Depending on the integration, it represents a test specimen that is either a unit volume, a unit area, or a unit length in size. The scale parameter corresponds to the stress level at which $63.2 \%$ of the unit sized specimens would fail in tension. The units of the scale parameter are determined by the integration type. For a volume integration, $\sigma_{0}$ has the units of $\mathrm{MPa} \mathrm{mm}^{3 / \mathrm{m}}$, and for a surface integration, $\sigma_{0}$ has the units of $\mathrm{MPa} \mathrm{mm}^{2 / \mathrm{m}}$. The scale parameter has units of MPa $\mathrm{mm}^{1 / \mathrm{m}}$ for an edge or line integration.

A tlow chart of the life prediction algorithm used in this study is presented in Figure 4.11. This life prediction algorithm and much of the information that is now presented, are taken from the ORNL Technical Report Life Prediction Methodology for Ceramic Components of Advanced Heat Engines, Phase I, authored by Cuccio et al, from ASE, Phoenix AZ. Two computer programs known as CERAMIC and ERICA were developed by ASE and were used to perform the statistical calculations for the Weibull distribution. The algorithm begins in the upper left hand corner of Figure 4.11 with generating the required life prediction experimental database. This 
database should properly define the relevant strength properties of the design component at operating temperatures such as inert strength, slow crack growth, cyclic fatigue, and creep conditions. An expected lifetime of the component should also factor into the test program. At least two types of strength testing, such as flexure and tensile, are recommended for a test program in order to exploit a maximum number of strength limiting flaws inherent to the material and its processing.

A comprehensive fractographic analysis is performed to locate, identify, and characterize each fracture origin after strength testing is completed. After censoring, CERAMIC is used to perform the statistical data analysis to define the Weibull strength distribution parameters for each identified failure mode (censored) or for a single assumed failure mode (uncensored).

In the upper right hand comer of Figure 4.11 flowchart is the finite element analysis of the design component using ANSYS ${ }^{\mathrm{TM}}$ software; this stage can occur simultaneously with the previously mentioned mechanical strength tests. The finite element model should represent the features of the component and be subjected to appropriate thermo-mechanical boundary conditions.

The finite element method is an ideal framework for calculating the reliability of a series system. The reliability of each finite element can be calculated as a subelement or "component" of the entire model or "system". The product of all the reliability calculations from each finite element then becomes the reliability of the design component.

Once modeling the component with finite elements is satisfactorily completed, the results file is used as input into the ERICA computer program(an FE postprocessor program). ERICA reads the geometry and the stress field and performs numerical integration to determine $I$, the multiaxial and stress gradient factor that is also referred to as the "loading factor" in the literature and represented by the symbol " $k$ ". The multiaxial and stress gradient factor is used in determining the effective size of the component. The effective size is defined as the product of the multiaxial and stress gradient factor with a physical characteristic of the component, such as the volume, the surface area, or the edge length.

The combination of the censored or uncensored Weibull parameter estimates with the multiaxial and stress gradient factor are then used as input in the CERAMIC computer program. The CERAMIC program then estimates the failure probability prediction for the design component from the combined finite element modeling and test specimen strength data.

The probabilistic uniaxial stress model Weibull proposed was readily accepted while his multiaxial stress model was met with controversy (Cuccio et al., 1995). Several multiaxial stress theories have since been developed, and among which the Batdorf and Crose (1974), and the work of Evans (1977) are better known. It was shown by Tucker and Johnson (1993) that these two multiaxial stress theories are equivalent when assuming the same flaw type. The CERAMIC 
computer code utilizes the Evans formulation for multiaxial stress conditions. A description of the development of the multiaxial stress theory and use of maximum likelihood statistics for analyzing the Weibull strength distributions may be found in more detail in Cuccio et al. (1995) and Andrews (1999).

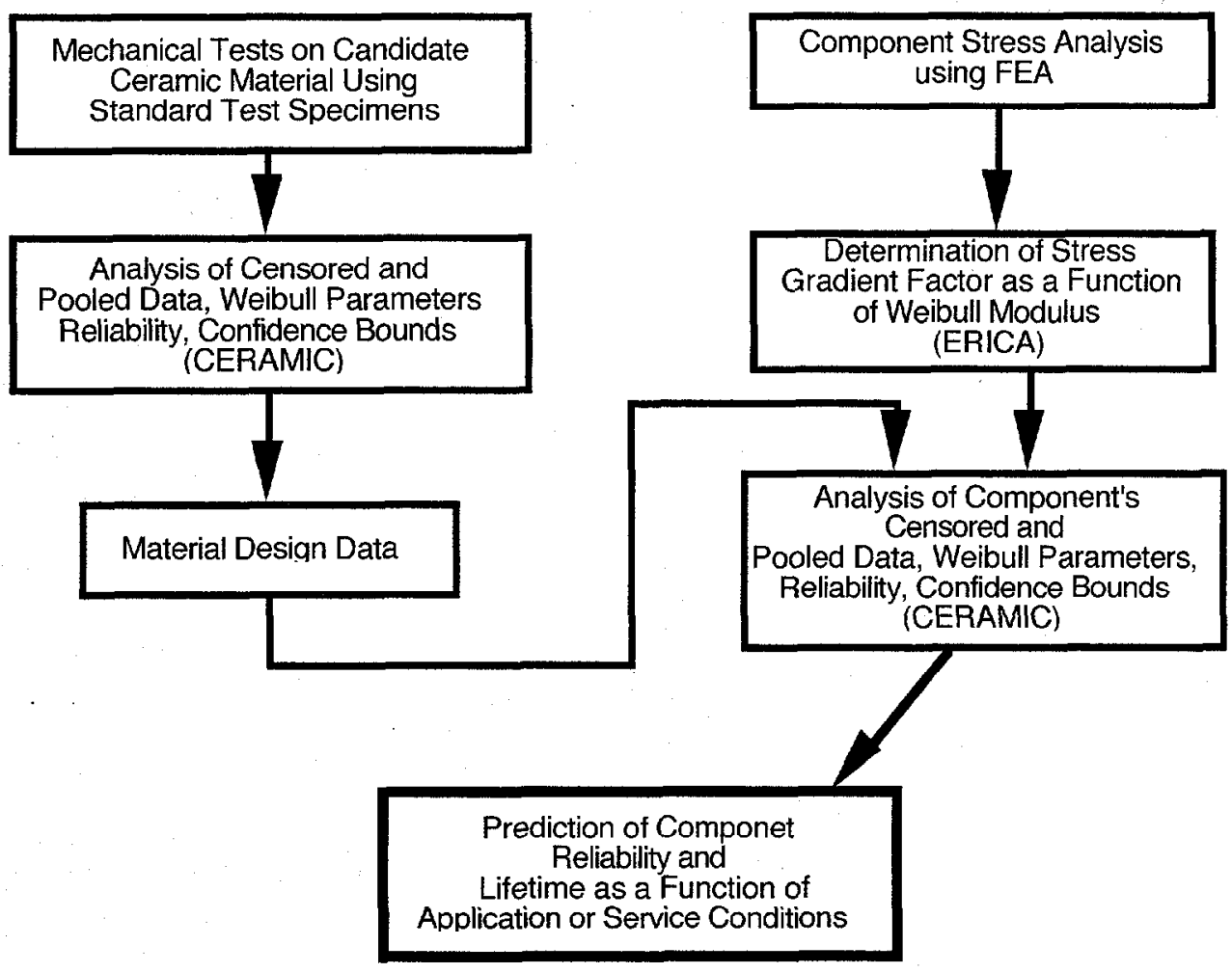

Figure 4.11. Flow chart of life prediction algorithm used in this study.

\subsection{Valve Mechanical Tests and Data Interpretation}

\subsubsection{Strength Testing Procedures and Facilities}

The intention of loading valves to failure was to compare "experimental" valve strength with "predicted" valve strength. The S149 ceramic valves were loaded to failure using a specially designed hydraulic test facility located at the $\mathrm{Y}-12$ plant at the ORNL. This test facility was designed and built as part of a Cooperative Research and Development Agreement (CRADA) 
between DDC and Lockheed Martin Energy Systems, Inc., on behalf of the DOE, Office of Defense Programs, Technology Transfer Initiative.

The hydraulic test facility could accommodate static and cyclic fatigue testing. In this study, only the static failure features of the facility were used. The test apparatus simulates the head of an S149 engine by incorporating actual valve guides and seat inserts. The maximum static pressure the system was capable of was $137.8 \mathrm{MPa}$. Figure 4.12 shows the hydraulic test facility.

To conduct a test, a valve was placed inside the simulated engine head after a new valve guide and seat insert were installed. An elastomeric seal (Model U12-175, Parker Seals, Salt Lake City, UT) was fitted around the valve head and placed between the valve and a valve seat adapter to prevent excess fluid loss (See Figure 4.13). The 8 volt excitation voltage to a pressure transducer (Model G831-300-20M, Dynisco Corp., Sharon, MA) installed on the engine head chamber was checked and if necessary, adjusted before each test. A pen recorder (Model VP6223S, Soltec Inc., San Francisco, CA) sketched the output voltage of the pressure transducer as pressure was applied. Loading was accomplished using a low volume high pressure hand pump (Model MK19, Star Hydraulics, River Grove IL). A multimeter (Model 87 , Fluke, Everett, WA) connected in parallel with the strip chart recorder displayed the maximum voltage at failure from the pressure transducer. The voltage was then converted to pressure units using a calibration factor. The rate of loading with the hand pump was rapid enough to induce valve failure within $10-20$ seconds.

After failure, the simulated engine head was disassembled and all valve pieces were collected and catalogued. The entire assembly was thoroughly cleaned with a commercial detergent and wiped down with ethyl alcohol, and a new valve guide and seat insert were pressed in the fixture. Approximately four valves could be tested in an eight hour period. 


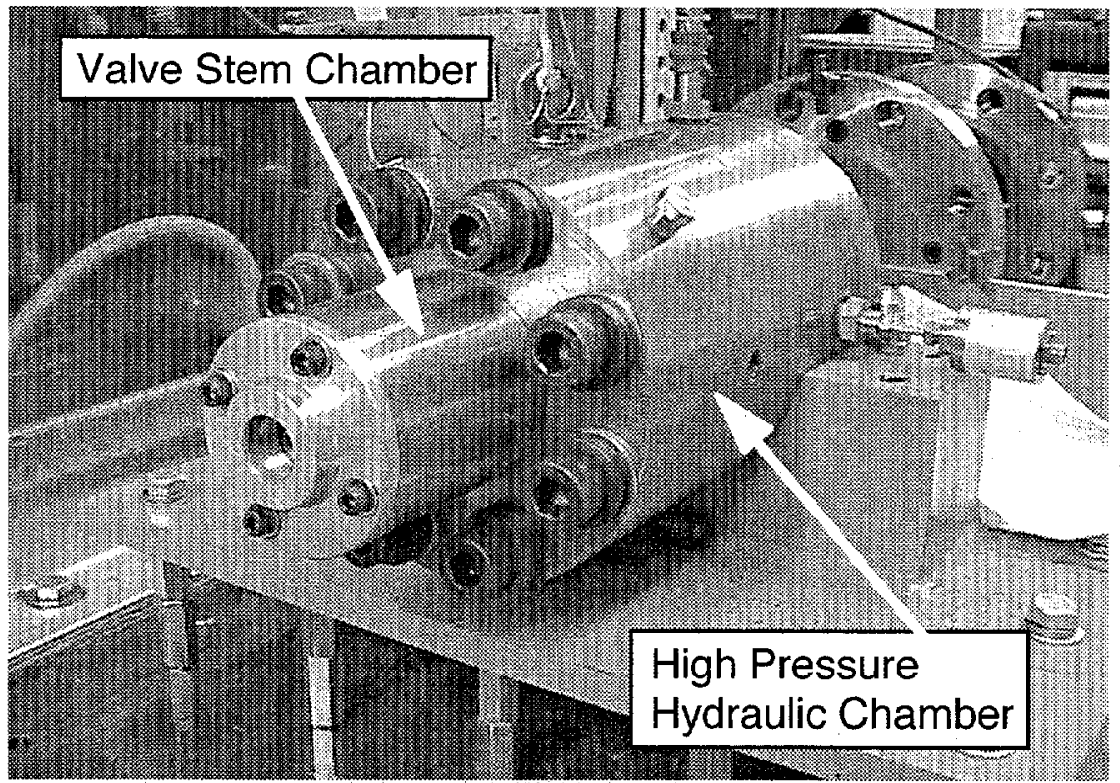

Figure 4.12. Hydraulic test facility for testing NT551 valves.

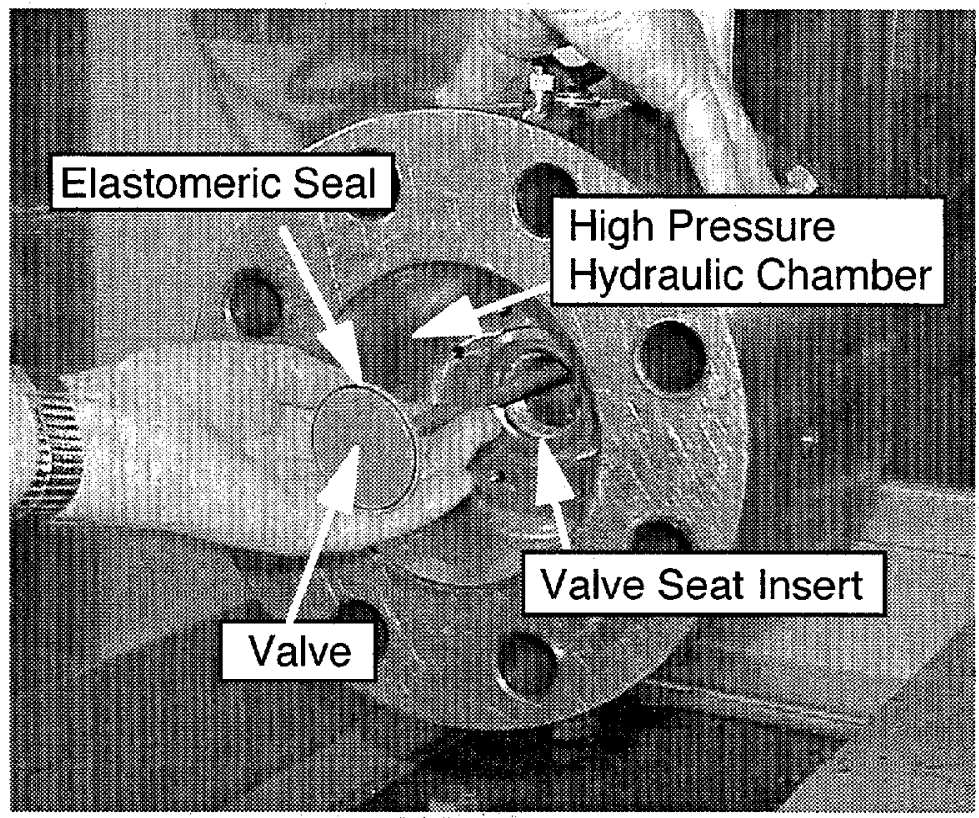

Figure 4.13. Installing valve with elastomeric seal into high pressure hydraulic chamber. 


\subsubsection{Fractographic and Censoring Procedures}

Fractography of the test valves followed the same procedures as outlined in Section 4.2 .3 of this dissertation using the ASTM C 1322 standard (1998) practice for fractographic analysis of ceramic materials.

The valve parts were ultrasonically cleaned in acetone for approximately 15 minutes to remove hydraulic fluid. Then the larger pieces of each valve were first examined using an optical stereo microscope in an attempt to locate the strength limiting flaw. Digital photomicrographs were made of every valve's failure origin. All tested valves were examined on two separate occasions and the results of each session compared for consistency. Representative samples of the different failure types were prepared for SEM analysis in the same manner as described for the test specimens in Section 4.2.3.

\subsection{Supplemental Testing and Analyses}

\subsubsection{Finite Element Modeling}

The geometry of a ceramic component can make the integration for the multiaxial and stress gradient factor (Eqs. 4.30, 4.31, and 4.32) intractable, and so an alternative method must be used. The integration is initially made possible through the use of finite element modeling of the ceramic component with appropriate boundary conditions. The result of finite element modeling is a complete stress field of the component at discrete points or nodes. The multiaxial and stress gradient factor can then be determined by combining the stress field information from finite element modeling along with a list of Weibull moduli in the range of interest. The computer program known as ERICA that was developed by ASE performs this task to calculate the multiaxial and stress gradient factor.

Two developed finite element models using ANSYS ${ }^{\mathrm{TM}}$ software (Version 5.4, Houston, PA) were used as input into the ERICA computer program. The finite element models developed were for the cylinder test specimen in four-point flexure and the diesel exhaust valve at combustion. A finite element model, previously developed for the modified ORNL tension specimen, was also used in this study (Wereszczak et al., 1996). Table 4.5 lists the material properties used for the finite element models.

The cylindrical finite element model was a three-dimensional linear elastic model which used eight noded brick elements while the valve model used axisymmetric linear elastic four noded quad elements. Contact elements were used between the load pins and the cylindrical specimen and 
between the valve and the seat insert. A two step solution was used for both models. In the first step, the cylinder and valve were displaced and brought into contact with the loading pins and the seat insert, respectively. The second step removed the displacement solution and applied a load to the model.

Two planes of symmetry exist for the cylindrical geometry and loading condition allowing a finite element model to be one-fourth actual size.

However, a one-half actual size model was chosen for the following reasons. The ERICA computer program calculates the multiaxial and stress gradient factor for every surface in the model, including symmetric plane surfaces. To remove a symmetric plane surface from the calculation, a file containing a list of nodes representing only the surfaces of interest is required for input into ERICA. To simplify the removal of symmetric planes (and the list of nodes for calculation), a one-half actual size finite element model was utilized. The required file for indicating the surface nodes of interest was easily generated, having only one small symmetric plane surface to delete from the entire nodal list.

All finite element models assumed linear elastic material properties. The multiaxial and stress gradient factor calculated from the resulting stress field is independent of the applied load. The only constraint for applied loads to the finite element models is that the resulting stress field must remain within the elastic regime of the material. For the cylinder model, an arbitrary load of $200 \mathrm{~N}$ was applied on the top loading pin. For the valve model, a combustion pressure of $16 \mathrm{MPa}$ was applied on the face of the valve. No thermal loads were applied to the valve model since the valve strength tests were conducted at $20^{\circ} \mathrm{C}$.

The ANSYS ${ }^{\mathrm{TM}}$ software places the results of the analysis in a binary file with the extension of .rst, which is read by the ERICA program. The user of the ERICA program chooses the type(s) of integration to be performed; volume integration for volume-induced failures, surface integration for surface-induced failures and edge integration for edge failures. The ERICA program prompts the user for an input list of Weibull moduli. The output from ERICA is the multiaxial and stress gradient factor for each Weibull modulus entered. 
Table 4.5. Material properties of NT551, valve seat inserts, and load pins (cylinder in four-point flexure) used for finite element analysis.

(a) Pujari, 1998

\begin{tabular}{|l|c|c|c|}
\hline Material Property & $\begin{array}{c}\text { NT55 } \mathrm{Si}_{3} \mathrm{~N}_{4} \\
\text { Valve }\end{array}$ & $\begin{array}{c}\text { Nickel-based } \\
\text { Seat Insert }\end{array}$ & Steel Load Pin \\
& $(\mathrm{b})$ & \\
\hline Elastic Modulus (GPa) & 305 & 240 & 240 \\
\hline Poisson's Ratio & 0.28 & 0.30 & 0.30 \\
\hline Coefficient of Friction & 0.30 & 0.30 & 0.30 \\
\hline
\end{tabular}

(b) Allain, 1998

(c) Beer and Johnston, 1992

\subsubsection{Fracture Toughness}

Fracture toughness is a measure of a material's resistance to crack propagation and is often expressed in regards to the stress intensity factor, $K$. An ASTM provisional method (ASTM PS 70,1998 ) was used to determine the fracture toughness of NT551. Chevron v notch specimens were prepared by Chand Kare Technical Ceramics in Worchester, MA from already machined ASTM C 1161-B flexure specimens. At the center of the flexure bar, a v notch was made using a 320 diamond grit saw. The dimensional specifications for the chevron $\mathrm{v}$ notch specimens are presented in Figure 4.14.

An Instron electromechanical test machine (Model 6027, Instron, Canton, MA) was used to perform the three-point fracture toughness tests. The tests were conducted at 20,700 , and $850^{\circ} \mathrm{C}$ to examine the influence that temperature had on fracture toughness.

The bottom half of an $\alpha$-SiC four-point flexure fixture was used for the tests (see Figure 4.9). The specimens were placed on $\alpha$-SiC load bearing pins that were $40 \mathrm{~mm}$ apart. The load was applied to the specimen using a $\alpha$-SiC rod that had a chisel point end machined into its end.

The Instron was connected to an Apple computer which performed the data acquisition using a LabView software program (Version 2.2.1, Austin, TX). The cross-head displacement rate for the fracture toughness tests was $5 \mu \mathrm{m} /$ minute. At each temperature the compliance of the machine's load train assembly was recorded. The compliance data, a measure of the elastic nature of the load train and fixturing, was subtracted from the load displacement test data before calculating $K_{I C}$. Elevated temperature tests commenced when thermal equilibrium was reached (which was 
indicated when the thermal expansion of the load rod was stabilized). After completing the fracture toughness tests, measurements of $a_{\ell}, a_{l l}$, and $a_{12}$ (see Figure 4.14) were made using an optical comparator (Model V-12, Nikon, Melville, NY).

The load used to calculate the fracture toughness is the maximum load achieved followed by stable crack extension. This is illustrated in Figure 4.15. Unstable crack extension occurs when a decrease in the load is associated with no change in the displacement, as shown with the left side curve in Figure 4.15. Stable crack propagation, which is the curve on the right side, is indicated when a decrease in the load is associated with an increase in the displacement (i.e., a continuous and stable increase in specimen compliance). Tests that display unstable crack growth after reaching a maximum load were not used in the $K_{l C}$ calculation.

The following equation from the ASTM fracture toughness provisional method was used to calculate the fracture toughness (ASTM PS 70, 1998).

$$
K_{I C}=Y^{*}\left[\frac{P_{\max } L 10^{-6}}{B W^{3 / 2}}\right]
$$

where $P_{\text {max }}$ is the maximum load in Newtons, $L$ is the load span in mm, $B$ is the width in mm and $W$ is the height in $\mathrm{mm}$ of the specimen. The stress intensity factor coefficient from the ASTM PS-70 (1998), $Y^{*}$, was formulated using Bluhm's slice model and is

$$
\begin{aligned}
& Y^{*}=-13.119\left(a_{0} / W\right)+4.6377\left(a_{0} / W\right)+14.646\left(a_{0} / W\right) \\
& +6.6883\left(a_{1} / W\right)-6.9604\left(a_{1} / W\right)+3.64679\left(a_{1} / W\right) \\
& +17.768\left(a_{1} / W\right)\left(a_{0} / W\right)
\end{aligned}
$$

where $a_{0}$ is the initial crack length in $\mathrm{mm}$ and $a_{l}$ is the average of the two lengths in mm from the front of the specimen to the end of the $v$ notch (see Figure 4.14). The provisional method states that Eq. 4.20 has a maximum error of one percent when $0.382<a_{0}<0.420$ and $0.950<a_{1}<$ 1.00. Equations 4.19 and 4.20 were programmed in a LabView software routine that calculated the fracture toughness using the load displacement data file, the appropriate compliance data file, the notch's geometry, and the elastic properties of the $\mathrm{Si}_{3} \mathrm{~N}_{4}$. 


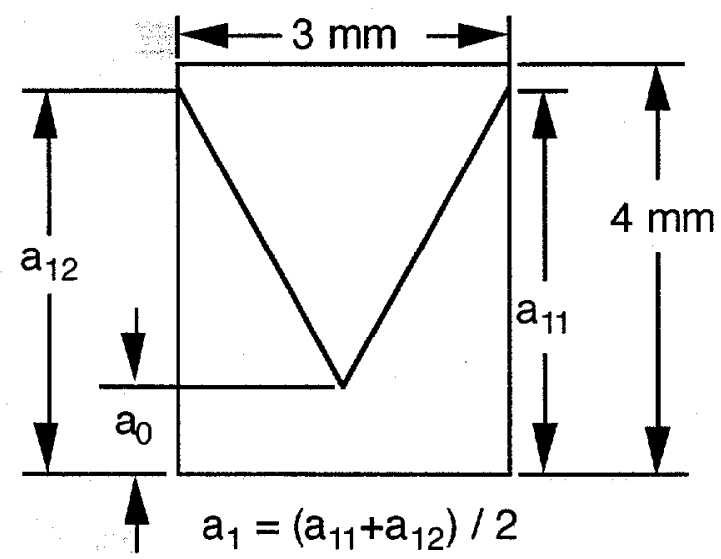

Figure 4.14. Chevron v notch dimensions.

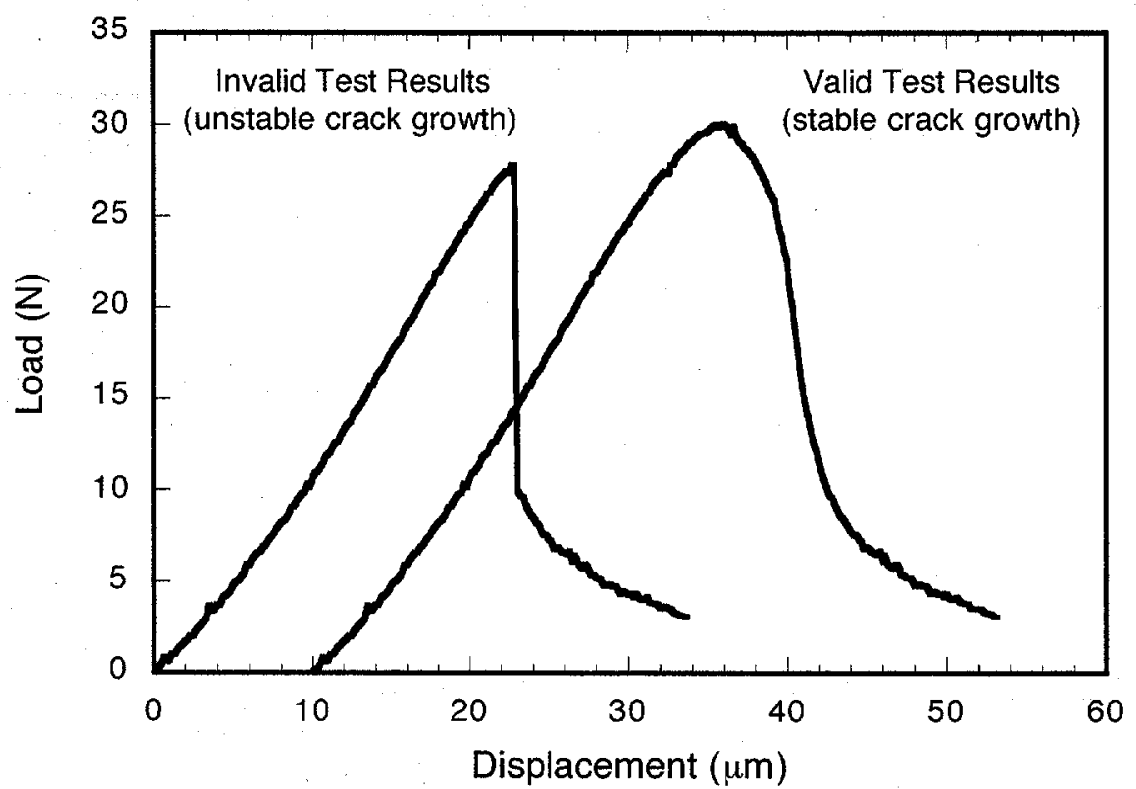

Figure 4.15. Examples of stable and unstable crack growth from chevron v notch load displacement data. 


\subsubsection{Surface Profilometry}

The surfaces of three test specimens and two S149 as-received valves were analyzed using a Series I Talysurf 120 profilometer (Rank Taylor Hobson, Leicester, England). Interest existed in examining the influence the relative surface roughness had toward strength and to compare the surface finishes of the valves to that of each test specimen.

The test specimens that were examined were an ASTM transverse flexure bar, a cylindrical flexure bar and a modified ORNL tension specimen. All test specimens were machined using a 320 diamond grit wheel but in separate machining processes. Each surface scan was $4 \mathrm{~mm}$ in length. The as-received valves analyzed consisted of one transversely machined and one longitudinally machined. The valve fillet radius region was selected since it was the region that contained the highest tensile stresses as predicted by finite element analysis. A $4 \mathrm{~mm}$ scan was made on each valve in this fillet radius region.

The Series $I$ instrument used a $2 \mu \mathrm{m}$ radius spherical stylus and a variable inductance transducer. The traverse speed for the scans was $1.0 \mathrm{~mm} / \mathrm{sec}$. The stylus arm was $60 \mathrm{~mm}$ in length and applied a 70-100 mgf to the surface. Under these conditions the manufacturer states the resolution of the surface scan to be $32 \mathrm{~nm}$. 


\section{RESULTS}

Over the course of this research, three vintages of NT551 were strength tested. A complete mechanical characterization was made of NT551 vintage three, which is presented in this chapter. SGNIC deemed this vintage three to be most representative of the NT551 valves, so its measured properties and analyses were systematically examined.

Table 5.1 presents the uncensored Weibull distribution parameters for the three vintages tested at the loading rate of $36 \mathrm{~N} / \mathrm{s}$, and at 20 and $850^{\circ} \mathrm{C}$. At $20^{\circ} \mathrm{C}$, the Weibull modulus from vintage one was nearly $60 \%$ greater in value than the Weibull moduli from vintage two and three, which were equivalent at a 95 percent confidence level. The characteristic strengths of the three vintages tested at $20^{\circ} \mathrm{C}$ were of equal value at a $95 \%$ confidence level.

At $850^{\circ} \mathrm{C}$, the Weibull moduli for the three vintages were equivalent at a $95 \%$ confidence level. The characteristic strengths for two of the three vintages were equivalent at $850^{\circ} \mathrm{C}$. At a $95 \%$ confidence level, vintage two and three were statistically different by a margin of $7 \mathrm{MPa}$. Since these confidence values were so close to agreement, it was resolved that all three vintages were essentially equivalent at $850^{\circ} \mathrm{C}$. A complete listing of NT551 vintage three test results are presented in Appendix A, Experimental Results.

Table 5.1. Comparison of three NT551 vintages all tested at $36 \mathrm{~N} / \mathrm{s}$ loading rate and at 20 and $850^{\circ} \mathrm{C}$.

\begin{tabular}{|c|c|c|c|c|}
\hline Vintage & Temp $\left({ }^{\circ} \mathrm{C}\right)$ & No. & Weibull Modulus & $\begin{array}{c}\text { Characteristic } \\
\text { Strength }(\mathrm{MPa})\end{array}$ \\
\hline 1 & 20 & 50 & $22(17.9,26.4)$ & $838(826,849)$ \\
\hline 2 & 20 & 30 & $11.4(8.5,14.7)$ & $822(793,850)$ \\
\hline 3 & 20 & 30 & $9.4(7.0,12.3)$ & $805(772,839)$ \\
\hline 1 & 850 & 30 & $8.6(6.3,11.3)$ & $592(565,619)$ \\
\hline 2 & 850 & 30 & $7.5(5.7,9.4)$ & $643(609,676)$ \\
\hline 3 & 850 & 30 & $8.5(6.3,10.9)$ & $576(550,602)$ \\
\hline
\end{tabular}




\subsection{Weibull and Lognormal Distributions of NT551 Data}

Two sets of NT551 strength data were modeled using a Weibull and a lognormal distribution to examine the goodness-of-fit each distribution model had with the data. The Weibull distribution is probably the most widely used distribution function for modeling reliability due in part to its mathematical simplicity (Crowder et al., 1991). In addition, the Weibull distribution represents the strength distribution of most ceramic materials quite well. The lognormal is also a skewed distribution being asymmetric about the mean, and is used in reliability studies. Both distributions provide failure probabilities for only positive valued input, such as strength. This differs from other distributions, such as the Gaussian distribution, which can provide failure probabilities from negative input values.

The data chosen for this exercise represent the strength variance within a data set. One data set was chosen from the cylindrical flexure tests and has a small variance in the strength values. The other data set was chosen from ASTM C 1161-B flexure tests and has a greater variance in strength. The strength-limiting flaw for the cylindrical data set was extrinsic and the strengthlimiting flaw for the ASTM C 1161-B data set was intrinsic (see Section 4.2.3).

The median rank is a non-parametric method for assigning the failure probability to data (Crowder et al., 1991). By sorting data in ascending order, the failure probability is assigned using Eq. 4.41 presented in Section 4.2.4. This empirical method assumes the test specimens have all failed from the same flaw and that there are no suspended or run-out data points. The empirical survival function based on Eq. 4.41 is

$$
S=1-P_{f}=1-\frac{i-0.5}{n}
$$

A method to check the goodness-of-fit that a parametric model has with the data is to produce scatter plots using the data as the independent variable and the empirical survival function as the dependent variable. The adequacy of the parametric model can be examined graphically. The Weibull distribution is written as:

$$
\ln \{\ln S(\sigma)\}=m \ln (\sigma)-m \ln \left(\sigma_{0}\right)
$$

where $\sigma$ is the failure strength of the specimen in $\mathrm{MPa}$, and $m$ and $\sigma_{0}$ are the shape and scale parameters, respectively. By plotting the left hand side of Eq. 5.2 against $\ln$ (failure stress), an 
assessment of the Weibull model can be made. If the data is roughly linear, the model is considered suitable.

The same graphical process can be used for the lognormal distribution. The survivor function is

$$
S(\sigma)=1-\Phi\left(\frac{\ln (\sigma)-\mu}{\theta}\right)
$$

where $\Phi$ is the normal distribution function, $\mu$ and $\theta$ are the mean and standard deviation, respectively. Rearranging Eq. 5.3 yields

$$
\Phi^{-1}(1-S(\sigma))=\frac{\ln (\sigma)}{\theta}-\frac{\mu}{\theta}
$$

A plot of the left-hand side of Eq: 5.4 against $\ln$ (failure stress) should be roughly linear if the model is appropriate. Using this graphical method it is assumed that the empirical survivor function has an inverse function without explicitly fitting the model (Crowder et al., 1991).

Presented in Figures 5.1 and 5.2 are the goodness-of-fit graphs for ASTM C 1161-B flexure bars for the Weibull and lognormal distribution models. In each plot the data show a rough linear trend and it would be difficult to identify either model as a better fit. In Figures 5.3 and 5.4 the cylindrical flexure data is presented for the Weibull and lognormal models. The lognormal plot shows a stronger trend in linearity when compared to the Weibull model.

Another graphical goodness-of-fit test for the Weibull and the lognormal distributions is known as the probability-probability plot. It compares the distribution function of the model after having estimated values for the model parameters against the empirical survivor function (Eq. 5.1). If linearity is present then good agreement exists between the fitted model and the data.

The probability-probability plots for the ASTM C 1161-B specimens are presented in Figures 5.5 and 5.6. Both the Weibull and lognormal models show a linear trend but also contain an "s" curve in the data. Neither model stands out as being a better fit to the data.

The probability-probability plots for the cylindrical flexure specimens are presented in Figures 5.7 and 5.8. The data in both of these scatter plots show a stronger trend in linearity with the lognormal model then with the Weibull model, suggesting that the lognormal model may be a better fit to the data. 
Plotted in Figures 5.9 and 5.10 are the Weibull and lognormal density functions for the ASTM C 1161-B data set. Both distributions are asymmetric about a mean value; the Weibull shows a lengthened right tail while the lognormal shows a lengthened left tail. The larger right tail of a distribution function accounts for estimates of "early" failures while the larger left tail accounts for estimates of longer than average lifetimes.

Figures 5.11 and 5.12 show the Weibull and lognormal density functions for the cylindrical flexure data. The Weibull plot shows the same trend as found in Figures 5.9 for the ASTM C 1161-B flexure data, a longer right side tail. The lognormal plot shows a close resemblance to a Gaussian distribution being symmetric about the mean value.

The goodness-of-fit tests presented show that either distribution would be appropriate for the data with the cylindrical data being slightly favored by the lognormal distribution. The density functions show that as the variance in the data is reduced, the distribution tail for the lognormal models shifts from the right side to a more symmetric, or Gaussian-like distribution.

In this study the Weibull distribution was used to represent the strength of NT551 since it has been shown from this exercise to be equally comparable to the lognormal distribution. The strength of many ceramic materials is typically modeled using the Weibull distribution, and it was considered very appropriate for use in this study.

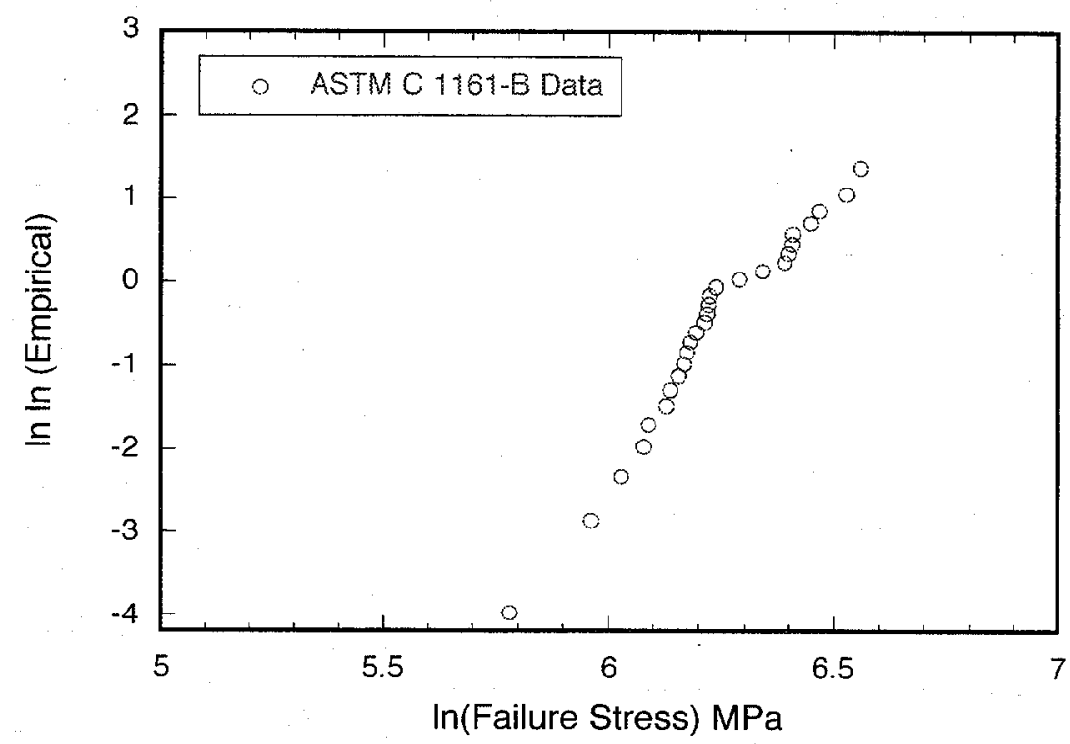

Figure 5.1. ASTM C 1161-B flexure data as a Weibull distribution. 


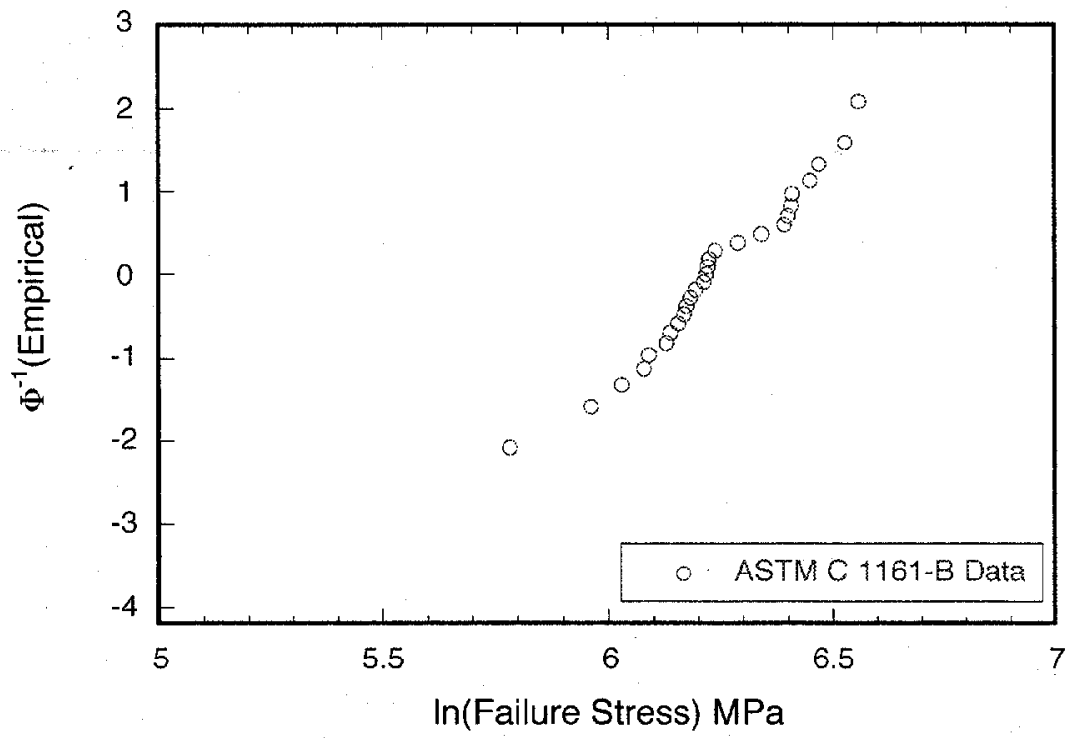

Figure 5.2. ASTM C 1161-B flexure data as a log normal distribution.

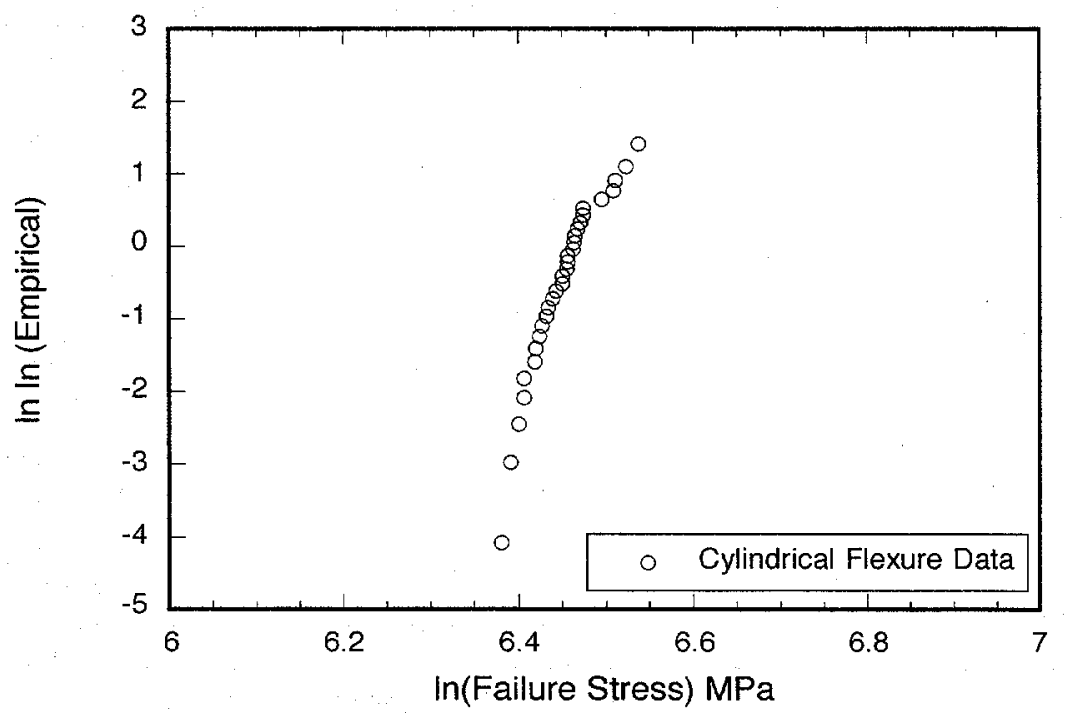

Figure 5.3. Cylindrical flexure data as a Weibull distribution. 


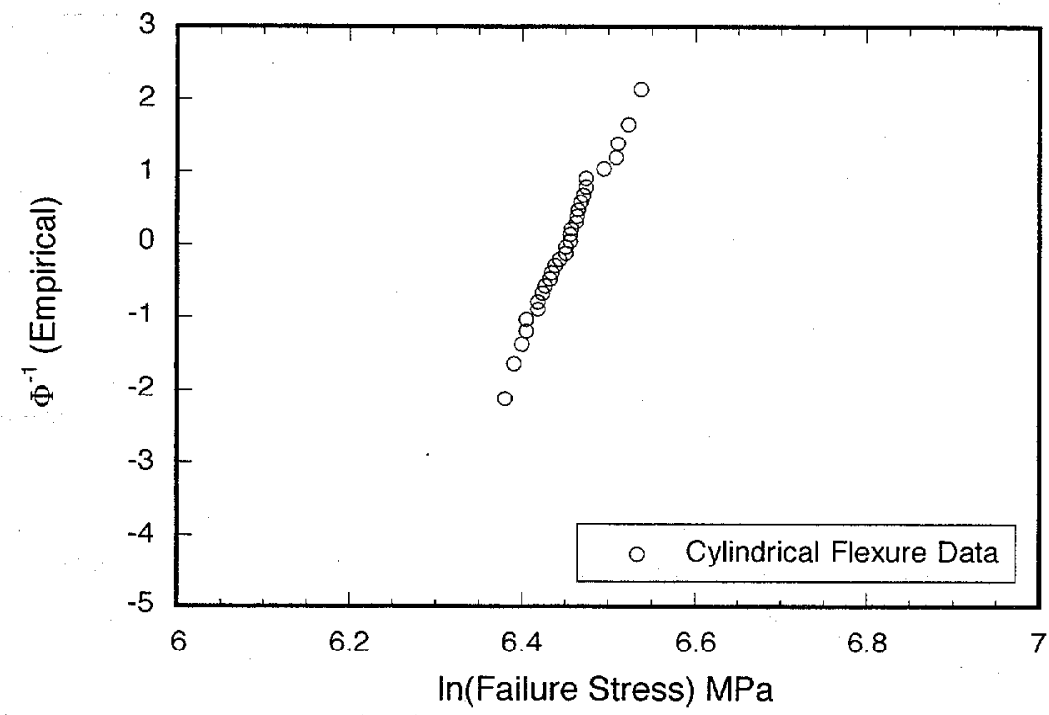

Figure 5.4. Cylindrical flexure data as a lognormal distribution.

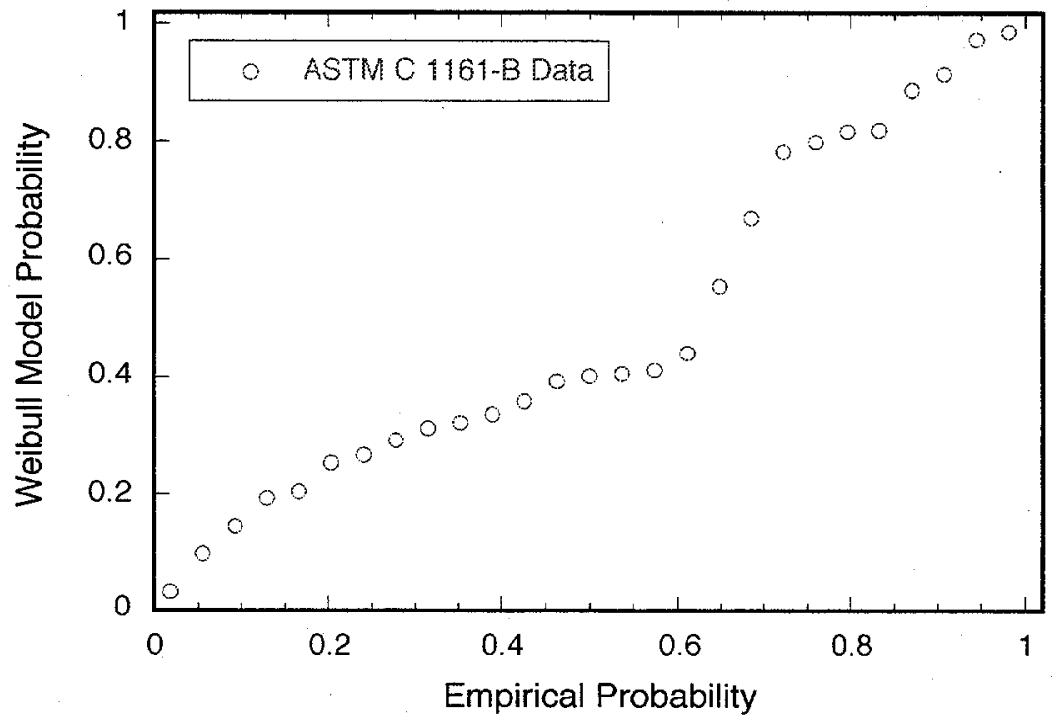

Figure 5.5. ASTM C 1161-B flexure data as a Weibull distribution probability-probability plot. 


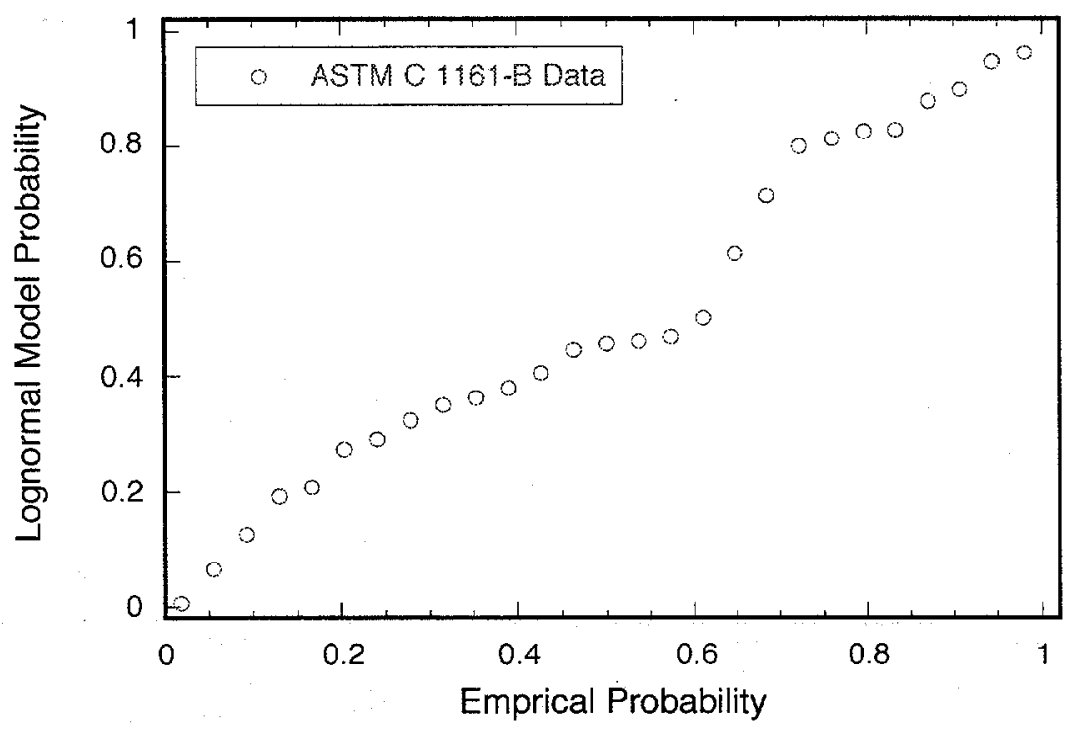

Figure 5.6. ASTM C 1161-B flexure data as a lognormal distribution probability-probability plot.

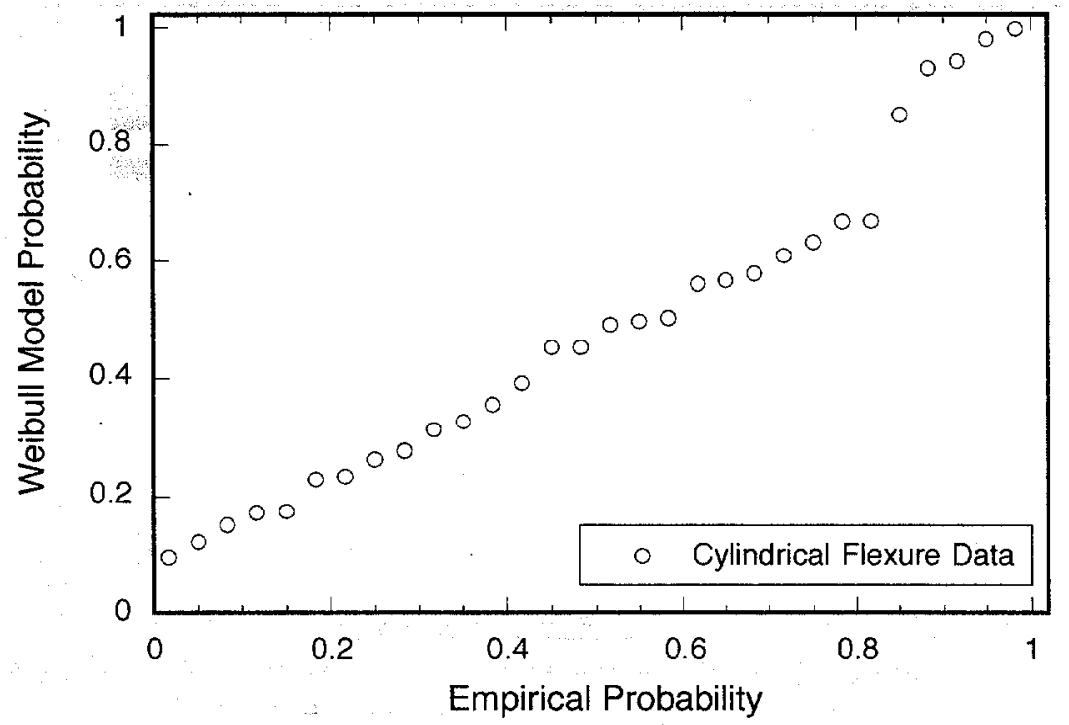

Figure 5.7. Cylindrical flexure data as a Weibull distribution probability-probability plot. 


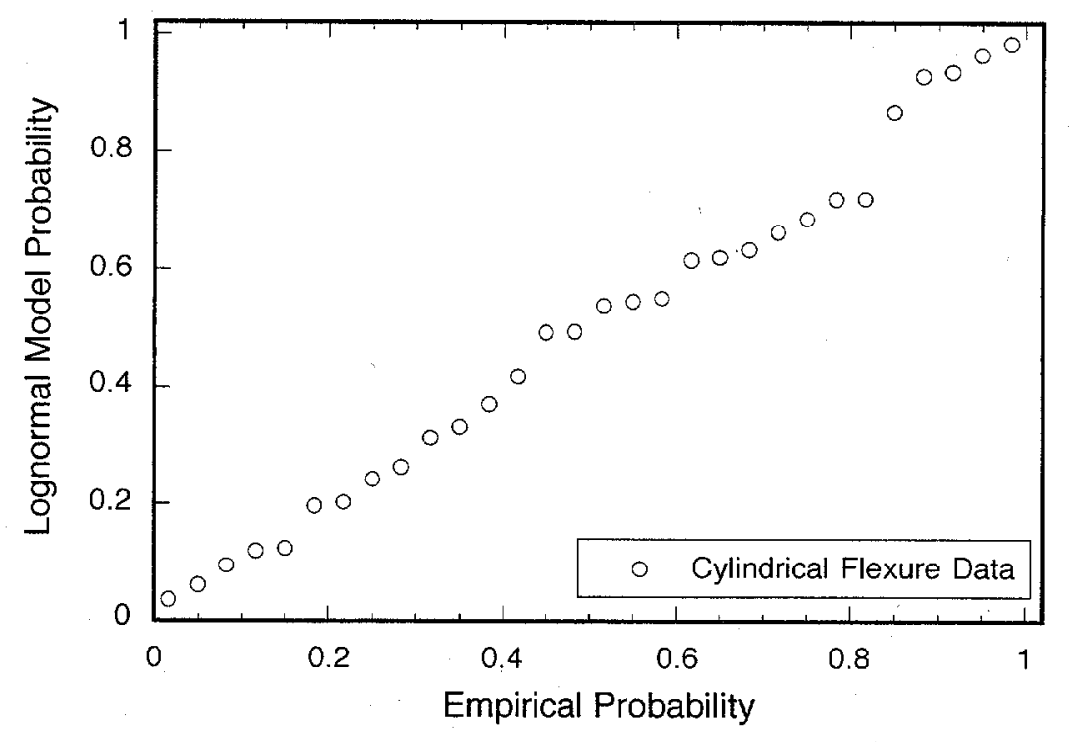

Figure 5.8. Cylindrical flexure data as a lognormal distribution probability-probability plot.

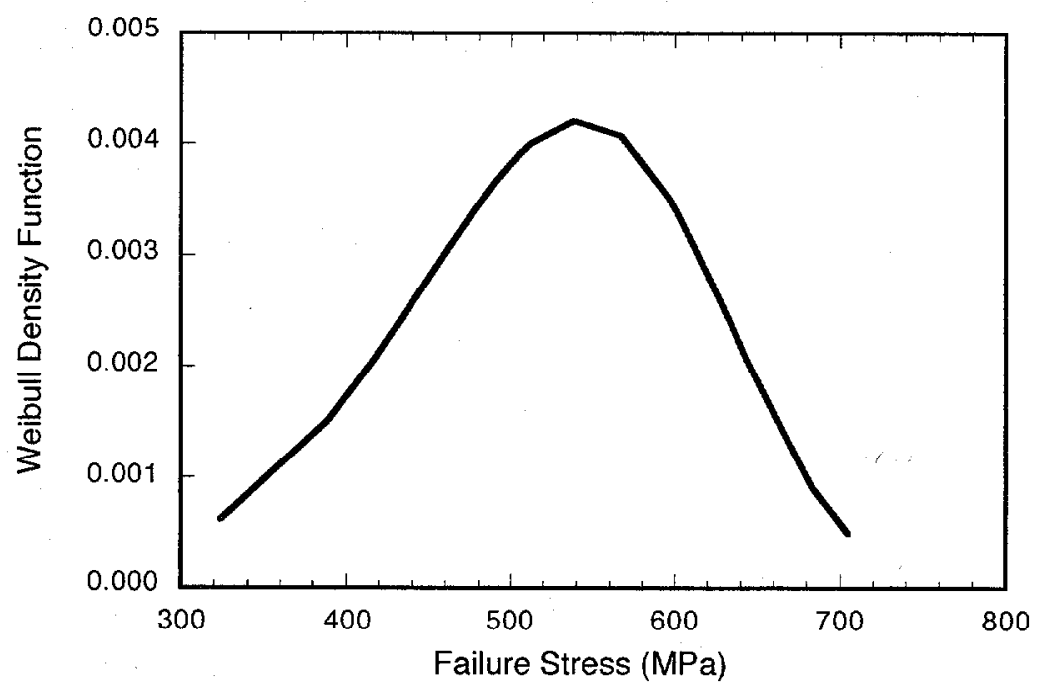

Figure 5.9. Weibull density function using ASTM C 1161-B flexure data. 


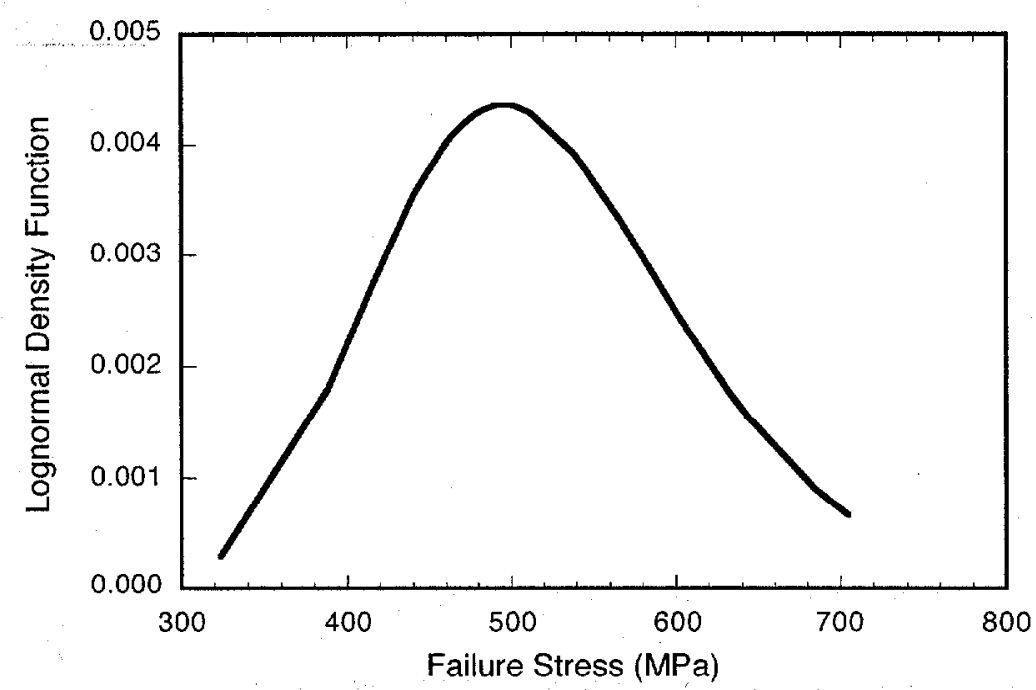

Figure 5.10. Lognormal density function using ASTM C 1161-B flexure data.

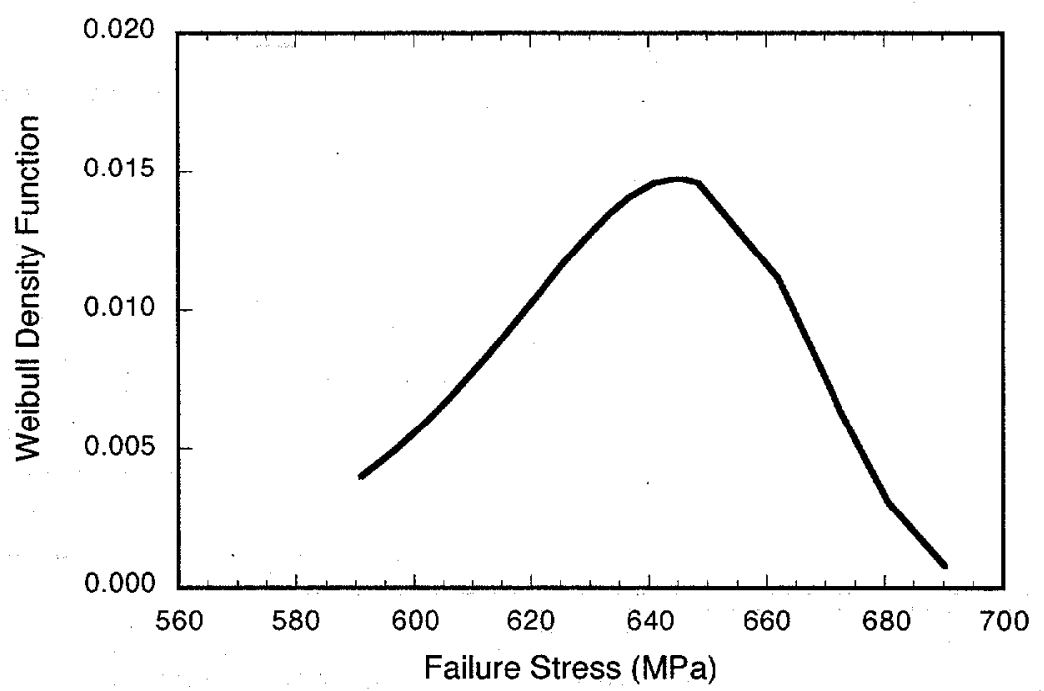

Figure 5.11. Weibull density function using cylindrical flexure data. 


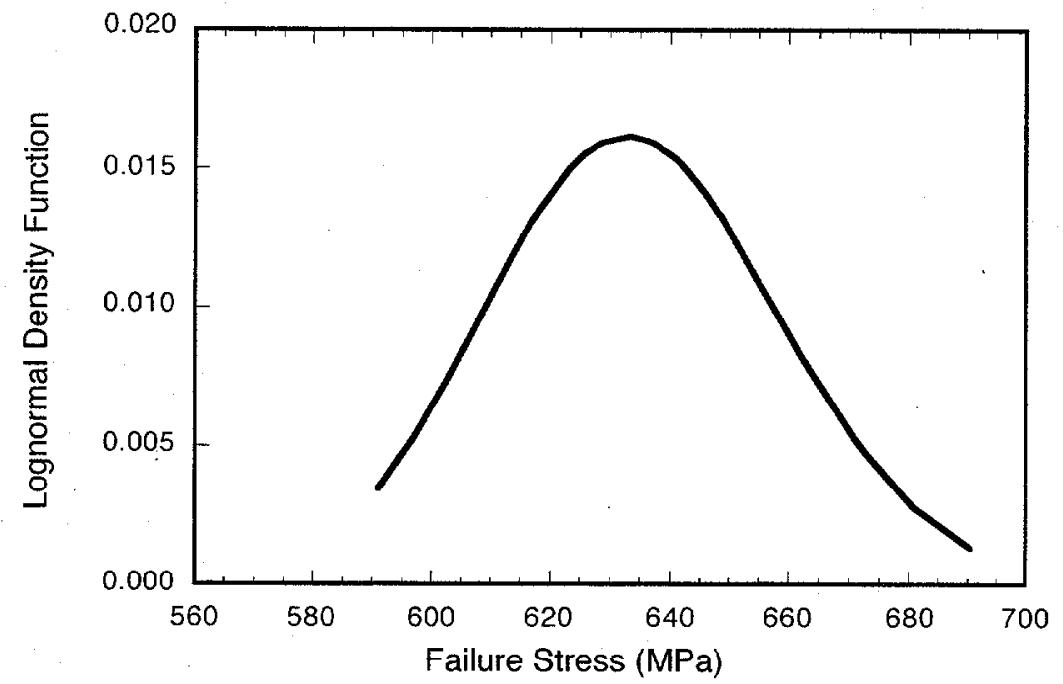

Figure 5.12. Lognormal density function using cylindrical flexure data.

\subsection{Fractographic Analyses of Test Specimens}

\subsubsection{Overview of NT551 Specimen Flaw Populations}

Determining the failure origin of a test specimen or component is an integral part of the process of censoring strength data. A total of four failure modes were identified from the test specimens; two intrinsic flaw types and two extrinsic flaw type. The designations and flaw type descriptions are as follows:

SUR1-MD and SUR2-MD--extrinsic flaw types introduced after material fabrication and located on the surface. The "SUR" and the "MD" in the SUR1-MD and SUR2-MD designations refer to surface damage due to machining. The SUR2-MD designation corresponds to the cylindrical flexure specimens while the SUR1-MD designation corresponds to all other test specimens. Both of these flaw types are relatively deep machining grooves made into the material. The centerless machining process used for the cylindrical flexure specimens produced unique machining grooves or patterns not found on the other test specimens; consequently, the SUR1-MD and SUR2-MD represent different failure types. These flaw types are not detectable by the naked eye and require optical and SEM methods for identification.

VOL-SF-an intrinsic or volume flaw type consisting of a region of compositional inhomogeneity in the secondary phase. These were designated as VOL-SF because they appeared 
to the naked eye as white snowflake (SF)-like patterns on the surface. There was a higher concentration of VOL-SF defects on the surface of the flexure bar but they were also found throughout the bulk of the material. These regions of compositional inhomogeneity sometimes ranged hundreds of microns in size. This flaw type is evident in Figure 4.5.

Figure 5.13 shows an optical view of an ASTM C 1161-B flexure bar that was polished to a mirror finish before imaging and contains regions of snowflakes. Figures 5.14 and 5.15 are high magnification secondary electron photomicrographs captured by the SEM of the same flexure bar. Figure 5.14 shows the NT551 microstructure in a region where there were no snowflakes while Figure 5.15 shows a region where snowflakes were identified. A pencil mark drawn on the flexure bar surface through a snowflake region (not shown in Figure 5.14) was used to locate them when viewed using the SEM. In Figure 5.15, there are several very dark regions at the grain boundaries (see arrows in Figure 5.15), while in Figure 5.14 there are very few dark regions at the grain boundaries. These dark areas captured by the SEM are the white snowflake regions shown in Figures 4.5 and 5.13.

To gain an understanding of the VOL-SF failure type, several investigations were conducted using the SEM facilities. The first hypothesis regarding the snowflake regions was that they denoted areas of porosity due to an apparent absence of the secondary phase (Andrews et al., 1999; Wereszczak et al., 1998). Using secondary electron SEM imaging there was a secondary phase apparently missing, as shown in Figures 5.15 and 5.16 (b)). The dark regions found at the grain boundaries are evidence of porosity.

By using backscatter electron (BSE) imaging technique at the same location, the apparent pores were identified as a compound with a relatively low atomic number. In the BSE image shown in Figure 5.16 (a), elements that have low atomic numbers are represented by the dark-toned regions, while elements of high atomic numbers are represented by the lighter-toned regions. An EDX (see Section 4.2.3) was used to further examine the dark regions presented by BSE imaging.

Elemental mapping captured images that indicate the presence and spatial distribution of a single element. Each point in the digital image contained a full $\mathrm{x}$-ray spectrum that was used to map the location of the particular elements. A series of these elemental mappings of the same snowflake region is presented in Figure 5.16 (c)-(h) along with the BSE image (a) and the secondary electron image (b). Images acquired using the EDX imaging indicated the presence of aluminum, yttrium, neodymium, nitrogen, oxygen, and silicon. EDS graphical representation of these images can be found in Appendix B, NT551 Vintage Three EDS Results.

The centrally located, dark in appearance grain boundaries in Figure 5.16 (a) and (b) are a region of snowflakes, while surrounding this central region are light in appearance grain boundaries that are non-snowflake regions. To the left of (a) and (b) in Figure 5.16 are the elemental maps of aluminum (c), yttrium (d), and neodymium (e). The lighter toned regions in 
each elemental map indicates the presence and spatial distribution of each element. Notice that the lighter toned regions are located at grain boundaries that are not snowflake regions.

To the right of (a) and (b) in Figure 5.16 are the elemental maps of nitrogen (f), oxygen (g) and silicon (h). Notice that nitrogen was detected in all regions except the grain boundaries, and that images $(\mathrm{g})$ and $(\mathrm{h})$ show a high concentration of oxygen and silicon in the regions corresponding to the snowflakes. The absence of neodymium and yttrium in these regions was evident from the dark tones captured in these EDX images. This was due to the relatively high atomic numbers neodymium (60) and yttrium (39) have when compared to the atomic numbers of nitrogen (7), oxygen (8), and silicon (14).

The conclusion from these elemental maps was that a separation in the secondary phase of NT551 had occurred or that the two different secondary phases existed during material processing. The composition of the secondary phase in snowflake regions was $\mathrm{SiO}_{2}$ while the composition of the secondary phase in the non-snowflake regions contained $\mathrm{Al}_{2} \mathrm{O}_{3}, \mathrm{Y}_{2} \mathrm{O}_{3}$, and $\mathrm{Nd}_{2} \mathrm{O}_{3}$. The snowflake areas contained regions of porosity as shown in the secondary electron SEM image, but it was believed that they were created by the mechanical polishing methods used in sample preparation. In some manner, portions of the $\mathrm{SiO}_{2}$ were selectively removed when polishing the sample, because it was likely not as hard as the $\mathrm{Al}_{2} \mathrm{O}_{3}-\mathrm{Y}_{2} \mathrm{O}_{3}-\mathrm{Nd}_{2} \mathrm{O}_{3}$ secondary phase, creating the porous appearance when examined using the SEM.

VOL-AGG--an intrinsic flaw type consisting of an optically dark speck found within the bulk of the material but predominantly around the outer perimeter in a reaction layer region of the test specimen. The AGG designation refers to an agglomerate flaw type which is a clustering of grains or other particles in a single region. Because of the visual contrast difference between the black agglomerate and the light gray bulk material color, these flaws could almost be seen with the naked eye and were approximately $20-40 \mu \mathrm{m}$ in size. This flaw type is also evident in Figure 4.5.

UNK - failure origins that could not be identified were classified as unknown. Photomicrographic images representing each failure mode are presented in the next section along with two examples of unidentified (UNK) failures. 

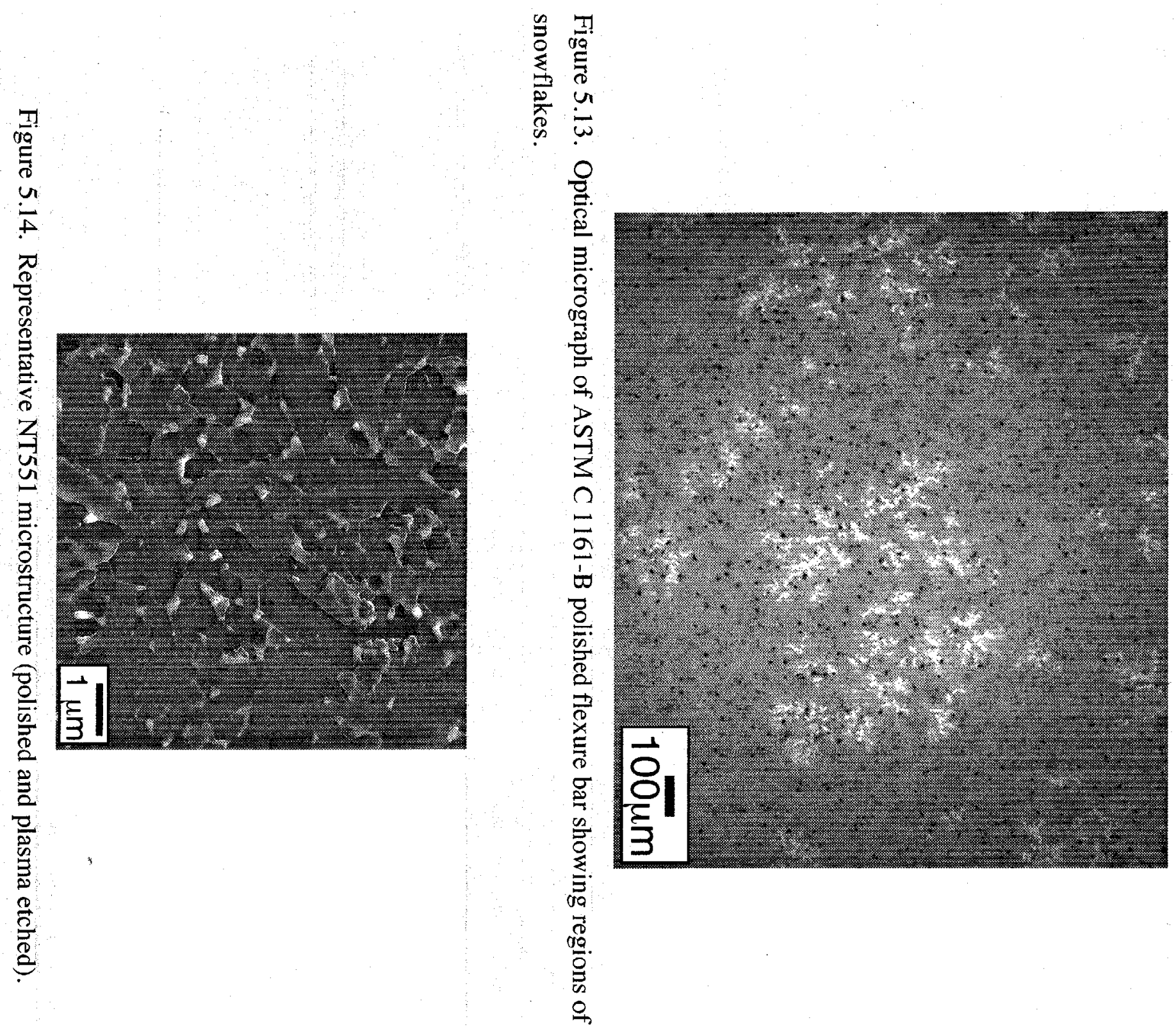


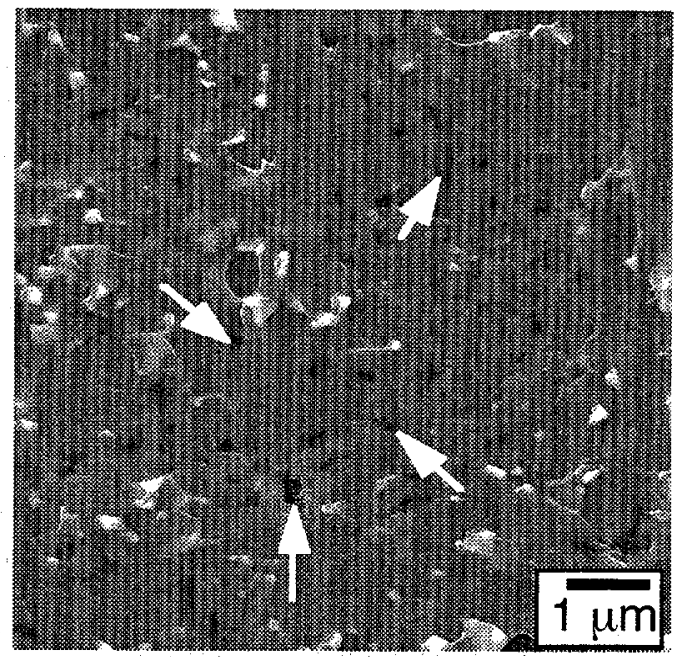

Figure 5.15. NT551 microstructure within snowflake region. Arrows point to locations in the secondary phase where preferential polishing had occurred.

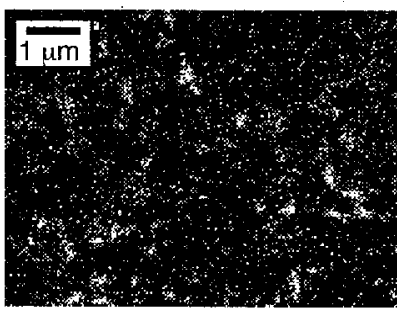

(c) Aluminum

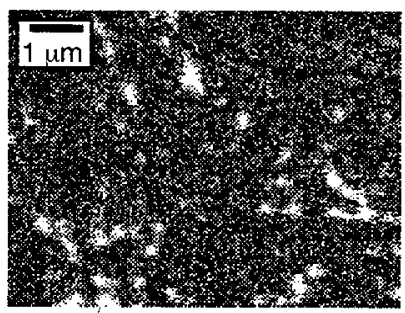

(d) Yttrium

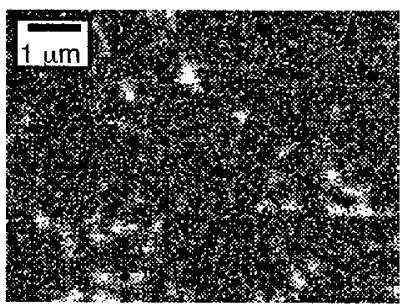

(e) Neodymium

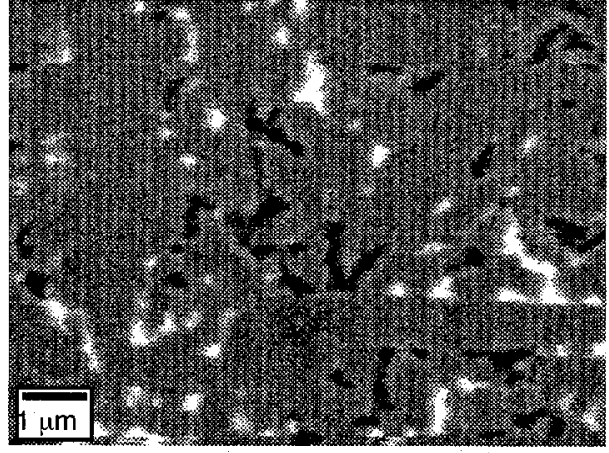

(a) Backscatter SEM image

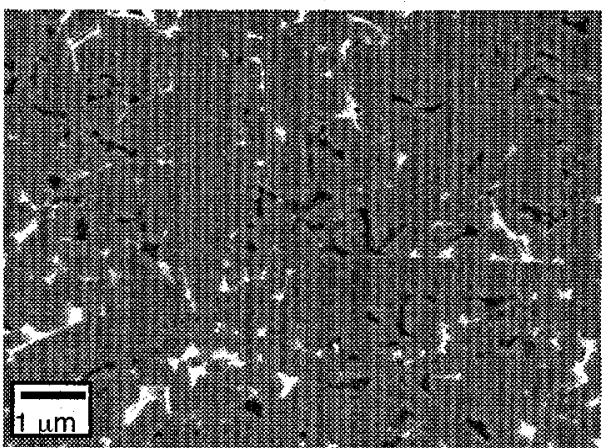

(b) Secondary electron SEM image

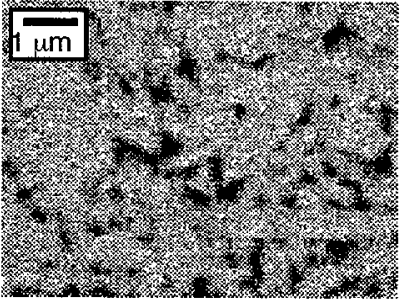

(f) Nitrogen

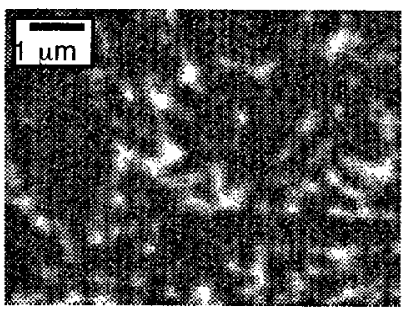

(g) Oxygen

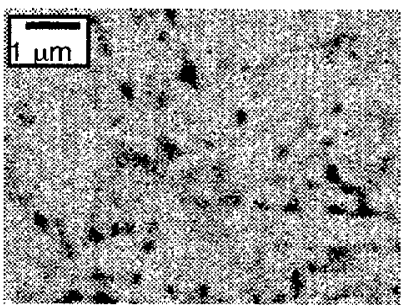

(h) Silicon

Figure 5.16. Elemental mapping of VOL-SF region. Images (a) and (b) are overall views while (c) through (h) present aluminum, yttrium, neodymium, nitrogen, oxygen, and silicon, respectively. 


\subsubsection{Fractography of Test Specimens}

Presented in this section are photomicrographic digital images illustrating the strength-limiting flaws identified through fractographic analysis. Nearly every test specimen was photographed, but for the sake of brevity, only representative images of all failure types will be shown. All test specimens were examined on three separate occasions using an optical stereo microscope.

Four modes of failure were identified through fractographic analysis; SUR1-MD, SUR2-MD, VOL-SF and VOL-AGG. Those specimens that were not identified as one of the above failure modes were catalogued as unknown (UNK). For the ASTM C 1161-B specimens without regard to machining orientation, $54 \%$ failed from VOL-SF, 37\% failed from SUR1-MD, $2 \%$ failed from VOL-AGG, and 7\% were unidentified or unknown failures. All of the cylindrical specimens failed due to SUR2-MD. The modified ORNL tension specimens exhibited 84 percent SUR1-MD failures, $11 \%$ VOL-AGG failures and 5\% VOL-SF failures.

\subsubsection{Surface-Induced Failure from Machining Damage (SUR1-MD, SUR2-MD)}

The dominant strength-limiting flaw for the modified ORNL tension specimens and for the ASTM C 1161-B transversely machined flexure specimens tested at $20^{\circ} \mathrm{C}$ was SUR1-MD. This surface-induced failure is a result of relatively deep grooves on the surface of the specimen due to the machining process. The orientation of these machining grooves on the surface of the specimens is orthogonal to the maximum applied tensile load. Examples of this strength-limiting flaw are presented in Figures 5.17 through 5.20.

Depicted in Figure 5.17 is a SUR1-MD failure from the transversely machined ASTM C 1161B specimen 30-12-2. This digital composite image shows the fracture plane in the top portion while the bottom portion shows the corresponding fracture tensile surface. The fracture mirror seen in the top portion of the composite image is the smooth region and is marked with a dashed line. Failure originates at the center of the fracture mirror; the semicircular shape of the fracture mirror indicates that failure originated at, or very near, the surface of the specimen. The corresponding fracture tensile surface image shows that the fracture plane coincides with one of the machining grooves on the surface. Illustrated in Figure 5.18 is the same flexure specimen failure surface viewed with the SEM. This image is taken at an oblique angle to the fracture surface and shows a portion of the fracture plane and corresponding tensile surface. Along the junction of the fracture and tensile surfaces as indicated with arrows, the image shows the remains of a relatively deep machining groove on the right and left sides.

Another digital composite image depicting a SUR1-MD failure is shown in Figure 5.19 that also comes from an ASTM C 1161-B transversely machined specimen (30-10-7). Corresponding 
about the fracture origin on the tensile surface are white regions that are snowflake-like in appearance. Again the fracture mirror in the upper half of the composite image is semicircular in shape (dashed line) and the fracture plane follows a machining groove in the lower half of the image. When comparing the fracture surface with the corresponding tensile surface, the snowflake region does not align itself with the fracture origin. A detail image of this fracture origin taken at an oblique angle to the fracture surface using the SEM is shown in Figure 5.20. Notice the remains of the relatively deep machining groove as indicated with arrows where the fracture plane meets the tensile surface.

All of the cylindrical flexure specimens failed from SUR2-MD and an example of this is shown in Figure 5.21 from specimen FF-29. The semicircular shaped fracture mirror shown with a dashed line indicates that failure began at or very near the tensile surface. The tensile surface shows that the failure plane is parallel to one of the machining grooves. In Figure 5.22, a SEM image of the same specimen is presented that is at an oblique angle to the fracture surface. Indicated with arrows are the remains of the machining groove where failure initiated. This imagc also illustrates along the tensile surface the depth of some of the grooves made during the machining process.

The last examples of images depicting a surface-induced failure due to machining are shown in Figures $5.23,5.24$, and 5.25 where again the specimens shown are from the cylindrical geometry. The fracture mirror in Figure 5.23 is semicircular in shape (see dashed line) and the fracture plane aligns itself with one of the machining grooves shown in the tensile surface. Figure 5.24 is a detail of the fracture plane from the same cylindrical specimen illustrating the grain structure and the depth of the machining groove $(2-3 \mu \mathrm{m})$ where portions of the machining groove are missing.

At higher magnifications, the fracture plane of another cylindrical specimen (SF-19) shows evidence of microcracking just below the machined surface (Figure 5.25). The arrows in Figure 5.25 point out several microcracks that are attributed to the high compressive stresses exerted during the machining process (Ott et al., 1997). The information from Figure 5.25 suggests that failures from machining damage, where portions of the machining groove are missing at the fracture surface, may be due to microcracking beneath the surface. 


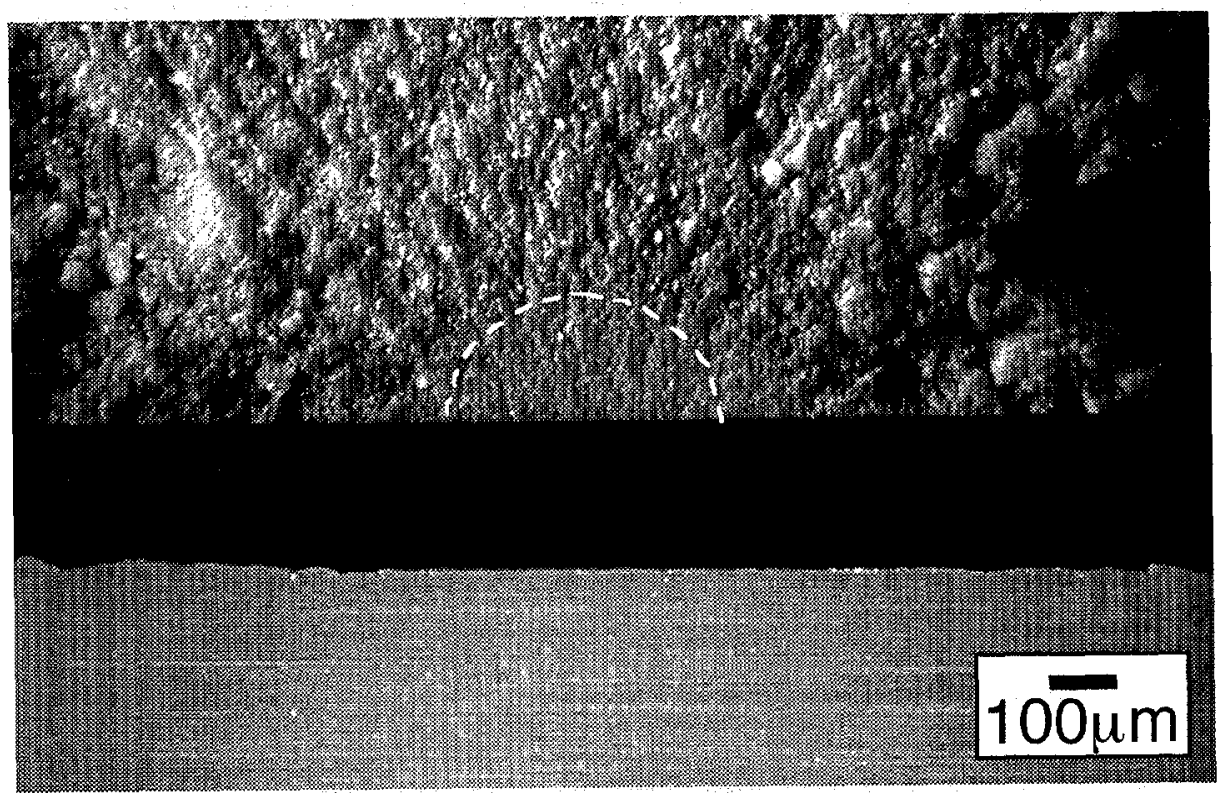

Figure 5.17. ASTM C 1161-B flexure specimen fracture and corresponding tensile surfaces.

Failure from machining damage (SUR1-MD). $\sigma_{\mathrm{f}}=509 \mathrm{MPa}$.

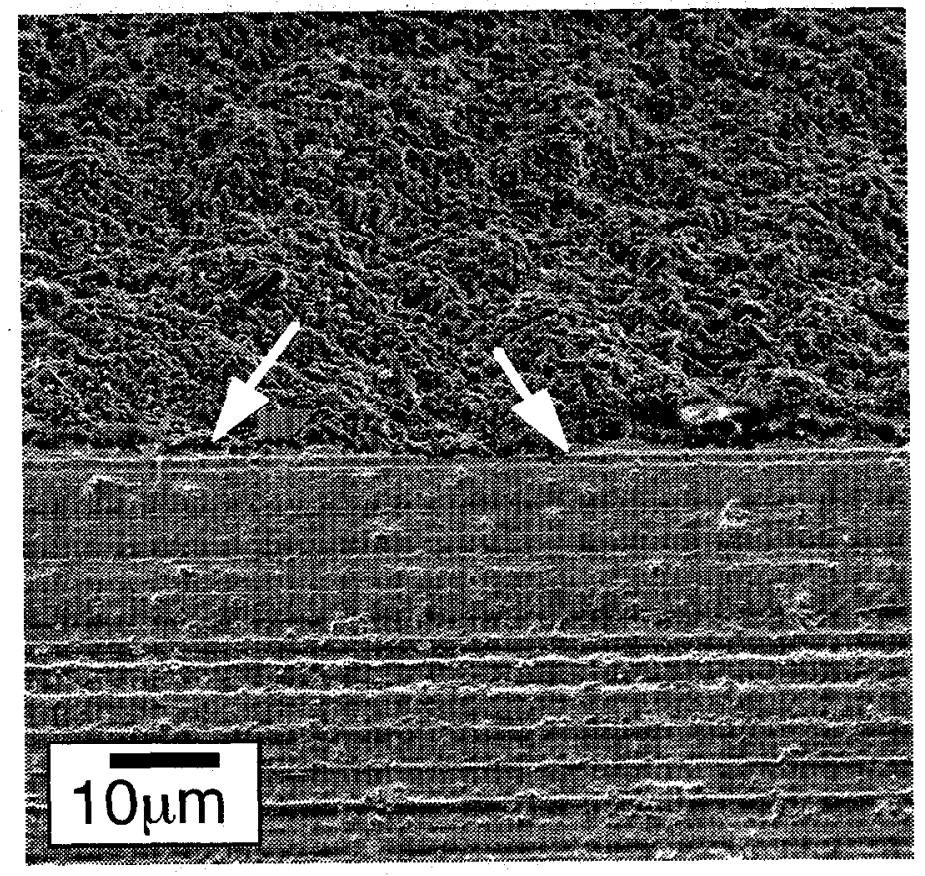

Figure 5.18. Detail of Figure 5.17 showing the remains of the machining groove where failure initiated. 


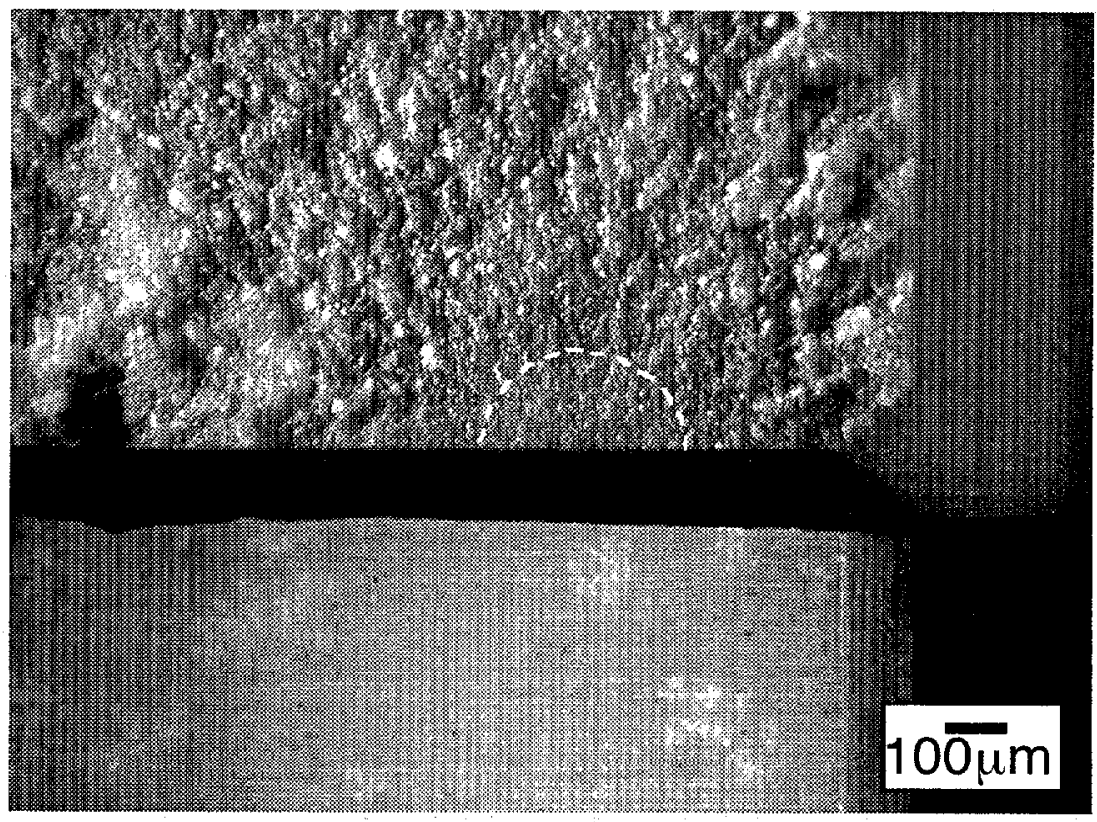

Figure 5.19. ASTM C 1161-B flexure specimen fracture and corresponding tensile surfaces. Failure from machining damage (SUR1-MD), $\sigma_{\mathrm{f}}=489 \mathrm{MPa}$.

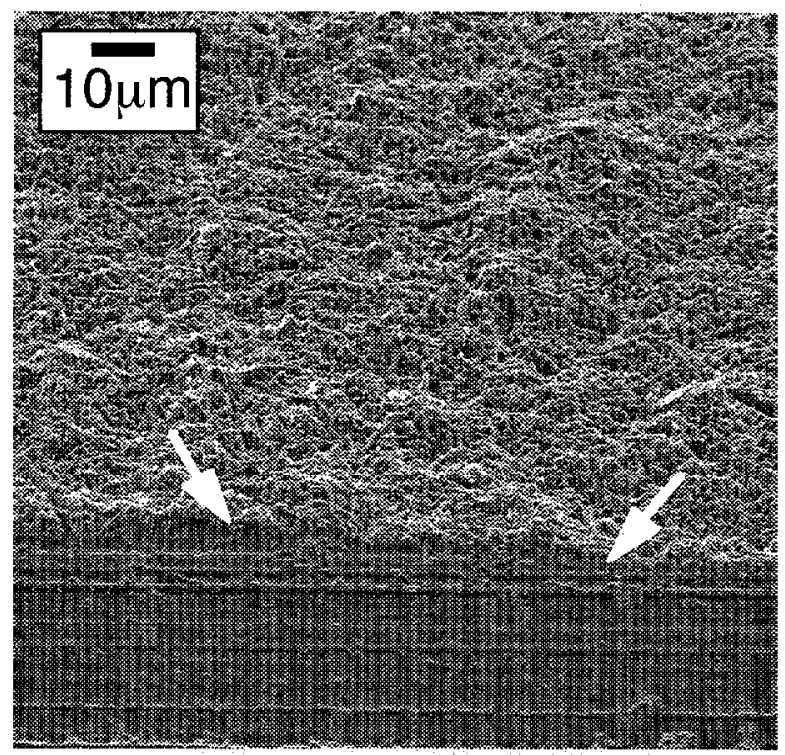

Figure 5.20. Detail of Figure 5.19 showing the remains of the machining groove where failure initiated. 


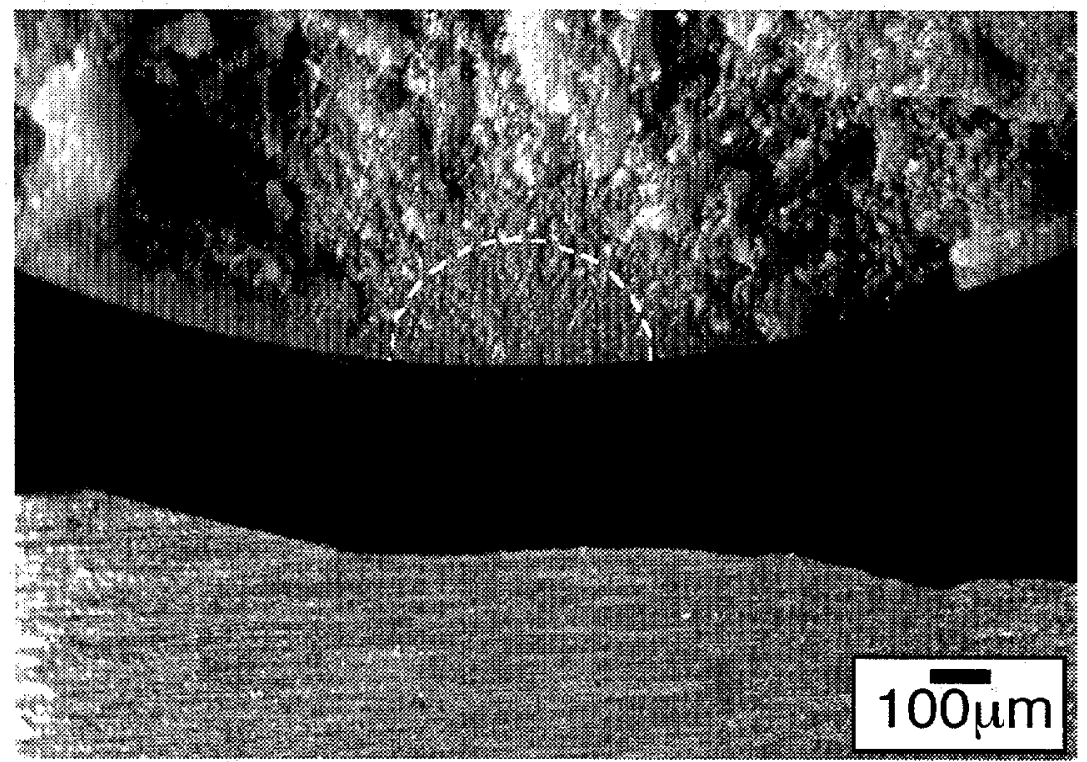

Figure 5.21. Fracture and corresponding tensile surfaces from FF-29 cylindrical specimen.

Failure due to machining damage (SUR2-MD). $\sigma_{\mathrm{f}}=633 \mathrm{MPa}$.

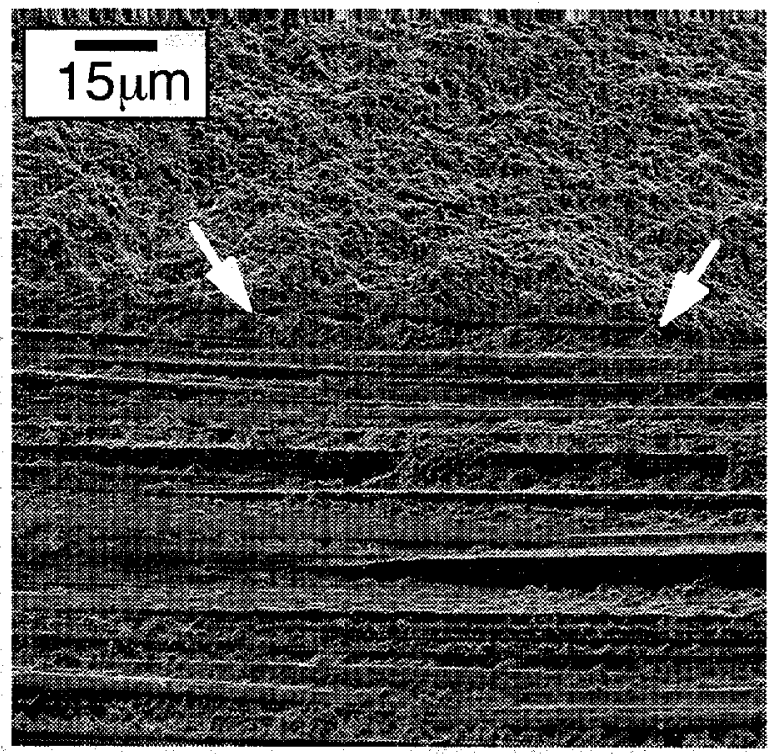

Figure 5.22. Detail of Figure 5.21 showing the machining groove where failure originated. 


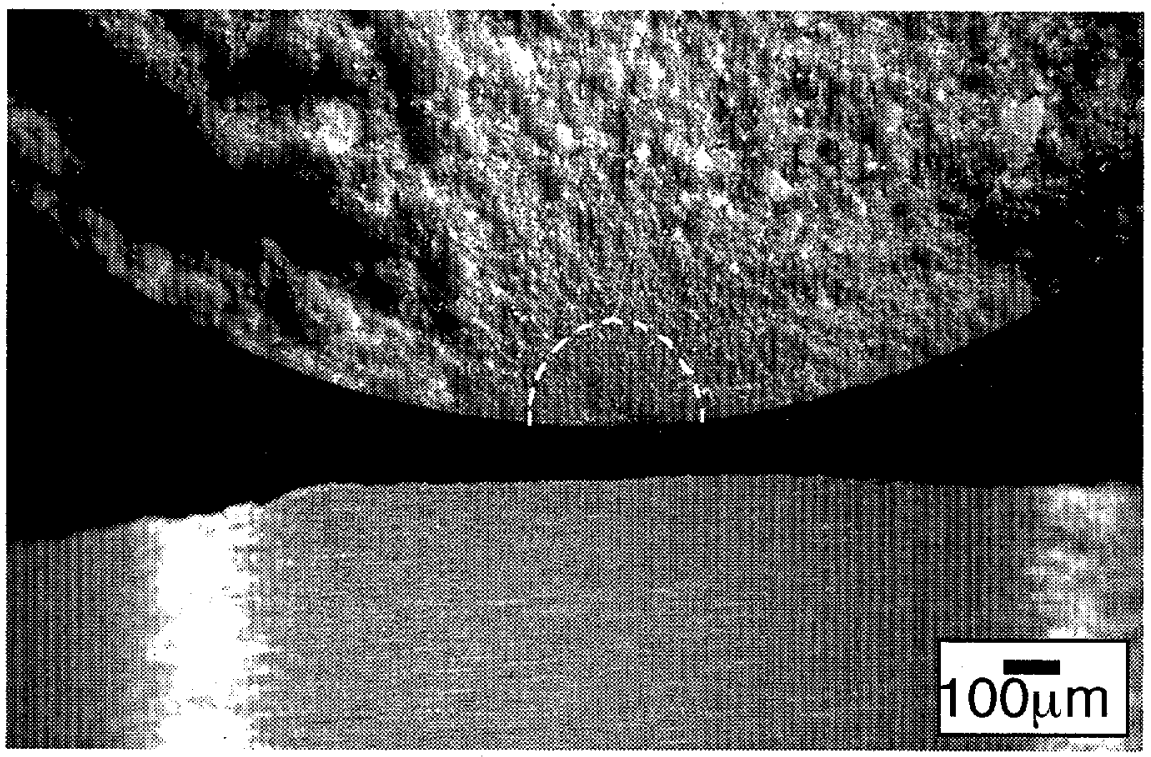

Figure 5.23. Fracture and corresponding tensile surfaces for SF-17 cylindrical specimen. Failure from machining damage (SUR2-MD). $\sigma_{\mathrm{f}}=496 \mathrm{MPa}$.

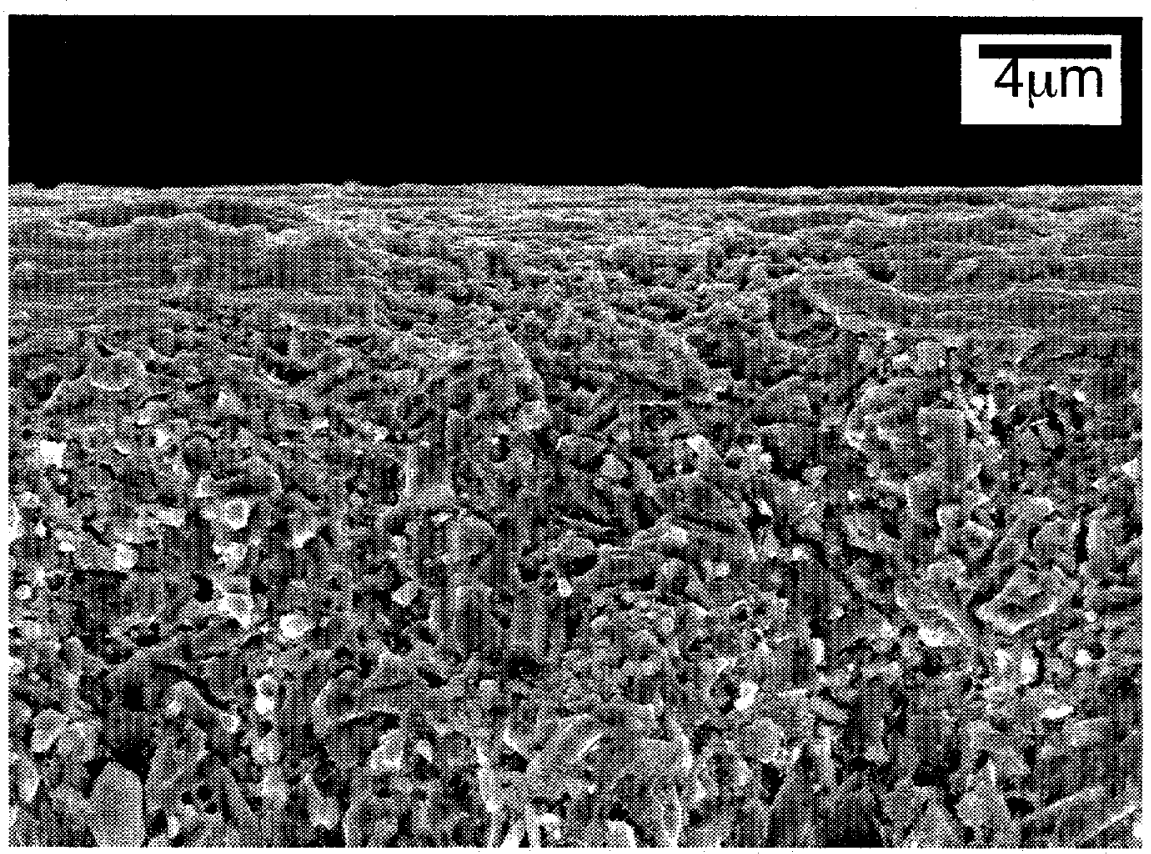

Figure 5.24. Detail of Figure 5.23 cylindrical specimen fracture surface. Failure from machining damage (SUR2-MD). 


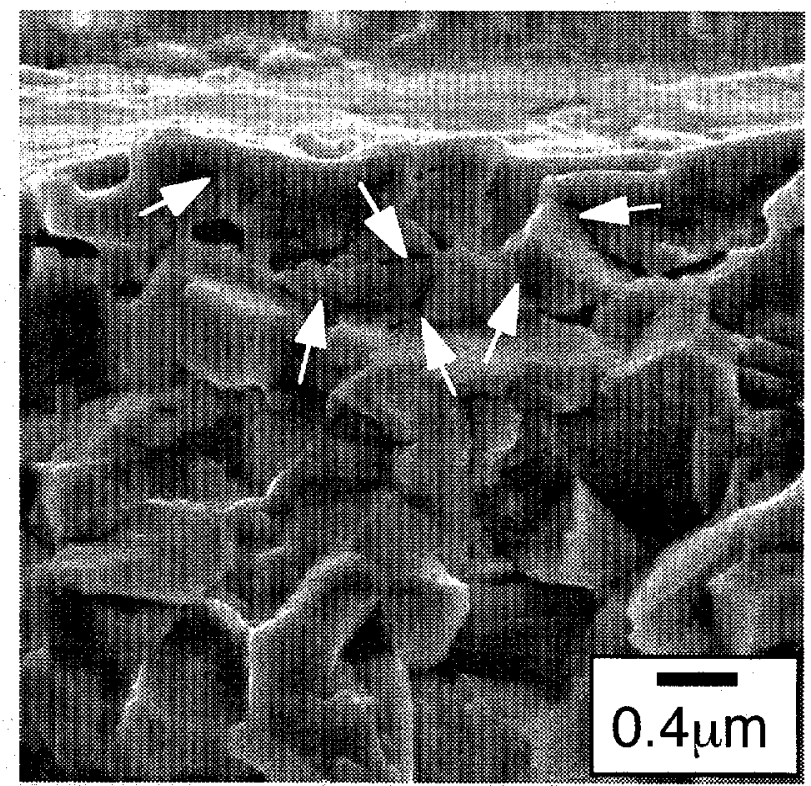

Figure 5.25. Detail of cylindrical specimen failure surface showing evidence of microcracking below machined surface. $\sigma_{\mathrm{f}}=500 \mathrm{MPa}$.

\subsubsection{Volume-Induced Failure From Compositional Inhomogeneity (VOL-SF)}

Two examples of this strength-limiting flaw are shown in Figures 5.26 and 5.27 and both are from ASTM C 1161-B flexure bars. The specimen in Figure 5.26 was transversely machined while the specimen in Figure 5.27 was longitudinally machined.

In Figure 5.26, the fracture surface appears shifted to the left and does not seem to align well with the corresponding tensile surface below. Although the images appear to be misaligned, this is not the case. The lighting conditions used when making the digital image of the tensile surface did not illuminate the chamfer on the left side enough for it to be seen in the image. The chamfer joins the tensile surface on the left side of the image and so the images give the appearance of being misaligned.

The shape of the fracture mirror in Figure 5.26 is difficult to ascertain and debatable. In one scenario, the fracture mirror appears larger than a semicircle while in a second scenario, the fracture mirror is semicircular. A fracture mirror greater than a semicircle would indicate that the failure origin is not located at the surface but within the volume of the material. The center of the fracture mirror consists of a lighter-toned region (see arrow). Although the fracture plane parallels one of the surface machining grooves, the larger fracture mirror suggests that the apparent origin of failure may not be due to the machining damage. In alignment with the apparent fracture origin is a 
white region of snowflakes on the tensile surface (see arrows), that is believed to be the strengthlimiting flaw for this specimen.

In Figure 5.27 the fracture mirror as shown with a solid line is relatively small compared to previously presented images of fracture mirrors. Somewhat difficult to see and marked with arrows in this image is a lighter-toned region on the tensile surface corresponding to the failure origin of the fracture mirror. This region, approximately the same size as that of the fracture mirror, shows a clustering of snowflakes that is believed to be the strength-limiting flaw for this specimen. The machining direction of this flexure specimen is longitudinally or parallel to the maximum applied tensile load.

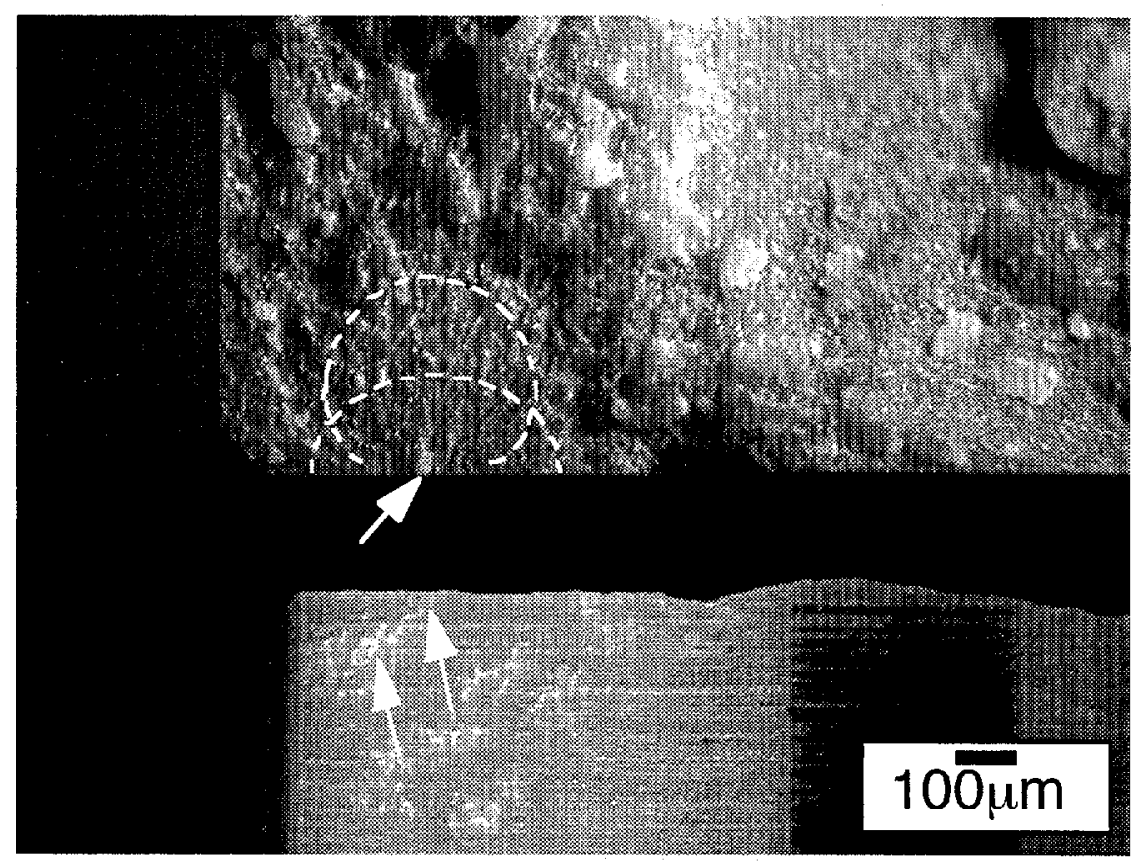

Figure 5.26. ASTM C 1161-B transversely machined flexure specimen fracture and corresponding tensile surfaces. Failure due to white snowflake regions (VOL-SF). $\sigma_{\mathrm{f}}=647 \mathrm{MPa}$. 


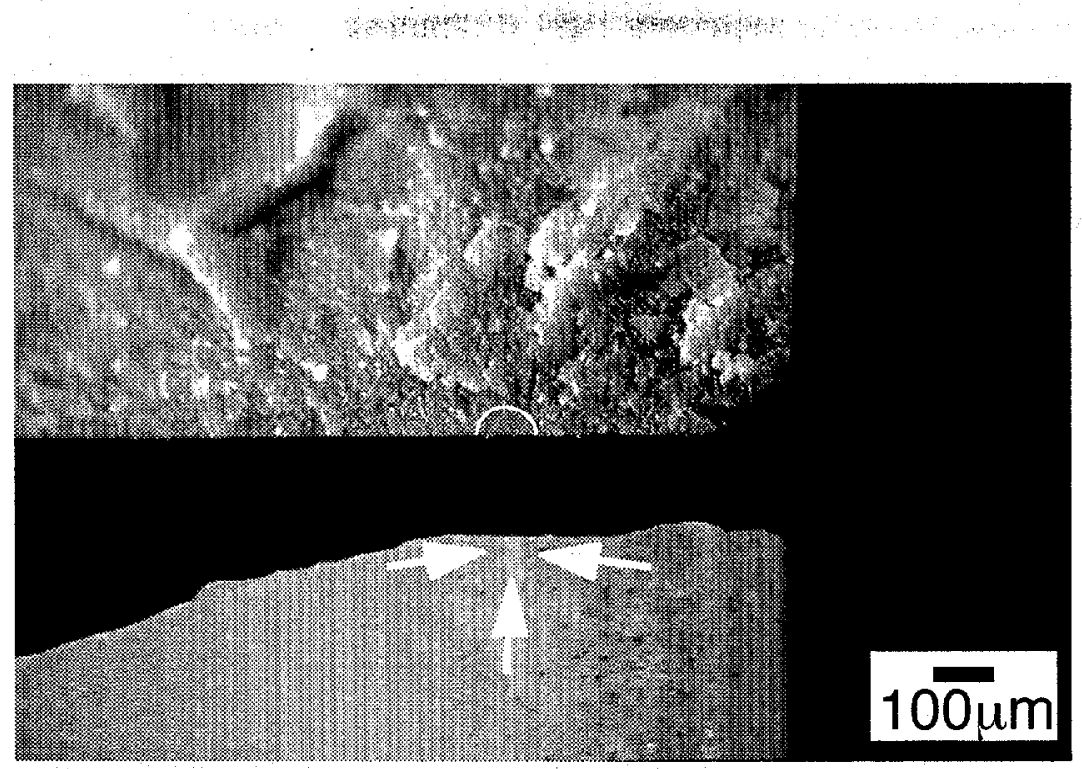

Figure 5.27. ASTM C 1161-B longitudinally machined flexure specimen fracture and corresponding tensile surfaces. Failure due to white snowflake regions (VOL-SF). $\sigma_{\mathrm{f}}=1128 \mathrm{MPa}$.

\subsubsection{Volume-Induced Failure From Agglomerates (VOL-AGG)}

The modified ORNL tension specimens had 4 out of 37 specimens fail from this type of failure, the greatest percentage of this failure mode found for any of the specimen geometries tested. The agglomerate is typically a clustering of grains or particles that are structurally weaker than the surrounding microstructure. For NT551, these agglomerates appear as black specks. Because of the contrast difference with the larger solid gray mass, their approximate 20-40 micron size can almost be seen by the naked eye and are readily viewable using an optical microscope. Specimens that failed from this flaw type did so at higher fracture loads than other flaw types due to agglomerate's small size.

Figure 5.28 shows the ASTM C 1161-B longitudinally machined specimen 30-11-10 fracture mirror and corresponding tensile surface. The small black agglomerate is located at the fracture origin. Shown in Figure 5.29 shows a detail of an agglomerate using the SEM taken from a modified ORNL tension specimen. The agglomerate appears to have a different microstructure when compared to the surrounding material structure. 


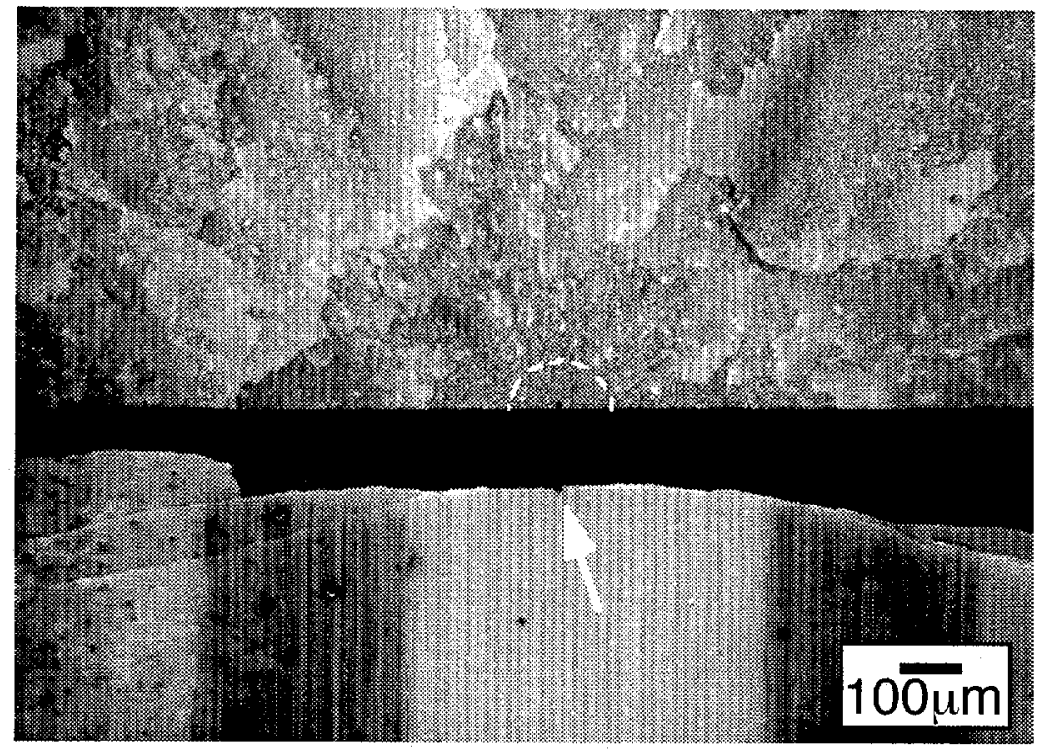

Figure 5.28. ASTM C 1161-B longitudinally machined flexure specimen fracture and corresponding tensile surfaces. Specimen failure from an agglomerate (VOL-AGG). $\sigma_{\mathrm{f}}=773 \mathrm{MPa}$.

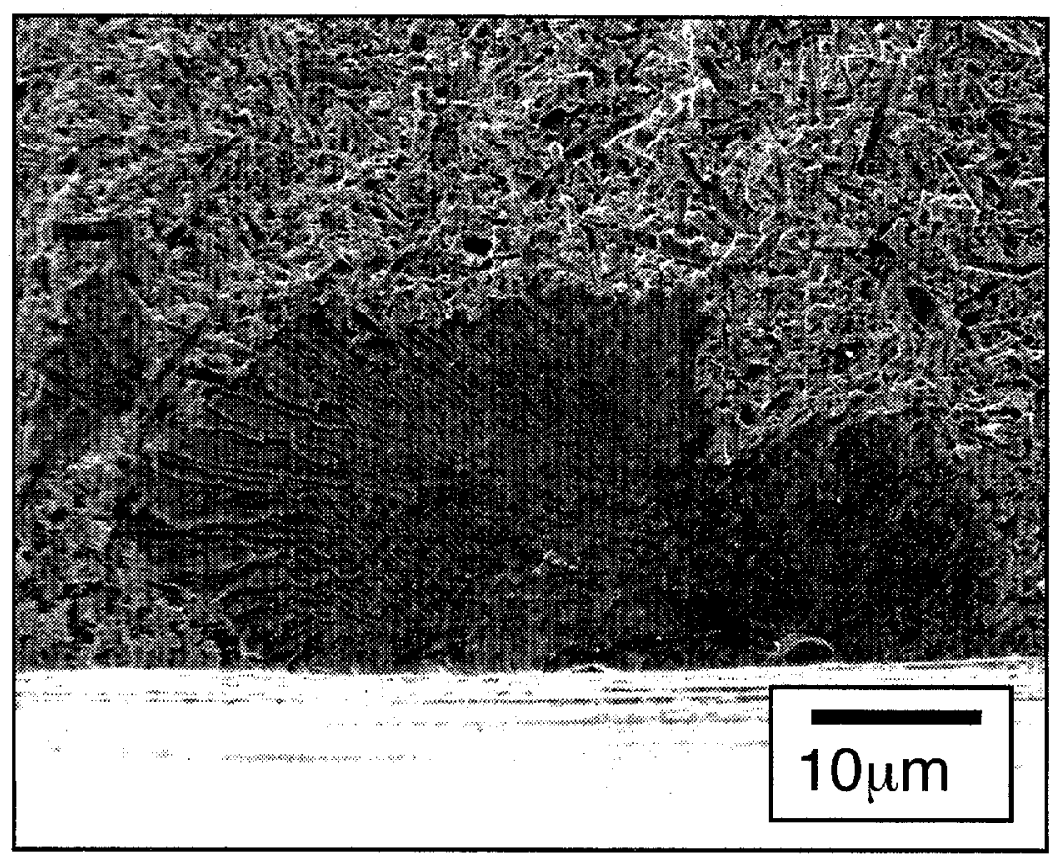

Figure 5.29. Detail of an agglomerate failure origin from a modified ORNL tension specimen (VOL-AGG). $\sigma_{\mathrm{f}}=714 \mathrm{MPa}$. 


\subsubsection{Unknown Failure Types}

In this study there were 21 failures that could not be identified as one of four failure types described earlier. All of these failures were from ASTM C 1161-B specimens that were transversely machined and tested at $850^{\circ} \mathrm{C}$. Figures 5.30 and 5.31 show two examples of failures that were not identified. In Figure 5.30, the fracture surface of a flexure specimen is shown. The fracture mirror appears to cover one-half of the entire fracture surface, originating at the lower lefthand corner. No white snowflake-like or black agglomerate regions were found near the apparent fracture origin. In addition, the fracture plane is located at an angle to the machining grooves found on the tensile surface. This specimen, 30-7-12, failed in flexure at a maximum tensile stress of $224 \mathrm{MPa}$, the lowest stress for the data set.

In Figure 5.31 is the ASTM C 1161-B flexure specimen 30-6-5 fracture surface and accompanying tensile surface. The fracture mirror is not clearly identifiable as shown in earlier photomicrographs and it is not certain whether the fracture origin is located at the surface or in the bulk of the material. On the tensile surface in the region of the fracture origin there are regions of snowflakes as well as black agglomerates. The plane of failure is parallel to a transverse machining groove indicating that perhaps machining damage was the mode of failure. Since the fracture origin and mirror do not associate with a single failure mechanism, the failure type was catalogued as unknown.

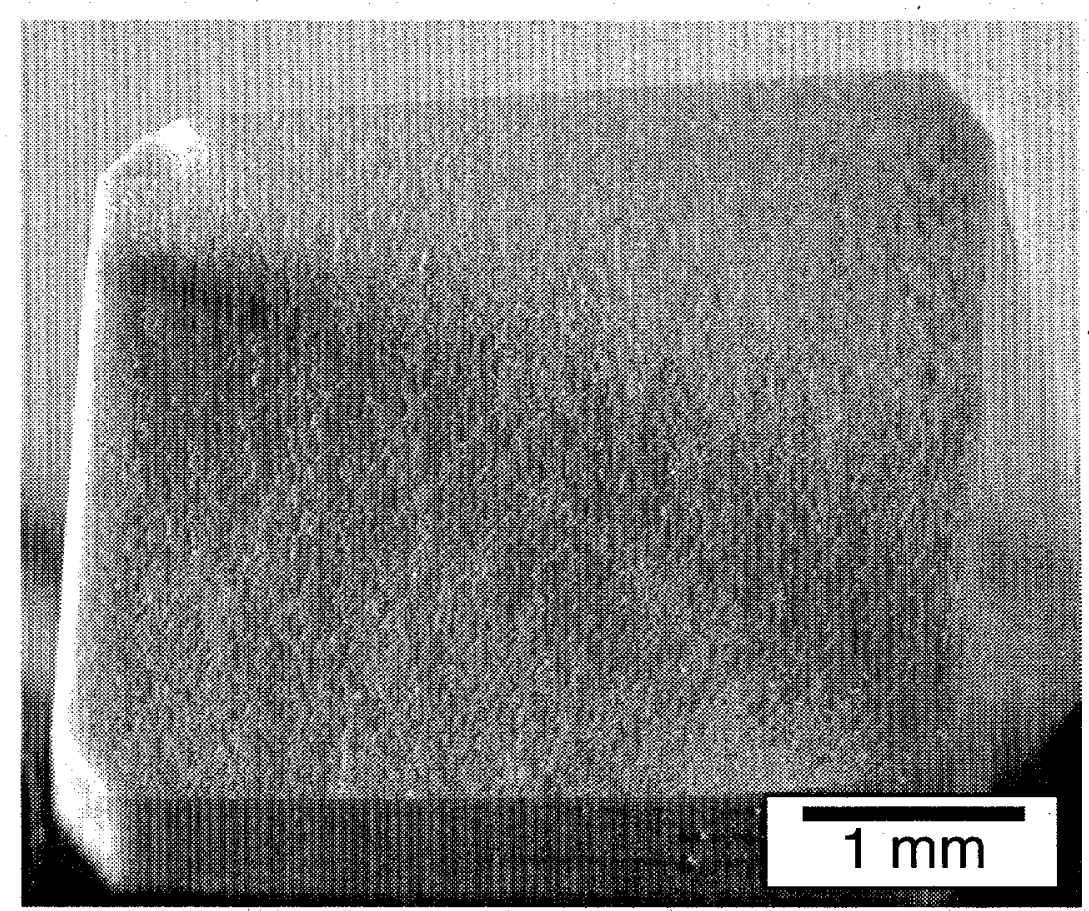

Figure 5.30. Unknown failure from an ASTM C 1161-B specimen. $\sigma_{\mathrm{f}}=224 \mathrm{MPa}$. 


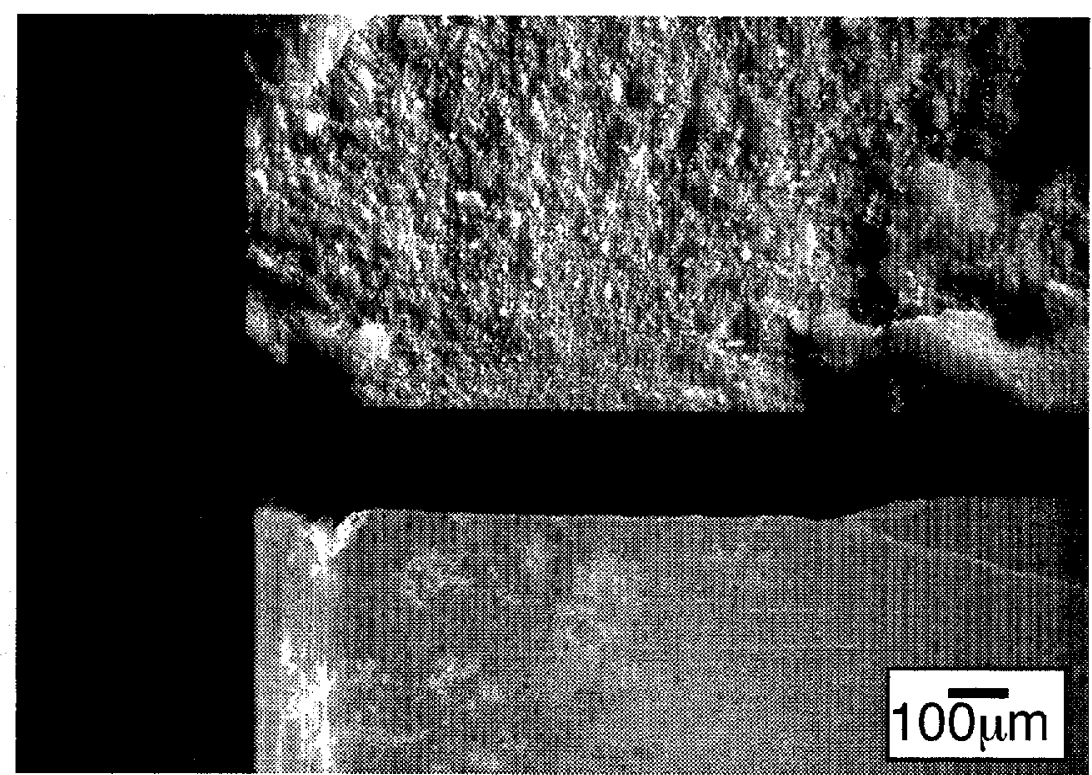

Figure 5.31. Unknown failure type from ASTM C 1161-B flexure specimen. $\sigma_{f}=527 \mathrm{MPa}$.

\subsection{Strength and Fatigue Distributions of NT551}

Presented in this section are the uncensored Weibull distribution results for the inert strength and dynamic fatigue of NT551. The transversely and longitudinally machined ASTM C 1116-B flexure data are presented first followed by the cylindrical flexure data and finally the modified ORNL tension data. The Weibull distributions of the fatigue behavior from the three specimen data sets are presented at the end of this section.

\subsubsection{Transversely Machined ASTM C 1161-B Flexure Bars}

\subsubsection{Uncensored Weibull Distributions}

The following test results for NT551 $\mathrm{Si}_{3} \mathrm{~N}_{4}$ from the ASTM C 1161-B specimens in four-point flexure are presented. These specimens were transversely machined with regard to the maximum tensile loading axis. The bar graphs in Figures 5.32 and 5.33 summarize the uncensored Weibull moduli and characteristic strengths of NT551 as a function of three loading rates $(36,0.36$, and $0.0036 \mathrm{~N} / \mathrm{s})$ and three temperatures $\left(20,700\right.$, and $\left.850^{\circ} \mathrm{C}\right)$. The $95 \%$ confidence values for each uncensored Weibull parameter are indicated by means of a boxed region at the end of each bar. Both Weibull parameters and their $95 \%$ confidence boundaries were determined using maximum 


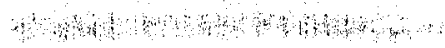

likelihood and likelihood ratio methods, respectively. Unless otherwise stated, all Weibull parameter comparisons made in this study are based upon a $95 \%$ confidence level.

As illustrated in Figures 5.32 and 5.33 , between 20 and $850^{\circ} \mathrm{C}$ the respective uncensored Weibull moduli ranged between 11.6 to 4.4 , while the uncensored characteristic strength ranged from $805 \mathrm{MPa}$ to $381 \mathrm{MPa}$. The uncensored Weibull modulus had a statistically significant decrease in value at the $850^{\circ} \mathrm{C}$ between the fastest loading rate of $36 \mathrm{~N} / \mathrm{s}$ and the two slower load rates of 0.36 and $0.0036 \mathrm{~N} / \mathrm{s}$. At all other test temperatures, the uncensored Weibull moduli were invariant with the loading rate. As Figure 5.33 illustrates, the uncensored characteristic strength had significant reductions in strength as a function of both temperature and loading rate. At $20^{\circ} \mathrm{C}$, the characteristic strength decreased steadily as the load rate decreased. The results from testing at $700^{\circ} \mathrm{C}$ showed no significant decrease in the characteristic strength as the loading rate changed. At $850^{\circ} \mathrm{C}$, a significant decrease in the characteristic strength occurred between the slowest load rate of $0.0036 \mathrm{~N} / \mathrm{s}$ and the load rates of 36 and $0.36 \mathrm{~N} / \mathrm{s}$.

The graphical form depicting the uncensored Weibull distributions and parameter estimates from the ASTM C 1161-B flexure bar data are presented in Figures 5.34-5.39. Figures 5.34-5.36 present the data at temperatures of 20,700 , and $850^{\circ} \mathrm{C}$, respectively, as a function of loading rate. Figures 5.37-5.39 present the data at loading rates of $36,0.36$, and $0.0036 \mathrm{~N} / \mathrm{s}$, respectively, as a function of temperature.

At $20^{\circ} \mathrm{C}$ (Figure 5.34), the uncensored characteristic strength of the flexure bars shows a steady reduction in strength of approximately $25 \%$ from the fastest loading rate to the slowest loading rate. The uncensored characteristic strength was $805 \mathrm{MPa}$ at $36 \mathrm{~N} / \mathrm{s}, 704 \mathrm{MPa}$ at 0.36 $\mathrm{N} / \mathrm{s}$, and $604 \mathrm{MPa}$ at $0.0036 \mathrm{~N} / \mathrm{s}$. At a 95 percent confidence level, all strength reductions are statistically significant. The uncensored Weibull modulus remained approximately 10 and was invariant to the loading rate.

ASTM C 1161-B flexure bars tested at $700^{\circ} \mathrm{C}$ (Figure 5.35) also show that the uncensored Weibull moduli were independent of the loading rate. The Weibull modulus was approximately 9 for all three load rates which was not statistically different than the uncensored Weibull moduli of approximately 10 found at $20^{\circ} \mathrm{C}$. When comparing the uncensored characteristic strengths for tests conducted at $700^{\circ} \mathrm{C}$, no significant difference was found between the three loading rates. However, a greater reduction in the uncensored characteristic strength occurred between the loading rate of $36 \mathrm{~N} / \mathrm{s}$ and $0.36 \mathrm{~N} / \mathrm{s}$.

In Figure 5.36 the data at different load rates are presented as a function of $850^{\circ} \mathrm{C}$. The uncensored Weibull modulus decreases approximately $50 \%$ from the fastest load rate $(36 \mathrm{~N} / \mathrm{s})$ to the slowest load rate $(0.0036 \mathrm{~N} / \mathrm{s})$ while the uncensored characteristic strength decreases approximately $34 \%$ between the same load rate range. These decreases in the Weibull moduli and the uncensored characteristic strength are statistically significant at a $95 \%$ confidence level. 
Figure 5.37 compares the data at temperatures of 20,700 , and $850^{\circ} \mathrm{C}$ at the load rate of $36 \mathrm{~N} / \mathrm{s}$. The uncensored Weibull modulus does not change significantly while the uncensored characteristic strength significantly decreases from $805 \mathrm{MPa}$ at $20^{\circ} \mathrm{C}$ to $593 \mathrm{MPa}$ at $700^{\circ} \mathrm{C}$ temperature. No significant decrease in the uncensored characteristic strength is seen between the 700 and $850^{\circ} \mathrm{C}$ test temperatures.

At the loading rate of $0.36 \mathrm{~N} / \mathrm{s}$ (Figure 5.38), the uncensored Weibull modulus is unchanged at the temperatures of 20,700 and $850^{\circ} \mathrm{C}$, while the uncensored characteristic strength significantly decreases between the 20 and $700^{\circ} \mathrm{C}$. No significant change in the uncensored characteristic strength is seen between 700 and $850^{\circ} \mathrm{C}$.

In Figure 5.39, data at the slowest load rate of $0.0036 \mathrm{~N} / \mathrm{s}$ is presented as a function of temperature. The uncensored Weibull modulus decreased approximately $62 \%$ between 20 and $850^{\circ} \mathrm{C}$ while the uncensored characteristic strength significantly decreased approximately $37 \%$ in the same range. The majority of the reduction in strength occurred between 700 and $850^{\circ} \mathrm{C}$.

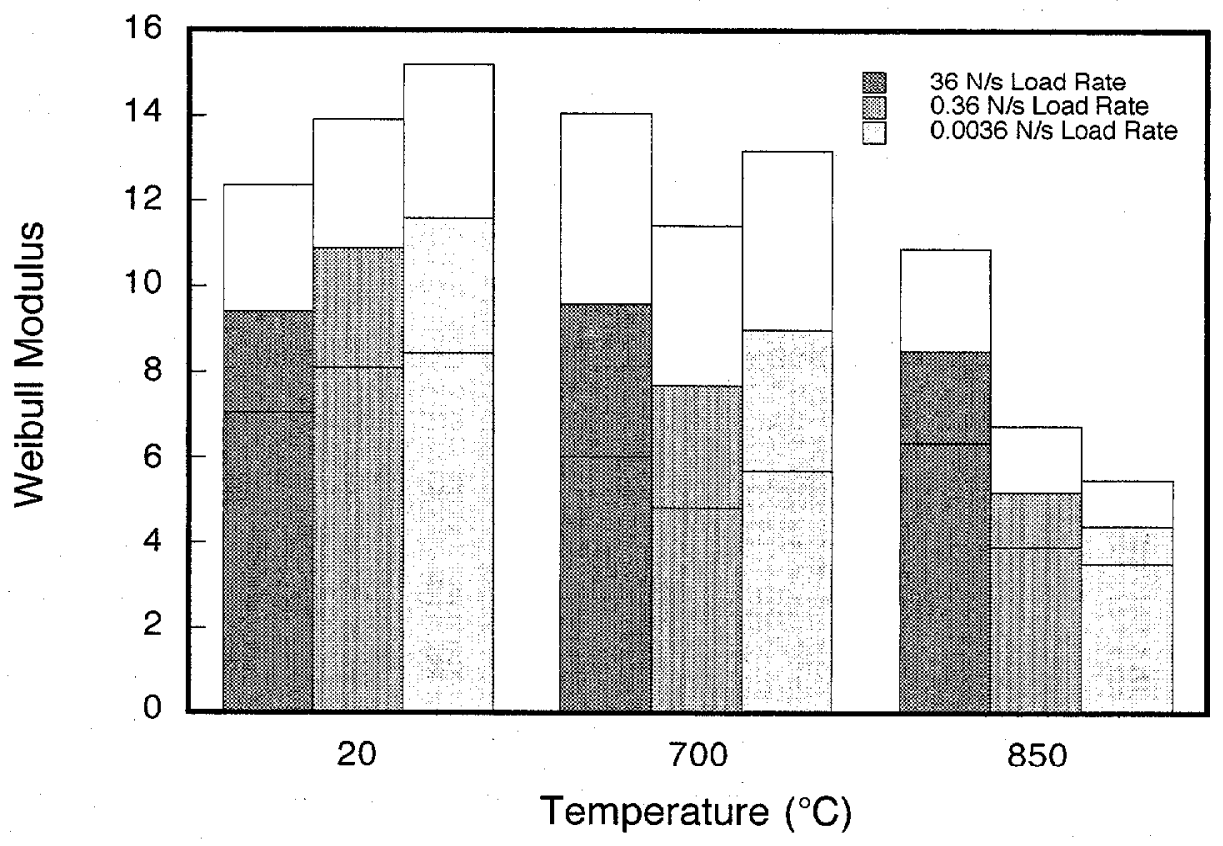

Figure 5.32. Temperature and load rate dependence of the Weibull modulus from ASTM C $1161-B$ transversely machined flexure specimens with $95 \%$ confidence bounds indicated. 


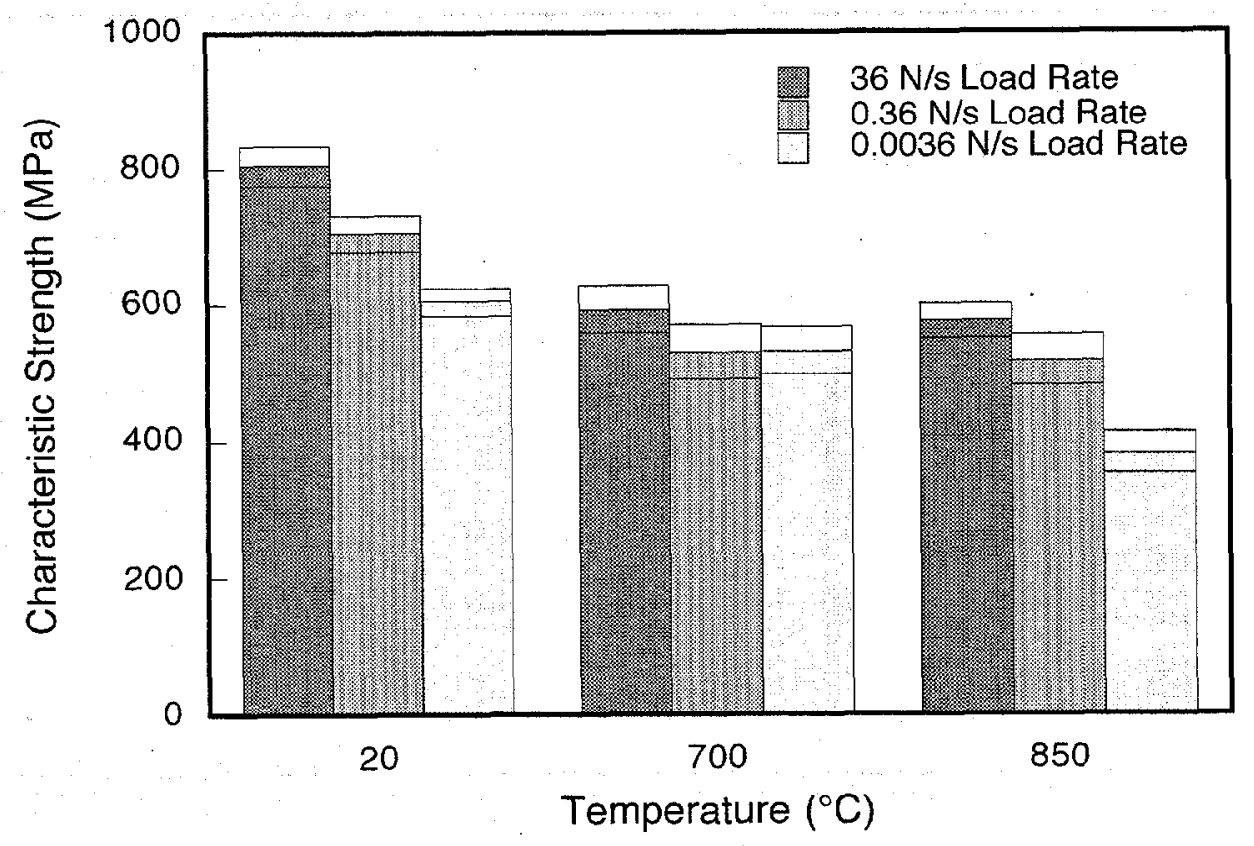

Figure 5.33. Temperature and load rate dependence of the Weibull characteristic strength from ASTM C 1161-B transversely machined flexure specimens with $95 \%$ confidence bounds indicated.

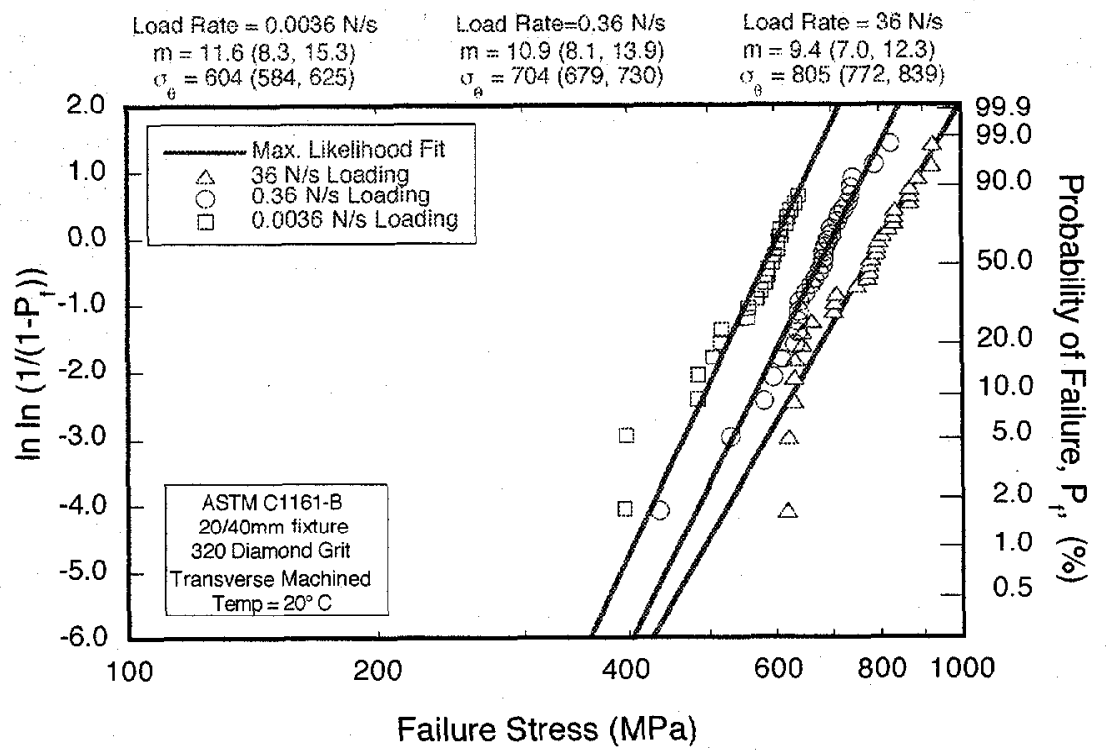

Figure 5.34. Load rate dependence of NT551 at $20^{\circ} \mathrm{C}$ from ASTM C 1161-B flexure bars. 


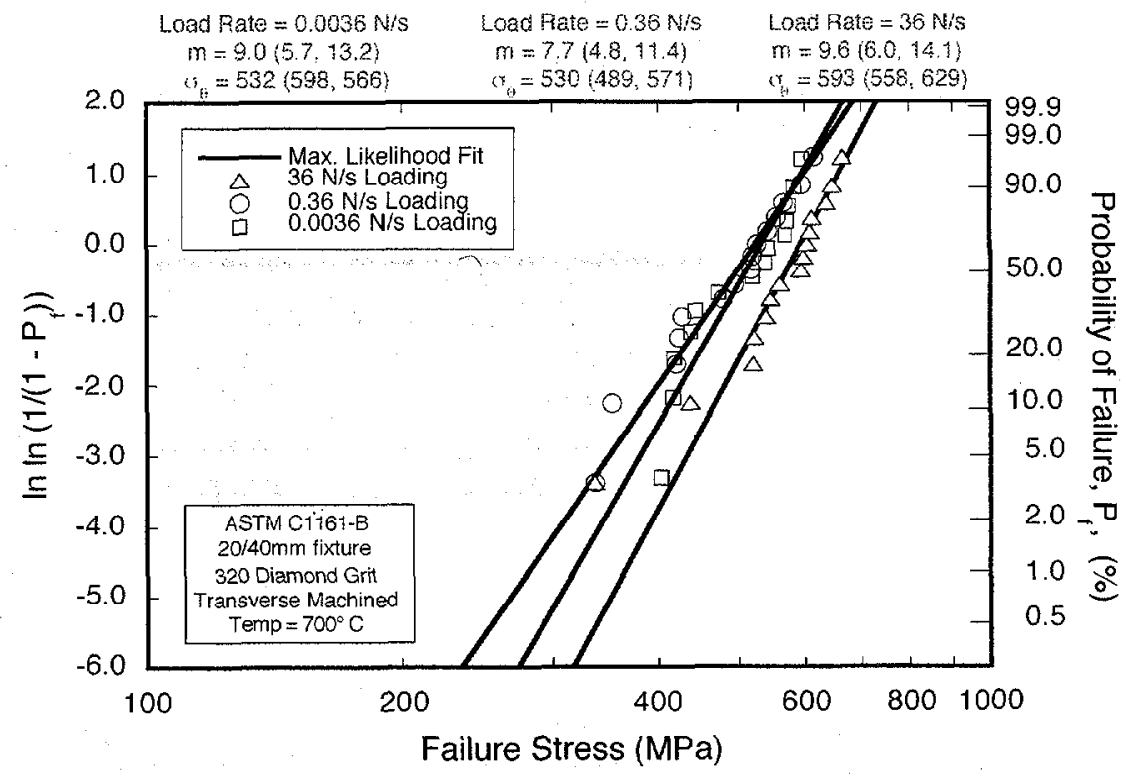

Figure 5.35. Load rate dependence of NT551 at $700^{\circ} \mathrm{C}$ from ASTM C 1161-B flexure bars.

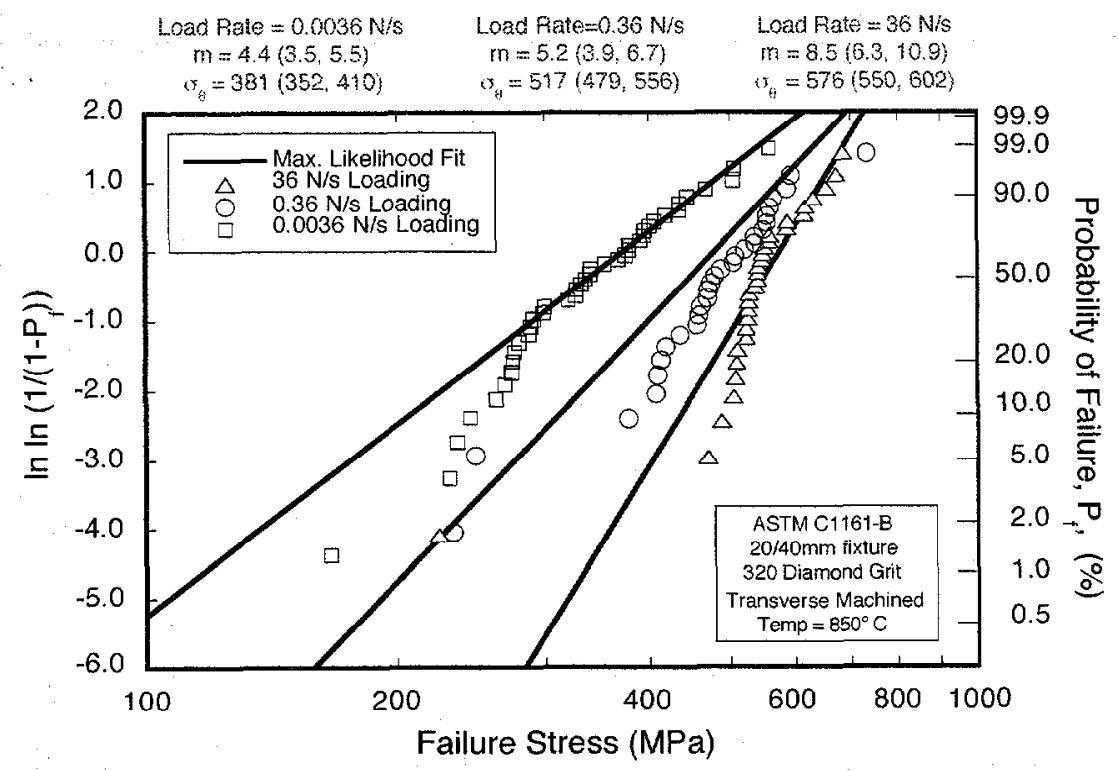

Figure 5.36. Load rate dependence of NT551 at $850^{\circ} \mathrm{C}$ from ASTM C 1161-B flexure bars. 


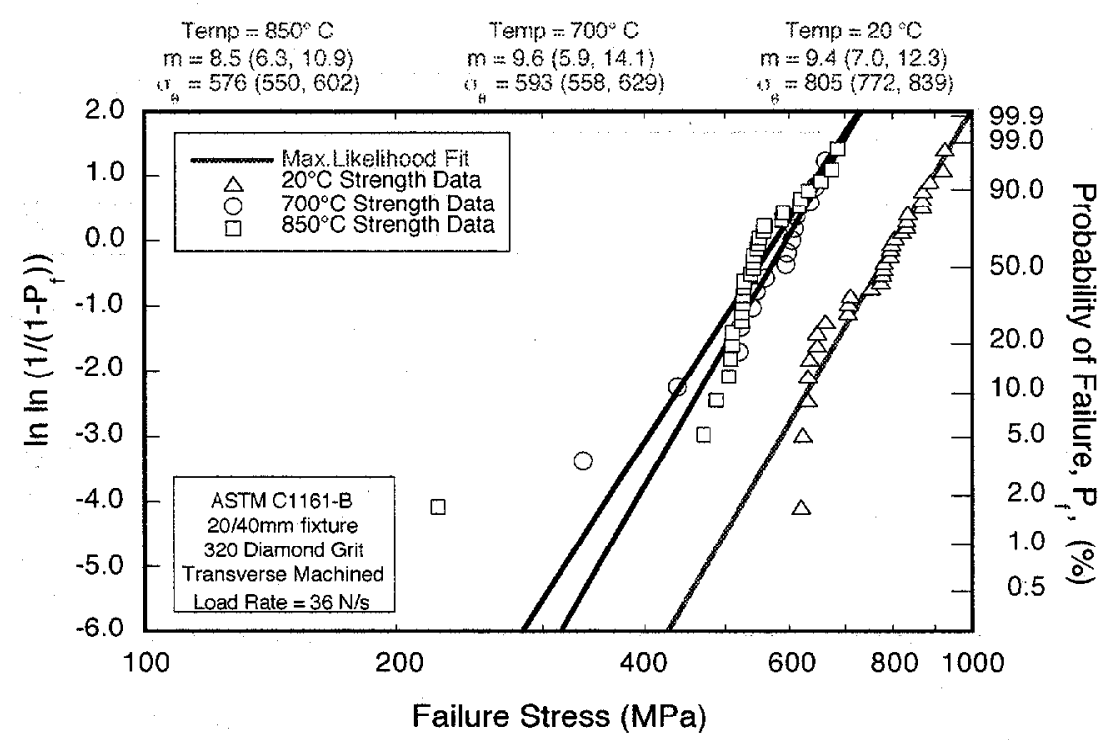

Figure 5.37. Temperature dependence of NT551 at $36 \mathrm{~N} / \mathrm{s}$ load rate for ASTM C 1161-B flexure bars.

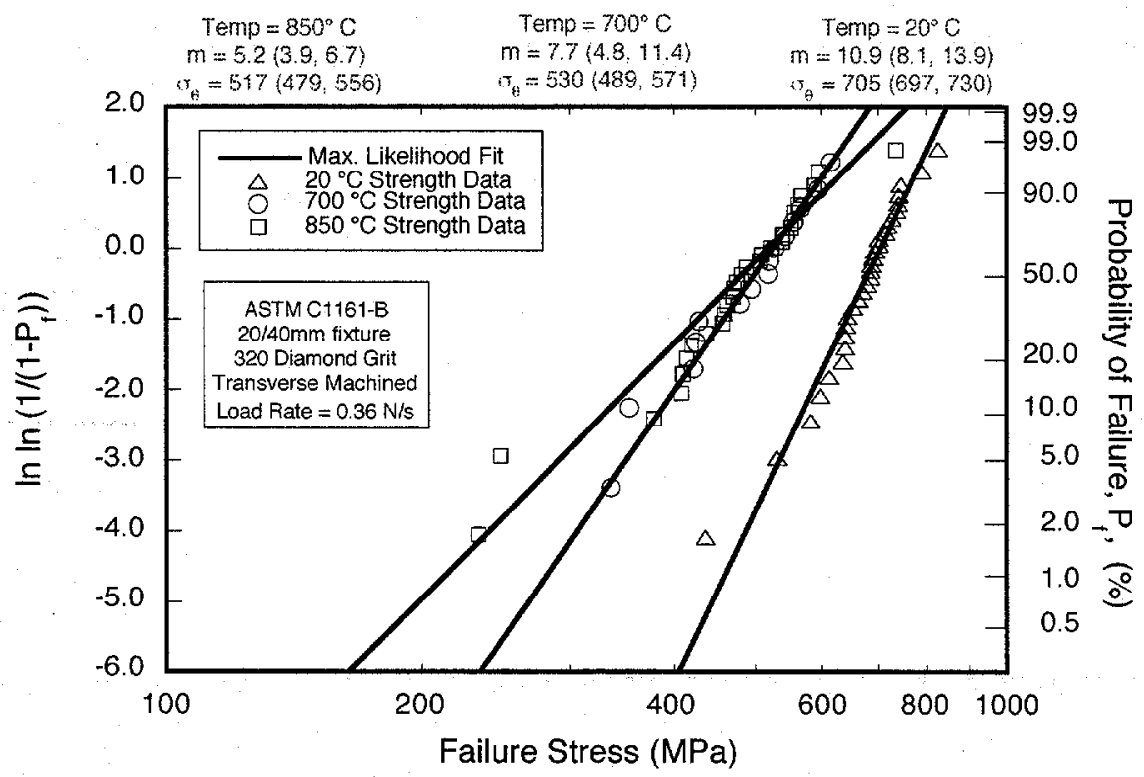

Figure 5.38. Temperature dependence of NT551 at $0.36 \mathrm{~N} / \mathrm{s}$ load rate for ASTM C 1161-B flexure bars. 


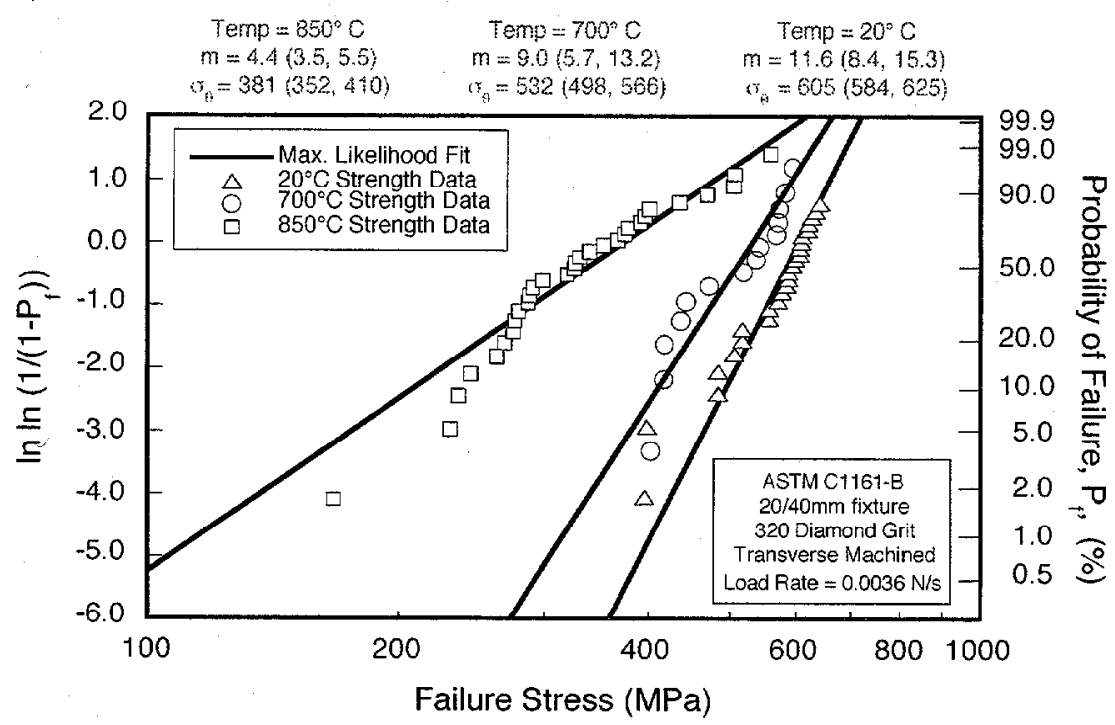

Figure 5.39. Temperature dependence of NT551 at 0.0036 N/s load rate for ASTM C 1161-B flexure bars.

\subsubsection{Weibull Distributions with Censored Strength Data}

Presented in Tables 5.2-5.4 are the fractographic results for ASTM C 1161-B flexure bars transversely machined and tested at the loading rates of $36,0.36$, and $0.0036 \mathrm{~N} / \mathrm{s}$ and at 20,700 , and $850^{\circ} \mathrm{C}$, respectively. The dominant mode of failure at $20^{\circ} \mathrm{C}$ for all three load rates was surfaceinduced failure from machining damage (SUR1-MD).

Fractographic results from specimens tested at $700^{\circ} \mathrm{C}$ (Table 5.3) show a change from the surface-induced failure mode (SUR1-MD) to a volume-induced failure mode (VOL-SF). In addition, the second volume-induced mode of failure, VOL-AGG, was identified on three test specimens. The dominant mode of failure at $700^{\circ} \mathrm{C}$ for all loading rates was VOL-SF.

The specimens tested at $850^{\circ} \mathrm{C}$ and at three loading rates are presented in Table 5.4. The dominant mode of failure at $36 \mathrm{~N} / \mathrm{s}$ load rate was SUR1-MD while at the slowest load rate of $0.0036 \mathrm{~N} / \mathrm{s}$ the mode of failure was VOL-SF. In addition, there were 10 unknown modes of failure (UNK) at $36 \mathrm{~N} / \mathrm{s}, 2$ UNK's at $0.36 \mathrm{~N} / \mathrm{s}$ and $9 \mathrm{UNK}$ 's at $0.0036 \mathrm{~N} / \mathrm{s}$ load rate. Three VOLAGG failures were identified at the $36 \mathrm{~N} / \mathrm{s}$ load rate and the one VOL-AGG failure was identified at the $0.0036 \mathrm{~N} / \mathrm{s}$ load rate.

Presented in Figure 5.40 is the uncensored Weibull distribution with $95 \%$ confidence bands of ASTM C 1161-B flexure bars tested at $20^{\circ} \mathrm{C}$ and at $36 \mathrm{~N} / \mathrm{s}$ loading rate. Plotted with the 
uncensored distribution are the 30 failure data points and their identified failure types. Of the 30 failures, 22 were due to SUR1-MD while the remaining 8 were due to VOL-SF. Looking at the trend in the data as the strength increases, one observes a negative "knee" or curvature in the distribution. This distinct grouping of each failure type suggests that the two flaw populations are compound multiple or exclusive flaw populations and not concurrent flaw populations (Johnson, 1979); two independent Weibull distributions may better fit the data. The 8 VOL-SF failures come from specimens machined from only two tiles. This suggests that these two tiles produced specimens that were uniquely different (i.e., weaker) when compared to the rest of the test data.

Table 5.5 and 5.6 compare the Weibull distribution parameters for the above data as concurrent and exclusive flaw populations, respectively. The Weibull modulus and scale parameter values for the SUR1-MD failure type are not significantly different when considering either a concurrent or exclusive flaw population. The Weibull modulus and scale parameter for the VOL-SF failure type are significantly different when considering the concurrent flaw population as compared to an exclusive flaw population. This significant difference in the Weibull censored parameters for the VOL- SF failure mode further supports the argument that the flaw populations are exclusive and not concurrent.

Figure 5.41 shows the uncensored Weibull distribution for ASTM C 1161-B flexure specimens tested at $20^{\circ} \mathrm{C}$ and at the loading rate of $0.36 \mathrm{~N} / \mathrm{s}$. There were $2 \mathrm{VOL}-\mathrm{SF}$ failures identified and 28 SUR1-MD failures identified. Table 5.7 compares the Weibull parameters for the two concurrent failure modes. The $95 \%$ confidence range for the Weibull parameters pertaining to the VOL-SF failure mode is very large since it results from only two data points. The scale parameter for the SUR1-MD failure mode at the $0.36 \mathrm{~N} / \mathrm{s}$ loading rate is approximately $13 \%$ lower than at the $36 \mathrm{~N} / \mathrm{s}$ loading rate (see Table 5.6).

The uncensored Weibull distribution for the ASTM C 1161-B flexure bars tested at $20^{\circ} \mathrm{C}$ and $0.0036 \mathrm{~N} / \mathrm{s}$ loading rate are presented in Figure 5.42. Of the 29 specimens tested, 24 failed due to SUR1-MD while 5 failed due to VOL-SF. The censored Weibull parameters for these failure types are presented in Table 5.8. The Weibull modulus for the VOL-SF failure mode is 3.6 and is similar to the value estimated for the $0.36 \mathrm{~N} / \mathrm{s}$ loading rate (see Table 5.7) for the same test temperaturc. The Weibull scale parameter for the VOL-SF failure mode reduced in value approximately $53 \%$ between the $0.36 \mathrm{~N} / \mathrm{s}$ and $0.0036 \mathrm{~N} / \mathrm{s}$ loading rates. The significance of this reduction in value is questionable due to the small number of data points involved; namely, two data points at $0.36 \mathrm{~N} / \mathrm{s}$ load rate and 5 data points at $0.0036 \mathrm{~N} / \mathrm{s}$ load rate. The Weibull moduli for the SUR1-MD failure mode at the loading rates of $0.36 \mathrm{~N} / \mathrm{s}$ and $0.0036 \mathrm{~N} / \mathrm{s}$ are equivalent at a $95 \%$ confidence level. The scale parameter reduces in value approximately $19 \%$ between the 0.36 $\mathrm{N} / \mathrm{s}$ loading rate and the $0.0036 \mathrm{~N} / \mathrm{s}$ loading rate. 
Figure 5.43 presents the uncensored Weibull distribution for the ASTM C 1161-B flexure bars tested at $700^{\circ} \mathrm{C}$ and at $36 \mathrm{~N} / \mathrm{s}$ along with the censored failure data. In Table 5.9 are the estimated censored Weibull parameters for two of the three failure modes identified; VOL-SF and SUR1MD. At $700^{\circ} \mathrm{C}$, only 15 specimens were tested at each loading rate. There were 11 VOL-SF failures followed by 3 SUR1-MD failures and then one VOL-AGG failure. A change in the dominant mode of failure from SUR1-MD to VOL-SF occurs when testing at the loading rate of 36 $\mathrm{N} / \mathrm{s}$ between 20 and $700^{\circ} \mathrm{C}$.

The uncensored Weibull distribution for ASTM C $1161-\mathrm{B}$ flexure bars at $700^{\circ} \mathrm{C}$ and $0.36 \mathrm{~N} / \mathrm{s}$ loading rate are shown in Figure 5.44. The censored Weibull parameters for the three failure modes identified for this data set are presented in Table 5.10. The dominant mode of failure was VOL-SF with 10 followed by 2 failures each from SUR1-MD and VOL-AGG failure modes. For the VOL-SF failure mode, both Weibull parameters are equivalent in value for the loading rates of $36 \mathrm{~N} / \mathrm{s}$ and $0.36 \mathrm{~N} / \mathrm{s}$.

The results from testing at $700^{\circ} \mathrm{C}$ and at the lowest loading rate $(0.0036 \mathrm{~N} / \mathrm{s})$ are presented in Figure 5.45 and the censored Weibull parameters for the two failure modes identified are presented in Table 5.11. Only 2 failures were attributed to SUR1-MD while the remaining 13 failures were attributed to VOL-SF. No dependence on stressing rate is observed for either the Weibull modulus or the scale parameter when comparing the censored parameters for the VOL-SF failure mode at the loading rates of $36,0.36$ and $0.0036 \mathrm{~N} / \mathrm{s}$.

Presented in Figure 5.46 is the uncensored Weibull distribution of ASTM C 1161-B flexure specimens tested at $850^{\circ} \mathrm{C}$ and $36 \mathrm{~N} / \mathrm{s}$. The censored Weibull parameters are presented in Table 5.12. There were three failure modes identified through fractographic analysis; 5 VOL-SF failures, 3 VOL-AGG failures and 12 SUR1-MD failures. In addition, there were 10 unidentified failures. The dominant mode of failure, SUR1-MD, is the same as for the tests conducted at $20^{\circ} \mathrm{C}$ and $36 \mathrm{~N} / \mathrm{s}$ loading rate. Within a $95 \%$ confidence level, the censored Weibull parameters for and are equivalent.

The uncensored Weibull distribution from the middle loading rate of $0.36 \mathrm{~N} / \mathrm{s}$ and the temperature of $850^{\circ} \mathrm{C}$ is presented in Figure 5.47, and Table 5.13 contains the censored Weibull parameters for the two identified modes of failure. The dominant mode of failure is VOL-SF with 21 followed by SUR1-MD with 6 failures. There were 2 UNK failures in this data. At $850^{\circ} \mathrm{C}$ and between the load rates of 36 and $0.36 \mathrm{~N} / \mathrm{s}$, the dominant mode of failure changes from SURI-MD to VOL-SF.

The last strength distribution for the transversely machined ASTM C 1161-B flexure bars that were tested at $850^{\circ} \mathrm{C}$ and $0.0036 \mathrm{~N} / \mathrm{s}$ loading rate is presented in Figure 5.48 and censored Weibull parameters are presented in Table 5.14. There were 10 specimens in this data set that were subjected to an unanticipated power failure. This allowed the temperature to return to $20^{\circ} \mathrm{C}$ and 
required restarting the test. Due to this power failure during testing, an additional 10 specimens were tested. Shown in Table 5.15 are the uncensored Weibull parameters based on three groups of data; 40 specimens tested, 30 specimens tested without a restart in the procedure, and 10 specimens that required restarting the test due to a power failure. The Weibull modulus and characteristic strength in all three cases are equivalent indicating that the power failure did not influence the failure probability distribution estimated from the specimen data. There were 30 VOL-SF failures identified, one VOL-AGG identified and $10 \mathrm{UNK}$. The dominant mode of failure, VOL-SF, is the same as all of the failures found from specimens tested at $700^{\circ} \mathrm{C}$, and for specimens tested at $0.36 \mathrm{~N} / \mathrm{s}$ and $850^{\circ} \mathrm{C}$.

Table 5.2. Number of specimens of each failure type for ASTM C 1161-B transversely machined specimens tested at $20^{\circ} \mathrm{C}$.

\begin{tabular}{|c|c|c|c|c|}
\hline Loading Rate (N/s) & VOL-SF & VOL-AGG & SUR1-MD & UNK \\
\hline 36 & 8 & 0 & 22 & 0 \\
\hline 0.36 & 2 & 0 & 28 & 0 \\
\hline 0.0036 & 5 & 0 & 24 & 0 \\
\hline
\end{tabular}

Table 5.3. Number of specimens of each failure types for ASTM C 1161-B transversely machined specimens tested at $700^{\circ} \mathrm{C}$.

\begin{tabular}{|c|c|c|c|c|}
\hline Loading Rate (N/s) & VOL-SF & VOL-AGG & SUR1-MD & UNK \\
\hline 36 & 11 & 1 & 3 & 0 \\
\hline 0.36 & 10 & 2 & 2 & 0 \\
\hline 0.0036 & 13 & 0 & 2 & 0 \\
\hline
\end{tabular}

Table 5.4. Number of specimens of each failure types for ASTM C 1161-B transversely machined specimens tested at $850^{\circ} \mathrm{C}$.

\begin{tabular}{|l|c|c|c|c|}
\hline Loading Rate (N/s) & VOL-SF & VOL-AGG & SUR1-MD & UNK \\
\hline 36 & 5 & 3 & 12 & 10 \\
\hline 0.36 & 21 & 0 & 6 & 2 \\
\hline 0.0036 & 30 & 1 & 0 & 9 \\
\hline
\end{tabular}




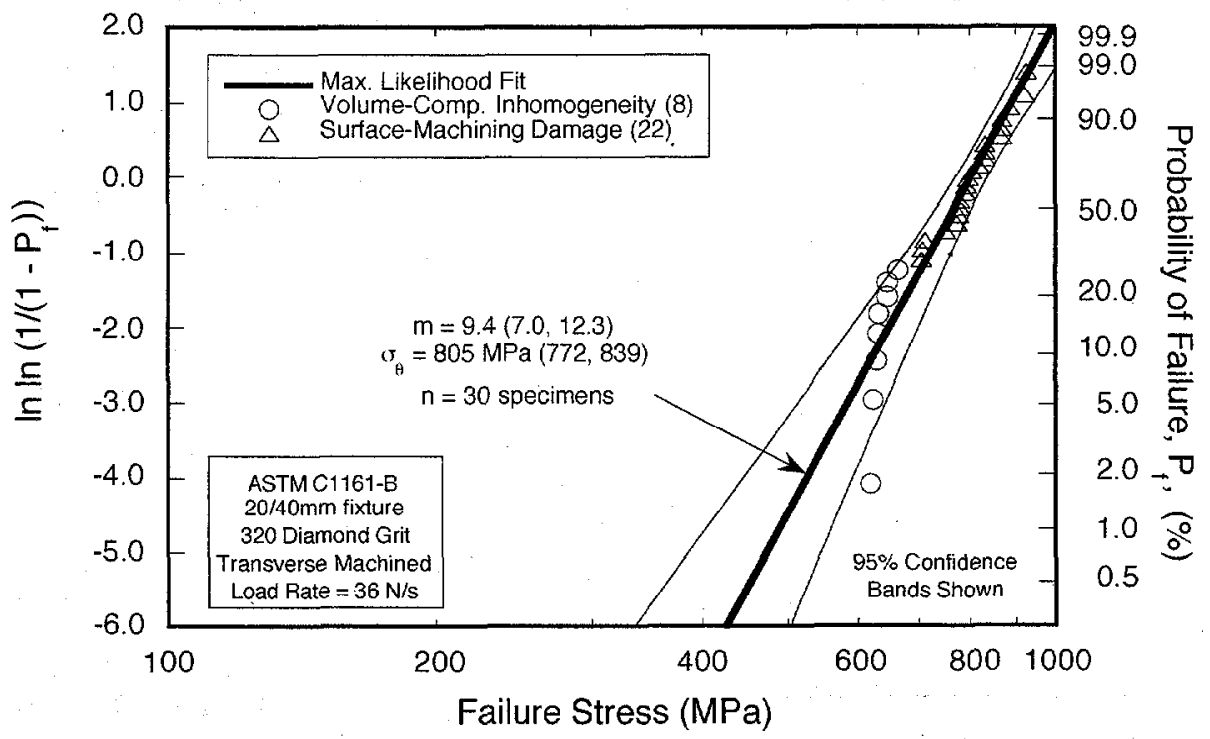

Figure 5.40. Uncensored Weibull distribution for ASTM C $1161-\mathrm{B}$ flexure specimens at $20^{\circ} \mathrm{C}$ and $36 \mathrm{~N} / \mathrm{s}$ load rate.

Table 5.5. ASTM C $1161-\mathrm{B}$ transversely machined flexure bars at $20^{\circ} \mathrm{C}$ and $36 \mathrm{~N} / \mathrm{s}$. Values in parentheses are $95 \%$ confidence bounds. Failure distributions are assumed concurrent.

\begin{tabular}{|l|c|l|}
\hline $\begin{array}{l}\text { Failure Mode / Number } \\
\text { of Specimens }\end{array}$ & $\begin{array}{l}\text { Weibull Shape Parameter } \\
\text { (Modulus) }\end{array}$ & $\begin{array}{l}\text { Weibull Scale } \\
\text { Parameter }^{(a)}\end{array}$ \\
\hline VOL-SF/8 & $4.3(2.1,7.5)$ & $1358(933,1358)^{(5)}$ \\
\hline SUR1-MD/22 & $14.3(10.3,19.0)$ & $1007(958,1099)$ \\
\hline
\end{tabular}

Table 5.6. ASTM C 1161-B transversely machined flexure bars at $20^{\circ} \mathrm{C}$ and $36 \mathrm{~N} / \mathrm{s}$. Values in parentheses are $95 \%$ confidence bounds. Failure distributions are assumed exclusive.

\begin{tabular}{|l|c|c|}
\hline $\begin{array}{l}\text { Failure Mode/Number } \\
\text { of Specimens }\end{array}$ & $\begin{array}{l}\text { Weibull Shape Parameter } \\
\text { (Modulus) }\end{array}$ & $\begin{array}{l}\text { Weibull Scale } \\
\text { Parameter }^{(a)}\end{array}$ \\
\hline VOL-SF/8 & $45(25,70)^{(0)}$ & $596(577,610)$ \\
\hline SUR1-MD/22 & $14.1(10.0,18.8)$ & $1010(959,1109)$ \\
\hline
\end{tabular}

(a) The Weibull scale parameter has units of MPa $\mathrm{mm}^{2 / m \text {-surace }}$ for surface failures and MPa $\mathrm{mm}^{3 / \mathrm{m} \text {-volume }}$ for volume failures.

(b) Due to the small censored sample size, the values of the Weibull shape parameter and associated $95 \%$ confidence bounds are extreme. 


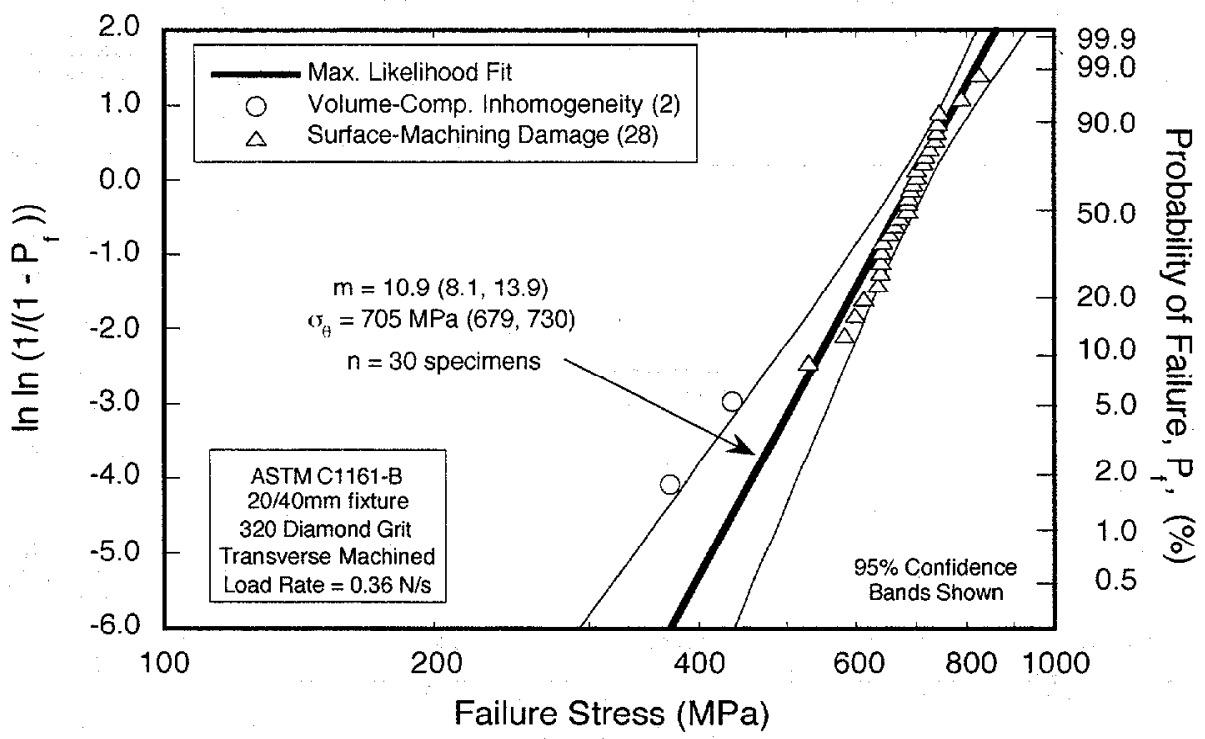

Figure 5.41. Uncensored Weibull distribution for ASTM C 1161-B flexure specimens tested at $20^{\circ} \mathrm{C}$ and $0.36 \mathrm{~N} / \mathrm{s}$ load rate.

Table 5.7. ASTM C 1161-B transversely machined flexure bars at $20^{\circ} \mathrm{C}$ and $0.36 \mathrm{~N} / \mathrm{s}$. Values in parentheses are $95 \%$ confidence bounds.

\begin{tabular}{|l|c|c|}
\hline $\begin{array}{l}\text { Failure Mode / Number } \\
\text { of Specimens }\end{array}$ & $\begin{array}{l}\text { Weibull Shape Parameter } \\
\text { (Modulus) }\end{array}$ & $\begin{array}{l}\text { Weibull Scale } \\
\text { Parameter }^{(a)}\end{array}$ \\
\hline VOL-SF/2 & $2.8(0.7,8.0)^{(\mathrm{c})}$ & $3038(883,3038)^{(\mathrm{b})}$ \\
\hline SUR1-MD/28 & $12.6(9.4,16.0)$ & $880(836,880)^{(0)}$ \\
\hline
\end{tabular}

(a) The Weibull scale parameter has units of $\mathrm{MPa} \mathrm{mm}{ }^{2 / m-s u r a c e}$ for surface failures and

MPa $\mathrm{mm}^{3 / \mathrm{m} \text {-volume }}$ for volume failures.

(b) Due to the small censored sample size, no value for the lower (upper) confidence limit was convergent.

(c) Due to the small censored sample size, the values of the Weibull shape parameter and associated 95\% confidence bounds are extreme. 


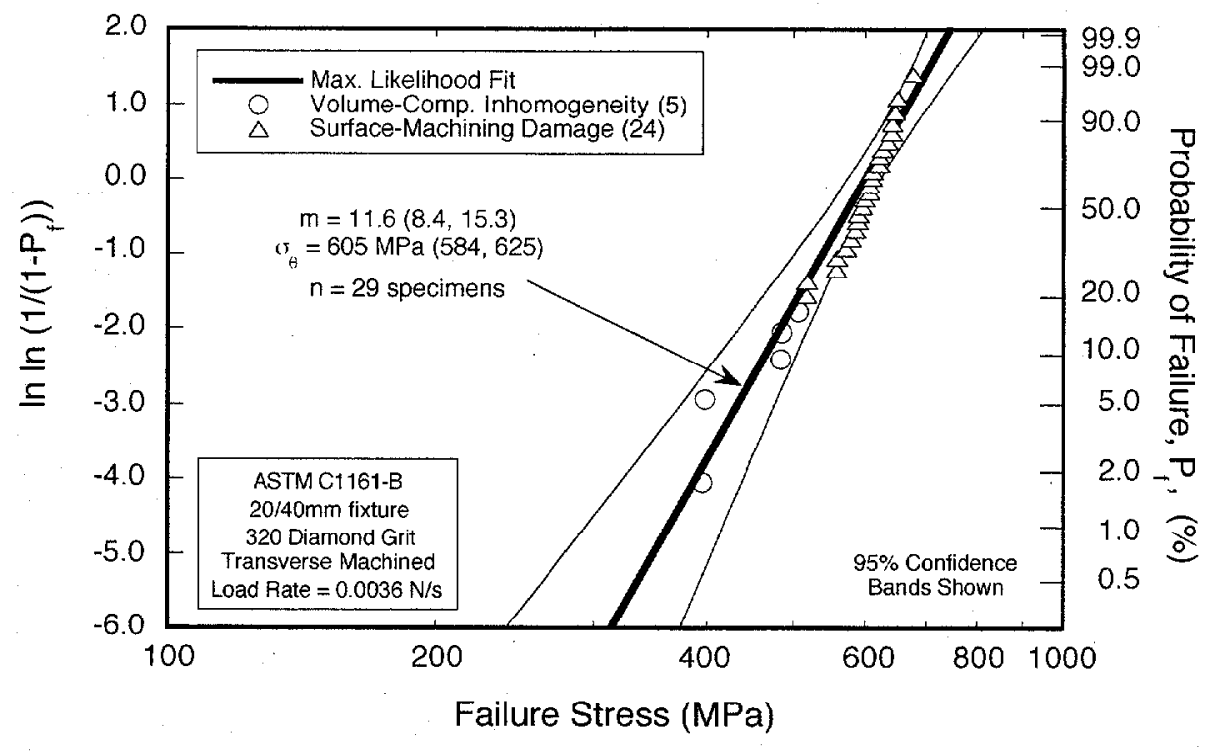

Figure 5.42. Uncensored Weibull distribution for ASTM C 1161-B flexure specimens tested at $20^{\circ} \mathrm{C}$ and $0.0036 \mathrm{~N} / \mathrm{s}$ load rate.

Table 5.8. ASTM C 1161-B transversely machined flexure bars at $20^{\circ} \mathrm{C}$ and $0.0036 \mathrm{~N} / \mathrm{s}$. Values in parentheses are 95 percent confidence bounds.

\begin{tabular}{|l|c|c|}
\hline $\begin{array}{l}\text { Failure Mode / Number } \\
\text { of Specimens }\end{array}$ & $\begin{array}{l}\text { Weibull Shape Parameter } \\
\text { (Modulus) }\end{array}$ & $\begin{array}{l}\text { Weibull Scale } \\
\text { Parameter }^{(a)}\end{array}$ \\
\hline VOL-SF/5 & $3.6(1.3,7.3)$ & $1417(746,1417)^{(\text {b) }}$ \\
\hline SUR1-MD/24 & $18.1(13.1,24.0)$ & $709(683,755)$ \\
\hline
\end{tabular}

(a) The Weibull scale parameter has units of $\mathrm{MPa} \mathrm{mm}^{2 / m-s u r a c e}$ for surface failures and $\mathrm{MPamm}^{3 / \mathrm{m}-\text { volume }}$ for volume failures.

(b) Due to the small censored sample size, no value for the lower (upper) confidence limit was convergent. 


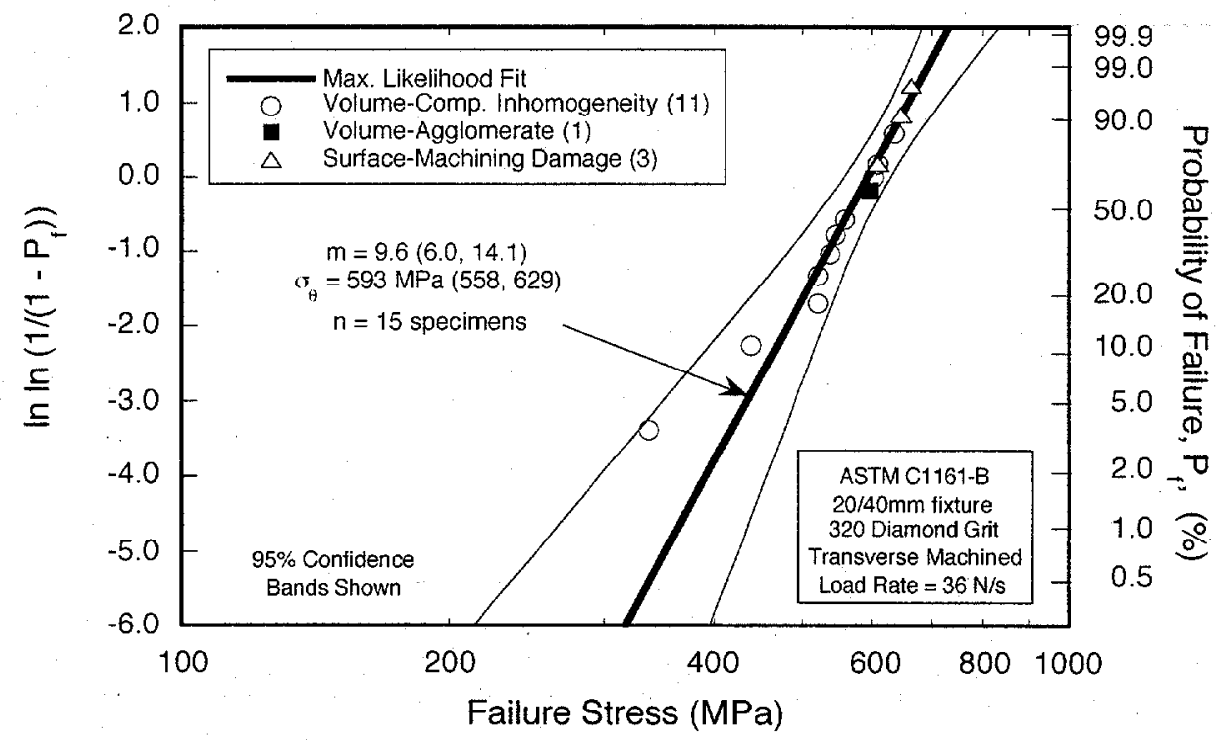

Figure 5.43. Uncensored Weibull distribution for ASTM C 1161-B flexure specimens tested at $700^{\circ} \mathrm{C}$ and $36 \mathrm{~N} / \mathrm{s}$ load rate.

Table 5.9. ASTM C 1161-B transversely machined flexure bars at $700^{\circ} \mathrm{C}$ and $36 \mathrm{~N} / \mathrm{s}$. Values in parentheses are $95 \%$ confidence bounds.

\begin{tabular}{|l|l|l|}
\hline $\begin{array}{l}\text { Failure Mode / Number } \\
\text { of Specimens }\end{array}$ & $\begin{array}{l}\text { Weibull Shape Parameter } \\
\text { (Modulus) }\end{array}$ & $\begin{array}{l}\text { Weibull Scale } \\
\text { Parameter }^{\left({ }^{a}\right)}\end{array}$ \\
\hline VOL-SF/11 & $7.2(4.1,11.5)$ & $618(556,618)^{(\mathrm{c})}$ \\
\hline VOL-AGG/1 & $\mathrm{n} / \mathbf{a}^{(b)}$ & $\mathrm{n} / \mathbf{a}^{(0)}$ \\
\hline SUR1-MD/3 & $44.2(17.9,89)^{(\mathrm{d})}$ & $683(664,769)$ \\
\hline
\end{tabular}

(a) The Weibull scale parameter has units of $\mathrm{MPa} \mathrm{mm}^{2 \text {-surace }}$ for surface failures and $\mathrm{MPa} \mathrm{mm}^{3 / \mathrm{m} \text {-volume }}$ for volume failures.

(b) Estimating Weibull distribution parameters for a single sample size has no relevance.

(c) Due to the small censored sample size, no value for the lower (upper) confidence limit was convergent.

(d) Due to the small censored sample size, the values of the Weibull shape parameter and associated $95 \%$ confidence bounds are extreme. 


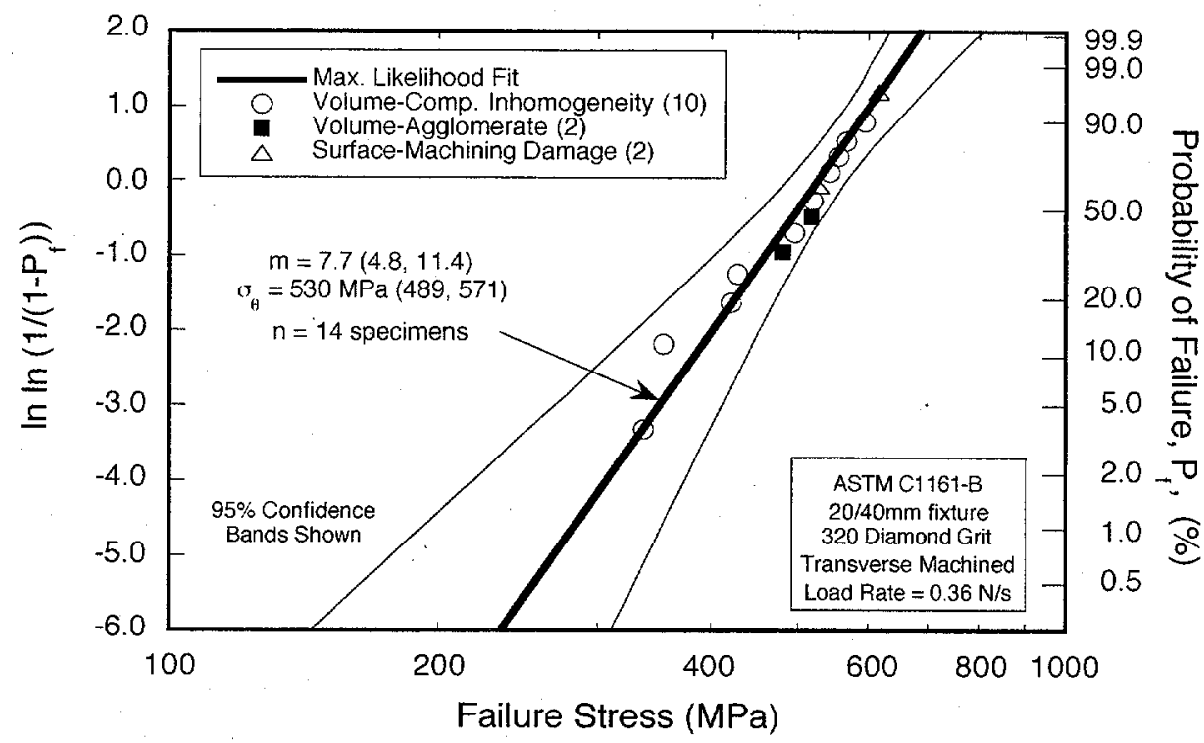

Figure 5.44. Uncensored Weibull distributions for ASTM C 1161-B flexure specimens tested at $700^{\circ} \mathrm{C}$ and $0.36 \mathrm{~N} / \mathrm{s}$ load rate.

Table 5.10. ASTM C $1161-\mathrm{B}$ transversely machined flexure bars at $700^{\circ} \mathrm{C}$ and $0.36 \mathrm{~N} / \mathrm{s}$. Values in parentheses are $95 \%$ confidence bounds.

\begin{tabular}{|l|c|l|}
\hline $\begin{array}{l}\text { Failure Mode / Number } \\
\text { of Specimens }\end{array}$ & $\begin{array}{l}\text { Weibull Shape Parameter } \\
\text { (Modulus) }\end{array}$ & $\begin{array}{l}\text { Weibull Scale } \\
\text { Parameter }^{(a)}\end{array}$ \\
\hline VOL-SF/10 & $6.5(3.6,10.4)$ & $576(508,837)$ \\
\hline VOL-AGG/2 & $8.5(1.9,20.8)^{(\mathrm{c})}$ & $651(536,651)^{(0)}$ \\
\hline SUR1-MD/2 & $22.5(6.7,51.3)^{(c)}$ & $680(626,680)^{(0)}$ \\
\hline
\end{tabular}

(a) The Weibull scale parameter has units of $\mathrm{MPa} \mathrm{mm}^{2 / \mathrm{m}-\text {-urrace }}$ for surface failures and MPa $\mathrm{mm}^{3 / \mathrm{m} \text {-volume }}$ for volume failures.

(b) Due to the small censored sample size, no value for the lower (upper) confidence limit was convergent.

(c) Due to the small censored sample size, the values of the Weibull shape parameter and associated 95\% confidence bounds are extreme. 


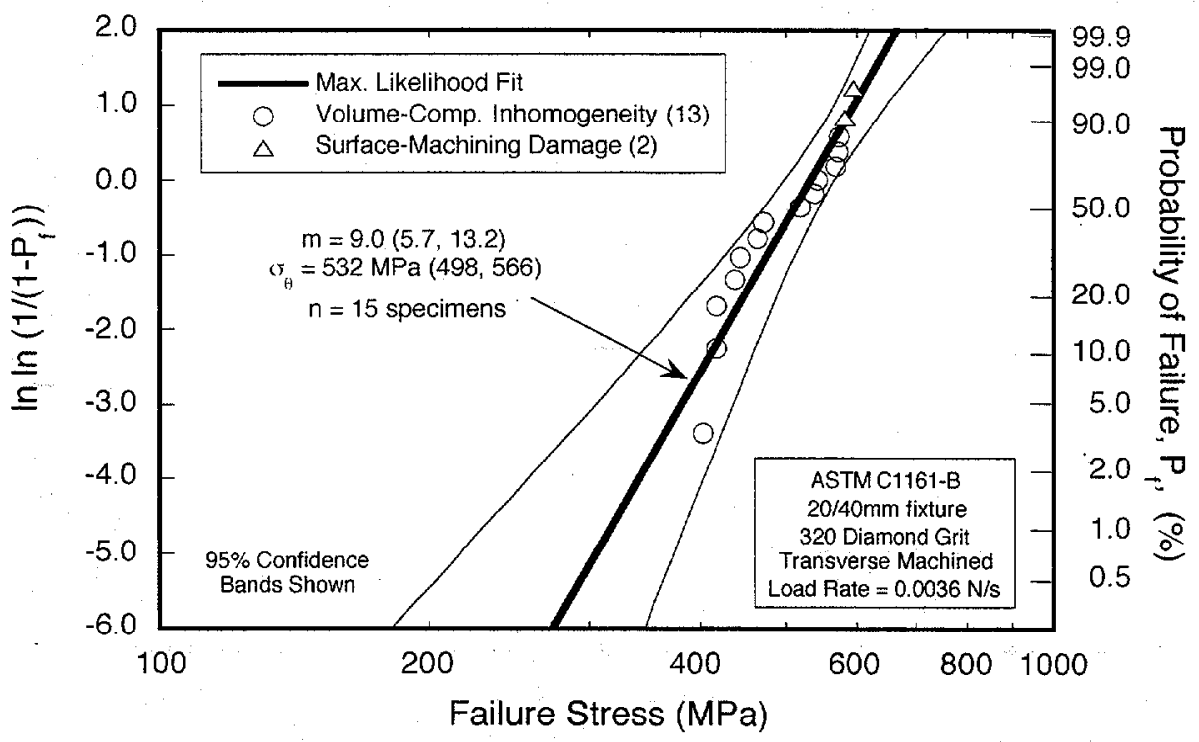

Figure 5.45. Uncensored Weibull distribution for ASTM C 1161-B flexure specimens tested at $700^{\circ} \mathrm{C}$ and $0.0036 \mathrm{~N} / \mathrm{s}$ load rate.

Table 5.11. ASTM C 1161-B transversely machined flexure bars at $700^{\circ} \mathrm{C}$ and $0.0036 \mathrm{~N} / \mathrm{s}$. Values in parentheses are $95 \%$ confidence bounds.

\begin{tabular}{|l|c|l|}
\hline $\begin{array}{l}\text { Failure Mode/ Number } \\
\text { of Specimens }\end{array}$ & $\begin{array}{l}\text { Weibull Shape Parameter } \\
\text { (Modulus) }\end{array}$ & $\begin{array}{l}\text { Weibull Scale } \\
\text { Parameter }^{(a)}\end{array}$ \\
\hline VOL-SF/13 & $7.8(4.7,11.8)$ & $533(492,654)$ \\
\hline SUR1-MD/2 & $117(37,117)^{(1)}$ & $599(593,634)$ \\
\hline
\end{tabular}

(a) The Weibull scale parameter has units of MPa $\mathrm{mm}^{2 / 2-\text {-surace }}$ for surface failures and MPa $\mathrm{mm}^{3 / \mathrm{m} \text {-volume }}$ for volume failures.

(b) Due to the small censored sample size, the values of the Weibull shape parameter and associated $95 \%$ confidence bounds are extreme. 


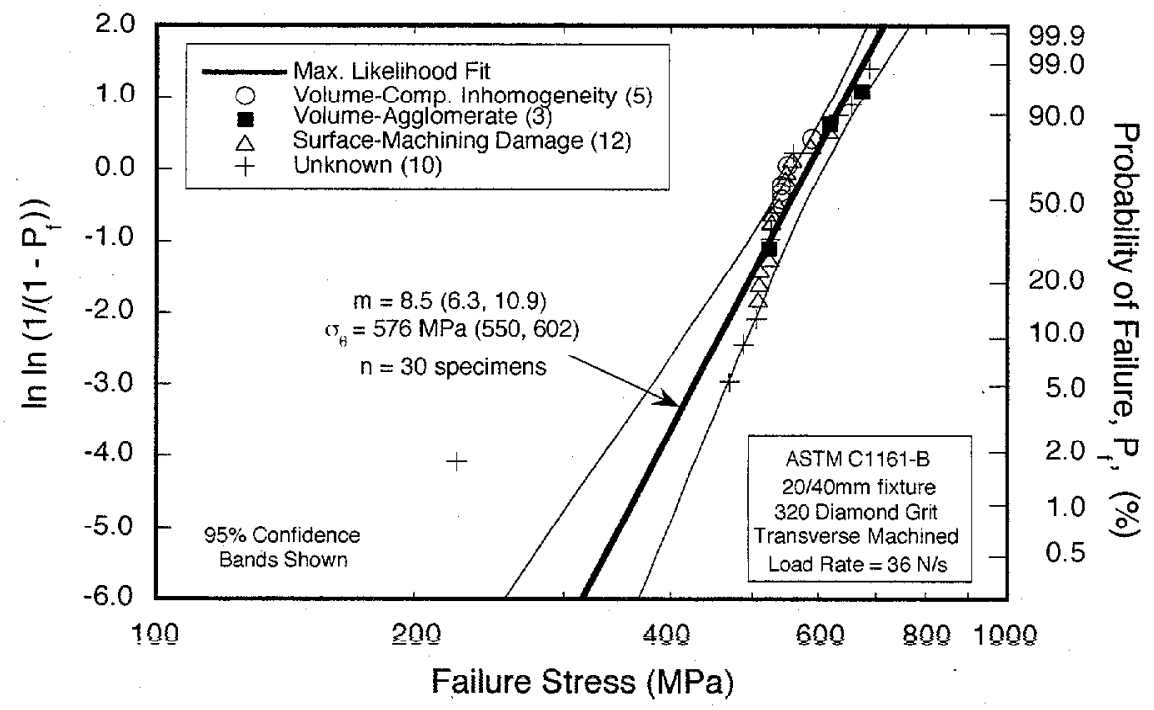

Figure 5.46. Uncensored Weibull distribution for ASTM C 1161-B flexure specimens tested at $850^{\circ} \mathrm{C}$ and $36 \mathrm{~N} / \mathrm{s}$ load rate.

Table 5.12. ASTM C 1161-B transversely machined flexure bars at $850^{\circ} \mathrm{C}$ and $36 \mathrm{~N} / \mathrm{s}$. Values in parentheses are $95 \%$ confidence bounds.

\begin{tabular}{|l|c|l|}
\hline $\begin{array}{l}\text { Failure Mode /Number } \\
\text { of Specimens }\end{array}$ & $\begin{array}{l}\text { Weibull Shape Parameter } \\
\text { (Modulus) }\end{array}$ & $\begin{array}{l}\text { Weibull Scale } \\
\text { Parameter }^{(a)}\end{array}$ \\
\hline VOL-SF/5 & $9.7(4.5,16.7)$ & $685(607,1132)$ \\
\hline VOL-AGG/3 & $15.5(6.4,29.4)^{(\mathrm{c})}$ & $648(605,917)$ \\
\hline SUR1-MD/12 & $8.8(5.4,12.8)$ & $925(925,1294)^{(b)}$ \\
\hline UNK /10 & $\mathrm{n} / \mathrm{a}^{(\mathrm{d})}$ & $\mathrm{n} / \mathbf{a}^{(\mathrm{d})}$ \\
\hline
\end{tabular}

(a) The Weibull scale parameter has units of MPa $\mathrm{mm}^{2 / m-s u r t a c e}$ for surface failures and MPa $\mathrm{mm}^{3 / \mathrm{m} \text {-volume }}$ for volume failures.

(b) Due to the small censored sample size, no value for the lower (upper) confidence limit was convergent.

(c) Due to the small censored sample size, the values of the Weibull shape parameter and associated 95\% confidence bounds are extreme.

(d) Unidentifiable failure modes are included in the censoring of failure data but no Weibull parameters are estimated for them. 


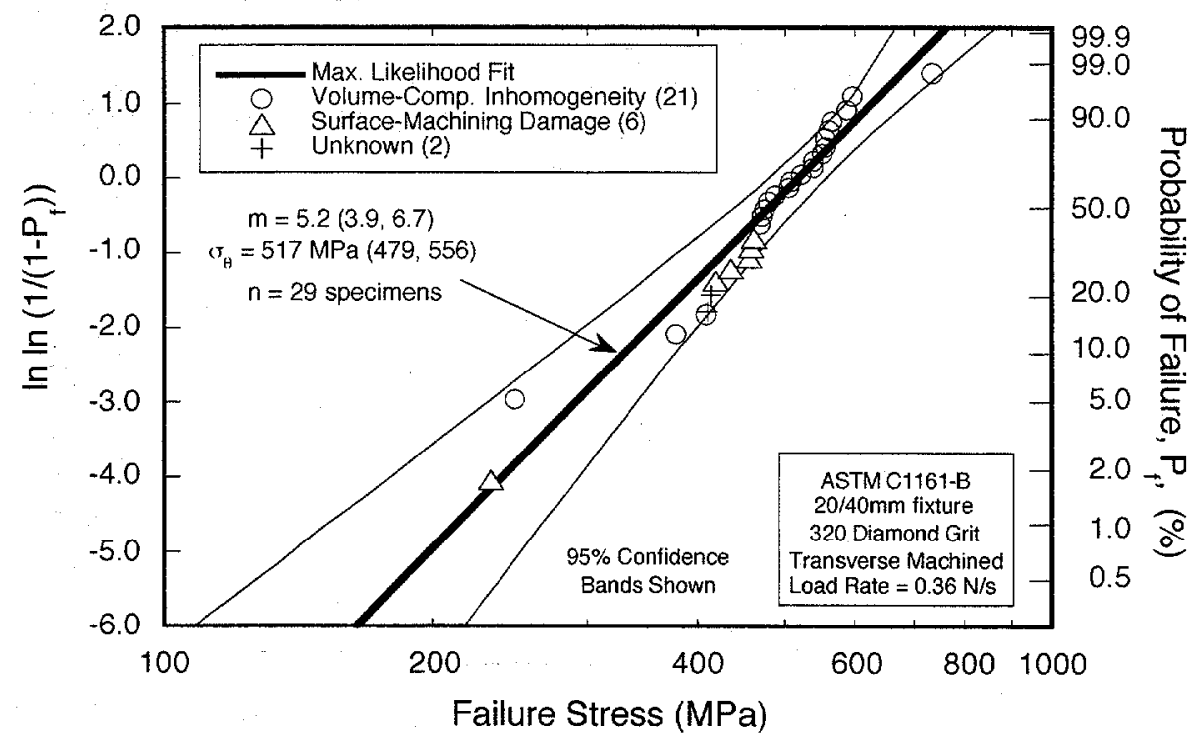

Figure 5.47. Uncensored. Weibull distribution for ASTM C 1161-B flexure specimens tested at $850^{\circ} \mathrm{C}$ and $0.36 \mathrm{~N} / \mathrm{s}$ load rate.

Table 5.13. ASTM C $1161-\mathrm{B}$ transversely machined flexure bars at $850^{\circ} \mathrm{C}$ and $0.36 \mathrm{~N} / \mathrm{s}$. Values in parentheses are $95 \%$ confidence bounds.

\begin{tabular}{|l|c|c|}
\hline $\begin{array}{l}\text { Failure Mode / Number } \\
\text { of Specimens }\end{array}$ & $\begin{array}{l}\text { Weibull Shape Parameter } \\
\text { (Modulus) }\end{array}$ & $\begin{array}{l}\text { Weibull Scale Parameter } \\
\text { (a) }\end{array}$ \\
\hline VOL-SF/21 & $6.6(4.8,8.5)$ & $578(534,672)$ \\
\hline SUR1-MD/6 & $3.5(1.5,6.2)$ & $2198(1096,2198)^{(0)}$ \\
\hline UNK/2 & $\mathrm{n} / \mathrm{a}^{(\text {c) }}$ & $\mathrm{n} / \mathrm{a}^{(c)}$ \\
\hline
\end{tabular}

(a) The Weibull scale parameter has units of MPa $\mathrm{mm}^{2 / m-\text { surace }}$ for surface failures and $\mathrm{MPa} \mathrm{mm}^{3 / \mathrm{m} \text {-volume }}$ for volume failures.

(b) Due to the small censored sample size, no value for the lower (upper) confidence limit was convergent.

(c) Unidentifiable failure modes are included in the censoring of failure data but no Weibull parameters are estimated for them. 


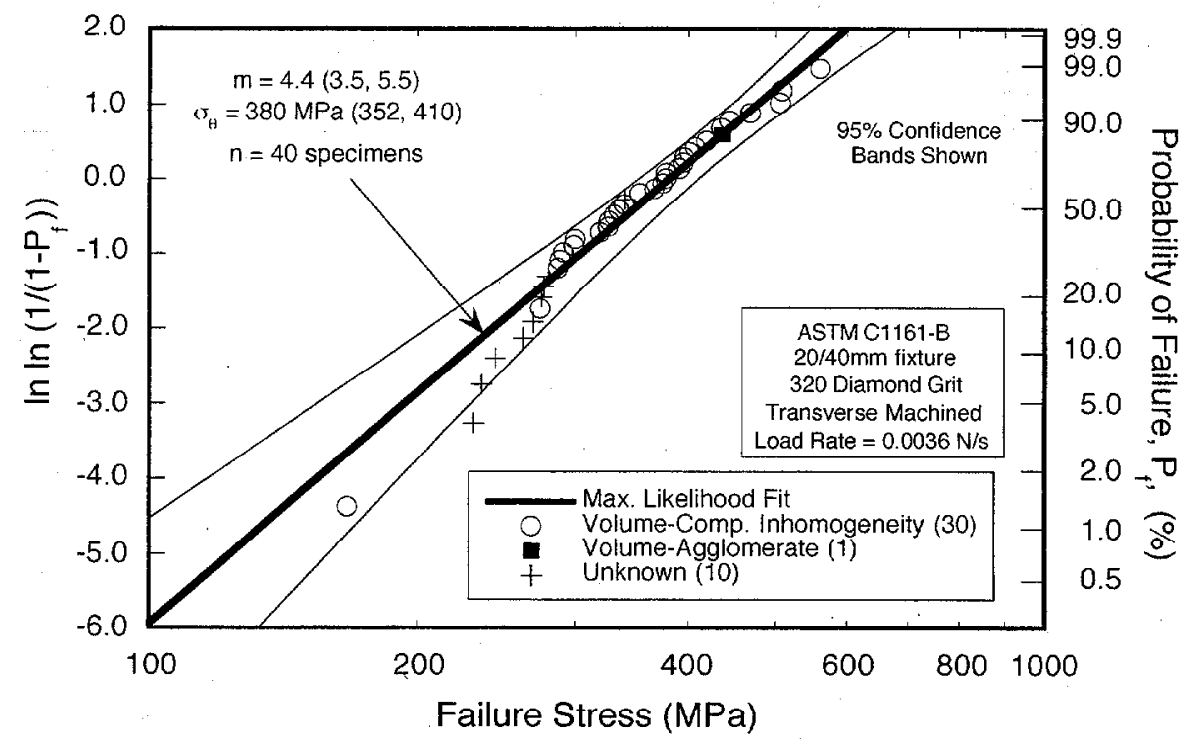

Figure 5.48. Uncensored Weibull distribution for ASTM C 1161-B flexure specimens tested at $850^{\circ} \mathrm{C}$ and $0.0036 \mathrm{~N} / \mathrm{s}$ loading rate.

Table 5.14. ASTM C 1161-B transversely machined flexure bars at $850^{\circ} \mathrm{C}$ and $0.0036 \mathrm{~N} / \mathrm{s}$. Values in parentheses are $95 \%$ confidence bounds.

\begin{tabular}{|l|c|l|}
\hline $\begin{array}{l}\text { Failure Mode / Specimen } \\
\text { Number }\end{array}$ & $\begin{array}{l}\text { Weibull Shape Parameter } \\
\text { (Modulus) }\end{array}$ & $\begin{array}{l}\text { Weibull Scale } \\
\text { Parameter }^{(\mathrm{a})}\end{array}$ \\
\hline VOL-SF/30 & $5.2(4.0,6.6)$ & $466(422,555)$ \\
\hline VOL-AGG/1 & $\mathrm{n} / \mathrm{a}^{(0)}$ & $\mathrm{n} / \mathbf{a}^{(0)}$ \\
\hline UNK/9 & $\mathrm{n} / \mathbf{a}^{(c)}$ & $\mathrm{n} / \mathbf{a}^{(c)}$ \\
\hline
\end{tabular}

(a) The Weibull scale parameter has units of MPa $\mathrm{mm}^{\text {2m-1m-surace }}$ for surface failures and MPa $\mathrm{mm}^{3 / \mathrm{m} \text {-volume }}$ for volume failures.

(b) Estimating Weibull distribution parameters for a single sample size has no relevance.

(c) Unidentifiable failure modes are included in the censoring of failure data but no Weibull parameters are estimated for them. 
Table 5.15. Power failure dependence on ASTM C 1161-B transversely machined flexure bars tested at $850^{\circ} \mathrm{C}$ and at $0.0036 \mathrm{~N} / \mathrm{s}$. Values in parentheses are $95 \%$ confidence bounds.

\begin{tabular}{|c|c|c|c|}
\hline $\begin{array}{l}\text { Number of } \\
\text { Specimens }\end{array}$ & Temp $\left({ }^{\circ} \mathrm{C}\right)$ & Weibull Modulus & $\begin{array}{l}\text { Characteristic Strength } \\
(\mathrm{MPa})\end{array}$ \\
\hline 40 & 850 & $4.4(3.5,5.5)$ & $381(352,410)$ \\
\hline 30 & 850 & $3.9(3.0,5.1)$ & $374(338,411)$ \\
\hline 10 & 850 & $8.3(4.7,13.2)$ & $396(361,431)$ \\
\hline
\end{tabular}

\subsubsection{Longitudinally Machined ASTM C 1161-B Flexure Bars}

\subsubsection{Uncensored Weibull Distributions}

Presented in this section are the results from ASTM C 1161-B flexure specimens that were machined in a direction parallel to the maximum tensile axis. These specimens were tested at 20 and $850^{\circ} \mathrm{C}$ and at a $36 \mathrm{~N} / \mathrm{s}$ loading rate. For this study only the temperature dependence of the longitudinal grinding orientation was examined. The longitudinally machined specimens were made using the same 320 diamond grit grinding wheel that machined the ASTM C 1161-B transversely machined specimens. The longitudinal machining direction on flexure specimens typically represents the upper bound for strength of the material when machining with the same 320 diamond grit wheel.

Figure 5.49 presents the uncensored Weibull distribution for ASTM C 1161-B longitudinally machined specimens tested at 20 and $850^{\circ} \mathrm{C}$ and at the loading rate of $36 \mathrm{~N} / \mathrm{s}$. A decrease of approximately $50 \%$ is observed in both the uncensored Weibull modulus and characteristic strength when the temperature increased from 20 to $850^{\circ} \mathrm{C}$. 


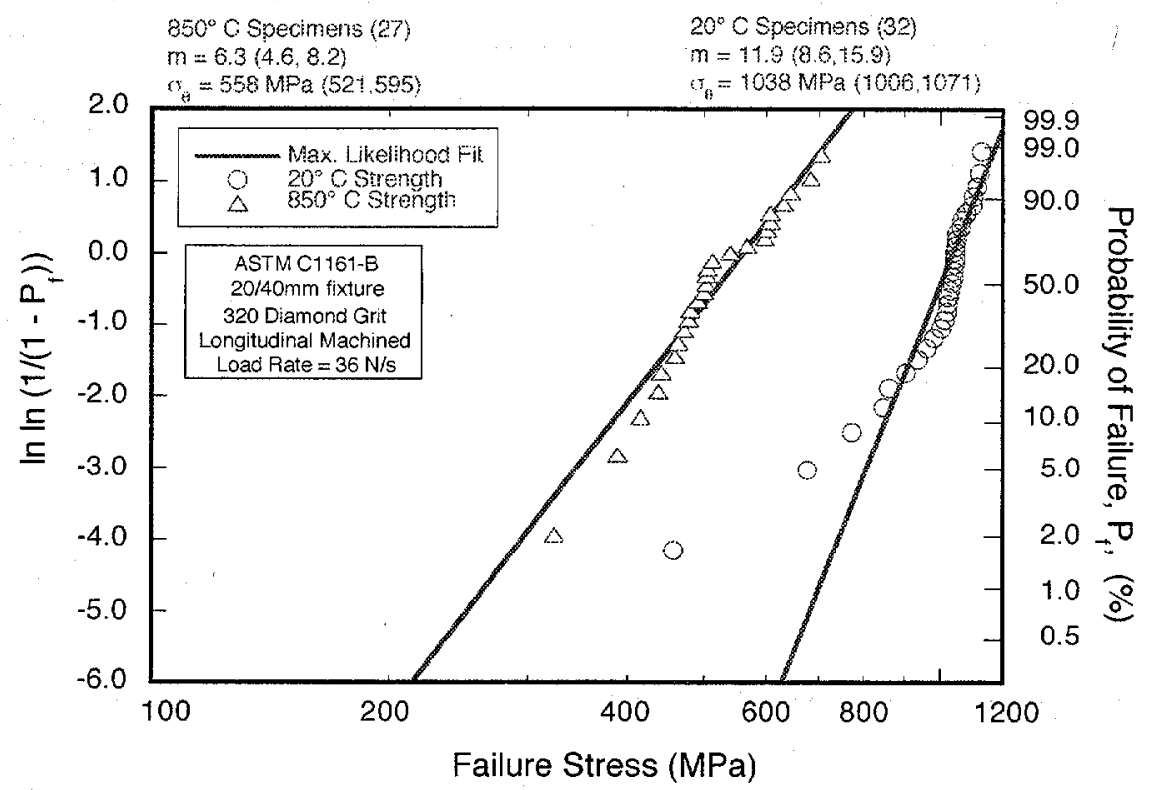

Figure 5.49. Temperature dependence for ASTM C 1161-B longitudinally ground flexure bars tested at $36 \mathrm{~N} / \mathrm{s}$ load rate.

\subsubsection{Weibull Distributions with Censored Strength Data}

Presented in Table 5.16 are the fractographic results for the longitudinally machined ASTM C $1161-\mathrm{B}$ specimens tested at $36 \mathrm{~N} / \mathrm{s}$ and at 20 and $850^{\circ} \mathrm{C}$. The dominant mode of failure for both data sets was VOL-SF having 23 out of 32 failures at $20^{\circ} \mathrm{C}$, and all 27 at $850^{\circ} \mathrm{C}$. At $20^{\circ} \mathrm{C}$, there were 8 SUR1-MD failures identified along with one VOL-AGG failure.

Under the same test conditions, the dominant mode of failure for the transversely machined specimens is different than for the longitudinally machined specimens. Comparing failure types at $36 \mathrm{~N} / \mathrm{s}$ and $20^{\circ} \mathrm{C}$ (Tables 5.2 and 5.16), the dominant mode of failure for the longitudinally machined specimens was VOL-SF while the dominant mode of failure for the transversely machined specimens was SUR1-MD. The same trend is observed when comparing the fractographic results at $36 \mathrm{~N} / \mathrm{s}$ and $850^{\circ} \mathrm{C}$, see Tables 5.16 and 5.4. The longitudinally machined specimens predominantly failed from VOL-SF while the transversely machined specimens predominantly failed from SUR1-MD.

Presented in Figures 5.50 and 5.51 are the uncensored flexure strengths for the ASTM C $1161-\mathrm{B}$ specimens longitudinally machined tested at $36 \mathrm{~N} / \mathrm{s}$ and at 20 and $850^{\circ} \mathrm{C}$, respectively. The failures types for each specimen are identified in each plot for each test condition. Tables 5.17 and 5.18 present the censored Weibull parameters for the data found in Figures 5.50 and 5.51. 
Looking at the VOL-SF failure mode, there are decreases in both the Weibull scale and modulus parameters by approximately 40 and $78 \%$, respectively, when the temperature increases from 20 to $850^{\circ} \mathrm{C}$.

Table 5.16. ASTM C $1161-\mathrm{B}$ specimens longitudinally machined and tested at $36 \mathrm{~N} / \mathrm{s}$ and at 20 and $850^{\circ} \mathrm{C}$. Number of specimens for each flaw type shown.

\begin{tabular}{|l|c|c|c|c|}
\hline Load Rate $(\mathrm{N} / \mathrm{s})$ Temp $\left({ }^{\circ} \mathrm{C}\right)$ & VOL-SF & VOL-AGG & SUR1-MD & UNK \\
\hline $36 \mathrm{~N} / \mathrm{s}, 20^{\circ} \mathrm{C}$ & 23 & 1 & 8 & 0 \\
\hline $36 \mathrm{~N} / \mathrm{s}, 850^{\circ} \mathrm{C}$ & 27 & 0 & 0 & 0 \\
\hline
\end{tabular}

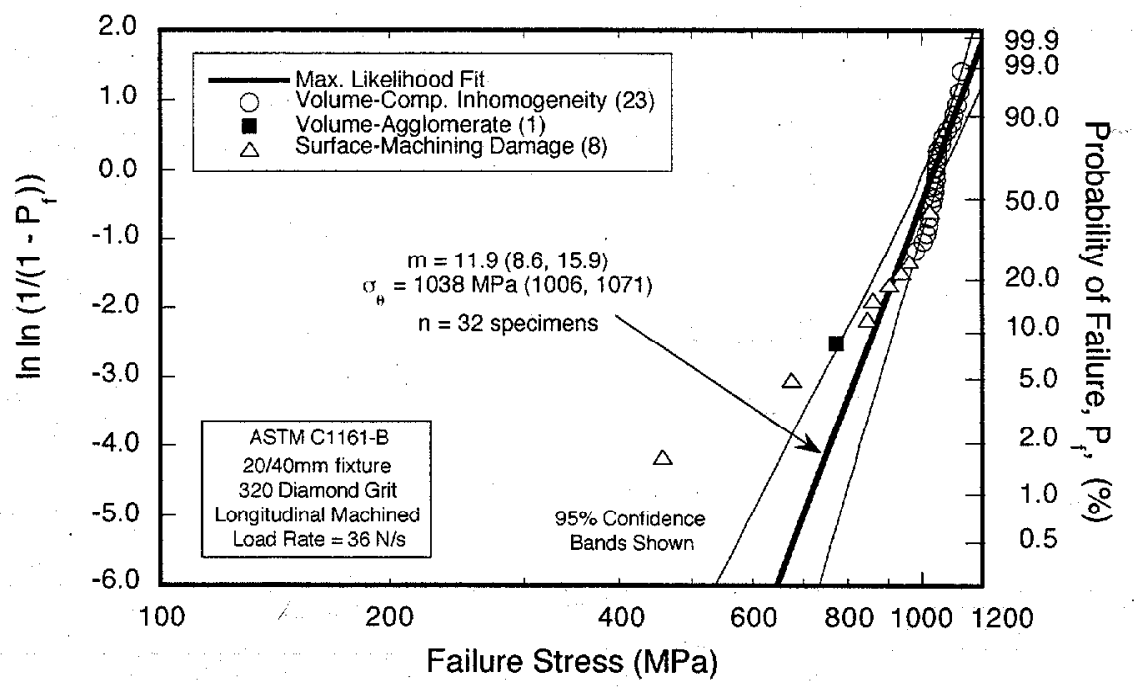

Figure 5.50. Uncensored Weibull distribution for ASTM C 1161-B flexure specimens longitudinally machined and tested at $20^{\circ} \mathrm{C}$ and $36 \mathrm{~N} / \mathrm{s}$ load rate. 
Table 5.17. ASTM C $1161-\mathrm{B}$ longitudinally machined flexure bars at $20^{\circ} \mathrm{C}$ and $36 \mathrm{~N} / \mathrm{s}$. Values in parentheses are $95 \%$ confidence bounds.

\begin{tabular}{|l|c|c|}
\hline $\begin{array}{l}\text { Failure Mode / Number of } \\
\text { Specimens }\end{array}$ & $\begin{array}{l}\text { Weibull Shape Parameter } \\
\text { (Modulus) }\end{array}$ & $\begin{array}{l}\text { Weibull Scale } \\
\text { Parameter }^{(a)}\end{array}$ \\
\hline VOL-SF/23 & $29(21,38)$ & $979(961,997)$ \\
\hline VOL-AGG/1 & $\mathrm{n} / \mathbf{a}^{(\mathrm{b})}$ & $\mathbf{n} / \mathbf{a}^{(\mathrm{b})}$ \\
\hline SUR1-MD / & $4.1(1.9,7.4)$ & $3235(1830,3235)^{(\mathrm{c})}$ \\
\hline
\end{tabular}

(a) The Weibull scale parameter has units of MPa $\mathrm{mm}^{2 / \mathrm{m}-\text { surace }}$ for surface failures and $\mathrm{MPa} \mathrm{mm}^{3 / \mathrm{m} \text {-volume }}$ for volume failures.

(b) Estimating Weibull distribution parameters for a single sample size has no relevance.

(c) Due to the small censored sample size, no value for the lower (upper) confidence limit was convergent.

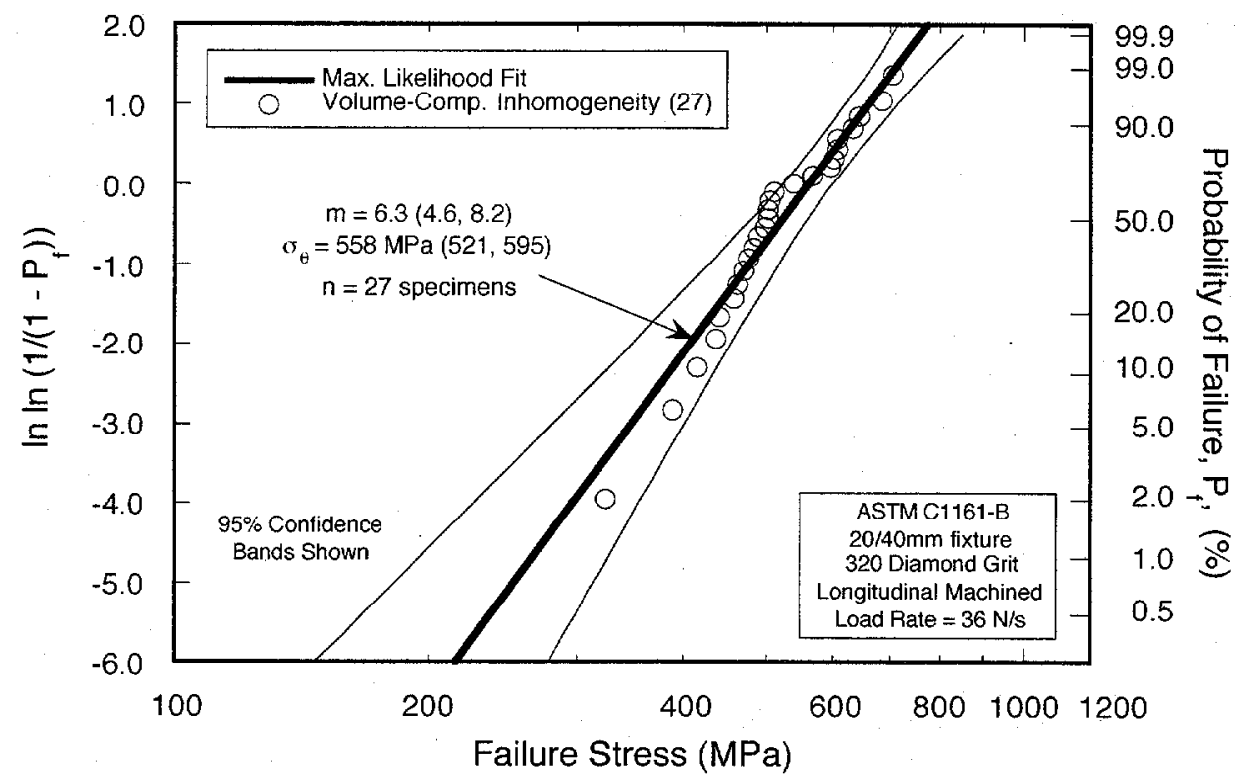

Figure 5.51. Uncensored Weibull distribution for ASTM C 1161-B flexure specimens longitudinally machined and tested at $850^{\circ} \mathrm{C}$ and $36 \mathrm{~N} / \mathrm{s}$ load rate. 
Table 5.18. ASTM C $1161-\mathrm{B}$ longitudinally machined flexure bars at $850^{\circ} \mathrm{C}$ and $36 \mathrm{~N} / \mathrm{s}$. Values in parentheses are $95 \%$ confidence bounds.

\begin{tabular}{|l|c|c|}
\hline $\begin{array}{l}\text { Failure Mode / Number of } \\
\text { Specimens }\end{array}$ & $\begin{array}{l}\text { Weibull Shape Parameter } \\
\text { (Modulus) }\end{array}$ & $\begin{array}{l}\text { Weibull Scale } \\
\text { Parameter }^{(a)}\end{array}$ \\
\hline VOL-SF/27 & $6.3(4.6,8.2)$ & $588(545,677)$ \\
\hline
\end{tabular}

(a) The Weibull scale parameter has units of MPa $\mathrm{mm}^{\text {sm-volume }}$ for volume failure.

\subsubsection{Machining Orientation and Strength for ASTM C 1161-B Flexure Specimens}

Figure 5.52 shows the effect of machining orientation with regard to the inert strength of ASTM C 1161-B flexure specimens at $20^{\circ} \mathrm{C}$. Figure 5.53 illustrates for the same test specimen tested at the same loading rate the effect that machining orientation has on the strength but at the temperature of $850^{\circ} \mathrm{C}$. The uncensored Weibull modulus estimates for the transversely and longitudinally machined specimens tested at $20^{\circ} \mathrm{C}$ are equivalent and approximately 10 . At $20^{\circ} \mathrm{C}$, the machining orientation had an influence on the characteristic strength. The longitudinally machined specimens had a characteristic strength that was $20 \%$ stronger than the transversely machined specimens.

At $850^{\circ} \mathrm{C}$ (Figure 5.53), the Weibull modulus for both machining orientations are again equivalent and approximately 7 , slightly less than estimates made at $20^{\circ} \mathrm{C}$. The characteristic strength for the two machining directions at $850^{\circ} \mathrm{C}$ are equivalent and approximately $560 \mathrm{MPa}$. These results suggest that at $850^{\circ} \mathrm{C}$ and at the loading rate of $36 \mathrm{~N} / \mathrm{s}$, the machining orientation of ASTM C 1161-B specimens has no influence on strength. 


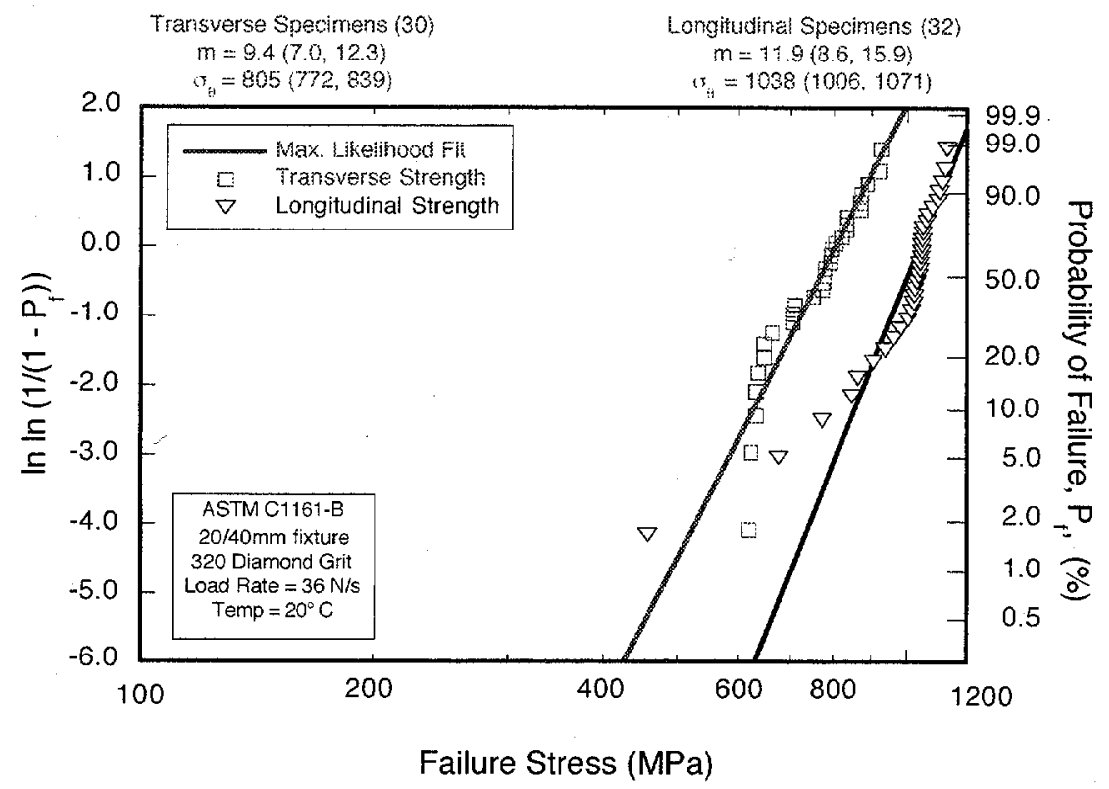

Figure 5.52. Strength as a function of machining orientation for ASTM C 1161-B flexure bars tested at $20^{\circ} \mathrm{C}$ and $36 \mathrm{~N} / \mathrm{s}$ load rate.

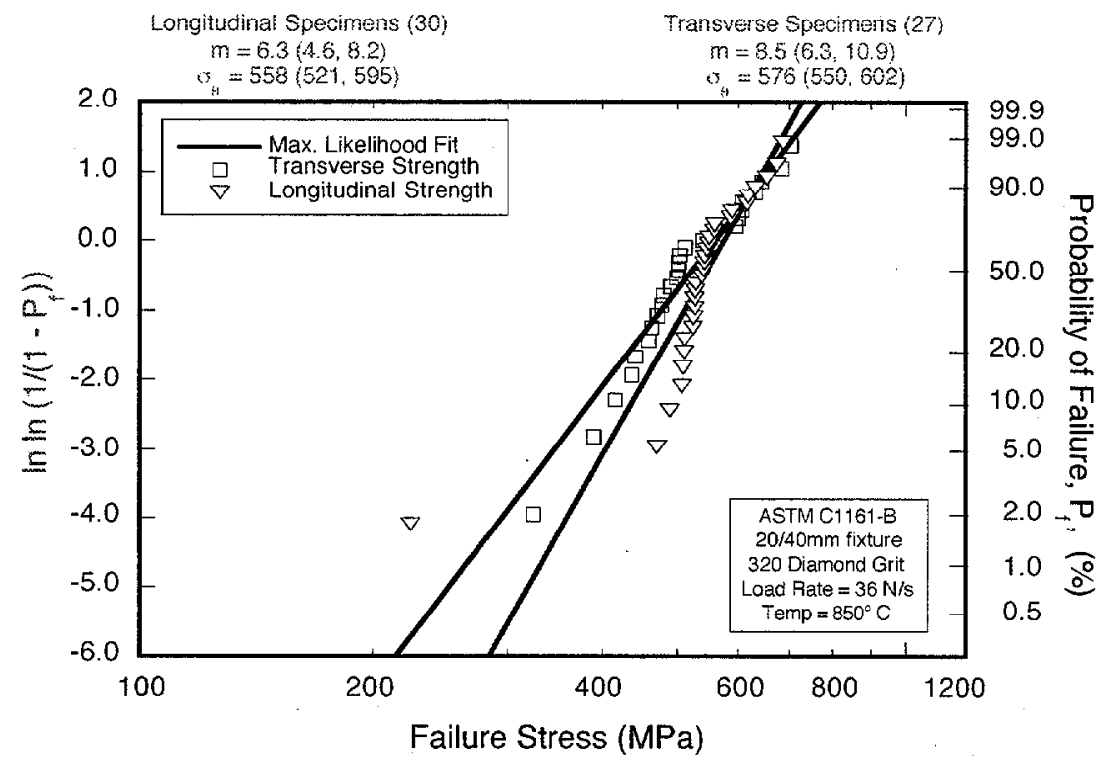

Figure 5.53. Strength as a function of machining orientation for ASTM C 1161-B flexure specimens tested at $850^{\circ} \mathrm{C}$ and $36 \mathrm{~N} / \mathrm{s}$ load rate. 


\subsubsection{Cylindrical Flexure Specimens}

The strength results from the cylindrical flexure specimen tests are presented in this section. The specimens were loaded to failure in four-point flexure at 14.67, 0.1467, and $0.001467 \mathrm{~N} / \mathrm{s}$ load rates. These loading rates were chosen in order to have the same stressing rates as those of the rectangular cross-section ASTM C 1161-B flexure bars, that were 30, 0.3, and $0.003 \mathrm{MPa} / \mathrm{s}$ (see Table 4.3).

The uncensored Weibull parameters are presented in Table 5.19 for the three loading rates at $20^{\circ} \mathrm{C}$ while Figure 5.54 presents the uncensored Weibull distributions. The Weibull moduli estimated for the threc load rates are equivalent at a 95 percent confidence level. The characteristic strengths estimated for the 14.67 and $0.1467 \mathrm{~N} / \mathrm{s}$ loading rates are equivalent and approximately $630 \mathrm{MPa}$. When the two faster load rates are compared to the $0.001467 \mathrm{~N} / \mathrm{s}$ load rate, the characteristic strength decreases to $516 \mathrm{MPa}$, which was a statistically significant difference.

Unique to this specimen geometry was the mode of failure identified, which is presented in Table 5.20. All specimens failed from surface-induced machining damage (SUR2-MD) regardless of the loading rates applied. In this situation, the censored Weibull moduli are the same as the uncensored estimates presented in Table 5.19.

The uncensored Weibull distributions for 14.67, 0.1467, and $0.001467 \mathrm{~N} / \mathrm{s}$ load rates are shown in Figures 5.55, 5.56, and 5.57, respectively. The censored Weibull parameters for the same three loading rates are presented in Tables 5.21, 5.22, and 5.23, respectively. The scale parameter, which in this case represents a unit area subjected to a uniform tension stress state, is slightly greater in value than the characteristic strengths presented in Table 5.19.

Table 5.19. Cylindrical transversely machined flexure bars tested at $20^{\circ} \mathrm{C}$. Values in parentheses are $95 \%$ confidence bounds.

\begin{tabular}{|c|c|l|c|}
\hline $\begin{array}{l}\text { Number of } \\
\text { Specimens }\end{array}$ & Test Rate (N/s) & Weibull Modulus & $\begin{array}{l}\text { Characteristic Strength } \\
(\mathrm{MPa})\end{array}$ \\
\hline 30 & 14.67 & $25.8(19.5,32.7)$ & $646(636,656)$ \\
\hline 30 & 0.1467 & $20.9(15.5,27.0)$ & $620(609,632)$ \\
\hline 30 & 0.001467 & $18.8(14.3,23.9)$ & $516(505,527)$ \\
\hline
\end{tabular}




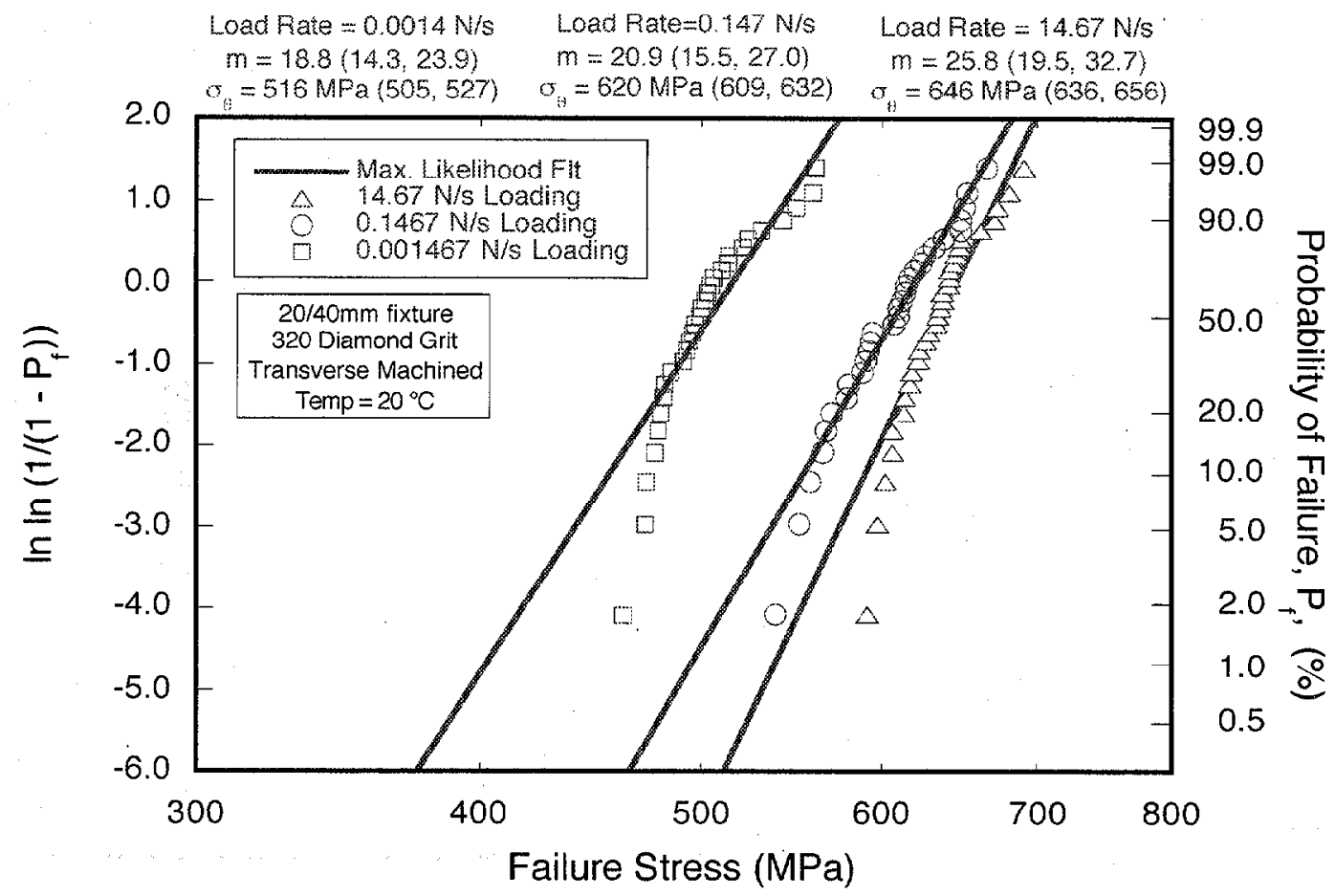

Figure 5.54. Strength dependence on load rate of cylindrical flexure specimens tested at $20^{\circ} \mathrm{C}$.

Table 5.20. Fractographic results for cylindrical four-point flexure specimen tested at $20^{\circ} \mathrm{C}$. Number of specimens for each flaw shown.

\begin{tabular}{|l|c|c|c|c|}
\hline Loading Rate (N/s) & VOL-SF & VOL-AGG & SUR2-MD & UNK \\
\hline 14.67 & 0 & 0 & 30 & 0 \\
\hline 0.1467 & 0 & 0 & 30 & 0 \\
\hline 0.001467 & 0 & 0 & 30 & 0 \\
\hline
\end{tabular}




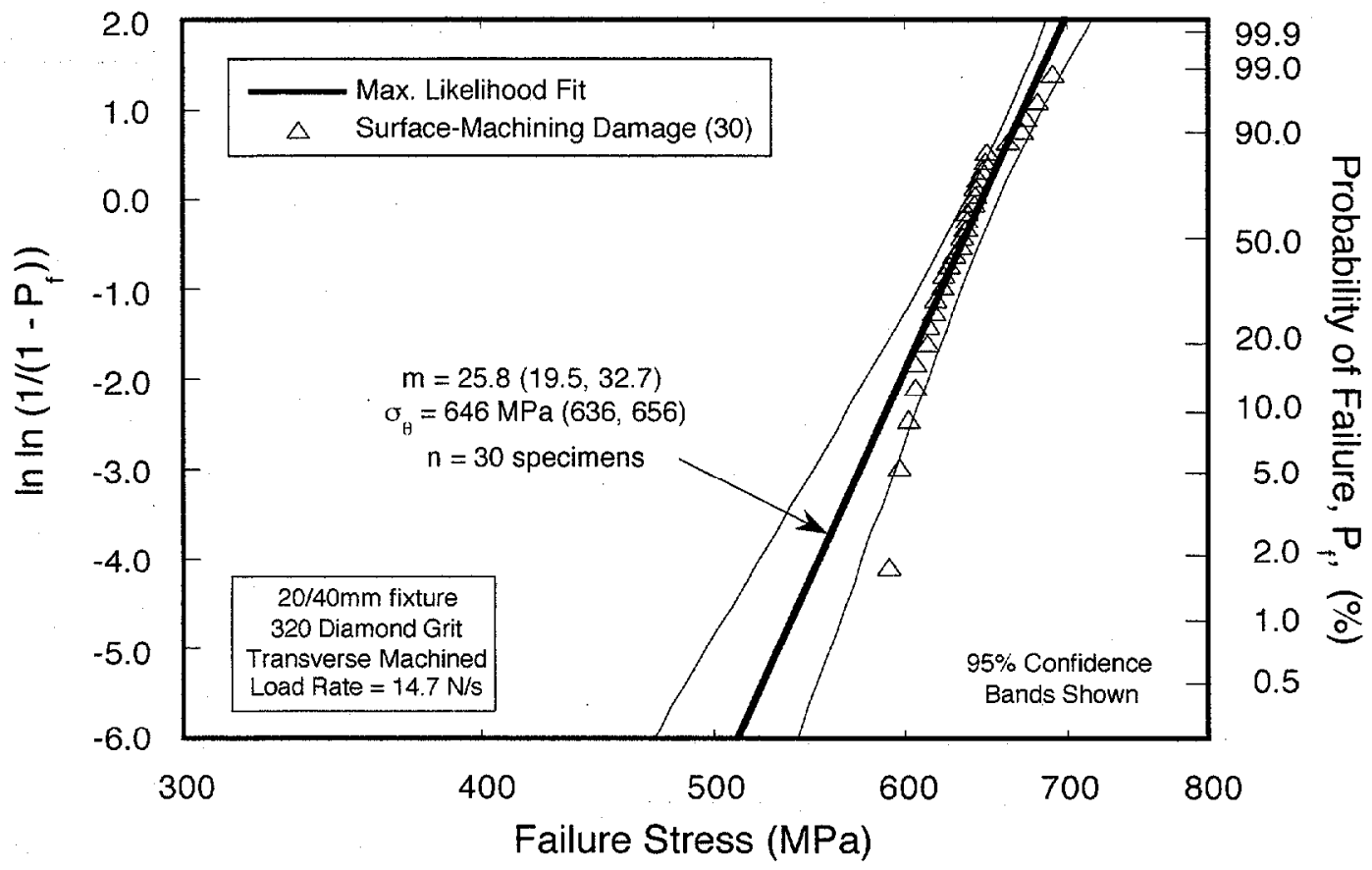

Figure 5.55. Uncensored Weibull distribution for cylindrical flexure specimens tested $20^{\circ} \mathrm{C}$ and $14.67 \mathrm{~N} / \mathrm{s}$ load rate.

Table 5.21. Cylindrical transversely machined flexure bars tested at $20^{\circ} \mathrm{C}$ and $14.67 \mathrm{~N} / \mathrm{s}$. Values in parentheses are $95 \%$ confidence bounds.

\begin{tabular}{|l|c|c|}
\hline $\begin{array}{l}\text { Failure Mode / Number of } \\
\text { Specimens }\end{array}$ & $\begin{array}{l}\text { Weibull Shape Parameter } \\
\text { (Modulus) }\end{array}$ & $\begin{array}{l}\text { Weibull Scale } \\
\text { Parameter }^{(a)}\end{array}$ \\
\hline SUR2-MD /30 & $25.8(19.5,32.7)$ & $684(670,709)$ \\
\hline
\end{tabular}

(a) The Weibull scale parameter has units of MPa $\mathrm{mm}^{2 / \mathrm{ml} \text {-unrace }}$ for surface failures. 


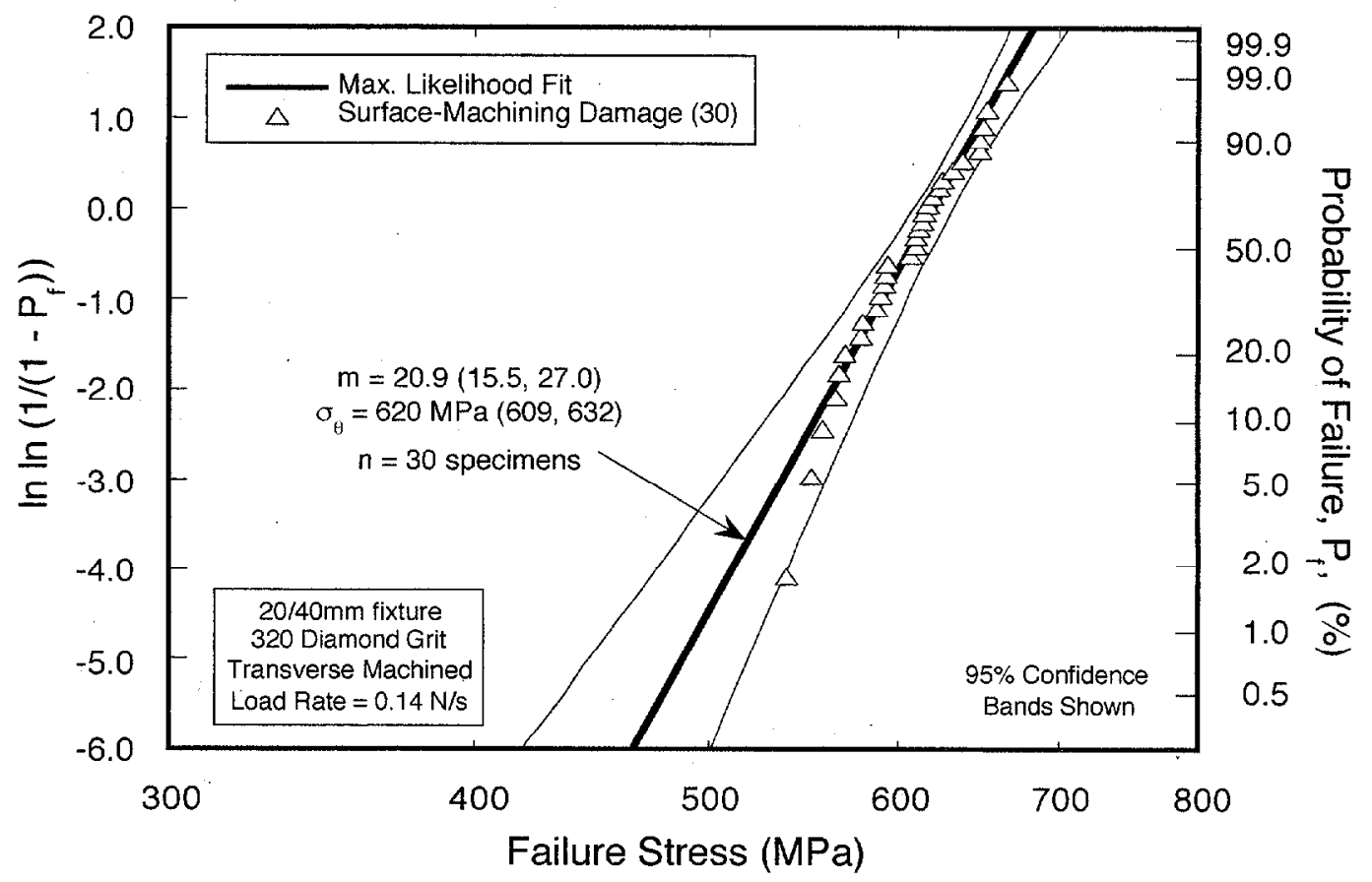

Figure 5.56. Uncensored Weibull distributions for cylindrical specimens tested at $20^{\circ} \mathrm{C}$ and $0.1467 \mathrm{~N} / \mathrm{s}$ load rate.

Table 5.22. Cylindrical transversely machined flexure bars tested at $20^{\circ} \mathrm{C}$ and $0.1467 \mathrm{~N} / \mathrm{s}$. Values in parentheses are $95 \%$ confidence bounds.

\begin{tabular}{|l|c|l|}
\hline $\begin{array}{l}\text { Failure Mode / Number of } \\
\text { Specimens }\end{array}$ & $\begin{array}{l}\text { Weibull Shape Parameter } \\
\text { (Modulus) }\end{array}$ & $\begin{array}{l}\text { Weibull Scale } \\
\text { Parameter }^{(a)}\end{array}$ \\
\hline SUR2-MD/30 & $21(15.5,27)$ & $674(655,707)$ \\
\hline
\end{tabular}

(a) The Weibull scale parameter has units of $\mathrm{MPa} \mathrm{mm}^{2 m-\text { sunace }}$ for surface failures. 


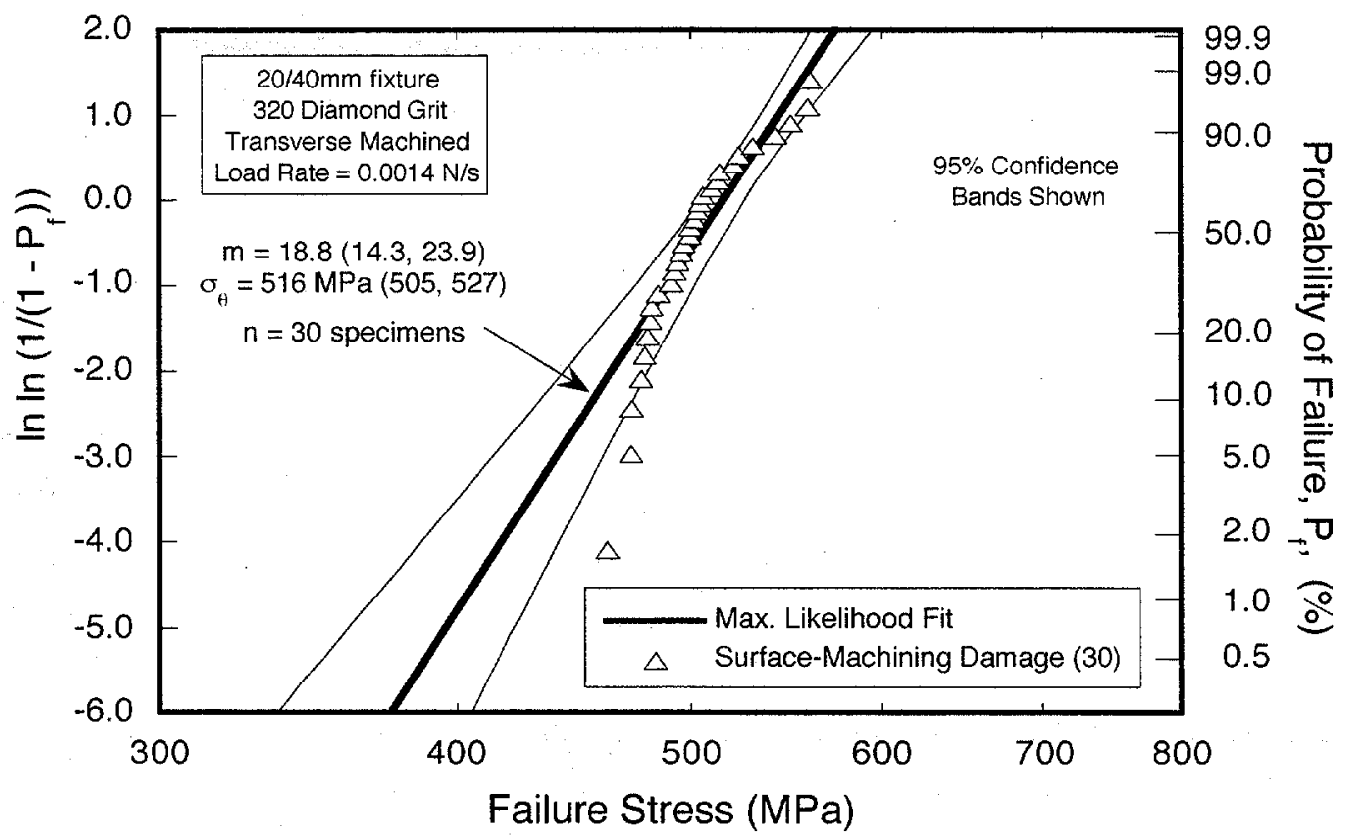

Figure 5.57. Uncensored Weibull distribution for cylindrical flexure specimens Tested at $20^{\circ} \mathrm{C}$ and $0.001467 \mathrm{~N} / \mathrm{s}$ load rate.

Table 5.23. Cylindrical transversely machined flexure bars tested at $20^{\circ} \mathrm{C}$ and $0.001467 \mathrm{~N} / \mathrm{s}$. Values in parentheses are $95 \%$ confidence bounds.

\begin{tabular}{|l|c|c|}
\hline $\begin{array}{l}\text { Failure Mode / Number of } \\
\text { Specimens }\end{array}$ & $\begin{array}{l}\text { Weibull Shape Parameter } \\
\text { (Modulus) }\end{array}$ & $\begin{array}{l}\text { Weibull Scale } \\
\text { Parameter }^{(a)}\end{array}$ \\
\hline SUR2-MD/30 & $18.8(14.3,23.9)$ & $569(552,599)$ \\
\hline
\end{tabular}

(a) The Weibull scale parameter has units of MPa $\mathrm{mm}^{2 / \mathrm{m} \text {-surace }}$ for surface failures. 


\subsubsection{Modified ORNL Tension Specimens}

\subsubsection{Uncensored Weibull Distributions}

The strength results from testing tension specimens at $20^{\circ} \mathrm{C}$ and at $288,2.88$, and $0.28 \mathrm{~N} / \mathrm{s}$ loading rates are presented. These loading rates were chosen in order to have the same stressing rates as those of the rectangular cross-section ASTM C 1161-B flexure bars and cylindrical flexure specimens; $30,0.3$, and $0.003 \mathrm{MPa} / \mathrm{s}$ (see Table 4.3).

The uncensored Weibull distributions for the three loading rates are illustrated in Figure 5.58 and presented in Table 5.24. No significant difference is seen in any of the uncensored Weibull parameters at the three loading rates except when comparing the characteristic strengths at the 288 $\mathrm{N} / \mathrm{s}$ load rate to the $0.028 \mathrm{~N} / \mathrm{s}$ load rate. In this instance, the characteristic strength shows a significant decrease in strength of approximately $20 \%$.

\subsubsection{Weibull Distributions with Censored Strength Data}

Table 5.25 lists the number of failure types for the modified ORNL tension specimens at the three loading rates. The dominant mode of failure for all load rates was SUR 1-MD. For the 288.6 $\mathrm{N} / \mathrm{s}$ load rate there were 11 SUR1-MD failures and 2 VOL-AGG failures identified. At the 2.886 and the $0.02886 \mathrm{~N} / \mathrm{s}$ load rates, there were 10 SUR1-MD failures and one each VOL-AGG and VOL-SF failures identified.

The uncensored Weibull distributions for the modified ORNL tension specimens tested at $20^{\circ} \mathrm{C}$ and at $288.6 \mathrm{~N} / \mathrm{s}, 2.8886 \mathrm{~N} / \mathrm{s}$ and $0.02886 \mathrm{~N} / \mathrm{s}$ with accompanying failure data are shown in Figures 5.59-5.61, respectively. The censored Weibull parameters for the modified ORNL tension specimens tested at $20^{\circ} \mathrm{C}$ and at $288.6 \mathrm{~N} / \mathrm{s}, 2.886 \mathrm{~N} / \mathrm{s}$ and $0.02886 \mathrm{~N} / \mathrm{s}$ are listed in Tables 5.265.28 , respectively. For the SUR1-MD failure mode, there was no significant difference found for the censored Weibull moduli at the three loading rates. The scale parameter for the SUR1-MD failure mode significantly decreased in value approximately $28 \%$ between the 288.6 between the 2.886 and $0.02886 \mathrm{~N} / \mathrm{s}$ load rates. No comparisons are made for the VOL-SF and VOL-AGG failure modes because of the small number of failures identified in each data set between the 2.88 and $0.028 \mathrm{~N} / \mathrm{s}$ load rates. No comparisons are made for the VOL-SF and VOL-AGG failure modes because of the small number of failures identified in each data set. 


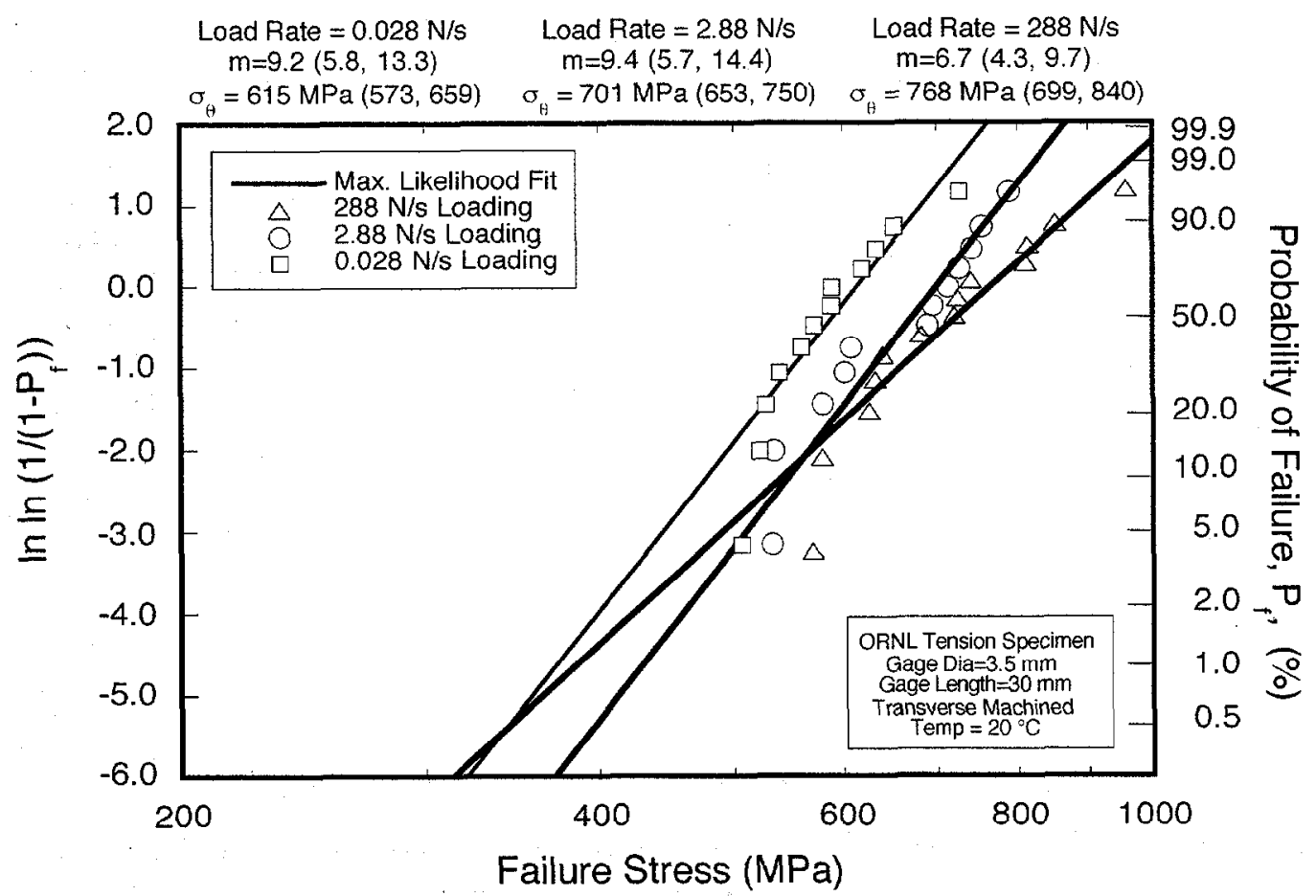

Figure 5.58. Strength dependence on load rate of modified ORNL tension specimens tested at $20^{\circ} \mathrm{C}$.

Table 5.24. Modified ORNL transversely machined tension specimens tested at $20^{\circ} \mathrm{C}$. Values in parentheses are $95 \%$ confidence bounds.

\begin{tabular}{|c|c|l|l|}
\hline $\begin{array}{l}\text { Number of } \\
\text { Specimens }\end{array}$ & Test Rate (N/s) & $\begin{array}{l}\text { Weibull } \\
\text { Modulus }\end{array}$ & $\begin{array}{l}\text { Characteristic Strength } \\
(\mathrm{MPa})\end{array}$ \\
\hline 13 & 288.6 & $6.7(4.3,9.7)$ & $768(699,840)$ \\
\hline 12 & 2.886 & $9.4(5.7,14.4)$ & $701(653,750)$ \\
\hline 12 & 0.02886 & $9.2(5.8,13.3)$ & $615(573,659)$ \\
\hline
\end{tabular}

Table 5.25. Fractographic results for the modified ORNL tension specimens tested at $20^{\circ} \mathrm{C}$. Number of specimens for each flaw type shown.

\begin{tabular}{|c|c|c|c|c|}
\hline Loading Rate (N/s) & VOL-SF & VOL-AGG & SUR1-MD & UNK \\
\hline 288.6 & 0 & 2 & 11 & 0 \\
\hline 2.886 & 1 & 1 & 10 & 0 \\
\hline 0.02886 & 1 & 1 & 10 & 0 \\
\hline
\end{tabular}




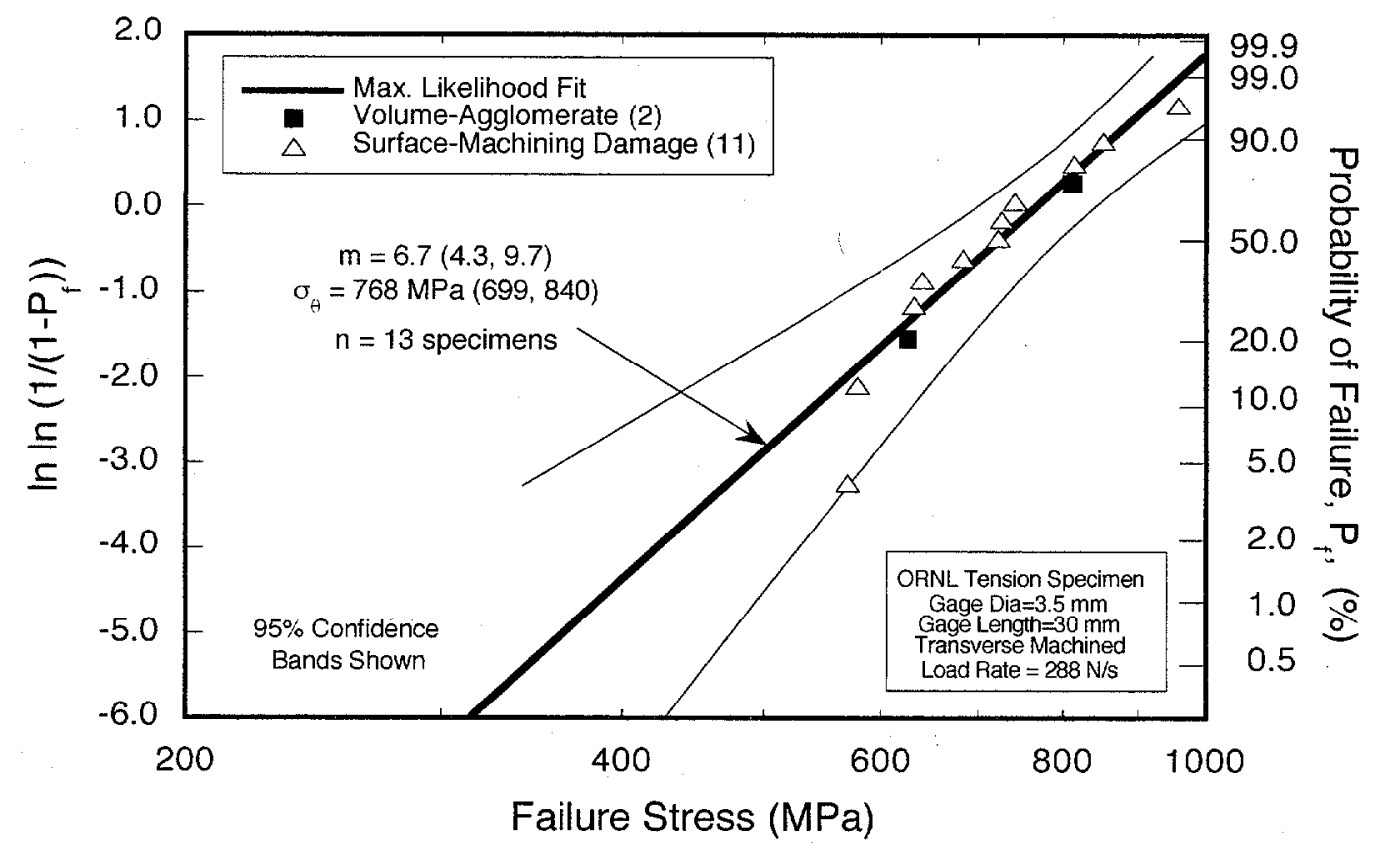

Figure 5.59. Uncensored Weibull distribution for modified ORNL tension specimens tested at $20^{\circ} \mathrm{C}$ and $288.6 \mathrm{~N} / \mathrm{s}$ load rate.

Table 5.26. Modified ORNL transversely machined tension specimens at $20^{\circ} \mathrm{C}$ and $288.6 \mathrm{~N} / \mathrm{s}$. Values in parentheses are $95 \%$ confidence bounds.

\begin{tabular}{|l|c|l|}
\hline $\begin{array}{l}\text { Failure Mode / Number of } \\
\text { Specimens }\end{array}$ & $\begin{array}{l}\text { Weibull Shape Parameter } \\
\text { (Modulus) }\end{array}$ & $\begin{array}{l}\text { Weibull Scale Parameter } \\
\text { (a) }\end{array}$ \\
\hline VOL-AGG /2 & $6.8(1.6,6.8)^{(0)}$ & $2353(1393,2353)^{(b)}$ \\
\hline SUR1-MD/11 & $6.7(4.1,9.9)$ & $1670(1320,1670)^{(0)}$ \\
\hline
\end{tabular}

(a) The Weibull scale parameter has units of MPa $\mathrm{mm}^{2 \text { 2m-surnace }}$ for surface failures and $\mathrm{MPa} \mathrm{mm}^{3 / \mathrm{m} \text {-volume }}$ for volume failures.

(b) Due to the small censored sample size, no value for the lower (upper) confidence limit was convergent. 


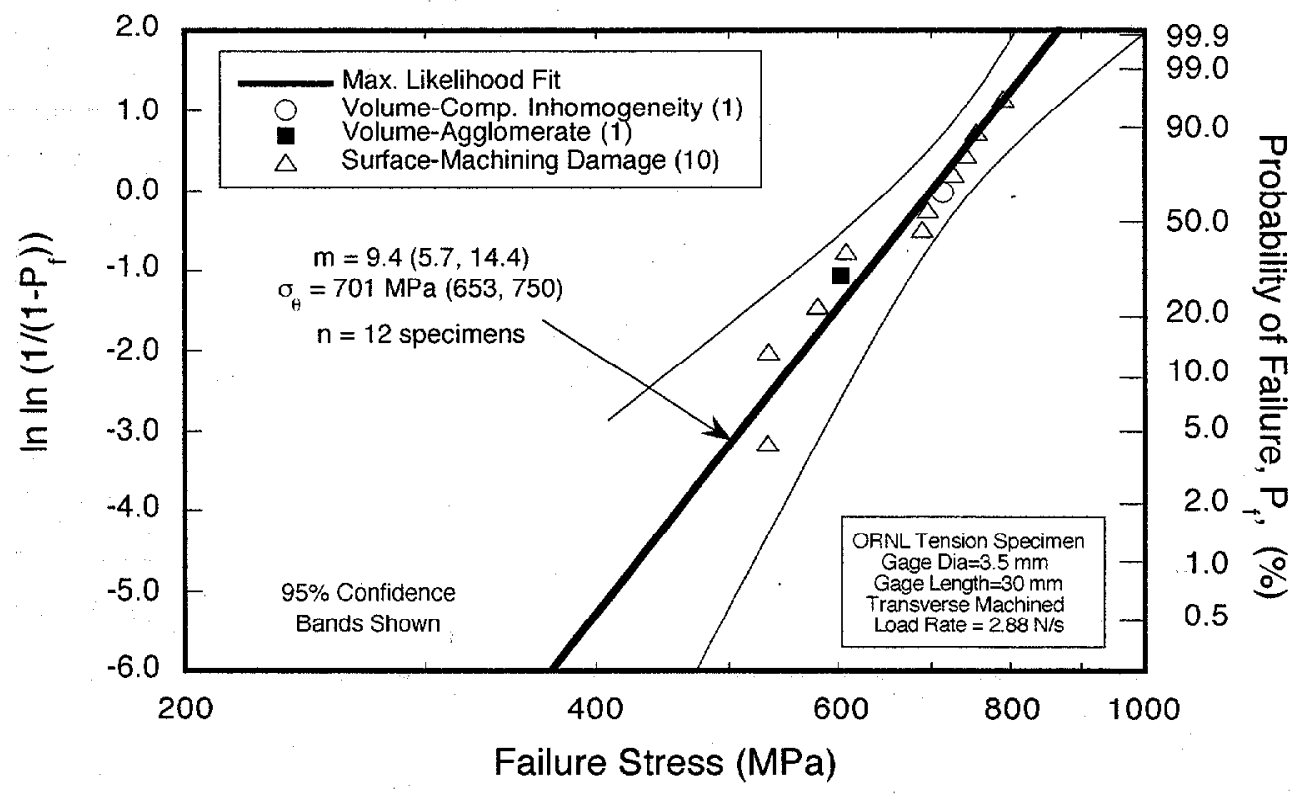

Figure 5.60. Uncensored Weibull distribution for modified ORNL tension specimens tested at $20^{\circ} \mathrm{C}$ and $2.886 \mathrm{~N} / \mathrm{s}$ load rate.

Table 5.27. Modified ORNL transversely machined tension specimens at $20^{\circ} \mathrm{C}$ and $2.886 \mathrm{~N} / \mathrm{s}$. Values in parentheses are $95 \%$ confidence bounds.

\begin{tabular}{|l|l|l|}
\hline $\begin{array}{l}\text { Failure Mode / Number of } \\
\text { Specimens }\end{array}$ & $\begin{array}{l}\text { Weibull Shape Parameter } \\
\text { (Modulus) }\end{array}$ & $\begin{array}{l}\text { Weibull Scale } \\
\text { Parameter }^{(\mathrm{a})}\end{array}$ \\
\hline VOL-SF/1 & $\mathbf{n} / \mathbf{a}^{(b)}$ & $\mathbf{n} / \mathbf{a}^{(b)}$ \\
\hline VOL-AGG / 1 & $\mathbf{n} / \mathbf{a}^{(b)}$ & $\mathbf{n} / \mathbf{a}^{(b)}$ \\
\hline SUR1-MD / 10 & $9.5(5.4,15.0)$ & $1211(992,1211)^{(c)}$ \\
\hline
\end{tabular}

(a) The Weibull scale parameter has units of $\mathrm{MPa} \mathrm{mm}$ 2/m-surace for surface failures and $\mathrm{MPa} \mathrm{mm}$ volume for volume failures.

(b) Estimating Weibull distribution parameters for a single sample size has no relevance.

(c) Due to the small censored sample size, no value for the lower (upper) confidence limit was convergent. 


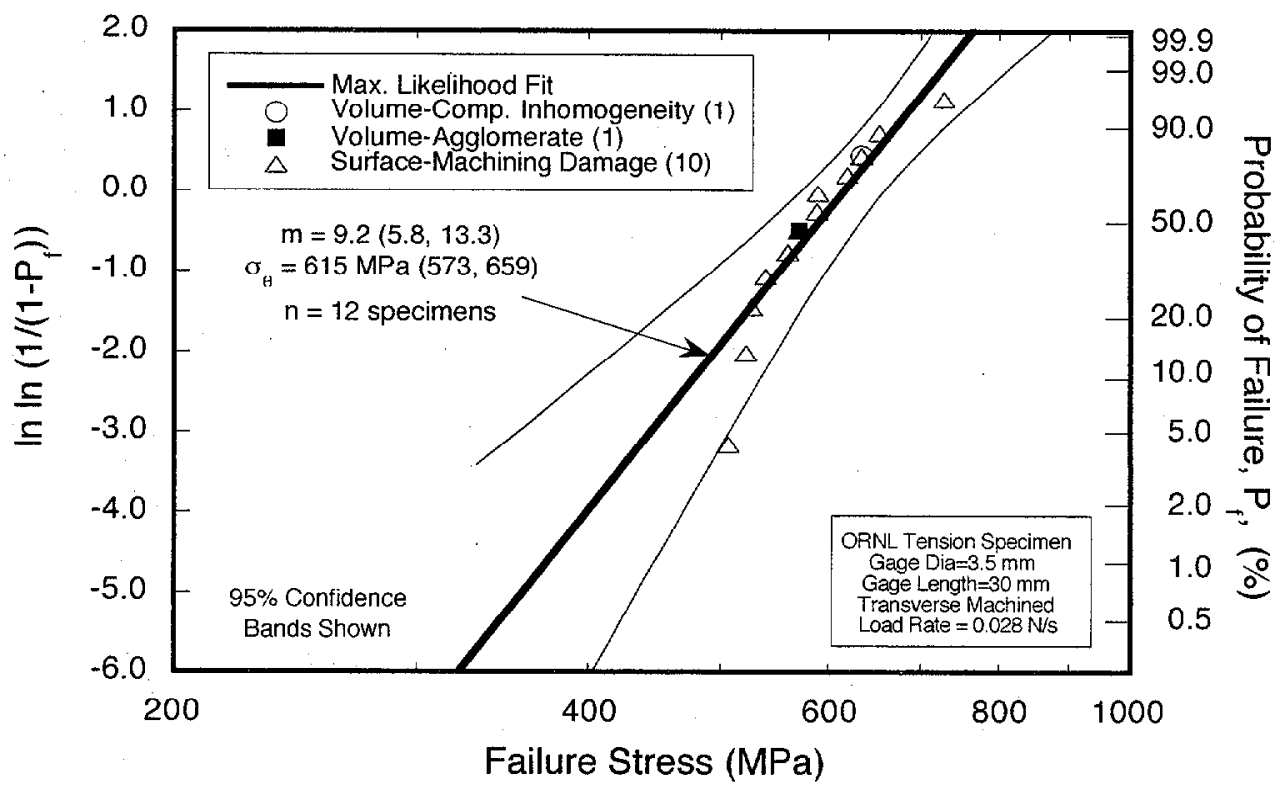

Figure 5.61. Uncensored Weibull distribution for modified ORNL tension specimens tested at $20^{\circ} \mathrm{C}$ and $0.02886 \mathrm{~N} / \mathrm{s}$ load rate.

Table 5.28. Modified ORNL transversely machined tension specimens at $20^{\circ} \mathrm{C}$ and $0.02886 \mathrm{~N} / \mathrm{s}$. Values in parentheses are $95 \%$ confidence bounds.

\begin{tabular}{|l|c|c|}
\hline $\begin{array}{l}\text { Failure Mode / Number of } \\
\text { Specimens }\end{array}$ & $\begin{array}{l}\text { Weibull Shape Parameter } \\
\text { (Modulus) }\end{array}$ & $\begin{array}{l}\text { Weibull Scale Parameter } \\
\text { (a) }\end{array}$ \\
\hline VOL-SF/1 & $\mathbf{n} / \mathbf{a}^{(0)}$ & $\mathrm{n} / \mathrm{a}^{(0)}$ \\
\hline VOL-AGG / 1 & $\mathrm{n} / \mathbf{a}^{(0)}$ & $\mathrm{n} / \mathrm{a}^{(0)}$ \\
\hline SUR1-MD $/ 10$ & $9.0(5.3,13.3)$ & $1098(911,1098)^{(0)}$ \\
\hline
\end{tabular}

(a) The Weibull scale parameter has units of MPa $\mathrm{mm}^{\text {2/m-surace }}$ for surface failures and $\mathrm{MPa} \mathrm{mm} \mathrm{mm}^{3 / \mathrm{m} \text {-volume }}$ for volume failures.

(b) Estimating Weibull distribution parameters for a single sample size has no relevance.

(c) Due to the small censored sample size, no value for the lower (upper) confidence limit was convergent. 


\subsubsection{Dynamic Fatigue Test Results}

NT551's susceptibility to the slow crack growth phenomena was examined by applying three stressing rates $(30,0.3$, and $0.003 \mathrm{MPa} / \mathrm{s})$ onto three different test specimen geometries. The susceptibility of a material to slow crack growth is measured by the value of the exponent $N$, estimated for the power-law equation representing steady crack growth. The greater the value of the exponent $N$, the less susceptible a material is to the slow crack growth phenomena. Presented in Figure 5.62 is a summary of the different slow crack growth parameter $N$ values determined for each test geometry and at the three test temperatures of 20,700 , and $850^{\circ} \mathrm{C}$. The $95 \%$ confidence boundaries for each $N$ value are indicated by a boxed region at the end of each bar.

Figure 5.62 shows that at the test temperatures of 20 and $700^{\circ} \mathrm{C}$, the slow crack growth parameter $N$ is approximately 35 for all specimen geometries tested. The wide confidence limits on the $700^{\circ} \mathrm{C}$ tests illustrate the influence that the number of test specimens has on the slow crack growth parameter $N$ value. At $850^{\circ} \mathrm{C}$, the slow crack growth parameter $N$ is estimated at 19 , which is a significant reduction within a $95 \%$ confidence boundary when compared to the $N$ values estimated for 20 and $700^{\circ} \mathrm{C}$.

Figure 5.63 compares the regression analysis used to estimate the slow crack growth parameter $N$ from the ASTM C1161-B flexure specimen at 20,700 , and $850^{\circ} \mathrm{C}$. As mentioned earlier, the $N$ value estimated for the 20 and $700^{\circ} \mathrm{C}$ tests are equivalent and approximately equal to 35 , and the $N$ values for the $850^{\circ} \mathrm{C}$ tests was significantly lower at a value of 19 . The $N$ values estimated from the ASTM C 1161-B specimens would indicate that NT551 is susceptible to slow crack growth, with a further increase in slow crack growth susceptibility at the temperature of $850^{\circ} \mathrm{C}$.

Presented in Figures 5.64 and 5.65 are the dynamic fatigue plots for the modified ORNL tension and the cylindrical flexure specimens, respectively. The cylindrical specimen estimate has a slightly higher $N$ value than the modified ORNL tension test results and the ASTM C 1161-B flexure tests conducted at $20^{\circ} \mathrm{C}$. Since the $N$ value is more qualitative than quantitative, the slow crack growth parameter estimates made from the three test specimens, that were tested at the three temperatures, are essentially equivalent with regard to quantifying the slow crack growth phenomena. 


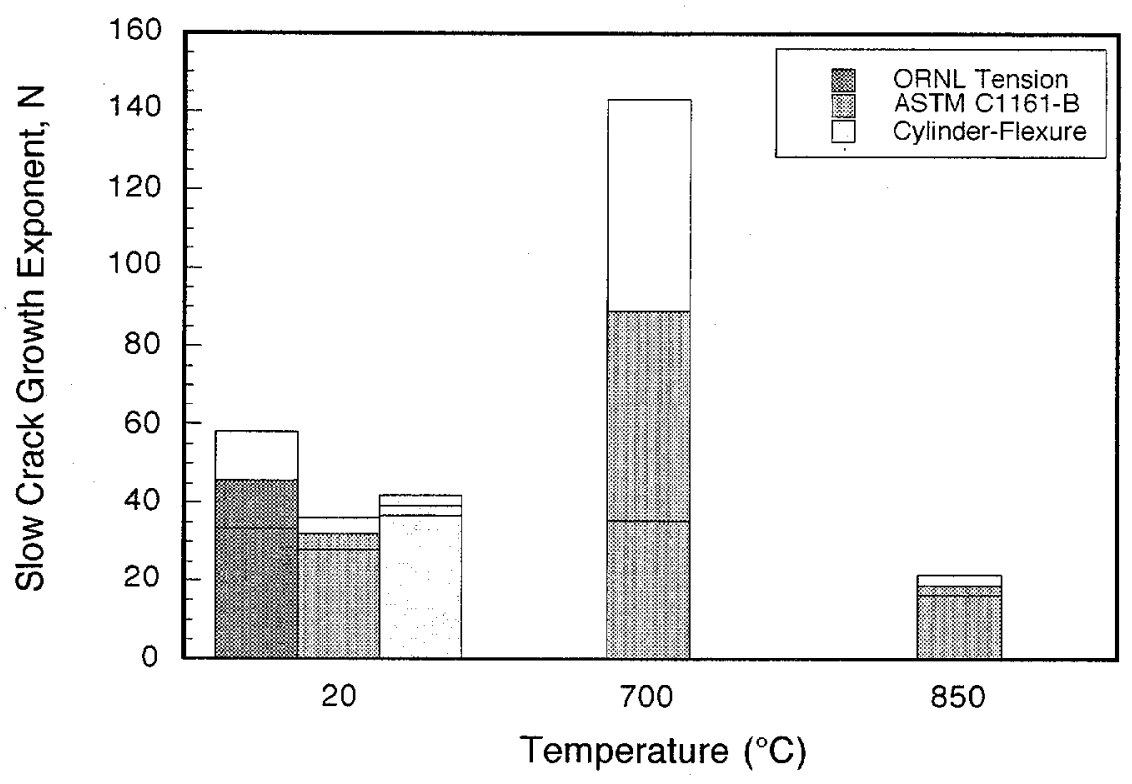

Figure 5.62. Summary of the slow crack growth parameter $N$ with $95 \%$ confidence bounds for three different test specimens and at three test temperatures.

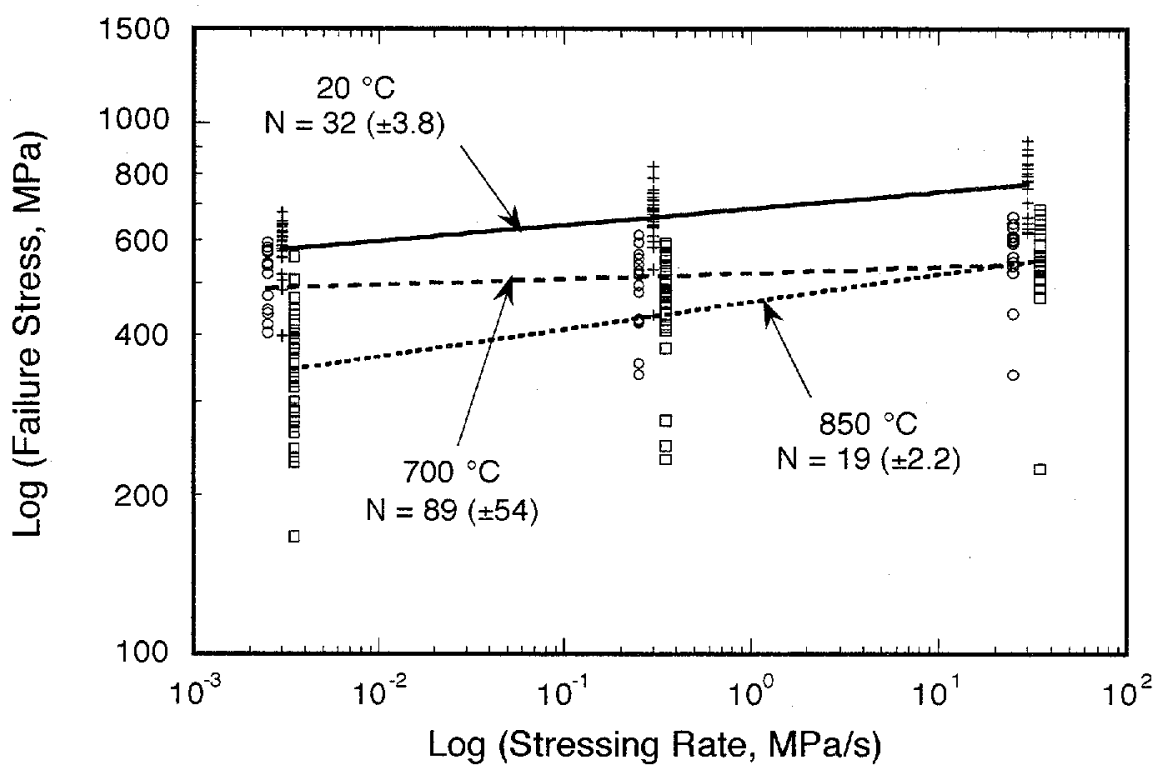

Figure 5.63. Slow crack growth regression analysis of ASTM C 1161-B flexure specimens tested at 20,700 and $850^{\circ} \mathrm{C}$. Values in parentheses are $95 \%$ confidence bounds. 


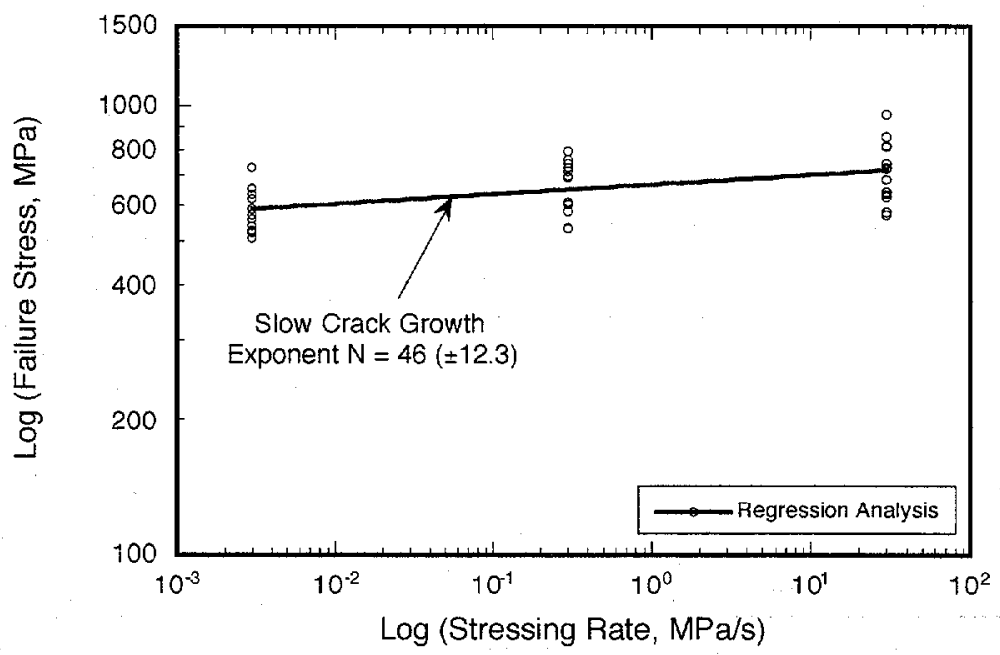

Figure 5.64. Slow crack growth regression analysis for the modified ORNL tension specimens tested at $20^{\circ} \mathrm{C}$. Values in parentheses are $95 \%$ confidence bounds.

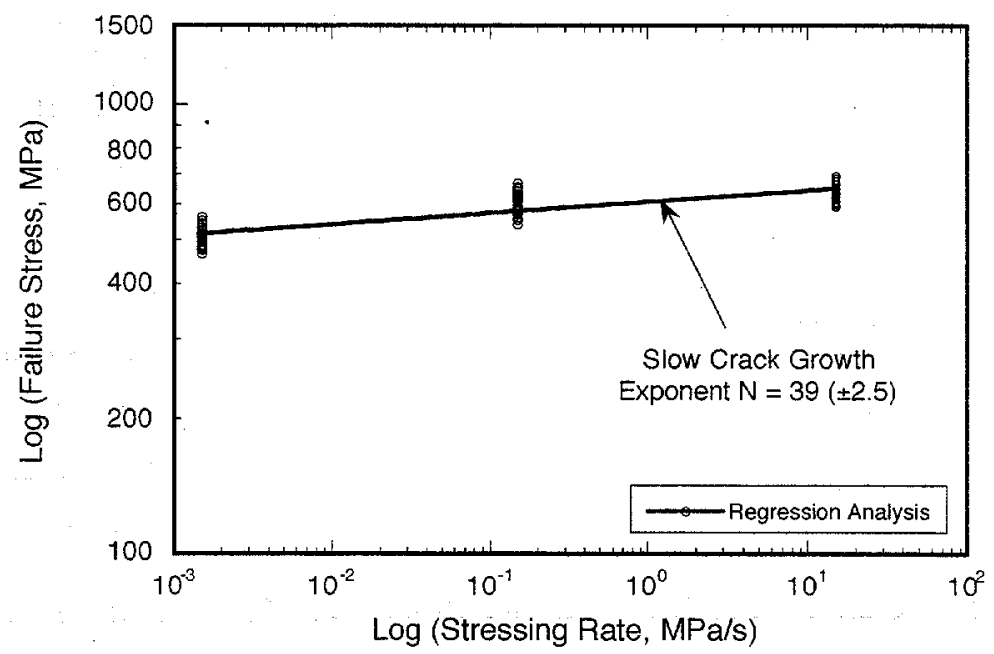

Figure 5.65. Slow crack growth regression analysis for cylindrical flexure specimens tested at $20^{\circ} \mathrm{C}$. Values in parentheses are $95 \%$ confidence bounds. 


\subsection{Supporting Tests and Analyses}

\subsubsection{Finite Element Modeling of Diesel Exhaust Valve}

Finite element analysis was performed using ANSYS ${ }^{\mathrm{TM}} 5.4$ software to determine the stress field of the valve at the combustion pressure of $16 \mathrm{MPa}$. The results from the analysis are shown in Figure 5.66. The model shows a maximum tensile stress of $160 \mathrm{MPa}$ located in the valve fillet radius and a maximum compressive stress of $83 \mathrm{MPa}$ along the valve seat. The location of the failure origins on all tested valves coincides with that of the high tensile stress area from the finite element model. This supports the assumption that the two-dimensional axisymmetric finite element model and associated boundary conditions represented the mechanical behavior ceramic valves tested.

The finite element model is an approximation to the mechanical behavior of the ceramic valves during inert strength tests. Sources of error associated with the finite element approximation include the following. It was assumed that the ceramic material was linear elastic, isotropic, and homogeneous. From Section 4.1 of this dissertation, it was illustrated in Figure 4.5 that NT551 was not a homogeneous material. These inhomogeneities, such as the reaction layer, snowflakes, and agglomerates, appeared nonuniformly distributed and were often times identified as the strength-limiting flaw. It is plausible to include that because of these inhomogeneities, the properties of NT551 were not isotropic as assumed.

The contact region between the ceramic valve seat and the metal valve seat insert was modeled using Coulomb friction. The assumed coefficient of friction for the contact elements was 0.30 ; however values from 0.1 to 0.5 for the friction coefficient were assigned to the model with no significant change in the stress field (Wereszczak et al., 1996). It is possible that the valves tested had some frictional effects than were not modeled with the finite element method. If so, the finite element model would estimate a greater strength than the actual valve failure data.

In order to assess the discretization error, two finite element models were made in which one model had approximately 2.5 times the number of elements than the other model. A means to assess this error in finite element modeling is to estimate the structural percentage error in energy norm, a feature explained in the Procedures volume of the ANSYS User's Manual (1994). It is a measure of the discontinuity of the stress field from element to element by calculating an energy error for each element. The structural percentage error in energy norm for the coarse meshed model was $12 \%$ and for the finer meshed model $7 \%$. The finer meshed model was used for the subsequent life prediction analysis. 


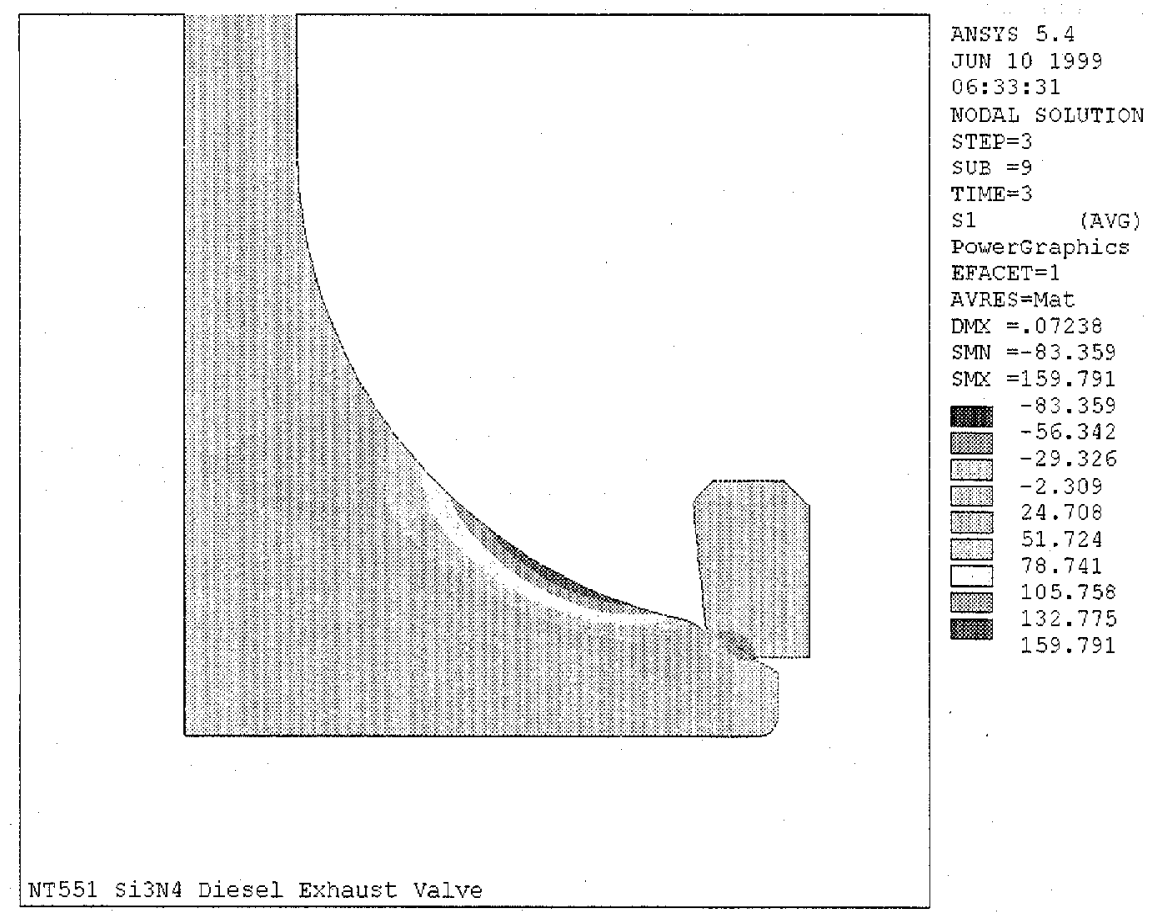

Figure 5.66. Finite element model of S149 valve using two-dimensional axisymmetric elements. A combustion pressure of $16 \mathrm{MPa}$ is applied to the model. Values in legend are MPa.

\subsubsection{Finite Element Analysis of a Cylinder in Four-Point Flexure}

A three-dimensional linear elastic model of a cylinder in four-point flexure was made using ANSYS 5.4 ${ }^{\mathrm{TM}}$ finite element software. The results from the two step loading scenario described in Section 4.4.1 are shown in Figure 5.67. The model shows a maximum tensile stress of $82.7 \mathrm{MPa}$ and a maximum compressive stress of $71.5 \mathrm{MPa}$. The location of the maximum tensile stress between the inner load pins was on the outer tensile surface. The maximum compressive stress was located at the point of contact between the top load pin and the cylinder. Stresses adjacent to the maximum compressive stress were tensile and ranged between 25 and $41 \mathrm{MPa}$. The bottom load pin had a similar stress field in the contact region. The maximum compressive stress was $59 \mathrm{MPa}$ and it was surrounded by tensile stresses ranging from 26 to $44 \mathrm{MPa}$.

Equation 4.2 presented in Section 4.2.1 calculated the maximum tensile stress of a cylinder in four-point flexure. The maximum tensile stress using Eq. 4.2 was $81.48 \mathrm{MPa}$ with a load of $200 \mathrm{~N}$, which is $1.5 \%$ less than the maximum tensile stress obtained by the finite element model. 
Sources of error in the finite element model are essentially the same as presented in Section 5.4.1 for the ceramic valve. To examine the discretization error, a second three-dimensional finite element model of the cylinder in four-point flexure was developed that increased the number of elements by nearly a factor of 12. A $50 \mathrm{~N}$ load was applied in the second step of the two stage solution. The largest tensile stress in the model was $272 \mathrm{MPa}$ while the largest compressive stress was $452 \mathrm{MPa}$. The location of the maximum tensile and compressive stresses were at the point of contact between the cylinder and the loading pins. On the top of the cylinder, the stresses adjacent to the maximum compressive stress were tensile and ranged between 229 and $265 \mathrm{MPa}$. On the bottom of the cylinder, the stresses surrounding the maximum compressive stress were tensile and ranged between 229 and $272 \mathrm{MPa}$. The maximum tensile stress located on the outer surfaces in the gage region was $40.4 \mathrm{MPa}$. Using Eq. 4.2 , the maximum tensile stress in the same region was calculated at $40.7 \mathrm{MPa}$, a difference of less than one percent from the stress obtained from finite element methods.

All of the cylindrical flexure specimens failed between the inner load spans, and there were no failures at the contact points of the cylinder and the loading pins. These high tensile stresses in the contact regions are unrealistic and believed to be an artifact of the finite element method. This refined mesh model was not used in subsequent analysis due to these stress singularities at the contact regions.

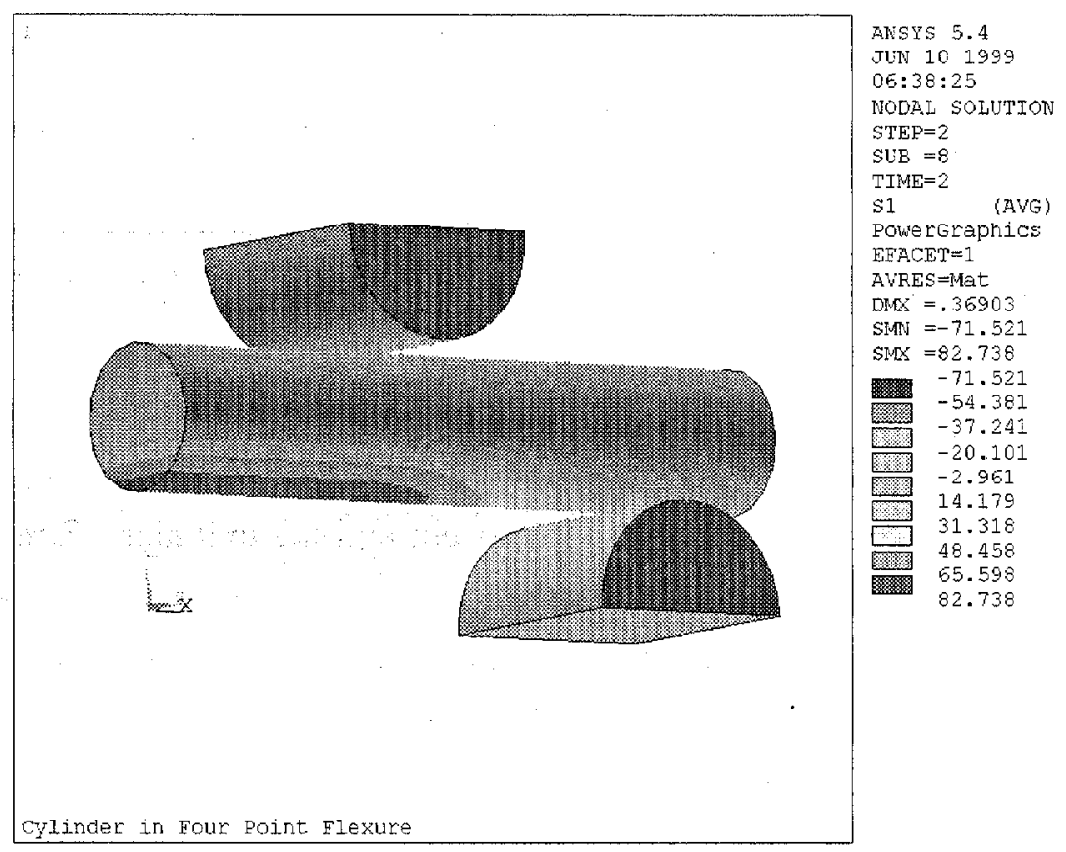

Figure 5.67. Finite element model of a cylinder in four-point flexure. Stress units are MPa. 


\subsubsection{Fracture Toughness and Other Material Properties}

Tests were conducted to determine the fracture toughness of NT551 as a function of temperature. A total of 16 specimens were tested; 5 specimens each for the temperatures of 20 and $850^{\circ} \mathrm{C}$ and 6 specimens at the temperature of $700^{\circ} \mathrm{C}$. The results of the fracture toughness tests are presented in Table 5.29.

Load-displacement diagrams were examined for each chevron $\mathrm{v}$ notch specimen tested to determine if stable crack growth had occurred after crack initiation. There were 4 specimens that exhibited unstable crack growth and these were not included in calculating the average $K_{I C}$ value.

The fracture toughness shows a slight decreasing trend as the temperature is increased. At the temperature of $20^{\circ} \mathrm{C}$, the fracture toughness was $6.3 \mathrm{MPa} V \mathrm{~m}$ while at the temperature of $700^{\circ} \mathrm{C}$ the fracture toughness decreased to $6.0 \mathrm{MPa} / \mathrm{m}$ and at the temperature of $850^{\circ} \mathrm{C}$ the fracture toughness was 5.7 MPa $\sqrt{\mathrm{m}}$. However, the standard deviations of the fracture toughness values (Table 5.29) show that between 20 and $700^{\circ} \mathrm{C}$ and between 700 and $850^{\circ} \mathrm{C}$, the fracture toughness is essentially equivalent and independent of temperature. Between 20 and $850^{\circ} \mathrm{C}$, there is a significant difference in the fracture toughness, but it is minimal $\left(6.147\right.$ at $20^{\circ} \mathrm{C}$ versus 5.945 at $\left.850^{\circ} \mathrm{C}\right)$. This difference in the fracture toughness values is questionable since they are based on 3 data points from the $20^{\circ} \mathrm{C}$ tests and 4 data points from the $850^{\circ} \mathrm{C}$ tests.

Figure 5.68 shows the fracture surface of a chevron v notch specimen. In the lower portion of the specimen near the start of the $\mathrm{v}$ notch there is the reaction layer region that goes across the entire width. Within the reaction layer are snowflakes and black agglomerates. This is more clearly seen in Figure 5.69, which is a detail of the notch region.

Presented in Table 5.30 are select NT551 material properties determined from this study, and these are compared to the NT551 material property data provided by SGNIC. The density measurements made in this study are approximately one percent less than the reported density from SGNIC. The flexure strengths listed in Table 5.30 are taken from ASTM C 1161-B longitudinally machined specimens. They are the uncensored characteristic strength of the flexure bar, and should not be confused with the Weibull scale parameter. All tests were conducted using the ASTM C 1161 standard (1998). Uncensored data was used to estimate the presented Weibull moduli. The characteristic strength found in this study at $20^{\circ} \mathrm{C}$ was approximately $7 \%$ greater than reported by SGNIC tested at $22^{\circ} \mathrm{C}$. The uncensored Weibull moduli reported by SGNIC at $22^{\circ} \mathrm{C}$ was between 40 and $60 \%$ greater than what this study determined, and as much as $69 \%$ greater at $850^{\circ} \mathrm{C}$ than the values found in this study. 
There was agreement with the Weibull modulus value when comparing vintage one data to SGNIC, but only at $20^{\circ} \mathrm{C}$. At $850^{\circ} \mathrm{C}$, the vintage one Weibull modulus was approximately $56 \%$ less than that reported by SGNIC.

The characteristic strength at $850^{\circ} \mathrm{C}$ listed by SGNIC was $40 \%$ greater than what was determined in this study. SGNIC used a steel four-point flexure fixture for the $22^{\circ} \mathrm{C}$ tests, and an $\alpha-\mathrm{SiC}$ fixture for the $850^{\circ} \mathrm{C}$ tests (Pujari, 1999). In this dissertation, all tests were conducted using the $\alpha-\operatorname{SiC}$ fixtures. However, it is doubtful that the difference in test fixtures would have such a strong influence on the characteristic strength values.

The fracture toughness as reported by SGNIC was $7.0 \mathrm{MPa} / \mathrm{m}$ while the fracture toughness was approximately 6.0 $\mathrm{MPa} \sqrt{\mathrm{m}}$ in this study. Possible reasons for the difference could be that different test methods were used to determine the fracture toughness. SGNIC used an indentation strength method while in this study the chevron $v$ notch method was used. It is not uncommon for ceramic materials to give different fracture toughness values based on test method (ASTM Provisional Method PS 70, 1998). This study found that NT551 had a slightly greater flexure strength and a smaller fracture toughness value at $20^{\circ} \mathrm{C}$, and significantly less characteristic strength at $850^{\circ} \mathrm{C}$ then reported by SGNIC. The uncensored Weibull moduli found in this study were significantly lower at both temperatures than the findings presented by SGNIC.

Table 5.29. ASTM C PS 70 (1998) chevron $v$ notch fracture toughness results at 20, 700 , and $850^{\circ} \mathrm{C}$. Tests conducted in air using a cross-head displacement of $5 \mu \mathrm{m} / \mathrm{minute}$.

\begin{tabular}{|c|c|c|}
\hline $20^{\circ} \mathrm{C} K_{l C}\left(\mathrm{MPa}^{\circ} \mathrm{m}^{1 / 2}\right)$ & $700^{\circ} \mathrm{C} K_{I C}\left(\mathrm{MPa}^{\prime} \mathrm{m}^{1 / 2}\right)$ & $850^{\circ} \mathrm{C} K_{I C}\left(\mathrm{MPa}^{\bullet} \mathrm{m}^{1 / 2}\right)$ \\
\hline 6.2 & 5.1 & 5.5 \\
\hline $8.0^{(\mathrm{a})}$ & $7.2^{\text {(a) }}$ & 6.0 \\
\hline $8.3^{(a)}$ & 6.2 & 5.8 \\
\hline 6.5 & 6.1 & 5.5 \\
\hline 6.3 & 6.1 & $7.3^{(a)}$ \\
\hline & 6.4 & \\
\hline Average $=6.3$ & Average $=6.0$ & Average $=5.7$ \\
\hline Standard Dev $=0.15$ & Standard Dev $=0.51$ & Standard Dev $=0.25$ \\
\hline
\end{tabular}

(a) Load-displacement data for these tests showed unsteady crack propagation and thus these are not valid by ASTM C PS 70 (1998) provisional test method. They are not included in the calculated average $K_{I C}$. 


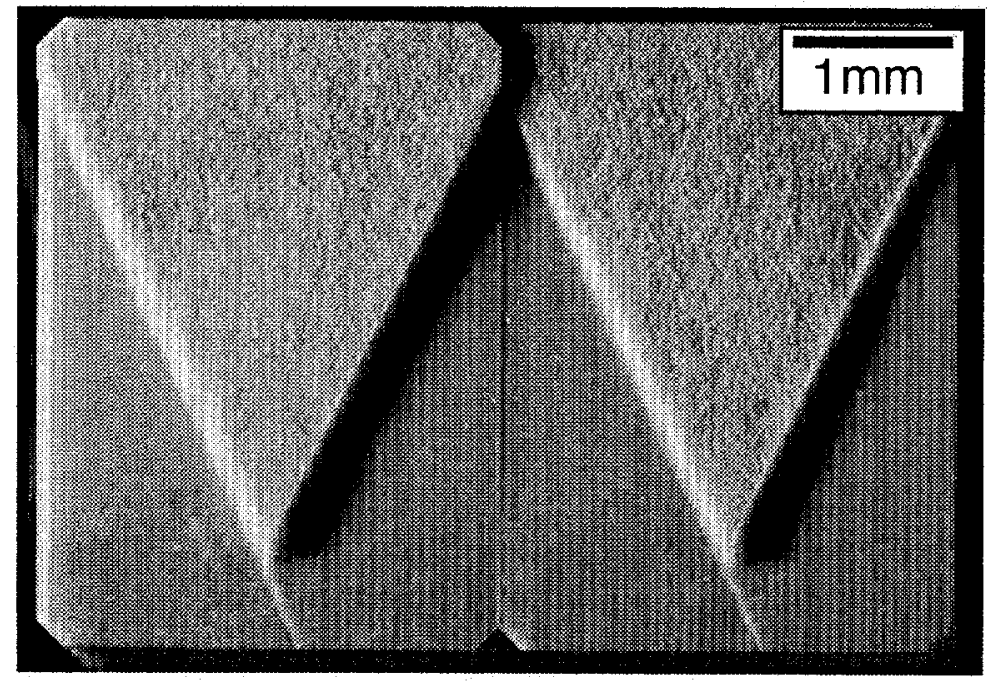

Figure 5.68. Chevron v-notch fracture surfaces.

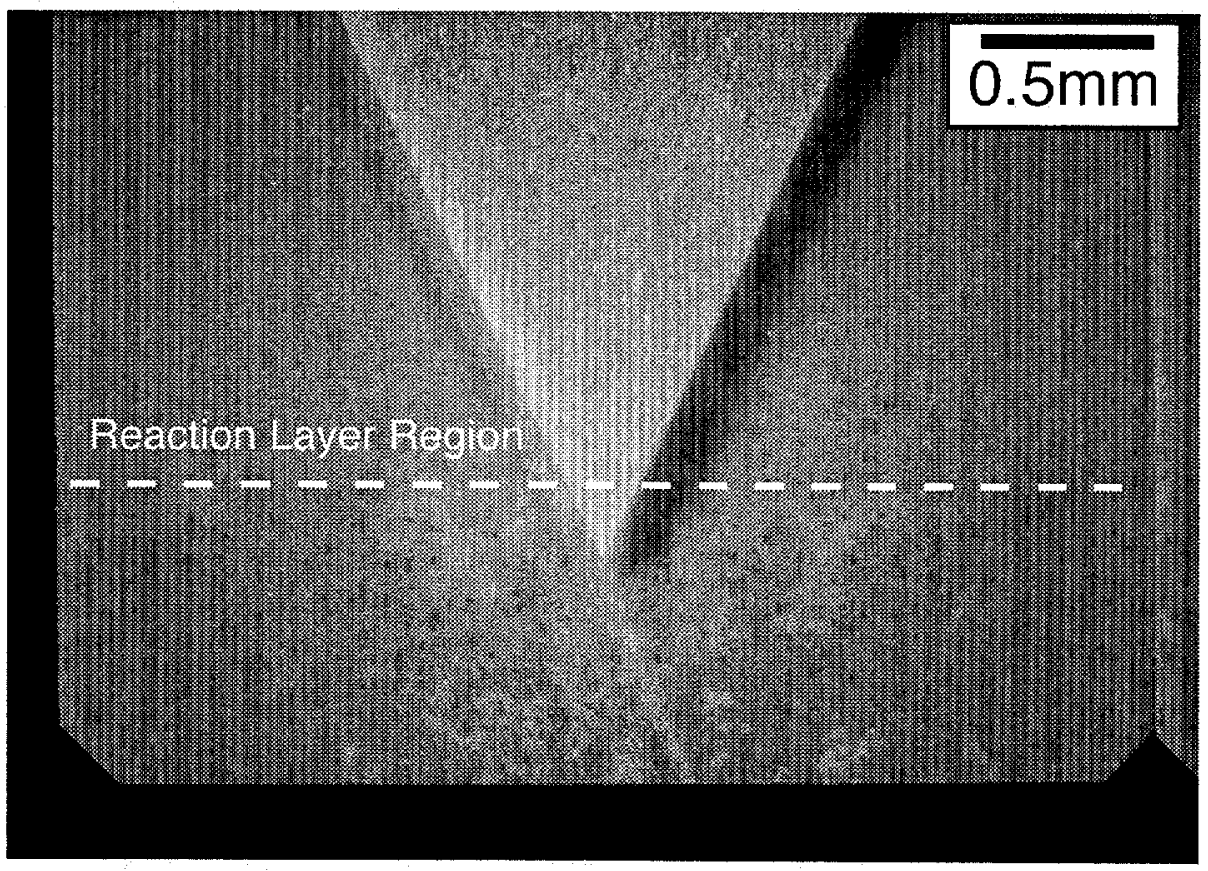

Figure 5.69. Chevron v-notch tip showing the presence of NT551 material inhomogeneities. 
Table 5.30. NT551 material properties determined in this study and material properties provided by SGNIC ${ }^{(a)}$.

(a) Pujari, 1998

\begin{tabular}{|l|c|c|}
\hline Mechanical Property & SGNIC Value & This Study \\
\hline Density $\left(\mathrm{g} / \mathrm{mm}^{3}\right)$ & $3.285-3.290$ & 3.25 \\
\hline Flexure Strength at $22^{\circ} \mathrm{C}(\mathrm{MPa})$ & 966 & 1038 \\
\hline Weibull Modulus at $22^{\circ} \mathrm{C}$ & $20-30$ & 11.9 \\
\hline Flexure Strength at $850^{\circ} \mathrm{C}(\mathrm{MPa})$ & 932 & 558 \\
\hline Weibull Modulus at $850^{\circ} \mathrm{C}$ & $>20$ & 6.3 \\
\hline Fracture Toughness $(\mathrm{MPa} \sqrt{\mathrm{m}})$ & 7.0 & 6.0 \\
\hline
\end{tabular}

\subsubsection{Surface Profilometry}

Presented in this section are the surface finish measurements over a $4 \mathrm{~mm}$ length of a cylindrical flexure bar, a modified ORNL tension specimen, and an ASTM C 1161-B transversely machined flexure specimen. In addition, the surface finish of a transversely and a longitudinally machined valve, in the fillet radius region, were measured over a $4 \mathrm{~mm}$ length. The results of these surface measurements are presented in Figure 5.70.

The average surface roughness for the modified ORNL tension specimen was $0.12 \mu \mathrm{m}$, while the ASTM C 1161-B flexure bar was $0.22 \mu \mathrm{m}$, and the cylindrical flexure bar was $0.46 \mu \mathrm{m}$. A 320 grit grinding wheel was used to machine the three specimens but using three different machining processes.

The transversely machined valve surface in the fillet radius region was three times rougher than the longitudinally machined valve in the same region. The average surface roughness for the transversely machined valve was $0.78 \mu \mathrm{m}$ while for the longitudinally machined valve the average surface roughness was $0.26 \mu \mathrm{m}$. The surface finish for the transversely machined valve was nearly twice the specified average roughness value of $40 \mu \mathrm{m}$, while the surface finish for the longitudinally machined valve was nearly 1.5 times as smooth than the specified average roughness value.

Figures 5.71-5.74 show the surface finishes of a modified ORNL tension specimen, an ASTM C 1161-B transversely machined flexure specimen, a cylindrical flexure specimen, and a section of the fillet radius region of a transversely machined valve, respectively. The SEM photomicrographs of the four surfaces agree with the profilometry measurements presented in Figure 5.70. Notice 
that the machining pattern from the cylindrical flexure specimen is similar to that of the transversely machined valve. This similarity may be due in part to the axis of symmetry by which each was machined.

While the test specimens were machined using a 320 diamond grit wheel, the diamond grit wheel used to finish the surface of the valves is not known. Assuming that each was machined using the same diamond grit wheel, the difference in surface roughness may be attributed to geometry; the machining of a curved surface as compared to a flat surface.

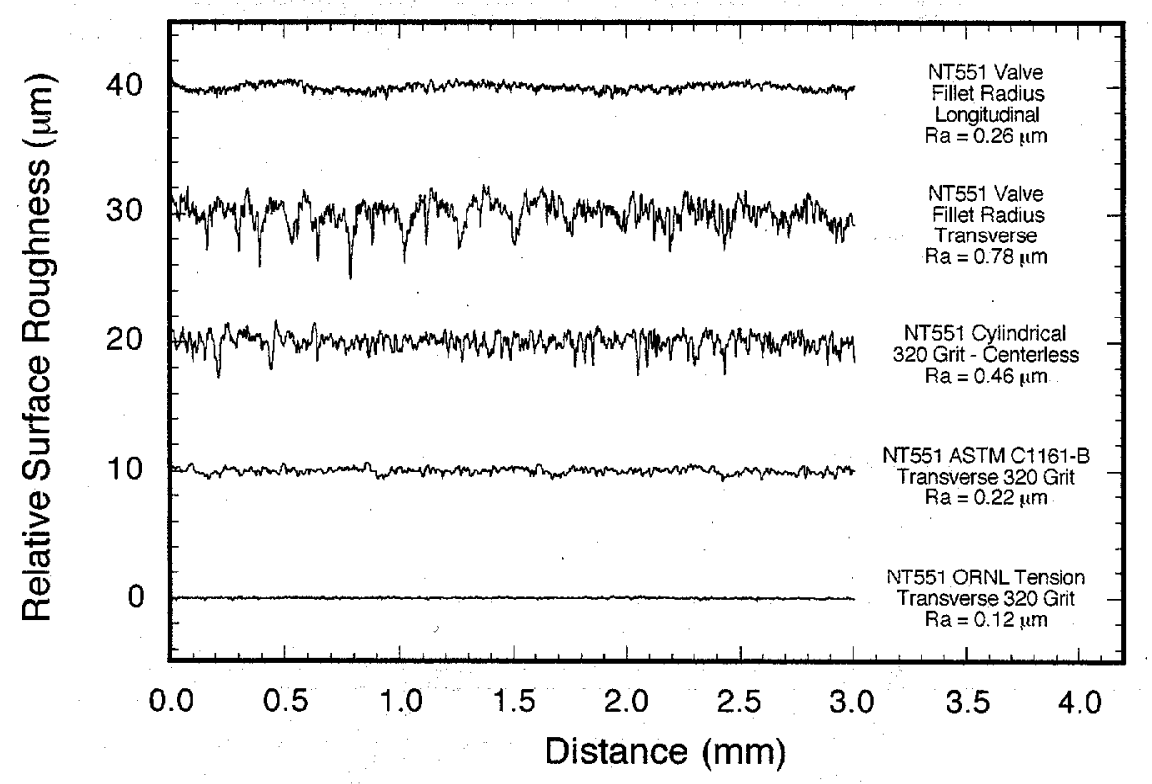

Figure 5.70. Surface profilometry of selected test specimens and valves. 


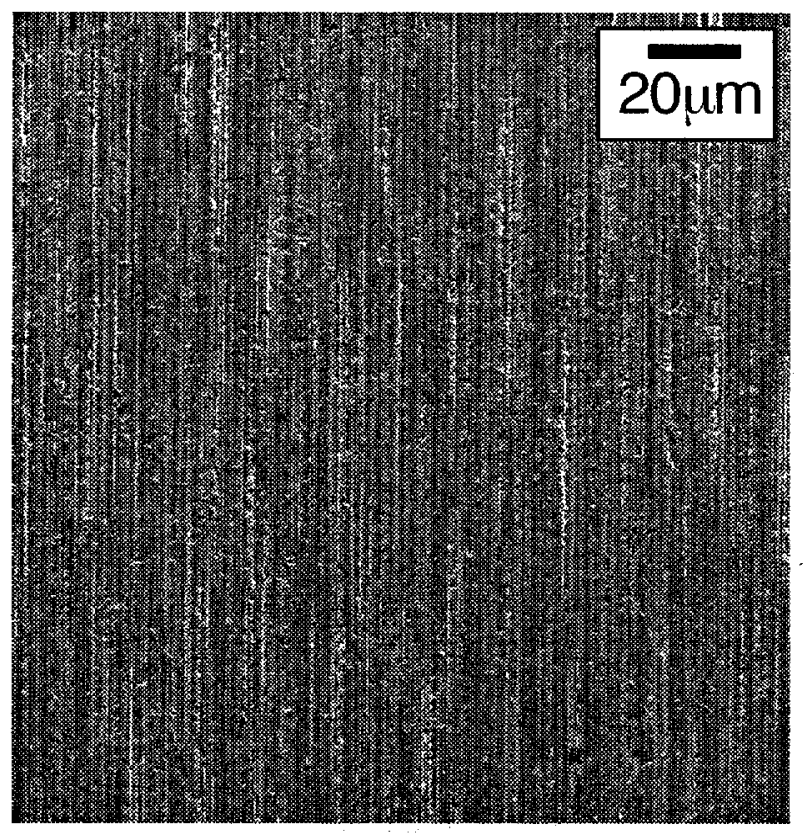

Figure 5.71. Surface finish from a modified ORNL tension specimen.

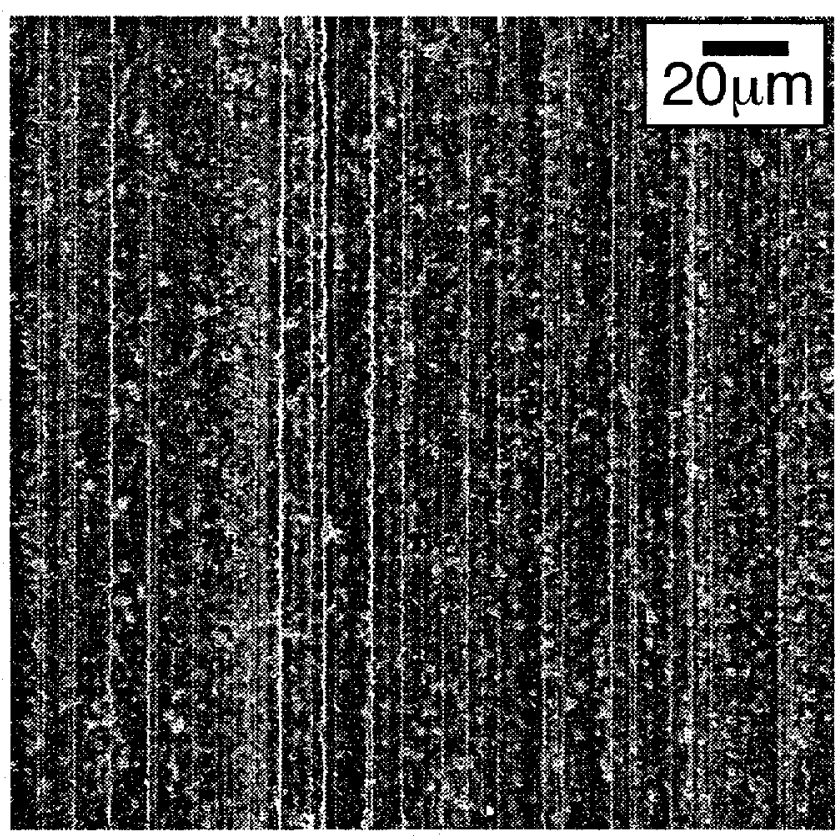

Figure 5.72. Surface finish from an ASTM C 1161-B transversely machined flexure bar. 


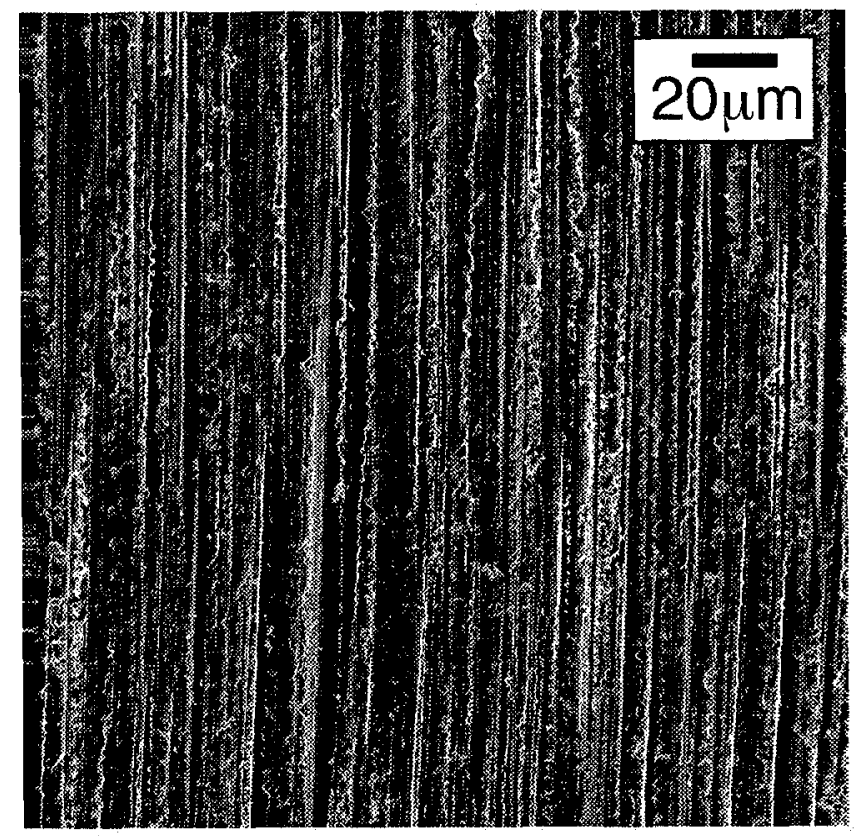

Figure 5.73. Surface finish from a cylindrical flexure bar.

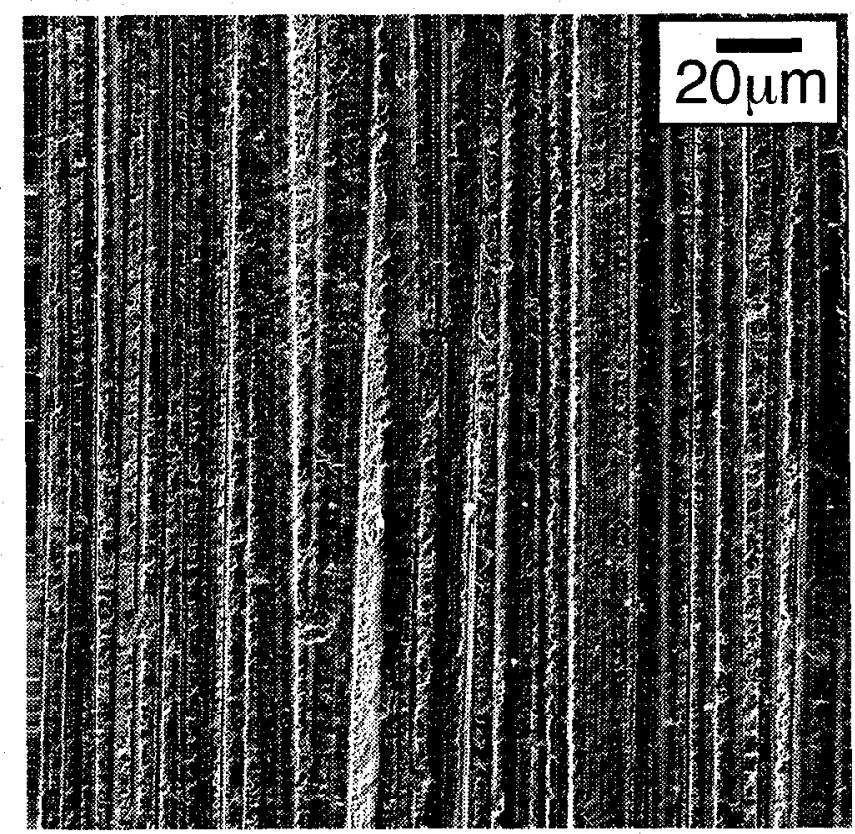

Figure 5.74. Surface finish from a transversely machined valve in the fillet radius region. 


\subsection{Measured and Predicted Strength Distributions of NT551 Valves}

\subsubsection{Fractography of S149 Diesel Exhaust Valves}

Presented in this section are digital photomicrographs from valve fracture surfaces. Of the 40 valves tested under ambient conditions and a rapid loading rate, 24 failed from volume-induced compositional inhomogeneities, 10 from surface-induced machining damage, 4 from volumeinduced agglomerates, and 2 that were not identified.

All valves tested (independent of failure type) failed from flaws located at their fillet radii where the tensile stresses were at a maximum. Figure 5.75 shows a major section of a valve after testing. The arrow points to the fracture mirror located in the fillet radius region of the valve. Representative examples of different flaw types that limited the strength of the valves follow.

Longitudinally machined valves predominantly failed from volume-induced flaws from compositional inhomogeneities. Shown in Figure 5.76 is the fracture and corresponding tensile surfaces of a longitudinally machined valve that failed from a VOL-SF flaw. The fracture mirror in the upper half of the image is outlined with a white line. On the tensile surface there are regions that are white and snowflake-like in appearance. The fracture origin appears to coincide with a region of snowflakes that is believed to have been the strength-limiting flaw for this valve.

Figure 5.77 shows another longitudinally machined valve that failed from a VOL-SF flaw. The fracture mirror in the top half of the image is marked with a white line. The bottom tensile surface shows regions of snowflakes, one of which coincides with the fracture origin. The cause of failure is believed to be the volume-compositional inhomogeneity found at the fracture origin.

An example of a surface-induced failure from machining from a transversely machined valve is shown in Figure 5.78. The surface appearance of the transversely machined valves was so similar to the surface of the cylindrical flexure specimens that for the sake of convenience, these valve failures were classified as SUR2-MD (see Figures 5.73 and 5.74). The transversely machined valves and the cylindrical flexure specimens were machined using different processes and it is plausible that each machining process created its own unique failure mechanism. The fracture mirror is located in the top of the image while the corresponding tensile surface is located in the lower half of the image. The fracture plane is parallel to one of the machining grooves that is believed to have induced failure.

. Figure 5.79 shows another transversely machined valve that failed from SUR2-MD. On the tensile surface are regions of snowflakes and black specks believed to be agglomerates. Despite the presence of these other failure mechanisms, the valve's strength-limiting flaw was a relatively deep machining groove. 
Figure 5.80 shows the fracture and corresponding tensile surfaces from a transversely machined valve that failed from an agglomerate. The fracture plane does coincide with a machining groove that suggests that machining damage may have been associated with failure initiation. However, the center of the fracture mirror contains a small black speck just below the surface that was believed to have induced failure.

Figure 5.81 shows the fracture plane of another longitudinally machined valve that failed from an agglomerate, located at the center of the fracture mirror. The critical flaw size at failure is defined from Eq. 4.5;

$$
a_{f}=\frac{1}{\pi}\left(\frac{K_{I C}}{\sigma_{f} Y}\right)^{2}
$$

where the terms $K_{I C}, Y, \sigma_{\mathrm{f}}$, have been defined from Eqs. 4.5, 4.6, and 4.21. The valve's failure stress was $685 \mathrm{MPa}$, the fracture toughness of NT551 was $6.0 \mathrm{MPa} V \mathrm{~m}$, and $Y=1.29$, assuming a semicircular flaw geometry. With this data, the critical flaw size calculates to $15 \mu \mathrm{m}$. The flaw size in Figure 5.81 is estimated at $15-20 \mu \mathrm{m}$, and that agrees with the critical flaw size calculation.

The predominant mode of failure for the engine-tested valves was VOL-SF and two examples of this failure mode are shown in Figures 5.82-5.83. The location of the strength-limiting flaw for the as-received valves was predominantly on the surface. For the engine-tested valves, 8 of the 15 valves had failure origins beneath the surface in the bulk of the material. Arrows point out the fracture origins in Figures 5.82-5.83. At the fracture origin, there are white snowflake-like in appearance regions suggesting that the strength-limiting flaw for both of these engine-tested valves was VOL-SF. 


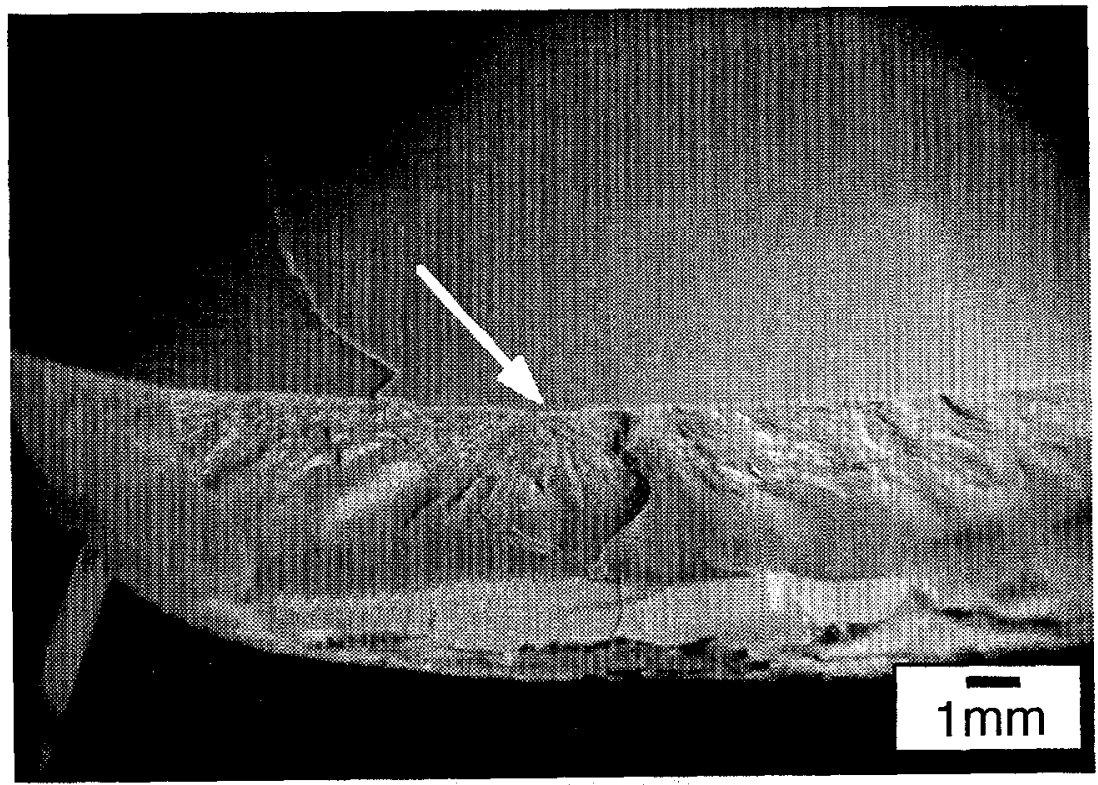

Figure 5.75. Fillet radius region of a valve taken to failure.

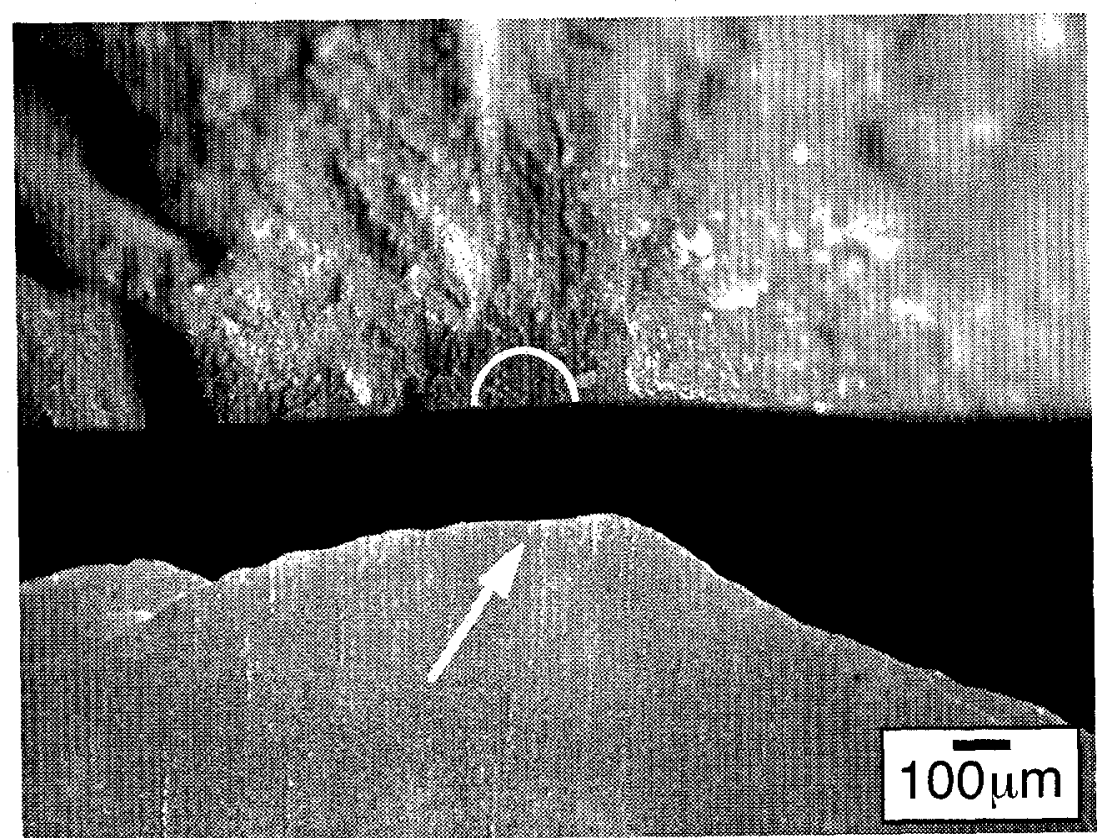

Figure 5.76. Fracture mirror and tensile surface of a longitudinally machined valve. Failure from VOL-SF. $\sigma_{\mathrm{f}}=1013 \mathrm{MPa}$. 


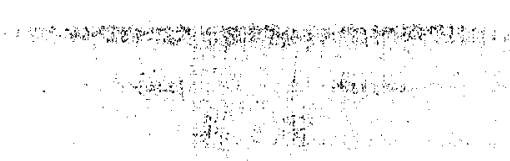

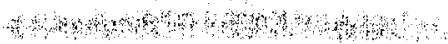

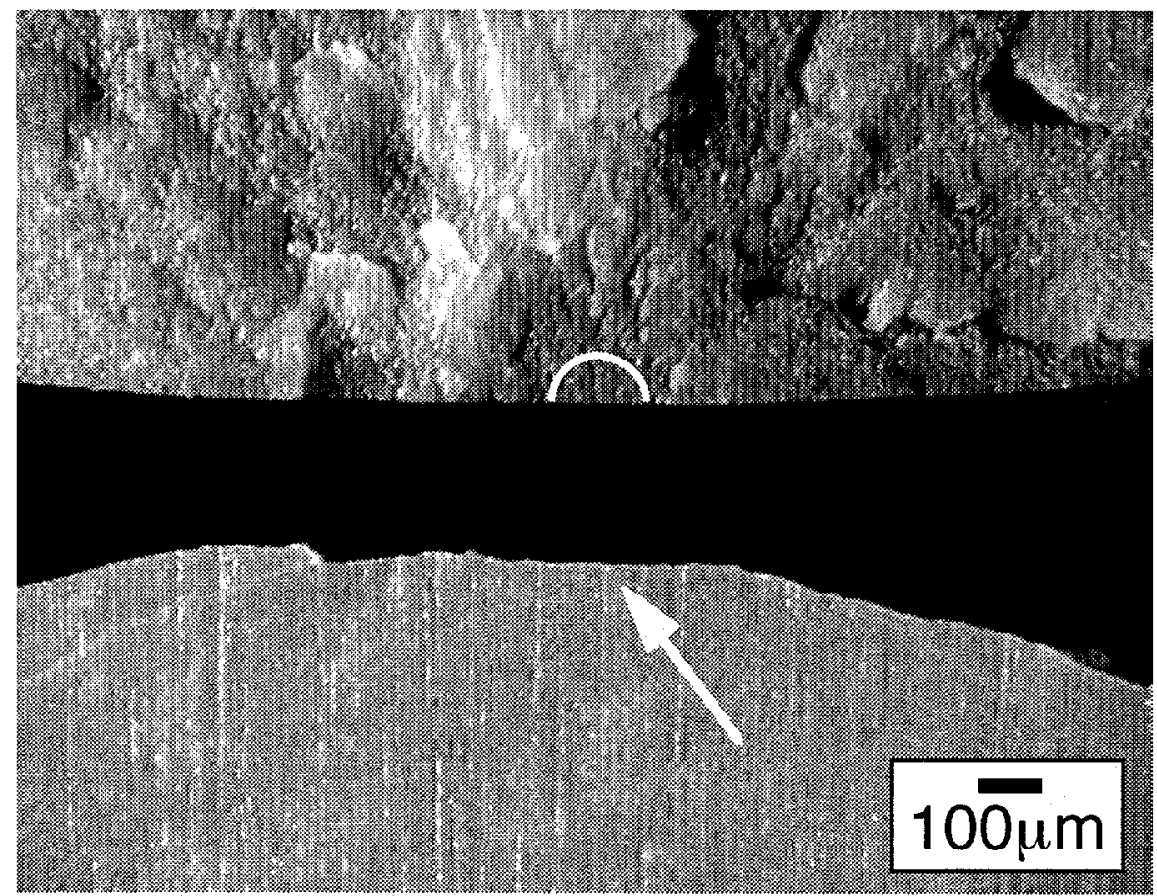

Figure 5.77. Fracture mirror and tensile surface from a longitudinally machined valve. Failure from VOL-SF. $\sigma_{\mathrm{f}}=1138 \mathrm{MPa}$.

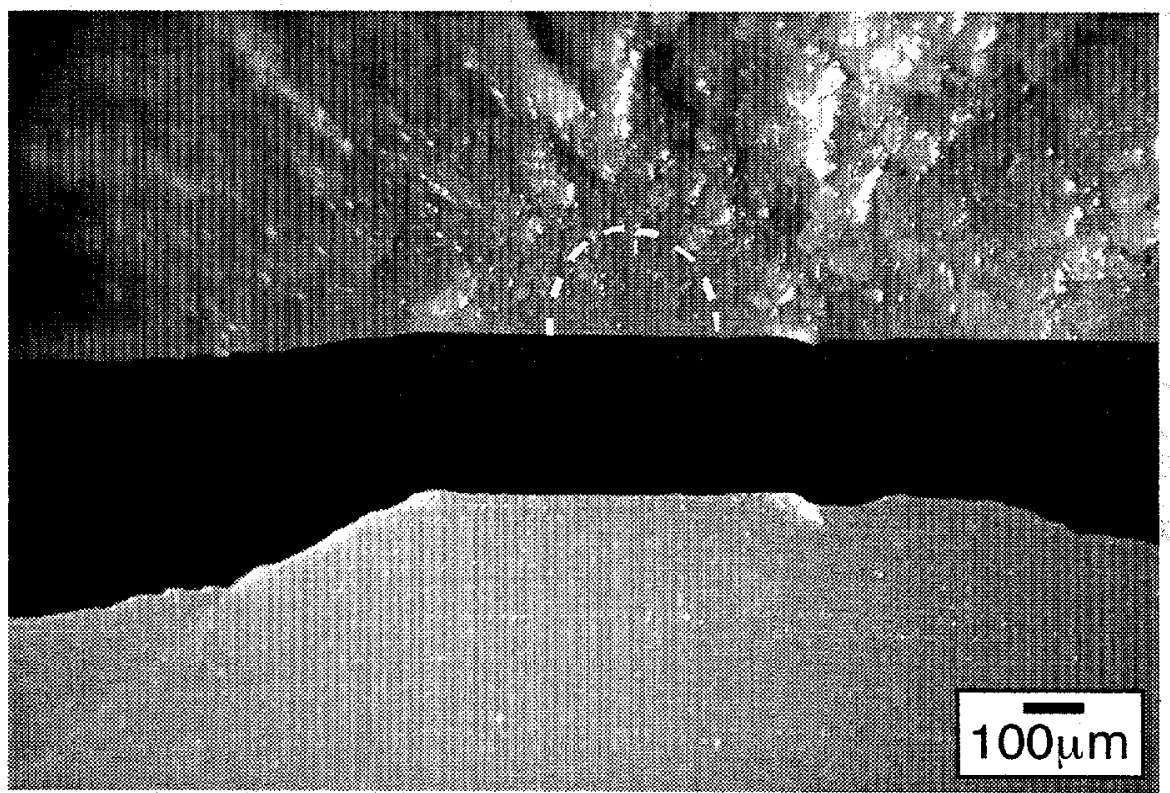

Figure 5.78. Fracture surface and tensile side of a transversely machined valve. Failure from SUR2-MD. $\sigma_{\mathrm{f}}=668 \mathrm{MPa}$. 


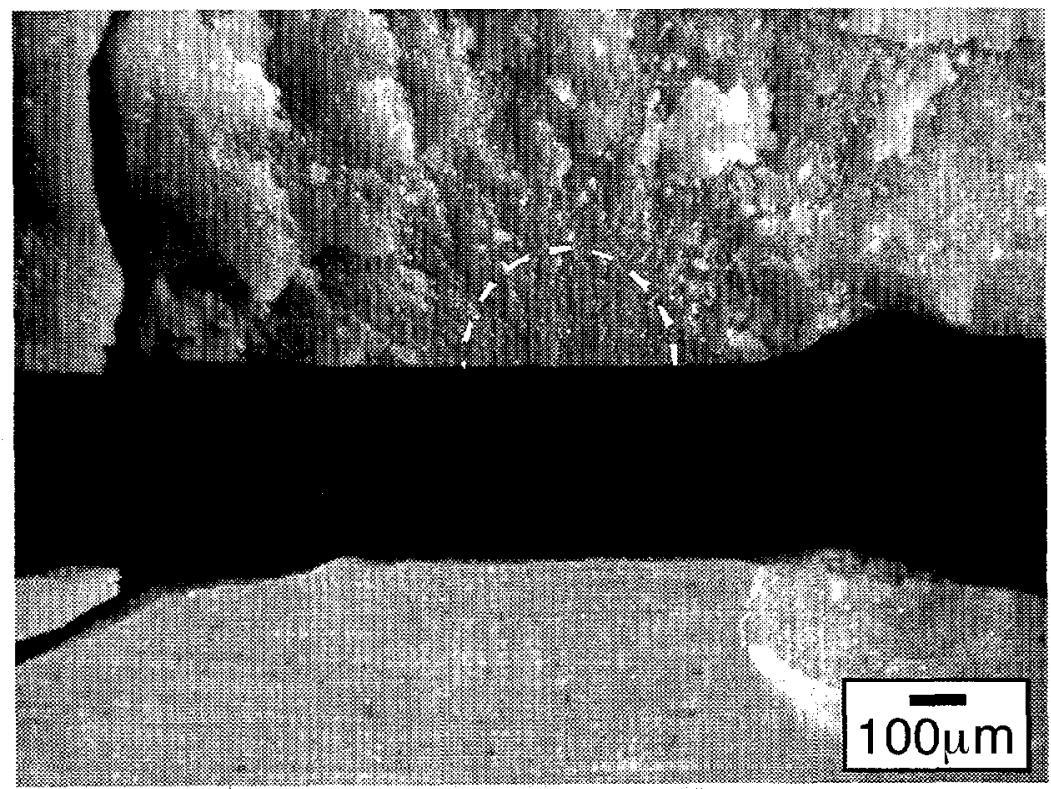

Figure 5.79. Fracture mirror and tensile surface of a transversely machined valve. Failure from SUR2-MD. $\sigma_{\mathrm{f}}=623 \mathrm{MPa}$.

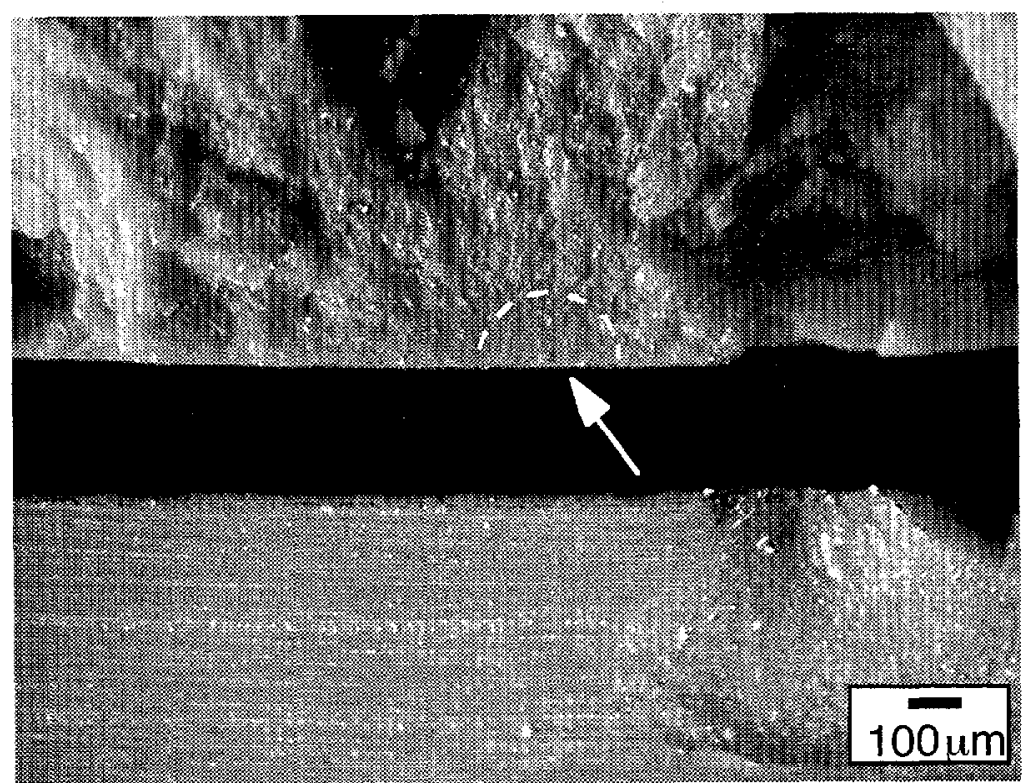

Figure 5.80. Fracture origin and tensile surface of a transversely machined valve. Failure from VOL-AGG. $\sigma_{\mathrm{f}}=634 \mathrm{MPa}$. 


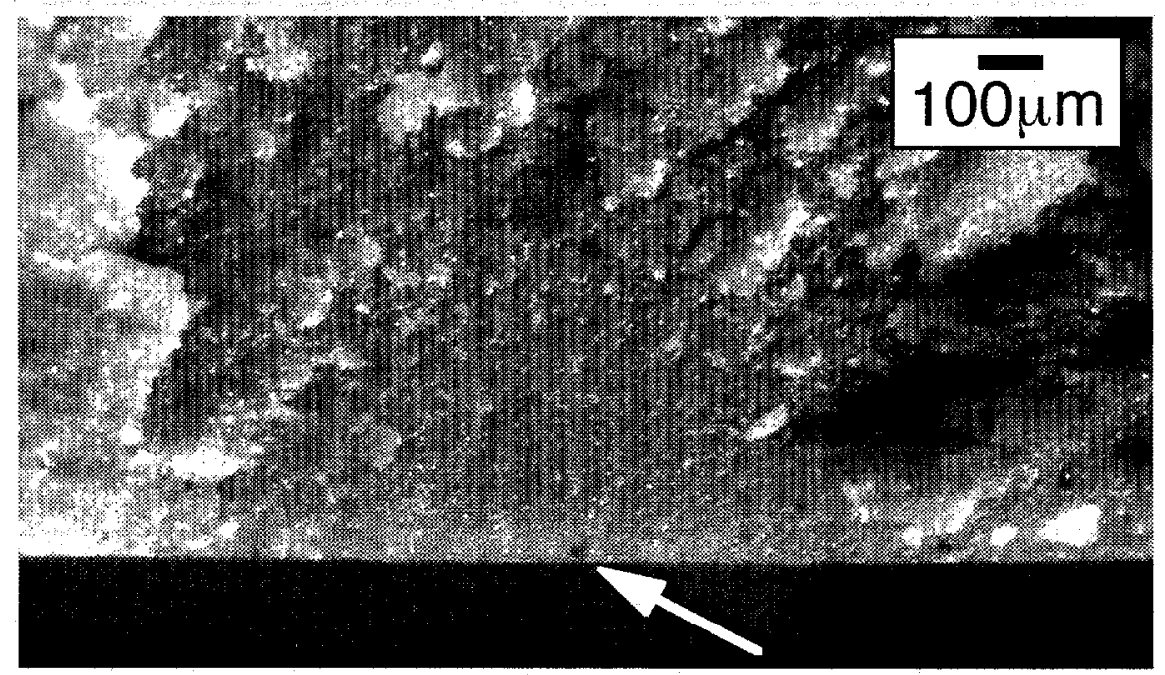

Figure 5.81. Fracture surface of a longitudinally machined valve. Failure from VOLAGG. $\sigma_{\mathrm{f}}=685 \mathrm{MPa}$.

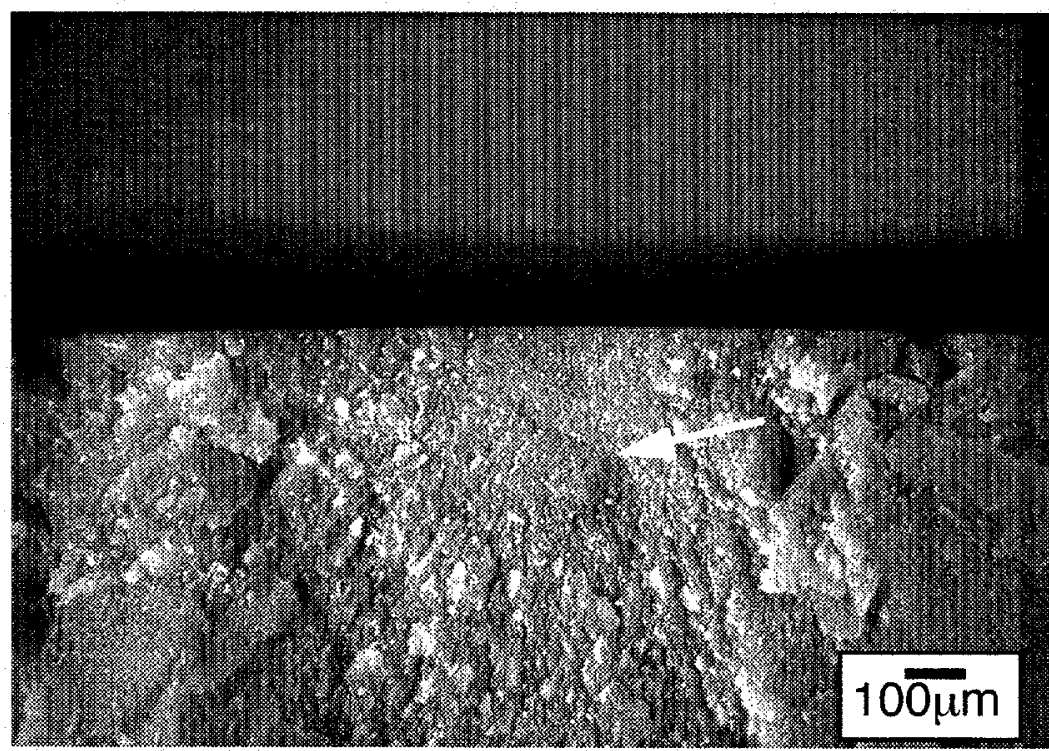

Figure 5.82. Fracture mirror of a longitudinally machined valve that was engine tested for 1000 hours. Arrow points to the fracture origin that is a volume flaw. $\sigma_{\mathrm{f}}=753 \mathrm{MPa}$. 


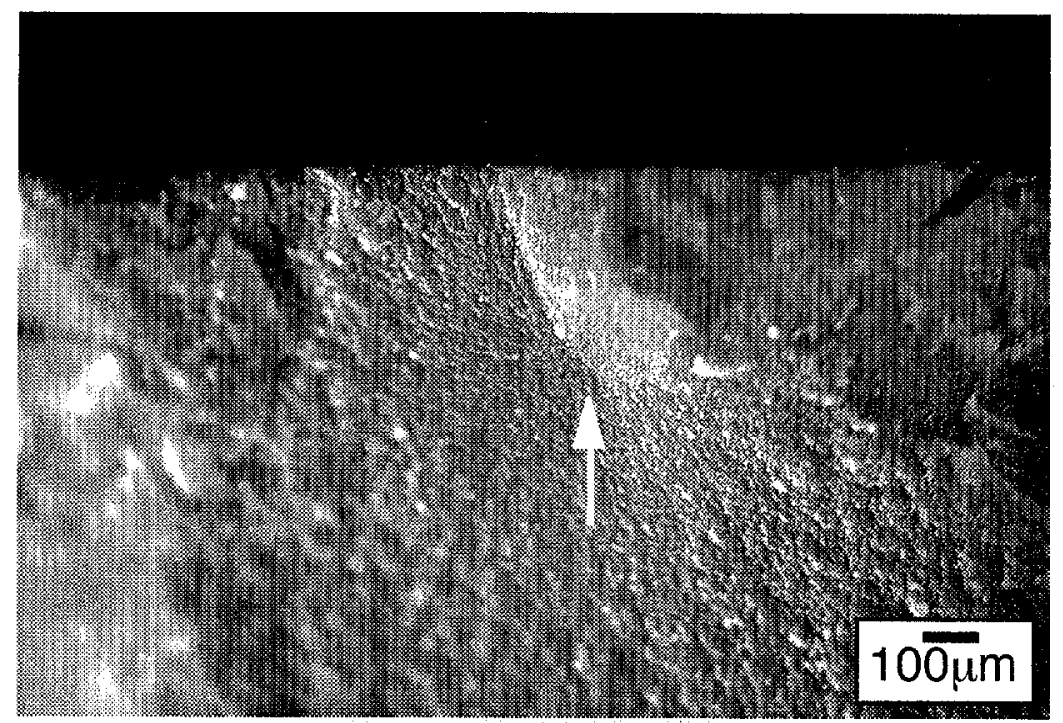

Figure 5.83. Fracture mirror of a longitudinally machined engine-tested valve (1000 hr). Arrow points to fracture origin that is a volume flaw. $\sigma_{\mathrm{f}}=765 \mathrm{MPa}$.

\subsubsection{Inert Strength of As-Received Valves}

Twenty-five S149 as-received diesel exhaust valves were loaded to failure at $20^{\circ} \mathrm{C}$ to examine the effect grinding orientation has on the valve inert strength. Of the 25 valves, 15 were machined transverse to the axis of symmetry while 10 were machined longitudinally, parallel to the axis of symmetry. All valve failures initiated from the surface on the fillet radius region where the maximum tensile stresses were anticipated from finite element analysis.

Presented in Table 5.31 are the fractographic results from the valve testing. The dominant mode of failure for the transversely machined valves was surface-induced from machining damage (SUR2-MD), while the dominant mode of failure for the longitudinally machined valves was volume-induced from compositional inhomogeneities (VOL-SF). Of the transversely machined valves, there were 3 failures each from VOL-SF and VOL-AGG failure modes. There was one longitudinally machined valve that the failure mode was unidentified.

Presented in Figures 5.84-5.85 are the uncensored Weibull distributions for the transversely and longitudinally machined valves, respectively. The maximum stress at the fillet radius region was $160 \mathrm{MPa}$, so the ratio of maximum stress to combustion stress is $160 / 16$ or 10 . The "Failure Stress" label on the abscissa of each graph refers to the stress in the fillet radius region of the valve calculated from an applied combustion pressure of $16 \mathrm{MPa}$. The type of failure for each valve is 
also presented with each Weibull distribution. The characteristic strength of the longitudinally machined valves is 36 to $46 \%$ greater than the transversely machined valves. The uncensored Weibull modulus for the longitudinally machined valves is $46 \%$ greater than the uncensored Weibull modulus for the transversely machined valves. However, the difference in the Weibull moduli for the longitudinally and transversely machined valves is not statistically significant at a $95 \%$ confidence level.

Table 5.31. Summary of as-received S149 diesel exhaust valve fractography. Number of valves for each flaw type shown.

\begin{tabular}{|l|c|c|c|c|}
\hline Valve Type / Number & VOL-SF & VOL-AGG & SUR2-MD & UNK \\
\hline Trans-As-Received /15 & 3 & 3 & 9 & 0 \\
\hline Long-As-Received/10 & 9 & 0 & 0 & 1 \\
\hline
\end{tabular}

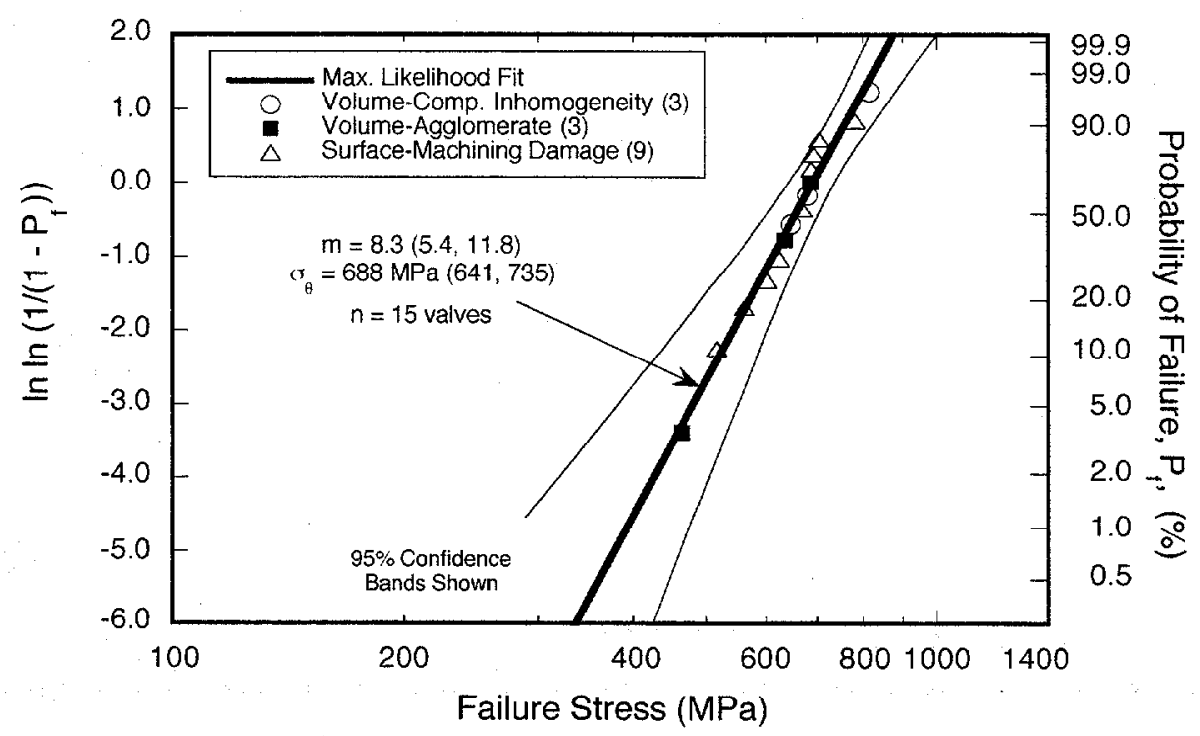

Figure 5.84. Inert strength Weibull distribution of S149 as-received transversely machined valves tested at $20^{\circ} \mathrm{C}$. 


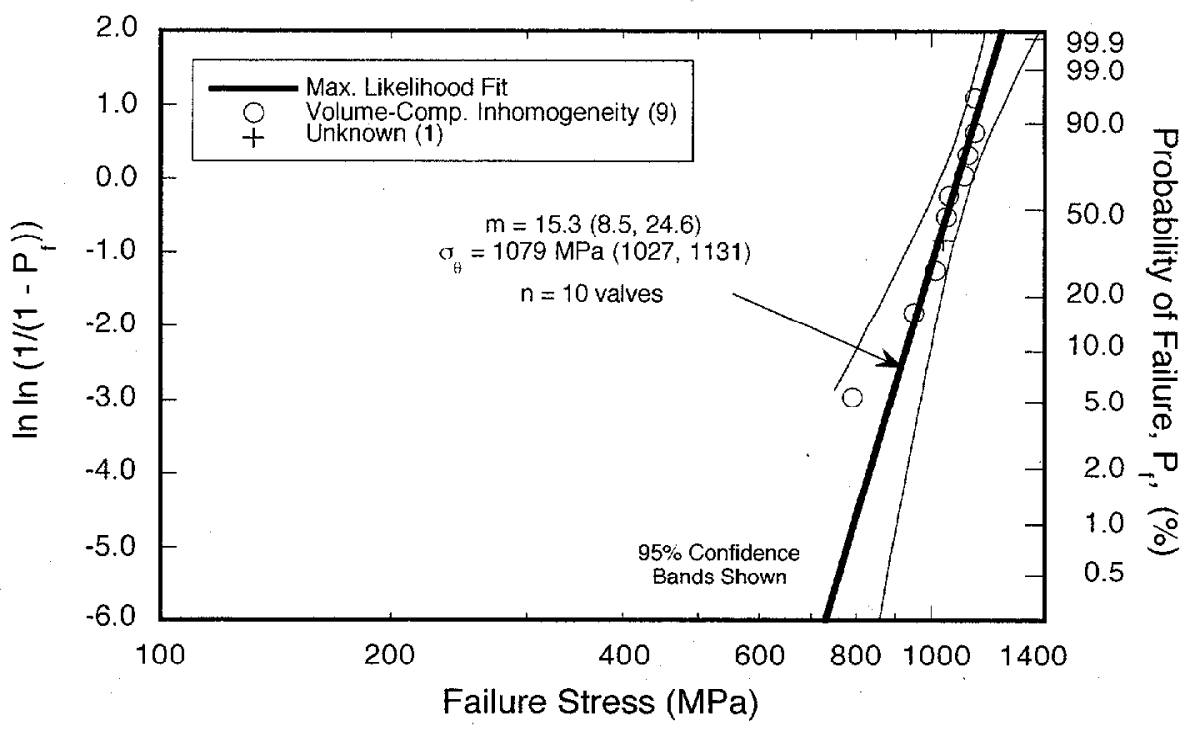

Figure 5.85. Inert strength Weibull distribution of S149 as-received longitudinally machined valves tested at $20^{\circ} \mathrm{C}$.

\subsubsection{Retained Strength of Engine-Tested Valves}

There were 15 engine-tested valves loaded to failure using the same hydraulic test facility in order to examine their retained strength. The tested valves consisted of 7 longitudinally machined valves and 8 transversely machined valves. The transversely machined valves had been engine tested for 1000 hours while the longitudinally machined valves had been engine tested for 166 hours. The cyclic engine tests, conducted by DDC, consisted of applying different loads at explicit engine speeds and for specified time periods.

The results of the fractographic analysis for the engine-tested valves are presented in Table 5.32. The dominant mode of failure for both valve machining orientations was VOL-SF and all failures initiated in the valve fillet radius region. The transversely machined valves had 6 VOL-SF failures, one SUR2-MD, and one UNK. All 7 of the longitudinally machined engine tested valves failed from VOL-SF. Compared to the as-received valves, the mode of failure for the longitudinally machined valves remained the same while the mode of failure changed from SUR2-MD to VOL-SF for the transversely machined valves. 
For the 8 transversely machined valves, 2 failure origins were located on the surface while 5 failure origins were located in the bulk of the material below the maximum tensile surface. Four of the longitudinally machined valves had strength-limiting flaws located on the surface while the remaining 3 were located in the bulk of the material below the maximum tensile surface.

Presented in Figures 5.86 and 5.87 are the uncensored Weibull distributions for the transversely and longitudinally machined valves, respectively. The Weibull modulus for the engine-tested transversely valves was 3.9 while for the engine-tested longitudinally valve the modulus was 6.9. The characteristic strength for the engine-tested transversely-machined valves was $636 \mathrm{MPa}$ while the characteristic strength for the engine-tested Iongitudinally-machined valves was $799 \mathrm{MPa}$. At a 95\% confidence level, the uncensored Weibull parameters for the enginctested longitudinally and transversely machined valves are equivalent.

For the transversely machined valves, there was approximately an $8 \%$ reduction in the characteristic strength and nearly a 50\% reduction in the uncensored Weibull modulus value between the as-received and the engine-tested valves. There was a reduction in the characteristic strength of approximately $26 \%$ and a reduction in the uncensored Weibull modulus of approximately $50 \%$ between the as-received and the engine-tested valves that were longitudinally machined. The reduction in the characteristic strength for the longitudinally machined enginetested valves was statistically significant while the reduction in the Weibull modulus is not statistically significant.

Table 5.32. Summary of engine-tested S149 diesel exhaust valve fractography. Number of valves for each flaw type shown.

\begin{tabular}{|l|l|l|l|l|}
\hline Valve Type / Number & VOL-SF & VOL-AGG & SUR2-MD & UNK \\
\hline Trans-Engine Tested $^{(a)} / 8$ & 6 & 0 & 1 & 1 \\
\hline Long-Engine Tested $^{(a)} / 7$ & 7 & 0 & 0 & 0 \\
\hline
\end{tabular}

(a) Transversely machined valves were engine tested for 1000 hours while longitudinally machined valves were engine tested for 166 hours. 


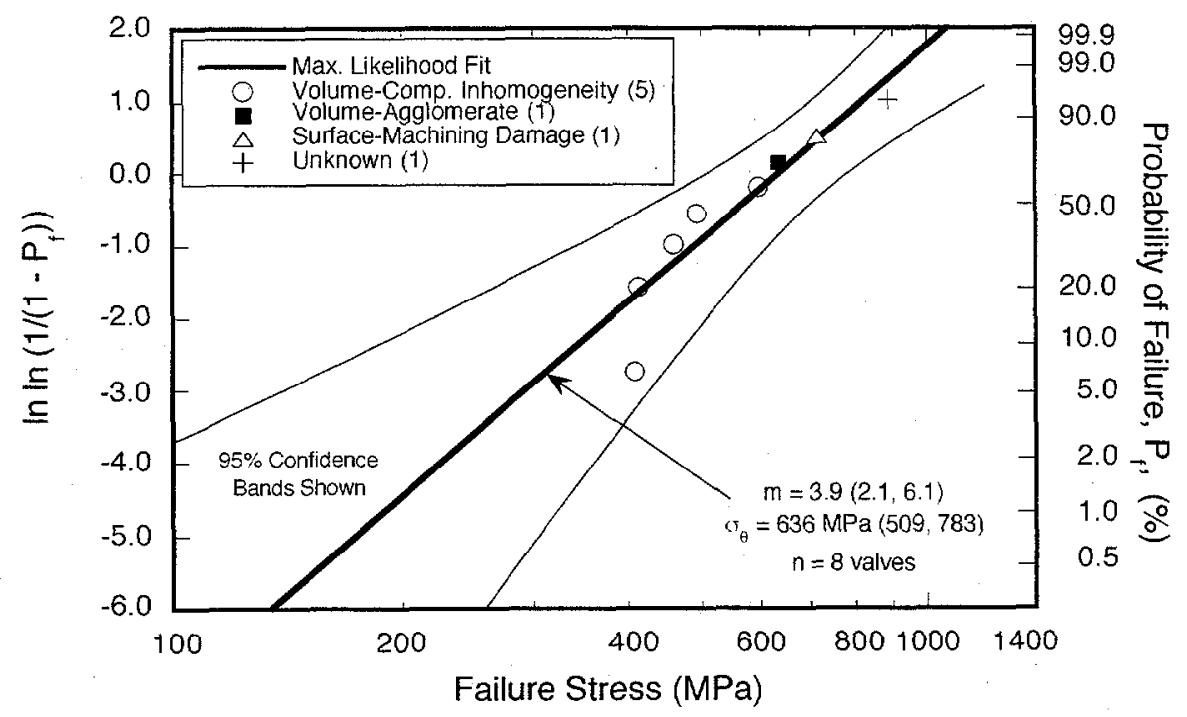

Figure 5.86. Retained strength Weibull distribution of S149 transversely machined 1000 hour engine tested valves.

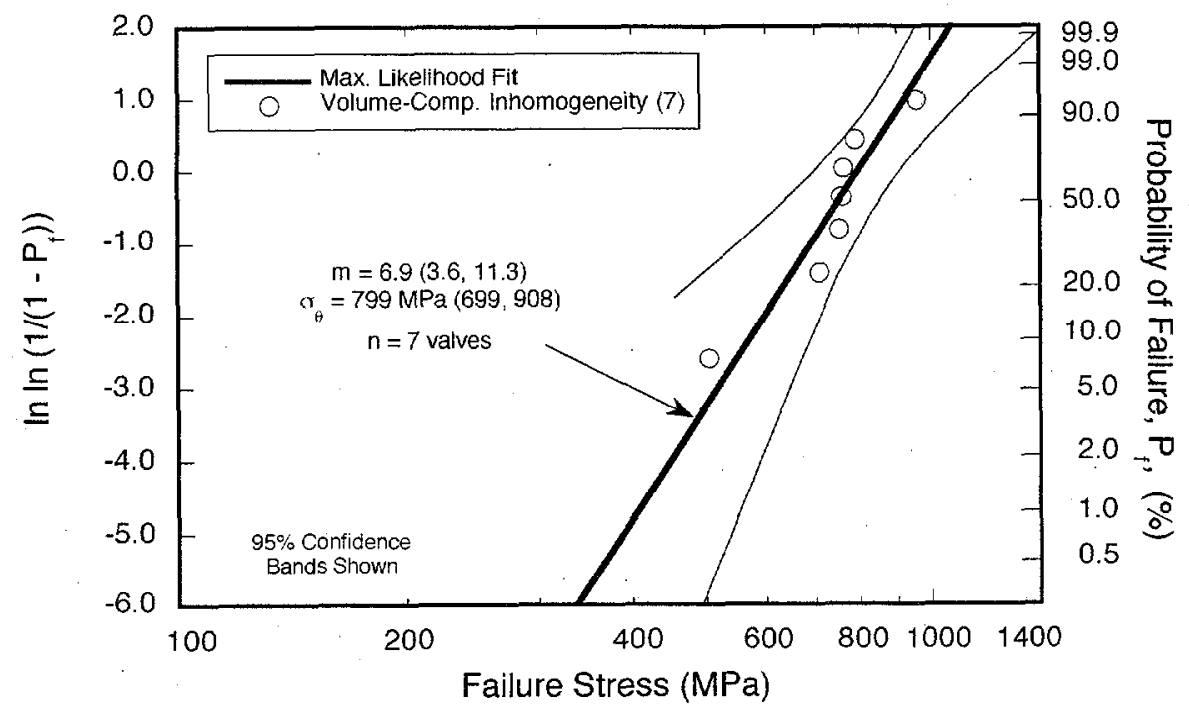

Figure 5.87. Retained strength Weibull distribution of S149 longitudinally machined 166 hour engine tested valves. 


\subsubsection{Predicted Inert Strength Distributions}

Presented in this section are the censored inert strength failure probability predictions for the S149 diesel exhaust valve. Censored strength data used as input into the life prediction algorithm were ASTM C 1161-B transversely machined, ASTM C 1161-B longitudinally machined, cylindrical flexure specimens, and modified ORNL tension specimens. All strength data used as input in the life prediction programs were from tests conducted at $20^{\circ} \mathrm{C}$.

Predictions were made for the VOL-SF and SUR1-MD failure modes using the ASTM C 1161-B transversely machined strength data. For the ASTM C 1161-B longitudinally machined specimens, predictions were made for the VOL-SF failure mode. Predictions for the SUR2-MD failure mode were made using the cylindrical flexure data while predictions for the SUR1-MD and VOL-AGG failure modes were made using the ORNL tension data.

Presented in Figures 5.88-5.91 are the inert strength failure probability predictions for the S149 valve. Censored inert strength valve data are included in each graph along with the failure probability distribution. The "Failure Stress" label on the abscissa of each graph refers to the maximum tensile stress found in the valve fillet radius region based on a combustion pressure of $16 \mathrm{MPa}$ (see Section 5.5.2). All identified valve failures were located in this high tensile stress region. Also indicated in each graph is the tensile stress in the valve fillet radius region when a combustion pressure of $16 \mathrm{MPa}$ was applied.

Figure 5.88 shows the failure probability distribution for the S149 diesel valve when using the ASTM C 1161-B transversely machined strength data as input. A maximum likelihood prediction line is shown for a surface failure from machining damage and for a volume failure from a compositional inhomogeneity. Each likelihood prediction is accompanied with a lower $95 \%$ confidence bound. Censored inert strength data from transversely machined valves tested at $20^{\circ} \mathrm{C}$ are included in the graph. The maximum likelihood prediction for both failure modes is more conservative than the valve strength data. The SUR1-MD valve strength data appears to have the same Weibull modulus as the predicted surface machining damage failure distribution. The VOL-SF valve strength data does not appear to have the same the Weibull modulus as the VOL-SF predicted failure distribution.

The inert strength distribution based on longitudinally machined ASTM C 1161-B flexure bars for the S149 diesel valve is presented in Figure 5.89. The dominant mode of failure for the test specimen as well as the longitudinally machined valves was VOL-SF. Shown with the failure probability prediction is the inert strength data from longitudinally machined valves tested at $20^{\circ} \mathrm{C}$. The maximum likelihood failure probability prediction is more conservative than the valve strength 
data. The VOL-SF valve strength data does not appear to have the same Weibull modulus as the VOL-SF failure probability prediction.

Figure 5.90 shows the valve inert strength failure probability distribution using cylindrical flexure data as input into the life prediction algorithm. The only mode of failure for these test specimens was SUR2-MD and shown along with the maximum likelihood prediction are the inert strength from transversely machined valves tested at $20^{\circ} \mathrm{C}$. As was illustrated in the previous figures, the maximum likelihood failure probability distribution is more conservative than the valve strength data. The Weibull modulus for the valve strength data was different than the Weibull modulus for the failure probability prediction.

Presented in Figure 5.91 is the valve inert strength failure probability prediction using the modified ORNL tension specimens as input into the life prediction programs. The two failure modes represented are SUR1-MD and VOL-AGG. The maximum likelihood failure predictions for both failure modes are more conservative than the inert strength of the transversely machined valves. The Weibull modulus for the transversely machined valve strength data correlates well with the Weibull modulus for the failure probability prediction. At the maximum tensile stress of $160 \mathrm{MPa}$, Figure 5.90 shows an approximately 2 percent chance of failure from SUR1-MD flaws while virtually no chance for failure from VOL-AGG flaws at the same stress level.

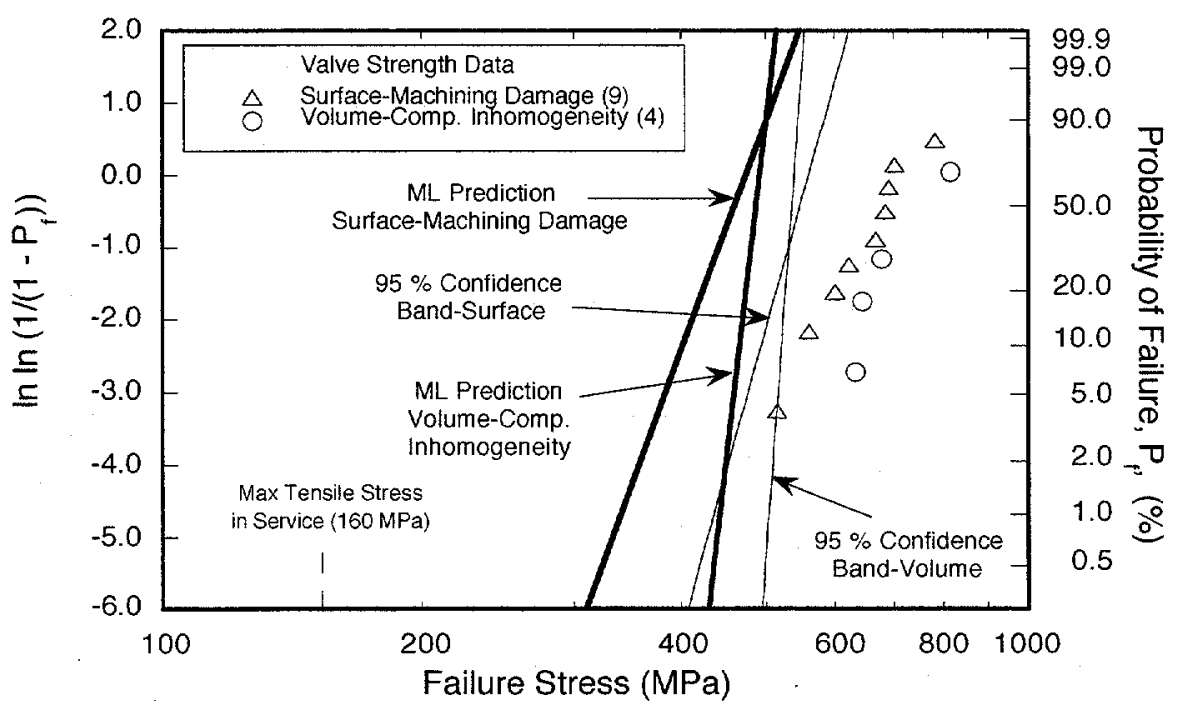

Figure 5.88. Inert strength failure probability prediction of S149 valves using ASTM C 1161-B transversely machincd flexure specimens. 


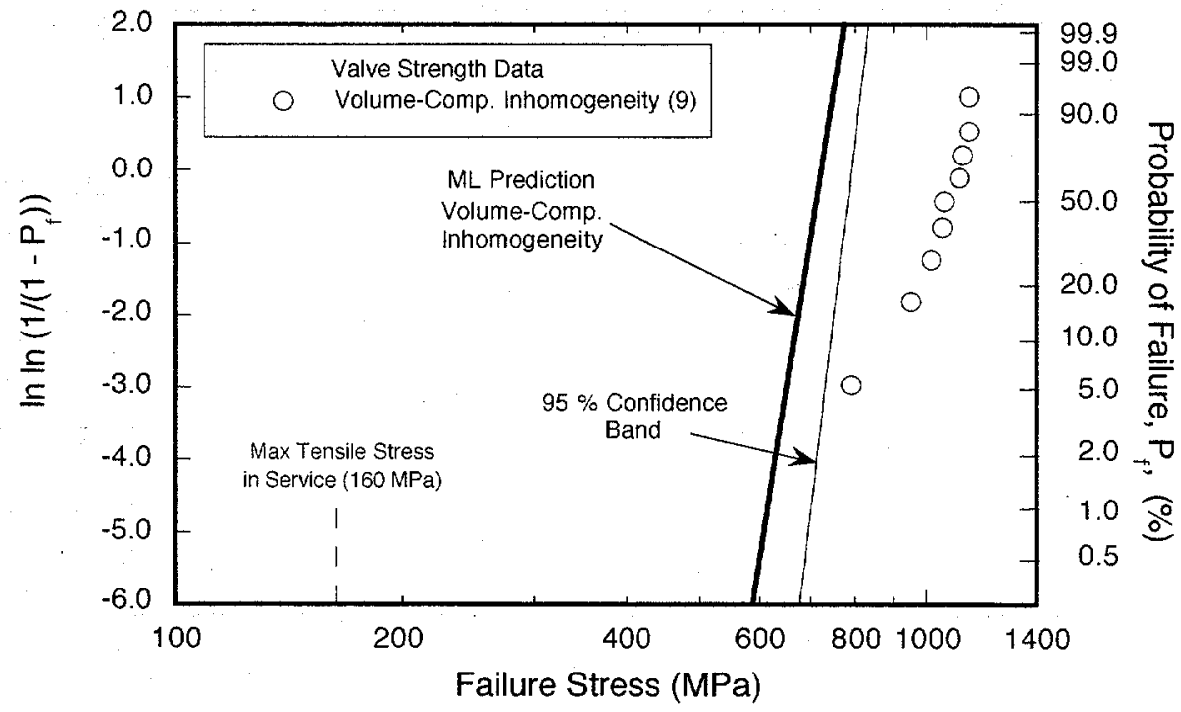

Figure 5.89. Inert strength failure probability prediction of S149 valves using ASTM C 1161-B longitudinally machined flexure specimens.

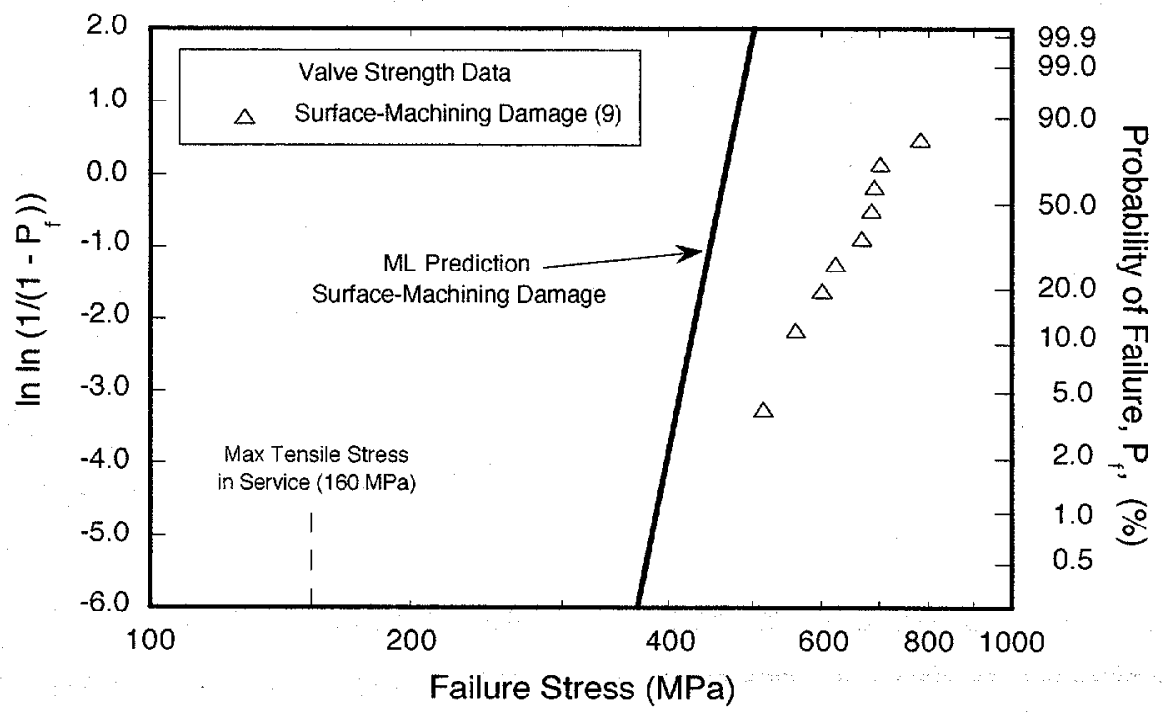

Figure 5.90. Inert strength failure probability prediction of S149 valves using cylindrical flexure data. 


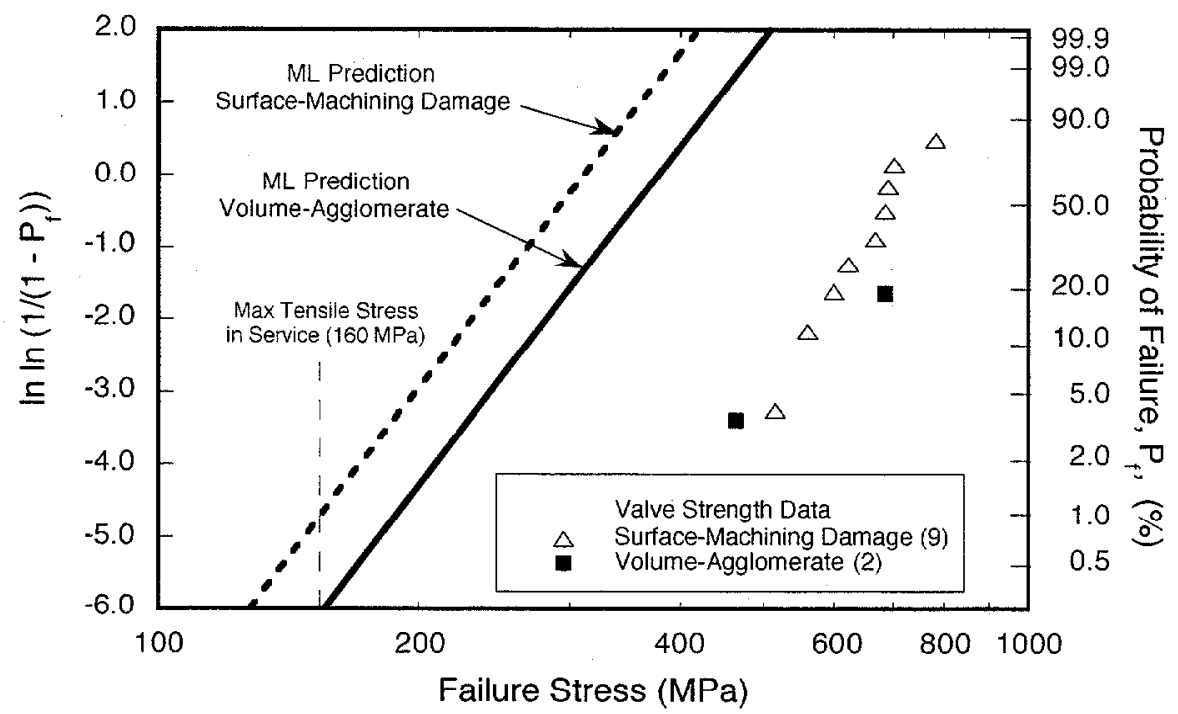

Figure 5.91. Inert strength failure probability prediction of S149 valves using modified ORNL tension data.

\subsubsection{Predicted Fatigue Performance of S149 Valves}

Presented in this section are estimates of the fatigue performance based on previously presented uncensored strength data. A method to model fatigue was to conduct flexure tests at several constant slow loading rates, as stated in the ASTM C 1368 standard (1998). By knowing the inert strength of a material, testing at a constant loading rate, and assuming the failure mechanism(s) at the inert strength tests are the same as the slow crack growth tests, the slow crack growth equation can be rearranged to give reduced strength based on an elapsed time period (see Eq. 4.9). Shown in the next four figures are estimates of strength degradation from a constant (static) applied load after one hour, one week, and one year of elapsed time.

Figure 5.92 shows the strength degradation based on ASTM C 1161-B transversely machined flexure tests conducted at $20^{\circ} \mathrm{C}$. Consider the maximum tensile stress of $160 \mathrm{MPa}$ estimated for the valve while in service. As shown in the plot, there is less than $0.5 \%$ chance of failure, from an applied constant load that produces $160 \mathrm{MPa}$ tensile stress in the valve, for all time spans. 
Figure 5.93 illustrates the fatigue performance derived from uncensored ASTM C 1161-B transversely machined flexure specimens tested at $850^{\circ} \mathrm{C}$. This analysis assumes that like the test specimens, the entire valve is at $850^{\circ} \mathrm{C}$. A static load is applied that produces a constant stress of $160 \mathrm{MPa}$ in the valve. The inert strength maximum likelihood estimate shows approximately a $10 \%$ chance for failure. After one hour has expired, the probability of failure increases to approximately $90 \%$. If the load continued for one week and beyond, failure is eminent.

The fatigue performance based on cylindrical flexure specimens tested at $20^{\circ} \mathrm{C}$ is presented in Figure 5.94. As shown in Figure 5.92, there is less than $0.5 \%$ chance for failure, when a constant load applied to the valve causes a $160 \mathrm{MPa}$ tensile stress in the fillet radius region of the valve, for all time spans.

Figure 5.95 shows the fatigue performance based on uncensored modified ORNL tension data. The slope of the maximum likelihood predictions are notably steeper than previously presented fatigue plots. At the inert strength level and a static load producing a stress of $160 \mathrm{MPa}$, there is chance for failure between 1 and $2 \%$. After one hour of service time, the probability of failure increases to nearly $3 \%$. After one week of loading at $160 \mathrm{MPa}$, the failure probability increases to $7 \%$ and after one year of constant load, the failure probability increases to just over $10 \%$.

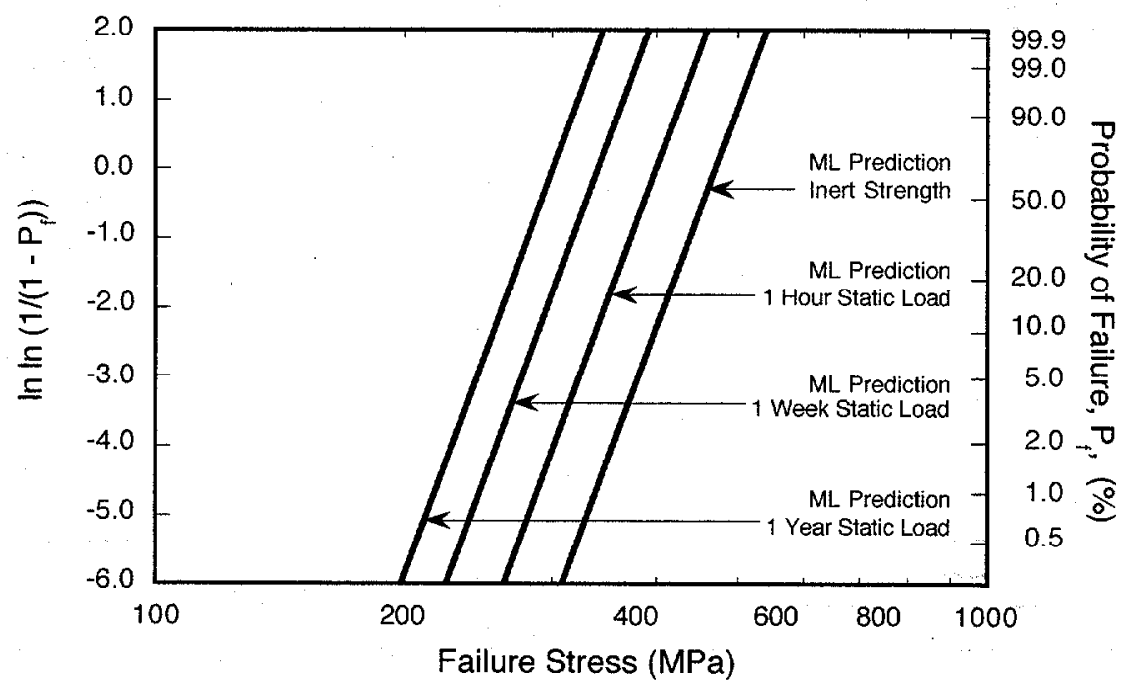

Figure 5.92. Predicted static fatigue performance of transversely machined S149 valves from ASTM C 1161-B transversely machined flexure specimens tested at $20^{\circ} \mathrm{C}$. 


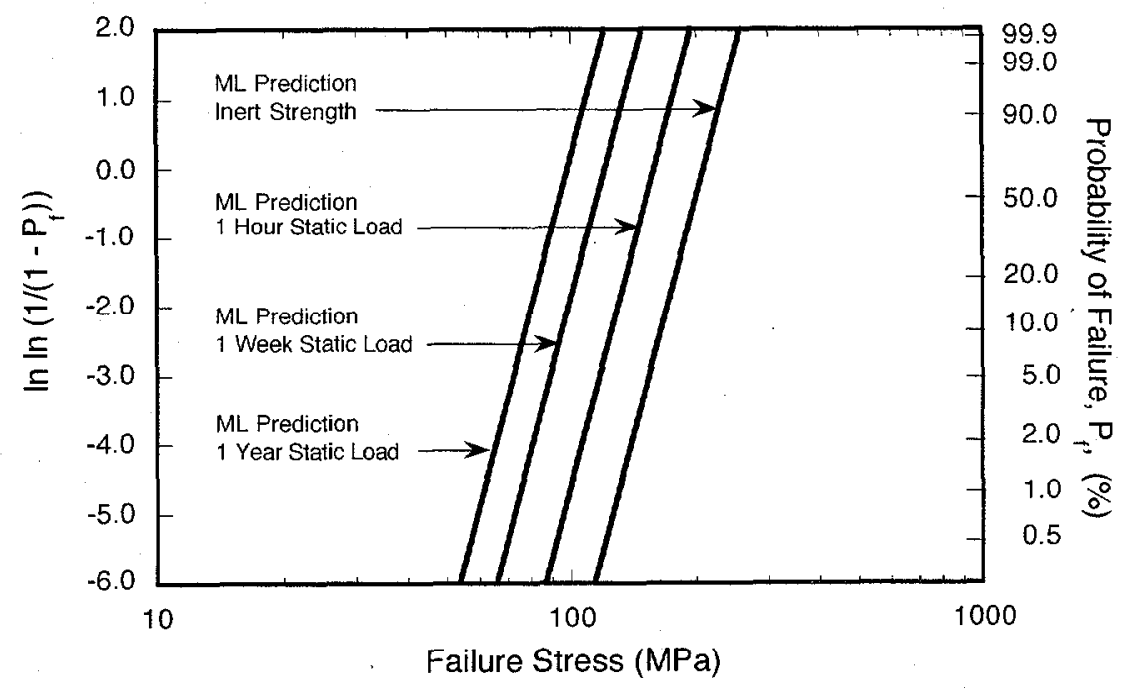

Figure 5.93. Predicted static fatigue performance of transversely machined S149 valves from ASTM C 1161-B transversely machined flexure specimens tested at $850^{\circ} \mathrm{C}$.

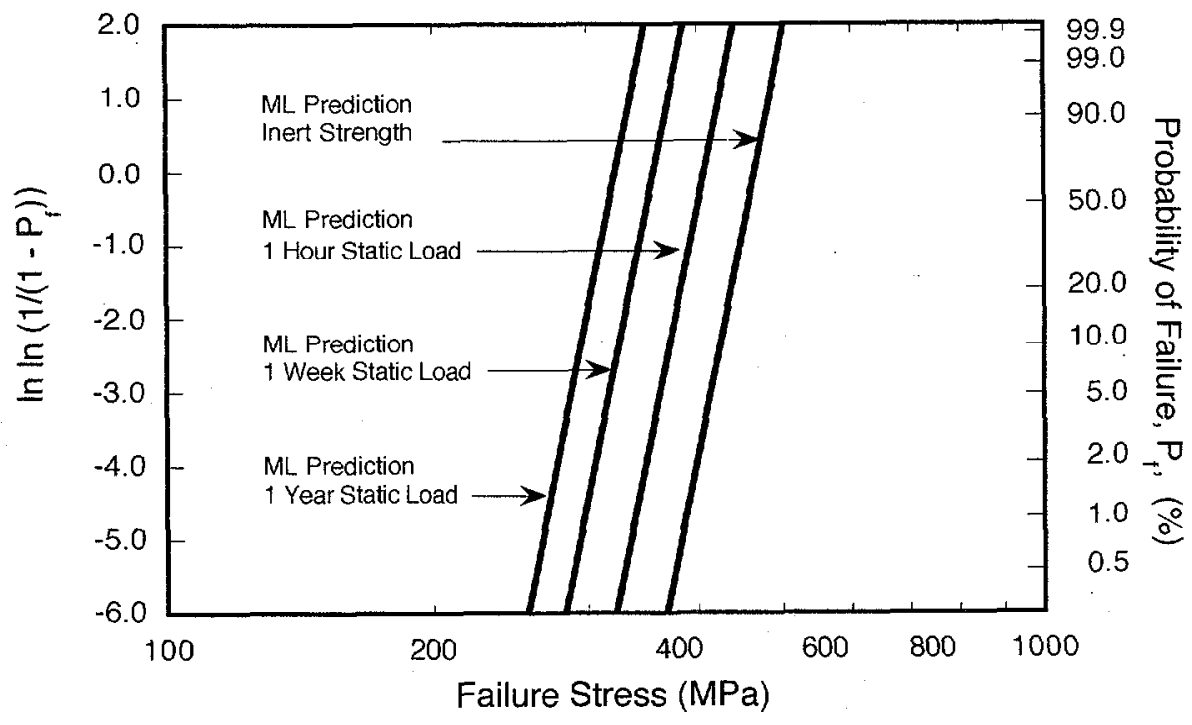

Figure 5.94. Predicted static fatigue performance of transversely machined S149 valves based on cylindrical flexure data tested at $20^{\circ} \mathrm{C}$. 


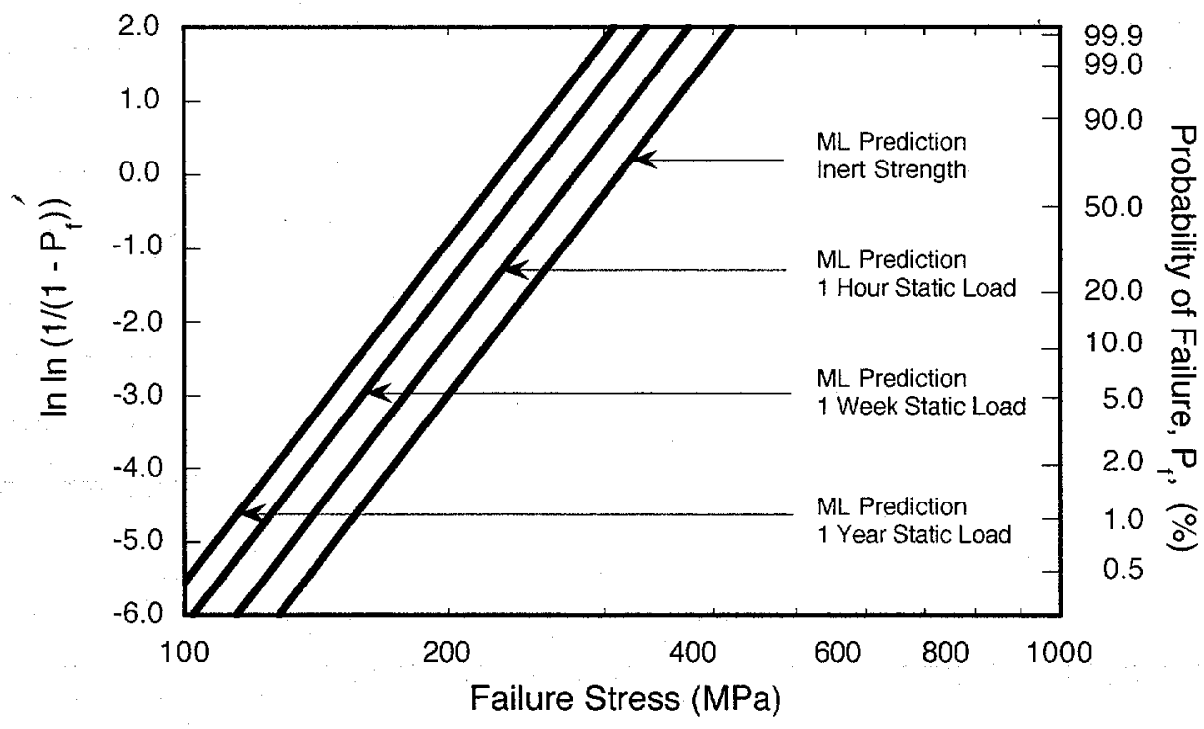

Figure 5.95. Predicted static fatigue performance of transversely machined S149 valves based on modified ORNL tension data generated at $20^{\circ} \mathrm{C}$. 


\section{DISCUSSION}

\subsection{General Observations}

This program tested three vintages of $N T 551 \mathrm{Si}_{3} \mathrm{~N}_{4}$ with the purpose of developing a materials database suitable for estimating the service life of a ceramic diesel exhaust valve. The first two NT551 vintages were not extensively tested. There was nearly a 30\% decrease in the characteristic strength between 20 and $850^{\circ} \mathrm{C}$ from the first vintage of NT551 when tested at $36 \mathrm{~N} / \mathrm{s}$ (see Table 5.1). Subsequent investigation by SGNIC of vintages one, two, and three lead to the discovery that the HIP'ing pressure for vintage one was inadvertently $10 \%$ of the process specification pressure. Initial test results from the second NT551 vintage showed only a $10 \%$ increase in the characteristic strength at $850^{\circ} \mathrm{C}$ over the first vintage tested. Process modifications aimed at improving the strength of NT551 at $850^{\circ} \mathrm{C}$ were introduced in a third vintage and it was delivered to ORNL. This version of NT551, vintage three, was therefore extensively examined for the life prediction program.

Table 5.1 illustrated that at each test condition the three NT551 vintages had essentially the same uncensored Weibull parameters (i.e., mechanical properties). The characteristic strength at $20^{\circ} \mathrm{C}$ for vintages one, two, and three were equivalent at a $95 \%$ confidence level, and at $850^{\circ} \mathrm{C}$, the characteristic strength for the three vintages were deemed equivalent at a $95 \%$ confidence level. Independent of temperature, 5 out of 6 uncensored Weibull moduli estimates from the three vintages were also found to be equivalent; the Weibull modulus for vintage one at $20^{\circ} \mathrm{C}$ was approximately $60 \%$ greater than the average of the other 5 uncensored Weibull moduli. The higher Weibull modulus for vintage one was due in part to a greater number of failures from the dominant failure mode. The dominant mode of failure (SUR1-MD) was $86 \%$ for vintage one, $80 \%$ for vintage two, and $73 \%$ for vintage three.

Process improvements made during the study to the HIP'ing stage and other control parameters had little influence on the strength of NT551 at $850^{\circ} \mathrm{C}$. The same decrease as a function of temperature was observed in the characteristic strength for all three vintages. Changes to the HIP'ing pressure parameter had little influence on the strength of NT551. Vintage one was HIP'ed at one-tenth of the pressure that was applied to vintage two and three, and the characteristic strengths of the three vintages were essentially equivalent for each test condition. Thus the benefit for further densification of the material (i.e. making it stronger) by HIP'ing is questionable.

The strength results from specimen testing at $850^{\circ} \mathrm{C}$ also emphasized the importance of determining mechanical properties for life prediction at component service temperatures. At the same loading rate, strength distributions of data generated at $850^{\circ} \mathrm{C}$ were significantly lower than strength distributions made using $20^{\circ} \mathrm{C}$ strength data (Figures 5.34-5.36). 
The application of censored data to Weibull and lognormal distributions illustrated that both distributions represented the data equally well (see Section 5.1). There was no significant difference in presenting the strength data using either a Weibull or a lognormal distribution. However, the Weibull distribution was chosen to represent the NT551 generated strength data since it has been used more extensively to model the strength of ceramic materials.

NT551 was not a homogeneous material as outlined in Section 4.1. There were dark reaction layer regions up to $1 \mathrm{~mm}$ in depth that encompassed the perimeter of the as-received stock material. Included in this reaction layer were a higher density of white snowflake-like regions and black agglomerates. This is clearly illustrated in Figure 4.5 (ASTM C 1161-B cross-section), Figure 4.6 (cylindrical stock cross-section), Figure 5.13 (polished specimen surface), Figure 5.31 (unknown failure example), and Figure 5.69 (fracture toughness specimen). As presented in the fractography Section 5.2.2, these inhomogeneities were often times the strength-limiting flaw of the test specimens.

Estimating the strength of the valve component from test specimen data was questionable since they were fabricated from an inhomogeneous material. The Weibull functional relationship of scaling size-to-strength assumed that the ceramic material was homogeneous, the strength-limiting flaws were uniformly distributed, and that flaws did not interact with each other (i.e., no crack coalescence). Since NT551 did not have a uniform flaw distribution, the size-to-strength calculations were likely in error. This was evident in Figures 5.88-5.91; a poor correlation existed among the three failure probability predictions for the valve when three different test specimen data sets were used as input.

The nature of the differing specimen geometries yielded further insights into the differing strength-limiting flaws, NT551's inhomogeneity, and how time-dependent loading influenced the dominant flaw type. The modified ORNL tension specimens were machined to a $3.5 \mathrm{~mm}$ gage diameter from an approximate $11 \mathrm{~mm}$ diameter stock material, that removed virtually all of the reaction layer region from the specimen. Comparing fractographic results of the modified ORNL tension specimens (Table 5.25) with the ASTM C 1161-B transversely machined flexure specimens (Table 5.2) indicated that the distribution of VOL-SF and VOL-AGG volume flaws in these specimens were nonuniform. At the fastest loading rate of $36 \mathrm{~N} / \mathrm{s}$, the ASTM C 1161-B flexure specimens had $27 \%$ failures due to VOL-SF while the modified ORNL tension specimens had no VOL-SF failures. At the slowest loading rate of $0.0036 \mathrm{~N} / \mathrm{s}$, the ASTM C 1161-B flexure specimens had $17 \%$ failures due to VOL-SF while the modified ORNL tension specimens had $8 \%$ of its failures due to VOL-SF. In addition, the tension specimens had $8 \%$ of their failures due to VOL-AGG while the flexure specimens had no such failures. At the middle load rate of $0.36 \mathrm{~N} / \mathrm{s}$, the ASTM C 1161-B flexure specimens had 7\% failures due to VOL-SF while the modified ORNL tension specimens had $8 \%$ failures due to VOL-SF. Two of the three load rate comparisons 
indicated that the modified ORNL tension specimens had a different flaw distribution (a lower density of strength-limiting VOL-SF and VOL-AGG flaws) than the ASTM C 1161-B flexure specimens.

\subsection{Material Properties of NT551}

The characteristic strength of NT551 was dependent on the temperature and the loading rate. This was illustrated in Figure 5.33, which compared the uncensored characteristic strength of ASTM C 1161-B transversely machined flexure bars at 20,700 , and $850^{\circ} \mathrm{C}$ and at $36,0.36$, and $0.0036 \mathrm{~N} / \mathrm{s}$. At 20 and $850^{\circ} \mathrm{C}$, there were significant decreases in the characteristic strength as the load rates decreased from $36 \mathrm{~N} / \mathrm{s}$ to $0.36 \mathrm{~N} / \mathrm{s}$ and then to $0.0036 \mathrm{~N} / \mathrm{s}$. This was not true at $700^{\circ} \mathrm{C}$, where the characteristic strength was invariant to the loading rate. The significant decrease in the characteristic strength between 20 and $700^{\circ} \mathrm{C}$ was due to the temperature change, independent of the loading rate. Between 700 and $850^{\circ} \mathrm{C}$, a significant decrease in the characteristic strength was observed only at the slowest load rate of $0.0036 \mathrm{~N} / \mathrm{s}$.

The ASTM C 1161-B longitudinally machined flexure specimens demonstrated the same strength degradation trends as observed with the ASTM C 1161-B transversely machined flexure specimens when the temperature was increased from 20 to $850^{\circ} \mathrm{C}$. There was approximately a $50 \%$ decrease in the characteristic strength at the $36 \mathrm{~N} / \mathrm{s}$ loading rate as illustrated in Figure 5.49 between 20 and $850^{\circ} \mathrm{C}$.

The uncensored Weibull moduli for the ASTM C 1161-B longitudinally machined specimens were essentially the same for 7 of the 9 test conditions, indicating that a change in the failure mechanism had occurred for two of the sets. The Weibull modulus is a parameter that determines the shape of the density function, as illustrated in Section 5.1, and is a measure of the variability in the data. The uncensored Weibull moduli for the ASTM C 1161-B transversely machined flexure bars tested at 20,700 , and $850^{\circ} \mathrm{C}$ and at $36,0.36$, and $0.0036 \mathrm{~N} / \mathrm{s}$ are shown in Figure 5.32. No trends are observed for Weibull moduli with regard to either temperature or loading rate. However, for two test conditions $\left(850^{\circ} \mathrm{C}\right.$ at $0.36 \mathrm{~N} / \mathrm{s}$ and $\left.0.0036 \mathrm{~N} / \mathrm{s}\right)$ the Weibull moduli were significantly lower in value, indicating that an increase in the variability of the strength data had occurred, and that a different dominant failure mechanism was activated.

Machining direction relative to the maximum applied tensile load influenced the strength of ASTM C 1161-B flexure bars, as shown in Figures 5.52 and 5.53. The strength dependence of NT551 on machining direction was found to be anisotropic at $20^{\circ} \mathrm{C}$ and isotropic at $850^{\circ} \mathrm{C}$. At $20^{\circ} \mathrm{C}$ and $36 \mathrm{~N} / \mathrm{s}$, the characteristic strength of the longitudinally machined specimens was approximately $20 \%$ higher for than transversely machined specimens. Between 20 and $850^{\circ} \mathrm{C}$ and at the same loading rate the characteristic strength decreased approximately $50 \%$ for the 
longitudinally machined specimens (Figure 5.49), and $30 \%$ for the transversely machined specimens (Figure 5.37). At $850^{\circ} \mathrm{C}$, the characteristic strengths of the longitudinally and the transversely machined specimens were also equivalent and approximately $565 \mathrm{MPa}$. The uncensored Weibull moduli for the ASTM C 1161-B longitudinally and transversely machined specimens tested at $36 \mathrm{~N} / \mathrm{s}$ were essentially equivalent at 20 and $850^{\circ} \mathrm{C}$.

NT551 was susceptible to slow crack growth at 20,700 , and $850^{\circ} \mathrm{C}$. The dynamic fatigue results in Section 5.3.6 indicated slow crack susceptibility regardless of the test specimen geometry (rectangular flexure, cylindrical flexure, and cylindrical tension) and corresponding test procedure. This was clearly illustrated in Figures 5.63-5.65.

The slow crack growth susceptibility was influenced by the density of inhomogeneities at $850^{\circ} \mathrm{C}$ but not at 20 or $700^{\circ} \mathrm{C}$ (see Figure 5.62). The slow crack growth parameter for the ASTM C 1161-B flexure bar was equivalent at 20 and $700^{\circ} \mathrm{C}$. At $850^{\circ} \mathrm{C}$, the slow crack parameter for the ASTM C 1161-B flexure bar showed a significant increase in the slow crack growth susceptibility. The ASTM C 1161-B flexure bar contained a greater density of inhomogeneities when compared to the other two test specimens.

The results from the chevron $v$ notch tests indicated that the fracture toughness of NT551 was independent of temperature between 20 and $850^{\circ} \mathrm{C}$ and had an average value of $6.0 \mathrm{MPa} V_{\mathrm{m}}$ (see Table 5.29). The fracture toughness reported by SGNIC was $7.0 \mathrm{MPa} V \mathrm{~m}$, and this difference may be due in part to the two different test methods (chevron $\mathrm{v}$ notch and indentation strength) that were used to obtain the fracture toughness values (see Table 4.1).

The largest discrepancy between data generated from this study and data provided by SGNIC concerned the uncensored characteristic strength and Weibull moduli for the longitudinally machined ASTM C 1161-B specimens tested at $850^{\circ} \mathrm{C}$, see Table 5.30. At this temperature, the characteristic strength determined by SGNIC was $932 \mathrm{MPa}$ while from this study the strength was assessed at $558 \mathrm{MPa}$, a difference of nearly $40 \%$. The uncensored Weibull moduli were also significantly greater than found from this study. The uncensored Weibull moduli at the load rate of $36 \mathrm{~N} / \mathrm{s}$ were 11.9 at $20^{\circ} \mathrm{C}$ and 6.3 at $850^{\circ} \mathrm{C}$, a decrease of nearly $50 \%$. SGNIC reported a Weibull moduli between 20 and 30 at $22^{\circ} \mathrm{C}$ and greater than 20 at $850^{\circ} \mathrm{C}$. The only uncensored Weibull moduli determined from this study that agreed with the SGNIC data came from different test specimens; vintage one ASTM C 1161-B transversely machined specimens tested at $20^{\circ} \mathrm{C}$ (Table 5.1) that had an uncensored Weibull modulus of 22, and two of the three cylindrical flexure specimen data sets tested at $20^{\circ} \mathrm{C}$ that had Weibull modulus between 20 and 30 (Table 5.19). The reasons for the discrepancies in the characteristic strength values are presently unknown; however, a plausible explanation for the differences in Weibull moduli may be related to machining techniques. The high Weibull moduli reported by SGNIC indicated that perhaps only one failure mechanism was dominant. For example, the censored Weibull modulus for the ASTM C 1161-B 
longitudinally machined specimens tested at $20^{\circ} \mathrm{C}$ and $36 \mathrm{~N} / \mathrm{s}(\mathrm{m}=29)$ agrees with the SGNIC data. This study identified four different concurrent failure populations for NT551 while the results of any fractographic analysis by SGNIC were not known.

The centerless machining of the cylindrical specimens created a unique extrinsic strengthlimiting flaw (SUR2-MD) such that all 90 cylindrical flexure specimens failed from it, see Sections 5.2 and 5.3.4. The uniqueness of this flaw type was believed to be due to the extensive subsurface machining damage not observed on the other test specimens, and relatively deeper machining grooves (and rougher surface finish). Figure 5.25 illustrated the subsurface microcracking for a cylindrical flexure specimen If the specimens tested by SGNIC incurred the same subsurface microcracking damage that was observed in the cylindrical flexure specimens, the flaw populations would have greater similarity such that the Weibull moduli would show closer agreement.

The centerless machining process could provide an economical means to remove the reaction layer region (and associated strength-limiting flaws) for axisymmetric geometries made from processed NT551. Stock material for the test specimen or ceramic component would initially be oversized when cast so that the reaction layer may be machined away without compromising component dimensions. After removing the reaction layer region with the centerless process, the specimen or component would resume previous employed machining operations. The added machining process may be justified by producing a homogeneous ceramic material with improved mechanical properties.

The difference in the characteristic strength at $850^{\circ} \mathrm{C}$ between the presently generated data and SGNIC are thought to be a result of different preparation methods of the test specimens from the processed billets. In this study, a significant portion of the $850^{\circ} \mathrm{C}$ test specimens included a reaction layer region (see Figure 4.5), while it is not known whether the specimens tested by SGNIC contained any such reaction layer region. It is plausible that by the removal of the reaction layer (and the majority of the associated material inhomogeneities) from the test specimens that the flexure strength of NT551 might be similar to the values reported by SGNIC in Table 5.30.

The surface profilometry results indicated that using the same 320 diamond grit wheel in three different machining process will not necessarily yield the same surface finish. In addition, no correlation was observed between the strength and the relative surface roughness for the specimens made from NT551. The modified ORNL tension specimens were made using a cylindrical grinder while the ASTM C 1161-B flexure specimens were made using a traditional surface grinding method. The cylindrical flexure specimens were made using a centerless machining process (see Figure 4.4). In Figure 5.70 the average surface roughness for the modified ORNL tension specimen was $0.12 \mu \mathrm{m}$, while the surface roughness of the ASTM C 1161-B flexure specimen 
was $0.22 \mu \mathrm{m}$, and the cylindrical flexure specimen was $0.46 \mu \mathrm{m}$. SEM Images taken of the surfaces agree with the surface profilometry measurements (Figures 5.71, 5.72, and 5.73).

\subsection{Fractography of NT551}

Fractographic analyses of NT551 $\mathrm{Si}_{3} \mathrm{~N}_{4}$ identified four unique mechanisms of failure, of which three were the strength-limiting modes for the ASTM C 1161-B transversely machined flexure bars. There were two intrinsic flaws, one due to compositional inhomogeneities and the other due to agglomerates. The other flaw type was extrinsic and due to surface damage from the machining process. Digital images and detailed descriptions of these failure mechanisms are presented in Section 5.2.2.

The dominant failure modes depended on temperature and loading rate. At $20^{\circ} \mathrm{C}$, the dominant mode of failure was SUR1-MD at all three loading rates. Between 20 and $700^{\circ} \mathrm{C}$, the dominant strength-limiting flaw changed from a surface-induced failure to a volume-induced failure. At $700^{\circ} \mathrm{C}$ the dominant mode of failure was VOL-SF at all three loading rates; the change in the dominant failure mechanism was only due to a change in the temperature, not loading rate. At $850^{\circ} \mathrm{C}$ and $36 \mathrm{~N} / \mathrm{s}$, the dominant mode of failure was SUR1-MD while at the load rates of 0.36 and $0.0036 \mathrm{~N} / \mathrm{s}$, the dominant mode of failure was VOL-SF. Between 700 and $850^{\circ} \mathrm{C}$, a change in the strength-limiting flaw was observed only when the loading rates decreased; volume-induced flaws became the strength-limiting mode of failure over the previous dominant surface-induced flaws.

Machining direction also influenced the dominant failure mode as a function of temperature. For the longitudinally machined ASTM C $1161-\mathrm{B}$ specimens tested at $36 \mathrm{~N} / \mathrm{s}$, there was no change in the dominant mode of failure between 20 and $850^{\circ} \mathrm{C}$ (see Tables 5.17-5.18). The dominant mode of failure for both test conditions was VOL-SF. However at $20^{\circ} \mathrm{C}$ there were 8 failures attributed to SUR1-MD, and at $850^{\circ} \mathrm{C}$ there were no other failure types identified except VOL-SF. Thus an increase of approximately $28 \%$ in the VOL-SF failure mode was observed between the temperatures of 20 and $850^{\circ} \mathrm{C}$ for the longitudinally machined specimens.

The temperature parameter had a greater influence over the loading rate parameter in activating any given dominant failure mechanism. Tests with cylindrical flexure and the modified ORNL tension specimens were conducted at three loading rates and only at $20^{\circ} \mathrm{C}$. Failure mechanism changes, as seen with the ASTM C 1161-B flexure specimens, were not observed with these two data sets.

NT551 undergoes a change of state as a function of temperature between 20 and $700^{\circ} \mathrm{C}$, and as functions of temperature and loading rate between 700 and $850^{\circ} \mathrm{C}$. The changes in state are evidenced by the nature of the differing dominant failure modes between 20 and $700^{\circ} \mathrm{C}$, and between 700 and $850^{\circ} \mathrm{C}$ (see Tables 5.2-5.4). 
A significant decrease in the scale parameter for intrinsic flaws (VOL-SF) along with little change in the scale parameter for extrinsic flaws (SUR1-MD) supports the notion that a change of state was occurring with NT551. The parameters that activated the proposed change of state greatly influenced the volume or bulk of the material and not the surface. Little change in the scale parameter was observed for the SUR1-MD failure mode as the temperature was increased. At the same loading rate and $20^{\circ} \mathrm{C}$, the ASTM C $1161-\mathrm{B}$ transversely machined specimens had a scale parameter of $1010 \mathrm{MPa} \mathrm{mm}{ }^{2 / m}$ for the SUR1-MD failure mode (Table 5.6). At $850^{\circ} \mathrm{C}$, the SUR1-MD failure mode for the ASTM C 1161-B transversely machined specimens had a scale parameter of $925 \mathrm{MPa} \mathrm{mm}^{2 / \mathrm{m}}$ (Table 5.12).

NT551's anisotropic strength behavior at $20^{\circ} \mathrm{C}$ and isotropic strength behavior at $850^{\circ} \mathrm{C}$ was likely a result of a change of state in the material. Figures 5.52 and 5.53 illustrate this behavioral shift for transversely and longitudinally machined ASTM C 1161-B flexure specimens.

At $36 \mathrm{~N} / \mathrm{s}$ and $20^{\circ} \mathrm{C}$, the ASTM C 1161-B longitudinally machined specimens predominantly failed from VOL-SF (Table 5.16) while the ASTM C 1161-B transversely machined specimens predominantly failed from SUR1-MD (Table 5.2). At the same loading rate, temperature was shown to have a strong influence on the scale parameter of VOL-SF failure types. Table 5.17 lists the scale parameter as $979 \mathrm{MPa} \mathrm{mm}{ }^{3 / m}$ for VOL-SF failures at $20^{\circ} \mathrm{C}$ while Table 5.18 lists the scale parameter as $588 \mathrm{MPa} \mathrm{mm}{ }^{3 / m}$ for VOL-SF failures at $850^{\circ} \mathrm{C}$, a significant decrease due to temperature.

The scatter in the censored strength data for ASTM C 1161-B transversely machined flexure bars was greater for the VOL-SF failure mode than for the SUR1-MD failure mode. The Weibull modulus was 18.1 for the ASTM C 1161-B flexure bars tested at $20^{\circ} \mathrm{C}$ and $0.0036 \mathrm{~N} / \mathrm{s}$ and where 24 of the 29 specimens failed from SUR1-MD (Table 5.8). The Weibull modulus was 5.2 for the ASTM C $1161-B$ flexure bars tested at $850^{\circ} \mathrm{C}$ and $0.0036 \mathrm{~N} / \mathrm{s}$ and where 30 out of 40 specimens failed from VOL-SF (Table 5.14). A significant increase in data variability occurred when the failure mode changed from SUR1-MD to VOL-SF. The large increase in data variability was again indicative of a change of state occurring with NT551.

Strength data obtained from the cylindrical flexure specimens were unique when compared to the other test specimens. The centerless machining process used to make the cylindrical specimens produced unique machining patterns on the surface that were unlike the ASTM C 1161-B flexure and modified ORNL tension specimens. The uniqueness of the cylindrical flexure specimen single failure mode was supported by the consistently high Weibull moduli estimated for the three data sets, see Table 5.19.

The importance of including more than one type of test specimen in the materials database is realized when comparing the fractographic results in Tables 5.20 and 5.25. The cylindrical flexure and the tension specimens were machined removing virtually all of the reaction layer region. The 
cylindrical specimens did not exploit any volume-induced flaws while the tension specimens had nearly 17 percent of its failures due to intrinsic flaw types. In addition, the tension specimens exploited both volume-induced failure modes identified in this study.

\section{4 $\mathrm{NT551}^{\mathrm{Si}_{3} \mathrm{~N}_{4}}$ Valves}

The as-received S149 valves followed the same strength distributions trends as the ASTM C 1161-B flexure tests conducted at $20^{\circ} \mathrm{C}$. The characteristic strength of the as-received longitudinally ground valves was approximately $35 \%$ higher than the characteristic strength of the as-received transversely ground valves (see Figures 5.84 and 5.85). The dominant mode of failure for the as-received transversely machined valves presented in Table 5.31 was extrinsic; surfaceinduced from machining damage. This was the same type of failure for the $20^{\circ} \mathrm{C}$ inert strength tests for the ASTM C 1161-B transversely machined flexure specimens (Table 5.2), the cylindrical flexure specimens (Table 5.20), and the modified ORNL tension specimens (Table 5.25). The dominant mode of failure for the as-received longitudinally machined valves was VOL-SF (Table 5.31), which was the same dominant mode of failure for the longitudinally machined ASTM C 1161-B flexure specimens (Table 5.16).

Intuitively one would expect good agreement between predictions made from test data and experimentally derived valve strength data since the valve test data had the same strength and fractographic trends that were observed with the test specimens. However, this was not the case. A poor correlation existed between prediction made from test data and the actual valve strength data due to the inhomogeneities found with NT551.

The engine-tested valves may have undergone a change of state due to engine testing. Comparing Tables 5.32 and 5.31, the transversely machined engine-tested valves predominantly failed from VOL-SF flaws while the transversely machined as-received valves failed from surfaceinduced flaws from machining damage. This change in failure mechanism was the same trend observed in the ASTM C 1161-B flexure specimens. The longitudinally machined as-received and the longitudinally machined engine-tested valves did not show this trend since both valve sets failed from only VOL-SF.

The change in the state of the NT551 material in the engine-tested valves resulted in a decrease in their strength. The characteristic strength of the transversely machined engine-tested valves was approximately $8 \%$ less than the characteristic strength of the transversely machined as-received valves (see Figures 5.84 and 5.86). The characteristic strength for the longitudinally machined engine-tested valves was approximately $26 \%$ less then the characteristic strength of the as-received valves (see Figures 5.85 and 5.87). 
The locations of many of the strength-limiting flaws for the engine-tested valves were not at the surface but in the bulk of the valve material. The actual characteristic strengths for the longitudinally and transversely machined engine-tested valves are likely to be less than reported. This region was likely at a lower stress state than the maximum tensile stress calculated at the surface. Examples of fracture origins located below the surface are illustrated in Figures 5.82 and 5.83.

The transversely machined 1000 hour engine-tested valves had greater strength retention than the longitudinally machined 166 hour engine-tested valves. Assuming that each valve set was tested using the same test parameters, then it is likely that the change in state occurred more rapidly with the 166 hour engine-tested valves than the 1000 hour engine-tested valves. The improved strength retention from the 1000 hour tested valves is likely due in part to a processing change with NT551. The valves subjected to the 1000 hour engine-tests were delivered to DDC in May 1997 (vintage one or two or before) while the valves subjected to the 166 hour tests were delivered in the Spring of 1998 (vintage three and beyond). Due to the proprietary nature of the valve engine tests, additional information regarding these valves was not available, and therefore does not allow for further relevant comparisons.

\subsection{Life Prediction and Fatigue Performance of $\mathrm{NT551} \mathrm{Si}_{3} \mathrm{~N}_{4}$ Valves}

This study has shown that the inhomogeneity of the NT551 $\mathrm{Si}_{3} \mathrm{~N}_{4}$ ultimately influenced the ability to produce a well-correlated life prediction. The life prediction algorithm assumed the ceramic material of interest was homogeneous at a macroscopic level and it also required that the strength-limiting flaws are uniformly distributed throughout the material. This study has shown that both of these assumptions were violated.

Removing different amounts of the reaction layer region by machining yielded different flaw population densities for each test specimen geometry and for the valves. The machining processes used to make the test specimens and the valves were different in that each removed different amounts of the reaction layer region, and thus many of the strength-limiting material inhomogeneities. For example, the machining processes that made the cylindrical flexure specimens and the modified ORNL tension specimens removed nearly all of the reaction layer. The ASTM C 1161-B flexure specimens removed very little of the reaction layer region while the valves appeared to have a portion of the reaction layer removed, somewhere between the amount removed for the tension specimens and the ASTM C 1161-B flexure bars.

The failure probabilities calculated using three different test specimen strength data sets to predict the inert strength of the valves were more conservative than the experimentally determined valve strength data. This is likely a result of the different flaw population densities that were 
nonuniformly distributed for each of the three test specimens that were used as input in the life prediction algorithm. Nonuniformly distributed flaw population densities of the valves were not the same as in the test specimens which further amplified that the assumptions were violated.

The life prediction algorithm requires that test specimens represent the same surface conditions as the component in design analysis too. The surface roughness of the as-received transversely machined valves was measured as $0.78 \mu \mathrm{m}$, which was significantly greater than any of the surface roughness measurements of the test specimens (see Figure 5.70). Intuitively, one would anticipate that the rougher valve surface finish would result in lower strength; however, this was not the case. The transversely machined valves were greater in strength than any of the predictions made based on test specimen data. Ott (1997) found that strength values from surface-induced failures may depend upon an assessment of the subsurface machining damage in addition to actual surface roughness. However, methods to assess the subsurface machining damage before initiating failure have not been fully developed. A plausible explanation for the lack of correlation between the surface roughness and strength may be due in part to not having an assessment of the subsurface damage for the test specimens and the valves tested. This further supports the argument that the distribution of strength-limiting flaws for the valves were not the same as any of the test specimens in the study.

The fatigue curves presented in Section 5.5.5 are based on uncensored slow crack growth data and show the valve's expected lifetimes under a constant load. The ASTM C 1161-B transversely machined specimens tested at $20^{\circ} \mathrm{C}$ produced very similar fatigue curves to the cylindrical flexure specimens, see Figures 5.92 and 5.94. At $850^{\circ} \mathrm{C}$, the ASTM C 1161-B transversely machined flexure specimens (Figure 5.93) produced a copy of the $20^{\circ} \mathrm{C}$ tests shifted to the left, representing lower fatigue resistant capabilities. The modified ORNL tension specimen shown in Figure 5.95 produced the least conservative fatigue prediction curves with a notably steeper slope. This may be due in part to the smaller number of specimens tested.

The fatigue model used in this study shows a dependence on how the test specimen was loaded to failure. The fatigue curves based on the flexure loading have equivalent Weibull moduli and appear as shifted copies of each other while the fatigue curves based on the tension data have a lower Weibull modulus and are more conservative in their fatigue prediction. Thus by using this fatigue model, a more conservative prediction is presented using tension data over flexure data.

The slow crack growth formulation does not include parameters that model variable loading or a change of state in the material due to elevated temperature environments or reduced loading rates, and therefore does not effectively predict fatigue under such circumstances. The slow crack growth fatigue plots serve as a first approximation to estimating the service life of the valve component. 
Although the slow crack growth formulation does not account for several experimental observations, it is doubtful that a model would be developed incorporating these phenomena. Of greater importance would be investigating the processing parameters to improve the fabrication of NT551 so that it would not exhibit these undesirable characteristics.

The results of the life prediction exercise should not be interpreted as a limitation of the algorithm. Instead the results emphasize the requirements that the ceramic materials for the test specimen and the design component must have the same flaw population(s), and that those flaw population(s) must be uniformly distributed. 


\section{CONCLUSIONS}

NT551 undergoes a change of state when exposed to elevated temperatures and when subjected to slow loading rates. This is supported by the following experimental observations:

- The dominant mechanism of failure changed from an extrinsic to an intrinsic flaw type when the temperature increased and the loading rate decreased.

- The strength of NT551 was found to significantly decrease as functions of increasing temperature and decreasing loading rate.

- The variability of the strength data significantly increased as the temperature increased.

The failure probability predictions based on test specimen strength data as input in the life prediction algorithm were conservative and did not correlate well with valve strength data for the following reasons.

- NT551 was inhomogeneous due to insufficiently controlled material processing.

- The strength limiting failure mechanisms for NT551 were not homogeneously distributed as assumed by the life prediction algorithm.

- Because of this nonuniformity, the strength limiting flaw populations exploited by the test specimens were not the same as the strength limiting flaw populations found for the valves. The life prediction algorithm requires that the test specimens have the same homogeneously distributed flaw population(s) as the design component. 


\section{SUGGESTIONS FOR FUTURE WORK}

Due to the potential impact of ceramic components on the automotive industry, a life prediction exercise similar this study should be repeated at a future date. However, in order to gain further knowledge into the life prediction algorithm and the implementation of ceramics in load bearing applications, the study should focus on components that are made from $\mathrm{Si}_{3} \mathrm{~N}_{4}$ whose materials processing operations have matured. The process operations need to consistently manufacture ceramic bulk materials that are homogeneous and isotropic.

Additional criteria for the ceramic valves for selecting a material beyond the requirements from this study include the following:

1) The inert strength of the material should be specified (e.g. $900 \mathrm{MPa}$ ) at the operating temperatures of the design component.

2) The slow crack growth parameter, $N$, should be specified (e.g. $N>50$ ), and should be invariant to test parameters such as temperature.

3) The strength and fatigue of the material in service environments and at operating temperatures should be considered.

This study demonstrated that test specimens must be of the same material composition and have the same uniform distribution of strength-limiting failure mechanisms as the design component. There are a few assurance tests that would confirm the test specimen as an accurate representative of the design component before beginning a life prediction study. If these assurance tests result in finding differences between the test specimen and the design component, then their conformity is questionable, and the success of subsequent life predictions would be suspect. Assurance testing should include the following:

4) Perform and compare $x$-ray diffraction from samples taken from the test specimen and the design component.

5) Perform and compare chemical analyses from samples taken from the test specimen and the design component.

6) Prepare sample cross-sections and capture optical and SEM digital images of the test specimen and the design component. Commercially available digital imaging software can be utilized to quantify and compare the homogeneity of the cross-sections. 
Future studies beyond this dissertation should include examining manufacturing methods for $\mathrm{Si}_{3} \mathrm{~N}_{4}$ that result in better bulk homogeneity and isotropic properties. Studies should also be funded examining the failure mechanisms of strength limited by surface flaws and the phenomena (i.e., residual stress, subsurface microcracking, etc.) that influence them. For example, a study that compares the grinding forces for each process presented in this dissertation to the resulting surface profilometry could provide additional insight into the mechanisms of surface failures. As demonstrated in this study as well as others, the influence of the surface state and strength are not well understood and additional knowledge is warranted. For the more ambitious researcher, studies should investigate fatigue in ceramic materials, since this phenomenon is not well understood. This is reflected by the fact that little data is available in the literature and testing for fatigue is quite laborious. 


\section{REFERENCES}

Allain, M., 1998, personal communication, Detroit Diesel Corp.

An Assessment of the Benefits of Ceramics in Automotive and Truck Engines, 1993, E. Mount, and D. Virag, eds., Automotive Consulting Group, Ann Arbor, MI.

Andrews, M. J., Wereszczak, A. A., and Breder, K., 1999, "Predictions of the Inert Strength Distribution of $\mathrm{Si}_{3} \mathrm{~N}_{4}$ Diesel Valves," in press, Ceramic Engineering and Science Proceedings, Vol. 20.

Andrews, M. J., "Life Prediction and Mechanical Reliability of NT551 Silicon Nitride," Ph.D. Thesis, Department of Mechanical Engineering, New Mexico State University, 1999.

Annual Energy Review 1998, 1998, K. E. Seiferlien, dir., DOE / EIA-0384(98), U.S. Department of Energy, Energy Information Administration, Washington, DC, pp. 1-113.

ANSYS User's Manual, Procedures, 1994, Swanson Analysis Systems, Inc., Houston, PA, Vol. I, Revision 5.0, pp. 11.22-11.23.

Ashby, M. F., and Jones, D. R. H., 1986, "Engineering Materials 2, An Introduction to Microstructures, Processing, and Design," International Series on Materials Science and Technology, Volume 39, Pergamon Press, Oxford, UK, pp. 147-178.

Asnani, M., and Kuonen, F. L., 1986, "Ceramic Valve and Seat Insert Performance in a Diesel Engine," Society of Automotive Engineers, Paper No. 850358.

ASTM C 1161, "Standard Test Method for Flexural Strength of Advanced Ceramics at Ambient Temperature," 1998, R. F. Allen, et al., eds., 1998 Annual Book of ASTM Standards, American Society for Testing and Materials, Vol. 15.01, Philadelphia, PA, pp. 304-313.

ASTM C 1239, "Standard Practice for Reporting Uniaxial Strength Data and Estimating Weibull Distribution Parameters for Advanced Ceramics," 1998, Allen, R. F., et al., eds., 1998 Annual Book of ASTM Standards, American Society for Testing and Materials, Vol. 15.01, Philadelphia, PA, pp. 354-371.

ASTM C 1273, "Standard Test Method for Tensile Strength of Monolithic Advanced Ceramics at Ambient Temperatures," 1998, R. F. Allen, et al., eds., eds., 1998 Annual Book of ASTM Standards, American Society for Testing and Materials, Vol. 15.01, Philadelphia, PA, pp. 383-400.

ASTM C 1322, "Standard Practice for Fractography and Characterization of Fracture Origins in Advanced Ceramics," 1998, R. F. Allen, et al., eds., 1998 Annual Book of ASTM Standards, American Society for Testing and Materials, Vol. 15.01, Philadelphia, PA, pp. 487-528.

ASTM C 1368, "Standard Test Method for Determination of Slow Crack Growth Parameters of Advanced Ceramics by Constant Stress-Rate Flexural Testing at Ambient Temperatures," 1998, R. F. Allen, et al., eds., 1998 Annual Book of ASTM Standards, American Society for Testing and Materials, Vol. 15.01, Philadelphia, PA, pp. 688-696. 
ASTM C PS 70, "Provisional Test Method for Determination of Fracture Toughness of Advanced Ceramics at Ambient Temperatures," 1998, R. F. Allen, et al., eds., 1998 Annual Book of ASTM Standards, American Society for Testing and Materials, Vol. 15.01, Philadelphia, PA; pp. 789-823.

Batdorf, S. B., "Some Approximate Treatments of Fracture Statistics for Polyaxial Tension," 1977, International Journal of Fracture, Vol. 13, No. 1, pp. 5-11.

Batdorf, S. B., and Crose, J. G., "A Statistical Theory for the Fracture of Brittle Structures Subjected to Nonuniform Polyaxial Stresses," 1974, Journal of Applied Mechanics, Vol. 41, No. 2 , pp. 459-464.

Batdorf, S. B., and Heinisch, H. L., Jr., "Weakest Link Theory Reformulated for Arbitrary Fracture Criterion," 1978, Journal of the American Ceramic Society, Vol. 61, No. 7-8, pp. 355-358.

Beer, F. P., and Johnston, E. R., Jr., 1992; Mechanics of Materials, 2nd Ed., McGraw-Hill, Inc., New York, NY, pp. 700-703.

Bluhm, J. I., 1975, "Slice Synthesis of a Three-Dimensional 'Work-of-Fracture' Specimen for Brittle Material," Engineering Fracture Mechanics, No. 7, pp. 593-604.

Boulet, J. A. M., 1988, "An Assessment of the State of the Art in Predicting the Failure of Ceramics," Final Report, ORNL/Sub/86-57598/1, Oak Ridge National Laboratory, Oak Ridge, TN.

Bright, E., Eckalbar, J. F., McEntire, B. J., Pujari, V. K., and Tricard, M., "Advanced Ceramic Manufacturing of SiAlON Exhaust Valves," 1996, Society of Automotive Engineers, Paper No. 960051.

Corum, J. M., Battiste, R. L., Gwaltney, R. C., and Luttrell, C. R., 1996, "Design Analysis and Testing of Ceramic Exhaust Valve for Heavy Duty Diesel Engine," CRADA Y12 92-0088 with Detroit Diesel Corporation, ORNLIM-13253, Oak Ridge National Laboratory, Oak Ridge, TN.

Crowder, M. J., Kimber, A. C., Smith, R. L., and Sweeting, T. J., 1991, Statistical Analysis of Reliability Data, Chapman \& Hall, London, UK, pp. 1-116.

Cuccio, J. C., Brehm, P., Fang, H. T., Hartman, J., Meade, W., Menon, M. N., Peralta, A., Song, J. Z., Strangman, T., Wade, J., Wimmer, J., and Wu, D. C., 1995, "Life Prediction Methodology for Ceramic Components of Advanced Heat Engines, Phase 1," ORNL/Sub/89-SC674/1, Oak Ridge National Laboratory, Oak Ridge, TN.

Erdogan, F., and Sih, G. C., 1963, "Crack Extension in Plates Under Plane Loading and Traverse Shear," Of Basic Engineering, Vol. 85, pp. 519-527.

Evans, A. G., 1977, "A General Approach for the Statistical Analysis of Multiaxial Fracture," Joumal of the American Ceramic Society, Vol. 61, No. 7-8, pp. 302-308.

Hamminger, R., and Heinrich, J., 1993, "Development of Advanced Silicon Nitride Valves for Combustion Engines and Some Practical Experience on the Road," Proceedings of the Materials Research Society Symposia, Vol. 287, pp. 513-518.

Hellen, T. K., and Blackburn, W. S., 1975, "Calculation of Stress Intensity Factors for Combined Tensile and Shear Loading," International Journal of Fracture, Vol. 11, pp. 605-613. 
Huber, J., and Heinrich, J., 1987, "Ceramics in Internal Combustion Engines," Proceedings of the 2nd European Symposium on Engineering Ceramics, Nov. 23-24, 1987, pp. 203-228.

Ichikawa, M., 1991, "Proposal of an Approximate Analytical Expression of Maximum Energy Release Rate of a Mixed Mode Crack in. Relation to Reliability Evaluation of Ceramic Components," Japan Society Materials Science, Joumal, Vol. 40, pp. 224-227.

Jadaan, O. M., Powers, L. M., Nemeth, N. N., and Janosik, L. A., 1993, "Methodology to Predict Delayed Failure Due to Slow Crack-Growth in Ceramic Tubular Components Using Data from Simple Specimens," Journal of Engineering Materials and Technology-Transactions of the American Society of Mechanical Engineers, pp. 204-210.

Jenkins, M. G., Ferber, M. K., Martin, R. L., Jenkins, V. T., and Tennery, V. J., "Study and Analysis of the Stress State in a Ceramic Button-Head Tensile Specimen," 1991, ORNLTM/11767, Oak Ridge National Laboratory, Oak Ridge, TN, pp. 39-43.

Johnson C. A., 1979, "Fracture Statistics in Design and Application," Technical Report No. 79CRD212, General Electric Company, Schenectady, NY.

Johnson, L. G., 1959, "The Statistical Treatment of Fatigue Experiments," Research Laboratories, General Motors, Detroit, MI, pp. 44-50.

Johnson, L. R., Teotia, A. P. S., and Hill, L. G., 1983, "A Structural Ceramics Research Program: A Preliminary Economic Analysis," ANL/CNSV-38, Argonne National Laboratory, Argonne, IL.

Kabat, D. M., Garwin, I. J., Hartsock, D. L., 1988, "Ceramic Valve Analysis, Reliability, and Test Results," SAE Technical Paper Series, Society of Automotive Engineers, Paper No. 880670.

Kamo, R., 1991, "Adiabatic Diesel Engines," ASM Engineered Materials Handbook, Ceramics and Glasses, S. J. Schneider Jr., ed., Vol. 4, pp. 987-994.

Larsen, R. P., and Vyas, A. D., 1988, "The Outlook for Ceramics in Heat Engines: Results of a Worldwide Delphi Survey," Society of Automotive Engineers Transactions, Vol. 97, Sec. 2, pp. 328-350.

Linder, H. A., Caspers, B., Hennicke, J., Feuer, H., and Petezenhauser, I., 1998, "Non-destructive Evaluation of $\mathrm{Si}_{3} \mathrm{~N}_{4}$ Valves by Ultrasonic Testing," Ceramic Forum International, July, pp. 31-34.

McEntire, B. J., Wills, R. W., and Southham, R. E., 1993, "The Development and Testing of Ceramic Components in Piston Engines," ORNL/Sub/86X-SG15IV, Oak Ridge National Laboratory, Oak Ridge, TN.

Nemeth, N. N., Powers, L. M., Janosik, L. A., and J. P. Gyekenyesi, 1993, "Ceramic Analysis and Reliability Evaluation of Structures (CARES/LIFE), Users and Programmers Manual, NASA TP-2916, National Aeronautics and Space Administration, Cleveland, OH, pp. 1.1-1.12, 6A.1-6B.15.

Nondestructive Testing Handbook, 1982, R. C. McMaster, ed., 2nd Ed., American Society for Nondestructive Testing, ASM International, pp. 14-15. 
Norman J. A., and Bass, F. M., 1987, "A Diffusion Theory Model of Adoption and Substitution for Successive Generations of High-Technology Products," Management Science, Vol. 33, No. 9, pp. $1069-1086$.

Ott, R. D., 1997, "Influence of Machining Parameters on the Subsurface Damage of a HighStrength Silicon Nitride," Ph.D. thesis, The University of Alabama at Birmingham, Birmingham, AL, pp. 1-26.

Ott, R. D., Breder, K., Watkins, T. R., Ferber, M. K., and Rigsbee, J. M., 1997, "Characterization of Machining-Induced Sub-Surface Damage of a High Strength Silicon Nitride," Ceramic Engineering and Science Proceedings, Vol. 18, Issue 4, pp. 93-103.

Pattimore, J., Dewitte, C., Nishio, A., 1994, "Mass Production Process for Ceramic Valves," Proceedings of the International Symposium on Automotive Technology and Automation, Aachen, Germany, October 31 - November 4, 1994, pp. 221-227.

Powers, L. M., Starlinger, A., and Gyekenyesi, J. P., 1992, "Ceramic Component Reliability with the Restructured NASA / CARES Computer Program," NASA TM - 105856, National Aeronautics and Space Administration, Cleveland, $\mathrm{OH}$.

Pujari, V., 1998, personal communication, Saint Gobain / Norton Industrial Ceramics Inc.

Pujari, V., 1999, personal communication, Saint Gobain / Norton Industrial Ceramics Inc.

Richerson, D. W., 1982, Modern Ceramic Engineering, Marcel Dekker, Inc., New York, NY, pp. 69-97, 260-273, 303-374.

Rodgers, G., Southam, R., Reinicke-Murmann, J., Kreuter, P., 1990, "Analysis of Potential Improvements in Engine Behavior Due to Ceramic Valve Train Components," Society of Automotive Engineers, Paper No. 900452.

Salem, J. A., Manderscheid, J. M., Freedman, M. R., and Gyekenyesi, J. P., 1991, "Reliability Analysis of a Structural Ceramic Combustion Chamber," International Gas Turbine and Aeroengine Congress and Exposition, Orlando, FL, June 3-6, 1991.

Shetty, D. K., 1987, "Mixed-Mode Fracture Criteria for Reliability Analysis and Design with Structural Ceramics," 32nd International Gas Turbine Conference and Exhibit, American Society of Mechanical Engineers, Vol. 109, pp. 282-289.

Smart, J., 1990, "The Determination of Failure Probability Using Weibull Probability Statistics and the Finite Element Method," Res Mechanica, Vol. 31, pp. 205-219.

Speece, M W., and McLachlan, D. L., 1992, "Forecasting Fluid Milk Package Type with a Multigeneration New Product Diffusion Model," IEEE Transactions on Engineering Management, Vol. 39; No. 2, pp. 169-175.

Tennery, V. J., Breder, K., Ferber, M. K., and Jenkins, M. G., 1993, "Study of the Flexure and Tensile Strength of a United States Silicon Nitride," IEA Annex II, Subtask 5, International Energy Agency, High Temperature Materials Laboratory, Oak Ridge National Laboratory, Oak Ridge, TN, pp. 3-43.

Tsuruzono, S., Yoshida, M., Ono, T., and Kaji, M., 1992, "Reliability Analysis of a Ceramic Turbine Wheel," Kyocera Central Research Laboratory Technical Report, Kagoshima, Japan. 
Tucker, W. T., and Johnson, C. A., 1993, "The Multiaxial Equivalence of Stressed Volume," Life Prediction Methodology and Data for Ceramic Materials, ASTM STP 1201, C. R. Brinkman and F. S. Duffy, eds., American Society for Testing and Materials, Philadelphia, PA, pp. 265-279.

Updike, S. H., and Nagle, P. D., 1988, "Ceramic Valve Train Components," SAE Technical Paper Series, Society of Automotive Engineers, Paper No. 880441.

Vyas, A., Stodolsky, F., and Hanson, D., 1995, "Future Market for Ceramics in Vehicle Engines and Their Impacts," Proceedings of the Second World Car Conference, Center for Environmental Research and Technology, January 22-24, 1995, pp. 154-176.

Watchman, J. B., 1996, Mechanical Properties of Ceramics, John Wiley \& Sons, New York, NY, pp. 89-116, 367-382.

Weibull, W., 1939, “ A Statistical Theory of the Strength of Materials," Ingeniörsvetenskapsakademien Handlinger, No. 151.

Weibull, W., 1951, " A Statistical Distribution Function of Wide Applicability," Journal of Applied Mechanics, Vol. 18, No. 3, pp. 293-297.

Wereszczak, A. A., 1996, "Heavy Vehicle Propulsion System Materials Program Semiannual Progress Report for April 1996 through September 1996," D. R. Johnson, ed., ORNLTM-13395, Oak Ridge National Laboratory, Oak Ridge, TN, pp. 174-192.

Wereszczak, A. A., Kirkland, T. P., Ferber, M. K., and Andrews, M. J., 1997, "Prediction of SiAION Diesel Valve Failure Probability Using AlliedSignal's CERAMIC and ERICA Life Prediction Codes," Ceramic Engineering and Science Proceedings, Vol. 18, Issue 3, pp. 475-484.

Wereszczak, A. A., Andrews, M. J., Kirkland, T. P., and Ferber, M. K., 1998, "Life Prediction of Ceramic Diesel Engine Components," Heavy Vehicle Propulsion System Materials Program Bimonthly Technical Progress Report to DOE Office of Transportation Technologies, Aug.-Sept. 1998, pp. 35-38.

Wiederhorn, S. M., 1974, "Subcritical Crack Growth in Ceramics," Fracture Mechanics of Ceramics, R. C. Brandt, D. P. H. Hasselman, and F. F. Lange, eds., Vol. 2, Plenum Publishing, New York, NY, pp. 613-646.

Wills, R. R., 1988, "Ceramic Engine Valves," Communications of the American Ceramic Society, Vol. 72, No. 7, pp. 1261-1264. 


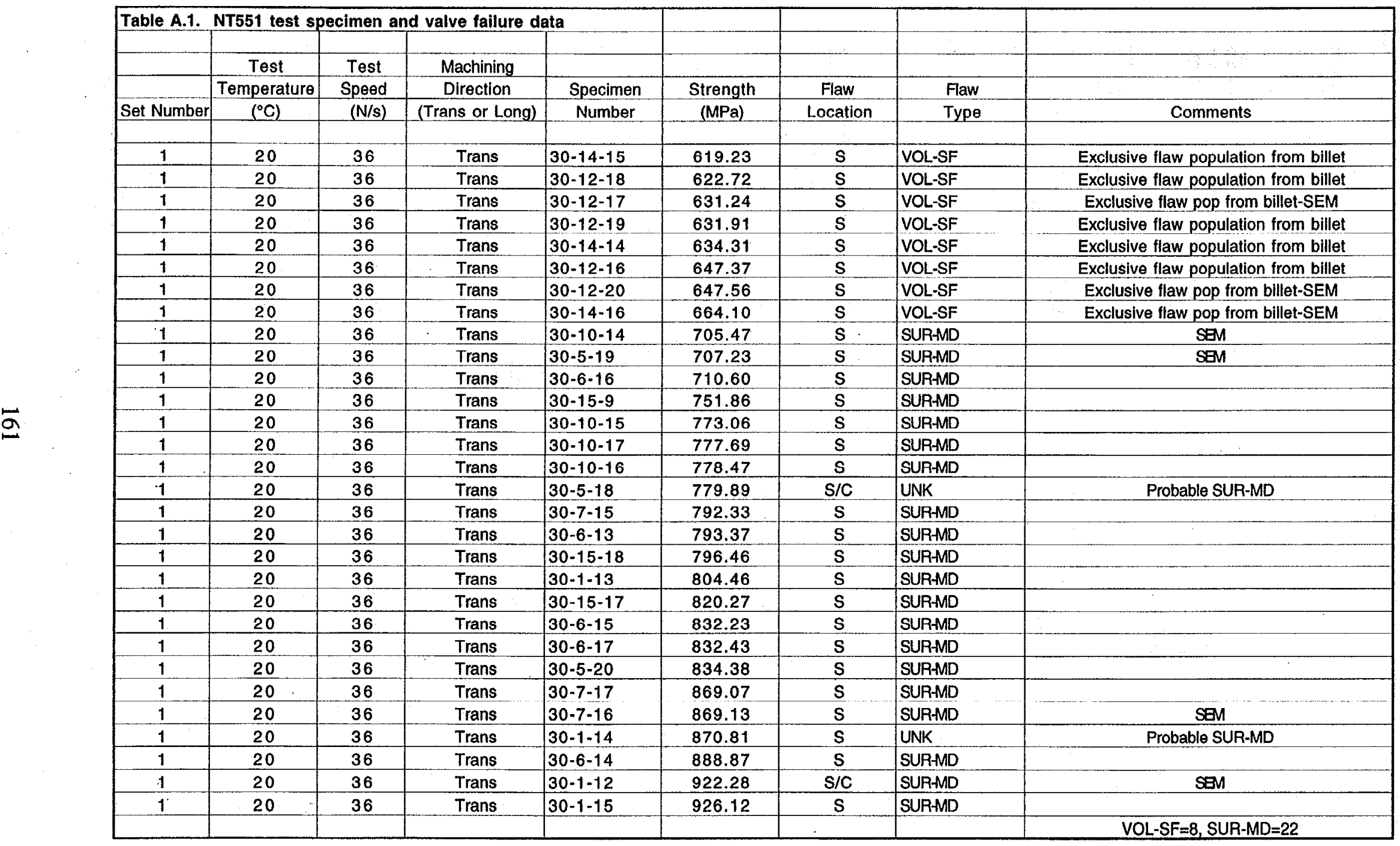




\begin{tabular}{|c|c|c|c|c|c|c|c|c|}
\hline & Test & Test & Machining & & & & & \\
\hline & Temperature & Speed & Direction & Specimen & Strength & Flaw & Flaw & \\
\hline Set Number & $\left({ }^{\circ} \mathrm{C}\right)$ & $(\mathrm{N} / \mathrm{s})$ & (Trans or Long) & Number & (MPa) & Location & Type & Comments \\
\hline$\therefore$ & & & & & & & & \\
\hline 2 & 20 & 0.36 & Trans & $29-32-8$ & 435.31 & 5 & VOL-SF & \\
\hline 2 & 20 & 0.36 & Trans & $30-15-3$ & 530.39 & $s$ & VOL-SF & \\
\hline 2 & 20 & 0.36 & Trans & $30-8-12$ & 582.25 & $S$ & SURAM & \\
\hline 2 & 20 & 0.36 & Trans & $29-18-11$ & 612.05 & $S$ & SURMD & \\
\hline 2 & 20 & 0.36 & Trans & $29-22-11$ & 634.66 & $s$ & SURAM & SEM \\
\hline 2 & 20 & 0.36 & Trans & $30-8-14$ & 639.45 & $s$ & SURAMD & \\
\hline 2 & 20 & 0.36 & Trans & $30-8-15$ & 639.71 & $s$ & SUR-MD & SEM \\
\hline 2 & 20 & 0.36 & Trans & $29-3-6$ & 641.32 & $\mathrm{~S}$ & SUR-MD & \\
\hline 2 & 20 & 0.36 & Trans & $30-1-3$ & 643.34 & $s$ & SUR-MD & \\
\hline 2 & 20 & 0.36 & Trans & $29-25-10$ & 653.88 & $s$ & SUR-MD & Evidence of handling damage \\
\hline 2 & 20 & 0.36 & Trans & $30-10-10$ & 663.45 & s & SUR-MD & SEM-check for VOL-SF \\
\hline 2 & 20 & 0.36 & Trans & $30-8-9$ & 667.56 & $s$ & SUR-MD & \\
\hline 2 & 20. & 0.36 & Trans & $30-8-16$ & 670.92 & s & SUR-MD & \\
\hline 2 & 20 & 0.36 & Trans & $29-16-14$ & 678.17 & $\mathbf{S}$ & SUA-MD & \\
\hline 2 & 20 & 0.36 & Trans & $30-8-10$ & 684.66 & s & SURAD & \\
\hline 2 & 20 & 0.36 & Trans & $30-7-9$ & 686.40 & $s$ & SURMD & \\
\hline 2 & 20 & 0.36 & Trans & $30-6-2$ & 687.46 & $S$ & SUAMD & \\
\hline 2 & 20 & 0.36 & Trans & $29 \cdot 22 \cdot 9$ & 690.67 & $S$ & SURAD & SEM \\
\hline 2 & 20 & 0.36 & Trans & $30-14-8$ & 694.79 & $S$ & SUR-MD & \\
\hline 2 & 20 & 0.36 & Trans & $30-3-10$ & 701.64 & $\mathrm{~s}$ & SURMD & SEM-check for VOL-SF \\
\hline 2 & 20 & 0.36 & Trans & $29 \cdot 3 \cdot 17$ & 701.66 & $s$ & SUR-MD & SQM \\
\hline 2 & 20 & 0.36 & Trans & $29-25-4$ & 713.92 & $\mathrm{~s}$ & SURMD & \\
\hline 2 & 20 & 0.36 & Trans & $30-14 \cdot 12$ & 717.68 & S & SURMD & \\
\hline 2 & 20 & 0.36 & Trans & $30-10-3$ & 726.28 & $s$ & SURMD & \\
\hline 2 & 20 & 0.36 & Trans & $30-6-1$ & 735.74 & $s$ & SUR-MD & SEM \\
\hline 2 & 20 & 0.36 & Trans & $29-3-16$ & 739.71 & $s$ & SUR-MD & SEM \\
\hline 2 & 20 & 0.36 & Trans & $29-3-9$ & 740.71 & s & SUR-MD & \\
\hline 2 & 20 & 0.36 & Trans & $29-3-3$ & 744.72 & $\mathbf{s}$ & SUR-MD & \\
\hline 2 & 20 & 0.36 & Trans & $30-14-17$ & 788.99 & S/C & SUR-MD & \\
\hline \multirow[t]{2}{*}{2} & 20 & 0.36 & Trans & $30-14-2$ & 825.48 & s & SUR-MD & SEM \\
\hline & & & & & & & & VOL-SF $=2, S U R-M D=28$ \\
\hline
\end{tabular}




\begin{tabular}{|c|c|c|c|c|c|c|c|c|}
\hline & Test & Test & Machining & & & & & \\
\hline & Temperature & Speed & Direction & Specimen & Strength & Flaw & Flaw & \\
\hline Set Number & $\left({ }^{\circ} \mathrm{C}\right)$ & $(\mathrm{N} / \mathrm{s})$ & (Trans or Long) & Number & (MPa) & Location & Type & Comments \\
\hline 3 & 20 & 0.0036 & Trans & $29-21-9$ & 233.74 & $s$ & UNK (n/a) & Failed out of gage region \\
\hline 3 & 20 & 0.0036 & Trans & $29-32-4$ & 395.79 & $\mathrm{C}$ & VOL-SF & \\
\hline 3 & 20 & 0.0036 & Trans & $29-32-7$ & 398.27 & $s$ & VOL-SF & SEM \\
\hline 3 & 20 & 0.0036 & Trans & $29-32-10$ & 505.68 & $\mathrm{~s} / \mathrm{C}$ & VOL-SF & \\
\hline 3 & 20 & 0.0036 & Trans & $29-18-14$ & 484.27 & $\mathrm{~S}$ & VOL-SF & \\
\hline 3 & 20 & 0.0036 & Trans & $30-15-11$ & 484.72 & $\mathbf{s}$ & VOL-SF & SEM \\
\hline 3 & 20 & 0.0036 & Trans & $30-9-3$ & 517.67 & $S$ & SURAMD & \\
\hline 3 & 20 & 0.0036 & Trans & $30-8.13$ & 517.43 & $s$ & SURMD & \\
\hline 3 & 20 & 0.0036 & Trans & $29-16-16$ & 584.76 & $\mathrm{C}$ & SURAMD & \\
\hline 3 & 20 & 0.0036 & Trans & $30-3-11$ & 596.40 & $S$ & SURAM & $\operatorname{SeM}$ \\
\hline 3 & 20 & 0.0036 & Trans & $30-3-3$ & 611.07 & $\mathrm{~s} / \mathrm{C}$ & SURMD & \\
\hline 3 & 20 & 0.0036 & Trans & $29-16-12$ & 622.29 & $S$ & SURMD & \\
\hline 3 & 20 & 0.0036 & Trans & 29-25-8 & 556.71 & $S$ & SURAD & \\
\hline 3 & 20 & 0.0036 & Trans & $30-8-2$ & 557.77 & $S$ & SURMD & \\
\hline 3 & 20 & 0.0036 & Trans & $30-5.5$ & 577.89 & $S$ & SURMD & $\therefore$ \\
\hline 3 & 20 & 0.0036 & Trans & $29-18-15$ & 606.03 & 5 & SURMD & \\
\hline 3 & 20 & 0.0036 & Trans & $29-22-14$ & 571.32 & 5 & SUR-MD & \\
\hline 3 & 20 & 0.0036 & Trans & $29-18-5$ & 642.15 & $S$ & SUR-MD & $\mathrm{SgM}$ \\
\hline 3 & 20 & 0.0036 & Trans & $30-5-1$ & 606.28 & $S$ & SURAMD & \\
\hline 3 & 20 & 0.0036 & Trans & $30-15-2$ & 588.29 & $\mathrm{~s}$ & SURMD & SEM \\
\hline 3 & 20 & 0.0036 & Trans & $29 \cdot 25 \cdot 12$ & 588.55 & $S$ & SURAM & \\
\hline 3 & 20 & 0.0036 & Trans & $29-3-5$ & 609.60 & $\mathrm{~s}$ & SURAMD & \\
\hline 3 & 20 & 0.0036 & Trans & $29-25-17$ & 600.08 & $s$ & SUR-MD & \\
\hline 3 & 20 & 0.0036 & Trans & $30-14-1$ & 645.94 & $s$ & SUR-MD & \\
\hline 3 & 20 & 0.0036 & Trans & $30-7-4$ & 620.49 & $S$ & SUR-MD & $\mathrm{SEM}$ \\
\hline 3 & 20 & 0.0036 & Trans & $30-7-5$ & 627.12 & $\mathrm{~S}$ & SURAMD & \\
\hline 3 & 20 & 0.0036 & Trans & $29-25-19$ & 634.75 & $S$ & SURAMD & \\
\hline 3 & 20 & 0.0036 & Trans & $30-6-7$ & 641.24 & $S$ & SUR-MD & \\
\hline 3 & 20 & 0.0036 & Trans & $29-21-12$ & 651.31 & $S$ & SUR-MD & . \\
\hline \multirow[t]{2}{*}{3} & 20 & 0.0036 & Trans & $29-3-13$ & 676.77 & $\mathrm{~S}$ & SUR-MD & SEM \\
\hline & & & & & & & & VOL-SF $=5$, SUR-MD $=24$ \\
\hline
\end{tabular}




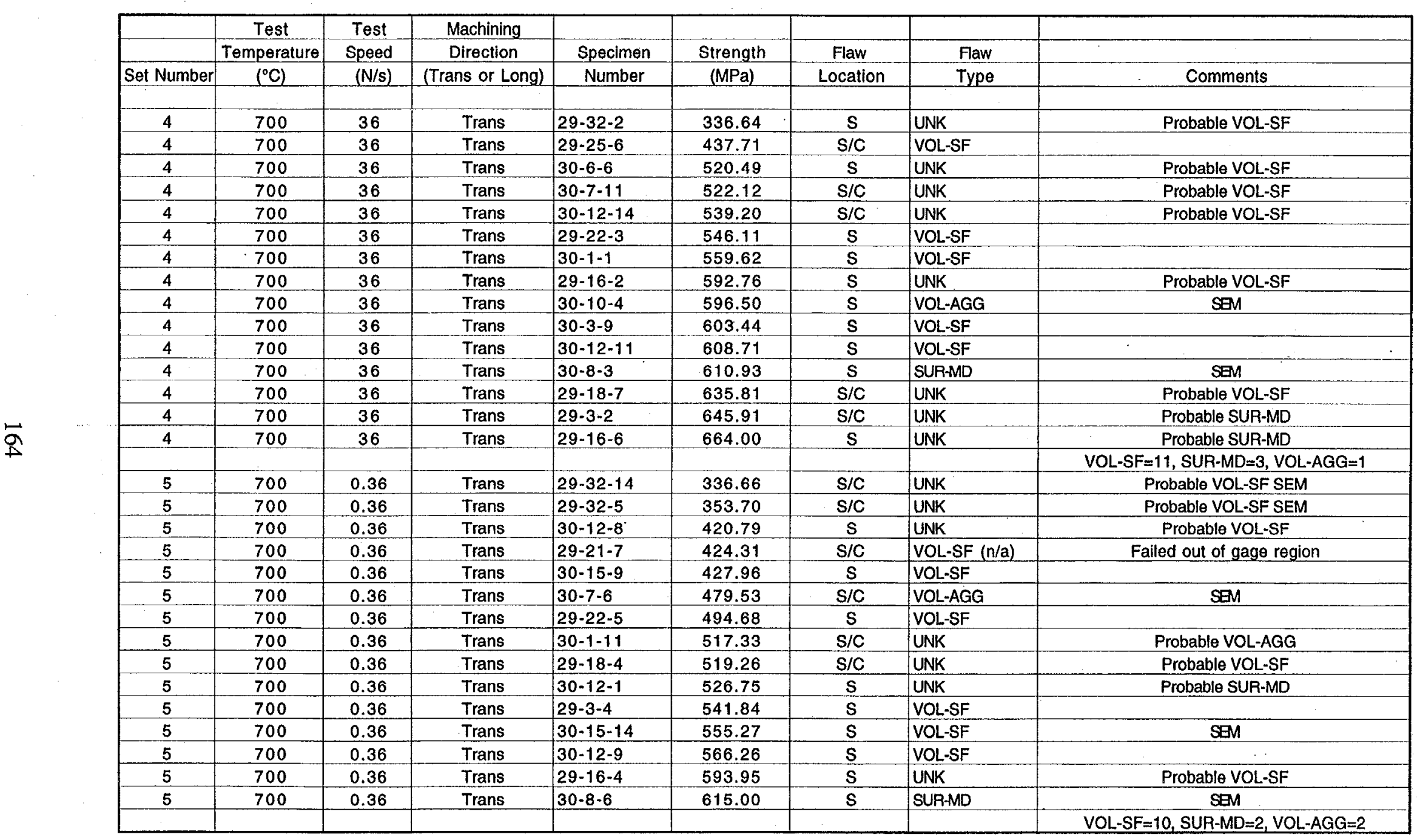




\begin{tabular}{|c|c|c|c|c|c|c|c|c|}
\hline & Test & Test & Machining & & & & & \\
\hline & Temperature & Speed & Direction & Specimen & Strength & Flaw & Flaw & \\
\hline Set Number & $\left({ }^{\circ} \mathrm{C}\right)$ & $(\mathrm{N} / \mathrm{s})$ & (Trans or Long) & Number & (MPa) & Location & Type & Comments \\
\hline 6 & 700 & 0.0036 & Trans & $30-15-7$ & 403.29 & 5 & VOL-SF & \\
\hline 6 & 700 & 0.0036 & Trans & $29-18-2$ & 417.23 & s & VOL-SF & SEM \\
\hline 6 & 700 & 0.0036 & Trans & $30-12-7$ & 418.21 & $\mathrm{~s}$ & VOL-SF & \\
\hline 6 & 700 & 0.0036 & Trans & $30-5-11$ & 437.68 & $\mathrm{~S} / \mathrm{C}$ & VOL-SF & \\
\hline 6 & 700 & 0.0036 & Trans & $29-18-9$ & 444.04 & $\mathrm{~S} / \mathrm{C}$ & VOL-SF & $\mathrm{SEM}$ \\
\hline 6 & 700 & 0.0036 & Trans & $29-21-6$ & 465.20 & $\mathrm{~s} / \mathrm{C}$ & VOL-SF & SEM \\
\hline 6 & 700 & 0.0036 & Trans & $30-6-8$ & 472.34 & $\mathrm{~S}$ & VOL-SF & $\mathrm{SEM}$ \\
\hline 6 & 700 & 0.0036 & Trans & $30-14-13$ & 519.00 & $s$ & VOL-SF & \\
\hline 6 & 700 & 0.0036 & Trans & $29-16-3$ & 538.13 & $s$ & VOL-SF & \\
\hline 6 & 700 & 0.0036 & Trans & $30-15-15$ & 542.83 & $s$ & VOL-SF & \\
\hline 6 & 700 & 0.0036 & Trans & $30-7-14$ & 568.83 & $\mathrm{~s}$ & VOL-SF & \\
\hline 6 & 700 & 0.0036 & Trans & $30-3-2$ & 571.47 & $S$ & UNK & Probable VOL-SF \\
\hline 6 & 700 & 0.0036 & Trans & $30-9-2$ & 573.39 & S & VOL-SF & \\
\hline 6 & 700 & 0.0036 & Trans & $29-3-11$ & 582.22 & 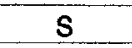 & SURMD & \\
\hline 6 & 700 & 0.0036 & Trans & $29-22-15$ & 595.17 & s & UNK & Probable SUR-MD \\
\hline & & & & & & & & VOL-SF $=13, S U R-M D=2$ \\
\hline 7 & 850 & 36 & Trans & $30-7-12$ & 224.17 & S & UNK & \\
\hline 7 & 850 & 36 & Trans & $30-5-12$ & 470.53 & $s$ & UNK & \\
\hline 7 & 850 & 36 & Trans & $30-10-7$ & 488.58 & $S$ & UNK & $\mathrm{SEM}$ \\
\hline 7 & 850 & 36 & Trans & $30-5-2$ & 506.33 & $\mathrm{~s}$ & UNK & SEM \\
\hline 7 & 850 & 36 & Trans & $30-12-2$ & 508.73 & $\mathrm{~s}$ & SURAD & $\mathrm{seM}$ \\
\hline 7 & 850 & 36 & Trans & $30-1-7$ & 509.84 & $s$ & UNK & Probable SUR-MD \\
\hline 7 & 850 & 36 & Trans & $30-10-6$ & 510.85 & $S$ & SURAMD & \\
\hline 7 & 850 & 36 & Trans & $30-10-1$ & 523.85 & 5 & SURAD & \\
\hline 7 & 850 & 36 & Trans & $30-5-6$ & 524.35 & $s$ & UNK & Probable VOL-AGG \\
\hline 7 & 850 & 36 & Trans & $30-12-3$ & 526.25 & $\mathrm{~s}$ & UNK & \\
\hline 7 & 850 & 36 & Trans & $30-6-5$ & 526.64 & $s$ & UNK & SEM \\
\hline 7 & 850 & 36 & Trans & $30-6-11$ & 527.57 & $s$ & UNK & Probable SUR-MD \\
\hline 7 & 850 & 36 & Trans & $30-1-2$ & 528.57 & S/C & UNK & Probable SUR-MD \\
\hline 7 & 850 & 36 & Trans & $30-1-5$ & 538.07 & $S$ & SURAD . & \\
\hline 7 & 850 & 36 & Trans & $30-15-13$ & 541.04 & $S$ & UNK & Probable VOL-SF \\
\hline 7 & 850 & 36 & Trans & $30-12-6$ & 541.53 & $\mathrm{~S} / \mathrm{C}$ & UNK & Probable VOL-SF \\
\hline 7 & 850 & 36 & Trans & $30-14-4$ & 542.55 & $\mathrm{~s}$ & UNK & Probable VOL-SF \\
\hline 7 & 850 & 36 & Trans & $30-7-3$ & 546.87 & $s$ & SURAM & . \\
\hline 7 & 850 & 36 & Trans & $30-14-10$ & 549.31 & $S$ & SURMD & \\
\hline
\end{tabular}




\begin{tabular}{|c|c|c|c|c|c|c|c|c|}
\hline & Test & Test & Machining & & & & & \\
\hline & Temperature & Speed & Direction & Specimen & Strength & Flaw & Flaw & \\
\hline Set Number & $\left({ }^{\circ} \mathrm{C}\right)$ & $(\mathrm{N} / \mathrm{s})$ & (Trans or Long) & Number & (MPa) & Location & Type & Comments \\
\hline & & & & & & & & \\
\hline 7 & 850 & 36 & Trans & $30-10-11$ & 551.08 & $S$ & UNK & Probable VOL-SF SEM \\
\hline 7 & 850 & 36 & Trans & $30 \cdot 6 \cdot 12$ & 558.14 & $\mathrm{~s}$ & SURMD & SEM \\
\hline 7 & 850 & 36 & Trans & $30-1-8$ & 559.42 & $S$ & UNK & \\
\hline 7 & 850 & 36 & Trans & $30-14-7$ & 586.82 & $\mathrm{~s}$ & SUR-MD & \\
\hline 7 & 850 & 36 & Trans & $30-12.5$ & 589.28 & $\mathrm{~s}$ & UNK & Probable VOL-SF \\
\hline 7 & 850 & 36 & Trans & $30-7-7$ & 616.20 & $S$ & SURMD & \\
\hline 7 & 850 & 36 & Trans & $30-7-1$ & 617.85 & $\mathrm{~s}$ & UNK & Probable VOL-AGG SEM \\
\hline 7 & 850 & 36 & Trans & $30-1-6$ & 632.04 & $\mathrm{~S}$ & UNK & \\
\hline 7 & 850 & 36 & Trans & $30-15-10$ & 654.64 & $\mathrm{~s}$ & UNK & \\
\hline 7. & 850 & 36 & Trans & $30-5-17$ & 673.97 & $\mathbf{S}$ & UNK & Probable VOL-AGG SEM \\
\hline 7 & 850 & 36 & Trans & $30-15-1$ & 686.35 & $S$ & UNK & \\
\hline & & & & & & & & VOL-SF $=5$, SUR-MD $=12$, VOL-AGG $\because 3, U N K=10$ \\
\hline 8 & 850 & 0.36 & Trans & $29-21-4$ & 233.40 & $\mathbf{S}$ & UNK & Probable SUR-MD SEM \\
\hline 8 & 850 & 0.36 & Trans & $29-21-14$ & 247.92 & $\mathbf{S}$ & UNK & Probable VOL-SF \\
\hline 8 & 850 & 0.36 & Trans & $29-21-3$ & 276.34 & $s$ & VOL-SF (n/a) & Failed out of gage region \\
\hline 8 & 850 & 0.36 & Trans & $30-12-13$ & 378.09 & $\mathbf{S}$ & UNK & Probable VOL-SF \\
\hline 8 & 850 & 0.36 & Trans & $29-32-13$ & 407.79 & $S / C$ & VOL-SF & \\
\hline 8 & 850 & 0.36 & Trans & $29 \cdot 18 \cdot 1$ & 409.83 & $\mathrm{~s}$ & UNK & $\operatorname{seM}$ \\
\hline 8 & 850 & 0.36 & Trans & $29-21-15$ & 414.02 & $\mathrm{~s}$ & UNK & $\operatorname{sen}$ \\
\hline 8 & 850 & 0.36 & Trans & $30-15 \cdot 4$ & 418.98 & $\mathrm{~S} / \mathrm{C}$ & UNK & Probable SUR-MD \\
\hline 8 & 850 & 0.36 & Trans & $29 \cdot 25 \cdot 5$ & 435.97 & $\mathrm{~S} / \mathrm{C}$ & UNK & Probable SUR-MD \\
\hline 8 & 850 & 0.36 & Trans & $29-25-11$ & 457.14 & $S$ & UNK & Probable SUR-MD \\
\hline 8 & 850 & 0.36 & Trans & $29-32 \cdot 12$ & 459.38 & $S$ & UNK & Probable SUR-MD \\
\hline 8 & 850 & 0.36 & Trans & $30-12-15$ & 461.75 & $S / C$ & SURMD & \\
\hline 8 & 850 & 0.36 & Trans & $30-7-2$ & 469.67 & $S$ & VOL-SF & \\
\hline 8 & 850 & 0.36 & Trans & $30-7-13$ & 471.19 & $\mathrm{C}$ & VOL-SF & \\
\hline 8 & 850 & 0.36 & Trans & $29-16-8$ & 474.95 & $\mathrm{~S}$ & VOL-SF & \\
\hline 8 & 850 & 0.36 & Trans & $30-15-5$ & 479.54 & $s / C$ & VOL-SF & \\
\hline 8 & 850 & 0.36 & Trans & $29-25-3$ & 487.88 & $S / C$ & VOL-SF & \\
\hline 8 & 850 & 0.36 & Trans & $29-22-10$ & 504.59 & $S / C$ & VOL-SF & \\
\hline 8 & 850 & 0.36 & Trans & $30-12-4$ & 508.39 & $\mathrm{~s} / \mathrm{C}$ & VOL-SF & \\
\hline 8 & 850 & 0.36 & Trans & $30-3-7$ & 521.60 & $s$ & UNK & Probable VOL-SF SEM \\
\hline 8 & 850 & 0.36 & Trans & $30-8-5$ & 537.70 & $s$ & VOL-SF & \\
\hline 8 & 850 & 0.36 & Trans & $29-16-15$ & 537.94 & $S$ & VOL-SF & SEM \\
\hline 8 & 850 & 0.36 & Trans & $29-25-20$ & 550.93 & $s$ & VOL-SF & SEM \\
\hline
\end{tabular}




\begin{tabular}{|c|c|c|c|c|c|c|c|c|c|}
\hline & & Test & Test & Machining & & & & & \\
\hline & & Temperature & Speed & Direction & Specimen & Strength & Flaw & Flaw & \\
\hline & Set Number & $\left({ }^{\circ} \mathrm{C}\right)$ & $(\mathrm{N} / \mathrm{s})$ & (Trans or Long) & Number & (MPa) & Location & Type & Comments \\
\hline & & & & & & & & & \\
\hline \multirow{35}{*}{$\sqrt[9]{ }$} & 8 & 850 & 0.36 & Trans & $29-16-9$ & 555.82 & $s$ & VOL-SF & \\
\hline & 8 & 850 & 0.36 & Trans & $29-16-10$ & 556.30 & $\mathrm{~s}$ & UNK & Probable VOL-SF \\
\hline & 8 & 850 & 0.36 & Trans & $29-22-8$ & 560.83 & $s$ & UNK & Probable VOL-SF \\
\hline & 8 & 850 & 0.36 & Trans & $30-3-17$ & 566.29 & $s / c$ & UNK & Probable VOL-SF \\
\hline & 8 & 850 & 0.36 & Trans & $29-16-13$ & 588.03 & $S / C$ & UNK & Probable VOL-SF SEM \\
\hline & 8 & 850 & 0.36 & Trans & $29-22-12$ & 594.78 & $\mathrm{~s}$ & UNK & Probable VOL-SF \\
\hline & 8 & 850 & 0.36 & Trans & $30-5-15$ & 734.33 & $S$ & UNK & Probable VOL-SF \\
\hline & & & & & & & & & VOL-SF $=21$, SUR-MD $=6$, UNK $=2$ \\
\hline & 9 & 850 & 0.0036 & Trans & $30-6 \cdot 9$ & 166.92 & $\mathrm{C}$ & VOL-SF & \\
\hline & 9 & 850 & 0.0036 & Trans & $30-5-13$ & 230.71 & $s$ & UNK & Unidentifiable volume flaw SEM \\
\hline & 9 & 850 & 0.0036 & Trans & $29-18-19$ & 235.71 & $S$ & UNK & Unidentifiable volume flaw SEM \\
\hline & 9 & 850 & 0.0036 & Trans & $30-10-12$ & 244.22 & $\mathbf{S}$ & UNK & Unidentifiable volume flaw \\
\hline & 9 & 850 & 0.0036 & Trans & $29-18 \cdot 17$ & 262.52 & $\mathrm{~S}$ & UNK & Unidentifiable volume flaw SEM \\
\hline & 9 & 850 & 0.0036 & Trans & $30-10-5$ & 268.65 & $\mathbf{S}$ & UNK & Unidentifiable volume flaw \\
\hline & 9 & 850 & 0.0036 & Trans & $30-15-12$ & 273.88 & $\mathbf{s}$ & VOL-SF & Test interrupted - power failure \\
\hline & 9 & 850 & 0.0036 & Trans & $29-21-11$ & 274.89 & $S$ & UNK & Unidentifiable volume flaw \\
\hline & 9 & 850 & 0.0036 & Trans & 29-32-6 & 276.18 & S/C & UNK & Unidentifiable volume flaw SEM \\
\hline & 9 & 850 & 0.0036 & Trans & $29-32-17$ & 279.14 & S/C & UNK & Unidentifiable volume flaw SEM \\
\hline & 9 & 850 & 0.0036 & Trans & $30-6-10$ & 286.93 & 5 & VOL-SF & SEM \\
\hline & 9 & 850 & 0.0036 & Trans & $30-1-9$ & 288.23 & $s$ & VOL-SF & \\
\hline & 9 & 850 & 0.0036 & Trans & $29-18-18$ & 290.62 & $S$ & VOL-SF & SEM \\
\hline & 9 & 850 & 0.0036 & Trans & $29-21-16$ & 298.68 & $\mathrm{~S} / \mathrm{C}$ & VOL-SF & \\
\hline & 9 & 850 & 0.0036 & Trans & $29-3-14$ & 299.45 & $s$ & VOL-SF & Test interrupted - power failure \\
\hline & 9 & 850 & 0.0036 & Trans & $29-32-15$ & 319.43 & $s$ & VOL-SF & \\
\hline & 9 & 850 & 0.0036 & Trans & $29-22-13$ & 326.20 & $\mathrm{~s}$ & VOL-SF & \\
\hline & 9 & 850 & 0.0036 & Trans & $29-25-1$ & 326.88 & $S$ & VOL-SF & \\
\hline & 9 & 850 & 0.0036 & Trans & $29-3-7$ & 330.70 & S/C & VOL-SF & \\
\hline & 9 & 850 & 0.0036 & Trans & $30-15-16$ & 334.31 & $\mathrm{~S} / \mathrm{C}$ & VOL-SF & Test interrupted - power failure \\
\hline & 9 & 850 & 0.0036 & Trans & $29-16-7$ & 339.48 & $\mathrm{~S}$ & VOL-SF & Test interrupted - power failure \\
\hline & 9 & 850 & 0.0036 & Trans & $29-32-1$ & 339.85 & $\mathrm{~S} / \mathrm{C}$ & UNK & \\
\hline & 9 & 850 & 0.0036 & Trans & $29-3-8$ & 353.10 & S/C & VOL-SF & \\
\hline & 9 & 850 & 0.0036 & Trans & $29 \cdot 18 \cdot 20$ & 367.17 & $\mathrm{~S}$ & VOL-SF & \\
\hline & 9 & 850 & 0.0036 & Trans & $29-22-16$ & 373.99 & $\mathrm{~S} / \mathrm{C}$ & VOL-SF & \\
\hline & 9 & 850 & 0.0036 & Trans & $30-3-6$ & 377.38 & S/C & VOL-SF & Test interrupted - power failure \\
\hline & 9 & 850 & 0.0036 & Trans & $29-3-12$ & 378.39 & $\mathrm{~S} / \mathrm{C}$ & VOL-SF & \\
\hline
\end{tabular}




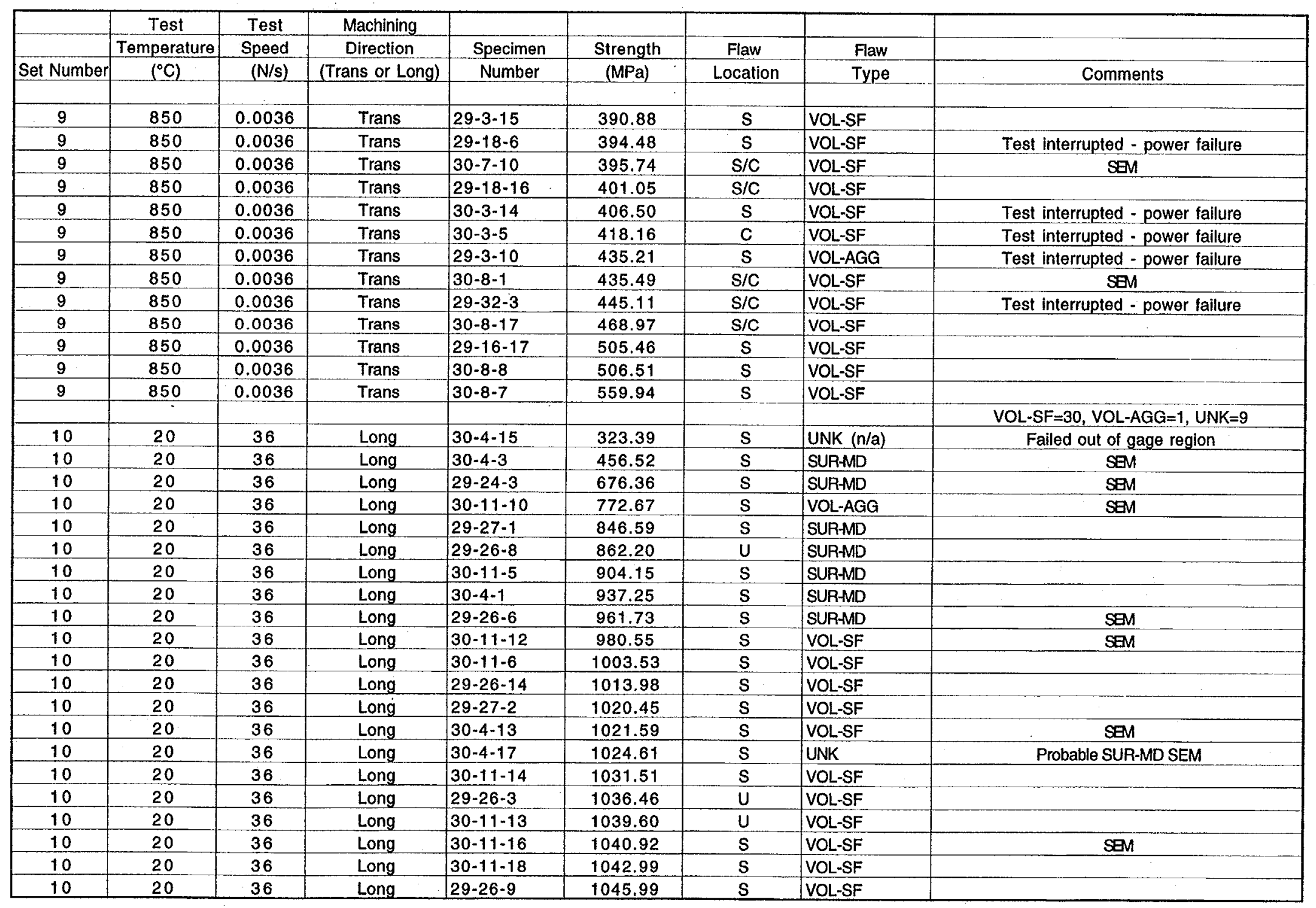




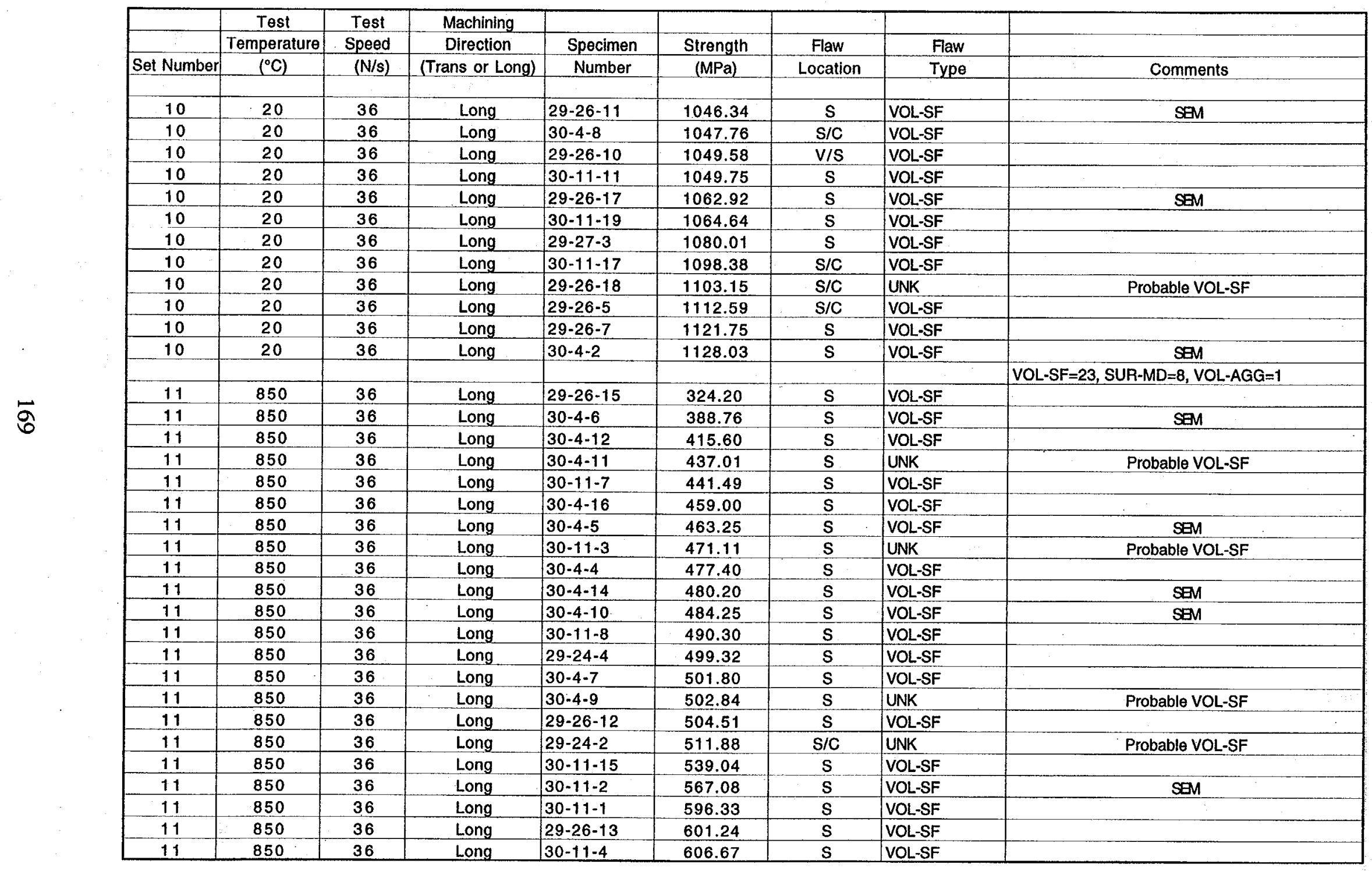




\begin{tabular}{|c|c|c|c|c|c|c|c|c|}
\hline & Test & Test & Machining & & & & & \\
\hline & Temperature & Speed & Direction & Specimen & Strength & Flaw & Flaw & \\
\hline Set Number & $\left({ }^{\circ} \mathrm{C}\right)$ & $(\mathrm{N} / \mathrm{s})$ & (Trans or Long) & Number & $(\mathrm{MPa})$ & Location & Type & Comments \\
\hline 11 & 850 & 36 & Long & $29-26-16$ & 607.29 & $s$ & VOL-SF & \\
\hline 11 & 850 & 36 & Long & $29-27-4$ & 632.09 & $S$ & VOL-SF & \\
\hline 11 & 850 & 36 & Long & $29-26-2$ & 644.22 & $\mathrm{~s}$ & VOL-SF & \\
\hline 11 & 850 & 36 & Long & $29-26-1$ & 684.21 & $\mathrm{~V} / \mathrm{S}$ & VOL-SF & \\
\hline 11 & 850 & 36 & Long & $30-11-9$ & 705.26 & $\mathrm{~s}$ & VOL-SF & \\
\hline 12 & 20 & 14.67 & Trans-Cylinder & FF. 18 & 591.00 & $s$ & SURMD & \\
\hline 12 & 20 & 14.67 & Trans-Gylinder & FF-21 & 596.97 & $S$ & SURAD & \\
\hline 12 & 20 & 14.67 & Trans-Cylinder & FF-7 & 602.24 & $S$ & SURMD & \\
\hline 12 & 20 & 14.67 & Trans-Cylinder & FF-5 & 605.52 & $S$ & SURMD & \\
\hline 12 & 20 & 14.67 & Trans-Cylinder & FF-11 & 605.92 & $S$ & SUR-MD & \\
\hline 12 & 20 & 14.67 & Trans-Cylinder & FF -19 & 613.21 & $S$ & SURMD & \\
\hline 12 & 20 & 14.67 & Trans-Cylinder & FF-10 & 613.65 & $s$ & SUR-MD & \\
\hline 12 & 20 & 14.67 & Trans-Cylinder & FF-1 & 616.92 & $s$ & SURMD & \\
\hline 12 & 20 & 14.67 & Trans-Cylinder & FF-16 & 618.44 & $s$ & SURMD & . \\
\hline 12 & 20 & 14.67 & Trans-Cylinder & FF-20 & 623.23 & $\mathrm{~s}$ & SURMD & \\
\hline 12 & 20 & $\$ 4.67$ & Trans-Cylinder & FF-22 & 625.76 & $S$ & SURAM & \\
\hline 12 & 20 & 14.67 & Trans-Cylinder & FF-28 & 628.85 & 5 & SURAM & $\operatorname{sen}$ \\
\hline 12 & 20 & 14.67 & Trans-Cylinder & FF-25 & 633.45 & $\mathrm{~s}$ & SURAMD & \\
\hline 12 & 20 & 14.67 & Trans-Cylinder & FF-29 & 633.47 & $s$ & SUR-MD & SEM \\
\hline 12 & 20 & 14.67 & Trans-Cylinder & FF-17 & 636.26 & $s$ & SUR-MD & \\
\hline 12 & 20 & 14.67 & Trans-Cylinder & FF-4 & 636.71 & $S$ & SURAD & \\
\hline 12 & 20 & 14.67 & Trans-Cylinder & FF- 8 & 637.09 & $S$ & SUR-MD & \\
\hline 12 & 20 & 14.67 & Trans-Cylinder & FF-24 & 641.18 & $S$ & SURMD & \\
\hline 12 & 20 & 14.67 & Trans-Cylinder & FF-15 & 641.54 & 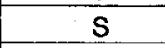 & SUR-MD & \\
\hline 12 & 20 & 14.67 & Trans-Cylinder & FF-6 & 642.35 & $s$ & SUR-MD & SEM \\
\hline 12 & 20 & 14.67 & Trans-Cylinder & FF-12 & 644.41 & $s$ & SURMD & \\
\hline 12 & 20 & 14.67 & Trans-Cylinder & FF-23 & 646.00 & $S$ & SUR-MD & \\
\hline 12 & 20 & 14.67 & Trans-Cylinder & $F F-26$ & 648.41 & $S$ & SUR-MD & \\
\hline 12 & 20 & 14.67 & Trans-Cyllinder & FF-2 & 648.46 & $s$ & SUR-MD & SeM \\
\hline 12 & 20 & 14.67 & Trans-Cylinder & $F F-14$ & 662.18 & $S$ & SURMD & \\
\hline 12 & 20 & 14.67 & Trans-Cyllnder & FF-27 & 671.10 & $s$ & SUR-MD & SEM \\
\hline 12 & 20 & 14.67 & Trans-Cylinder & $F F-13$ & 672.71 & $S$ & SUR-MD & \\
\hline
\end{tabular}




\begin{tabular}{|c|c|c|c|c|c|c|c|c|}
\hline & Test & Test & Machining & & & & & \\
\hline & Temperature & Speed & Direction & Specimen & Strength & Flaw & Flaw & \\
\hline Set Number & $\left({ }^{\circ} \mathrm{C}\right)$ & $(\mathrm{N} / \mathrm{s})$ & (Trans or Long) & Number & (MPa) & Location & Type & Comments \\
\hline & & & & $F F-30$ & 690.52 & $S$ & SUR-MD & $S U B-M D=30$ \\
\hline 13 & 20 & 0.1467 & Trans-Cylinder & MF-23 & 538.74 & $\mathrm{~s}$ & UNK & Probable SUR-MD \\
\hline 13 & 20 & 0.1467 & Trans-Cylinder & MF-22 & 551.98 & $S$ & UNK & Probable SUR-MD \\
\hline 13 & 20 & 0.1467 & Trans-Cylinder & MF-7 & 558.04 & $\mathrm{~s}$ & UNK & Probable SUR-MD \\
\hline 13 & 20 & 0.1467 & Trans-Cylinder & MF-26 & 564.90 & $s$ & UNK & Probable SUR-MD \\
\hline 13 & 20 & 0.1467 & Trans-Cylinder & MF-17 & 566.58 & $s$ & UNK & Probable SUR-MD \\
\hline 13 & 20 & 0.1467 & Trans-Cylinder & MF-12 & 569.69 & $s$ & SUR-MD & \\
\hline 13 & 20 & 0.1467 & Trans-Cylinder & $M F-25$ & 579.04 & $\mathrm{~s}$ & SURMD & \\
\hline 13 & 20 & 0.1467 & Trans-Cylinder & MF-9 & 579.50 & 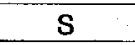 & SUR-MD & SaM \\
\hline 13 & 20 & 0.1467 & Trans-Cylinder & MF-15 & 587.92 & s & SUR-MD & \\
\hline 13 & 20 & 0.1467 & Trans-Cylinder & MF-30 & 589.54 & $s$ & UNK & Probable SUR-MD \\
\hline 13 & 20 & 0.1467 & Trans-Cylinder & MF-13 & 591.65 & $s$ & UNK & Probable SUR-MD SEM \\
\hline 13 & 20 & 0.1467 & Trans-Cylinder & MF-3 & 593.27 & s & SURMD & $\mathrm{SEM}$ \\
\hline 13 & 20 & 0.1467 & Trans-Cylinder & MF-21 & 594.03 & s & SURAD & \\
\hline 13 & 20 & 0.1467 & Trans-Cylinder & MF-11 & 607.30 & s & SURMD & \\
\hline 13 & 20 & 0.1467 & Trans-Cylinder & MF-2 & 609.73 & $\mathrm{~S}$ & SUR-MD & \\
\hline 13 & 20 & 0.1467 & Trans-Cylinder & MF-1 & 610.13 & $\mathrm{~s}$ & SURMD & \\
\hline 13 & 20 & 0.1467 & Trans-Cylinder & MF-20 & 611.74 & $S$ & SURMD & SEM \\
\hline 13 & 20 & 0.1467 & Trans-Cylinder & MF-29 & 613.80 & $s$ & SURMD & \\
\hline 13 & 20 & 0.1467 & Trans-Cylinder & MF-19 & 615.05 & s & SURMD & \\
\hline 13 & 20 & 0.1467 & Trans-Cylinder & MF-10 & 616.66 & s & UNK & Probable SUR-MD \\
\hline 13 & 20 & 0.1467 & Trans-Cylinder & $M F=4$ & 619.85 & $s$ & UNK & Probable SUR-MD \\
\hline 13 & 20 & 0.1467 & Trans-Cylinder & $M F-14$ & 623.49 & $s$ & UNK & Probable SUR-MD \\
\hline 13 & 20 & 0.1467 & Trans-Cylinder & MF-28 & 625.47 & $s$ & SURMD & \\
\hline 13 & 20 & 0.1467 & Trans-Cylinder & MF-5 & 631.56 & $s$ & SURMD & \\
\hline 13 & 20 & 0.1467 & Trans-Cylinder & MF-16 & 637.99 & s & UNK & Probable SUR-MD \\
\hline 13 & 20 & 0.1467 & Trans-Cylinder & MF-6 & 648.89 & $\mathrm{~s}$ & SURMD & \\
\hline 13 & 20 & 0.1467 & Trans-Cylinder & MF-18 & 649.31 & $s$ & SUR-MD & \\
\hline 13 & 20 & 0.1467 & Trans-Cylinder & MF-8 & 650.51 & $s$ & SURMD & \\
\hline 13 & 20 & 0.1467 & Trans-Cylinder & MF-24 & 652.53 & s & SUR-MD & SEM machining grooves \\
\hline 13 & 20 & 0.1467 & Trans-Cylinder & MF-27 & 666.23 & S & SUR-MD & . \\
\hline & & & & & & & & SUR-MD $=30$ \\
\hline 14 & 20 & 0.00147 & Trans-Cylinder & SF-18 & 462.08 & S & UNK & Probable SUR-MD Test interrupted P.F. \\
\hline 14 & 20 & 0.00147 & Trans-Cylinder & SF-23 & 472.53 & $s$ & UNK & Probable SUR-MD Test interrupted P.F. \\
\hline
\end{tabular}




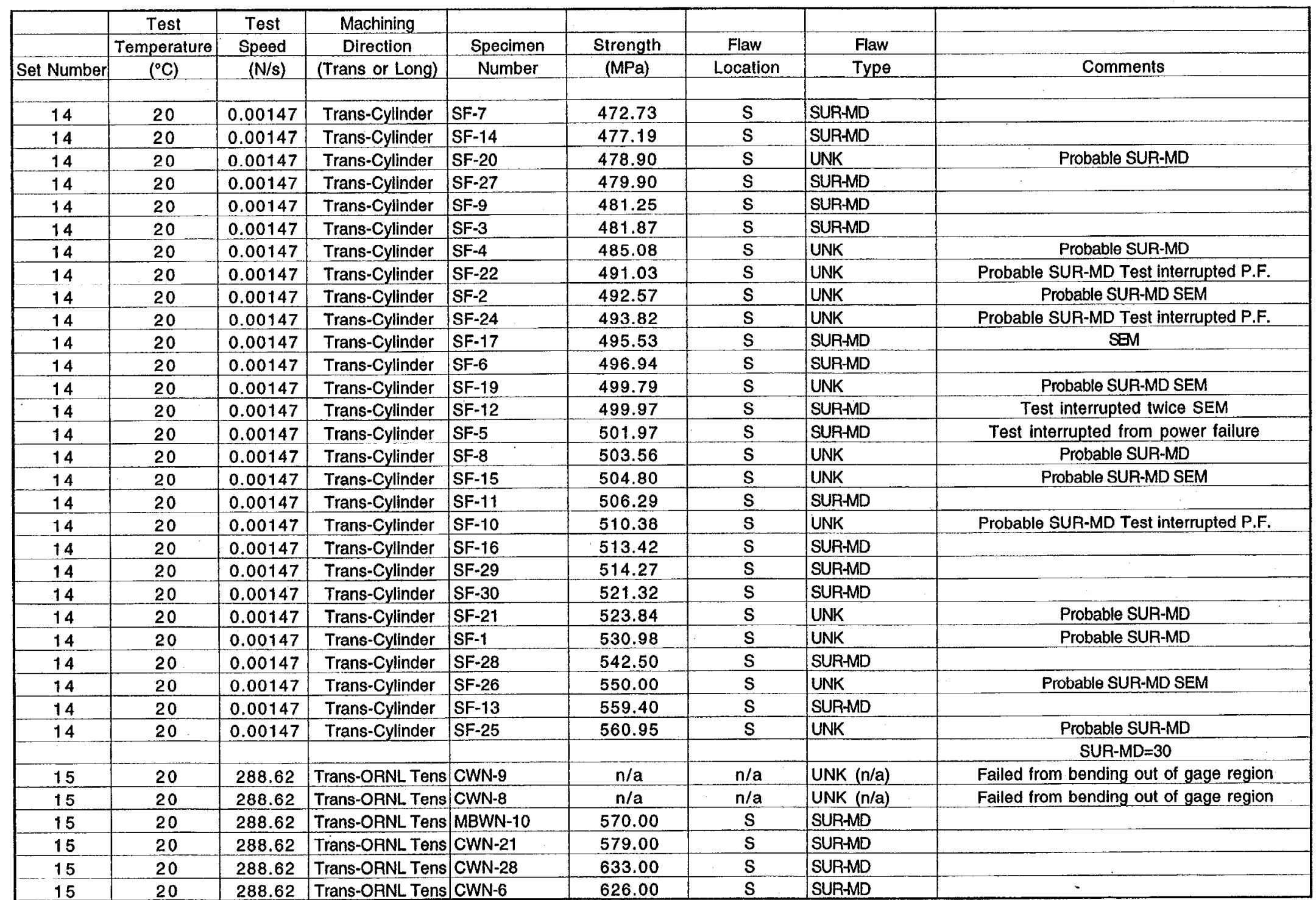




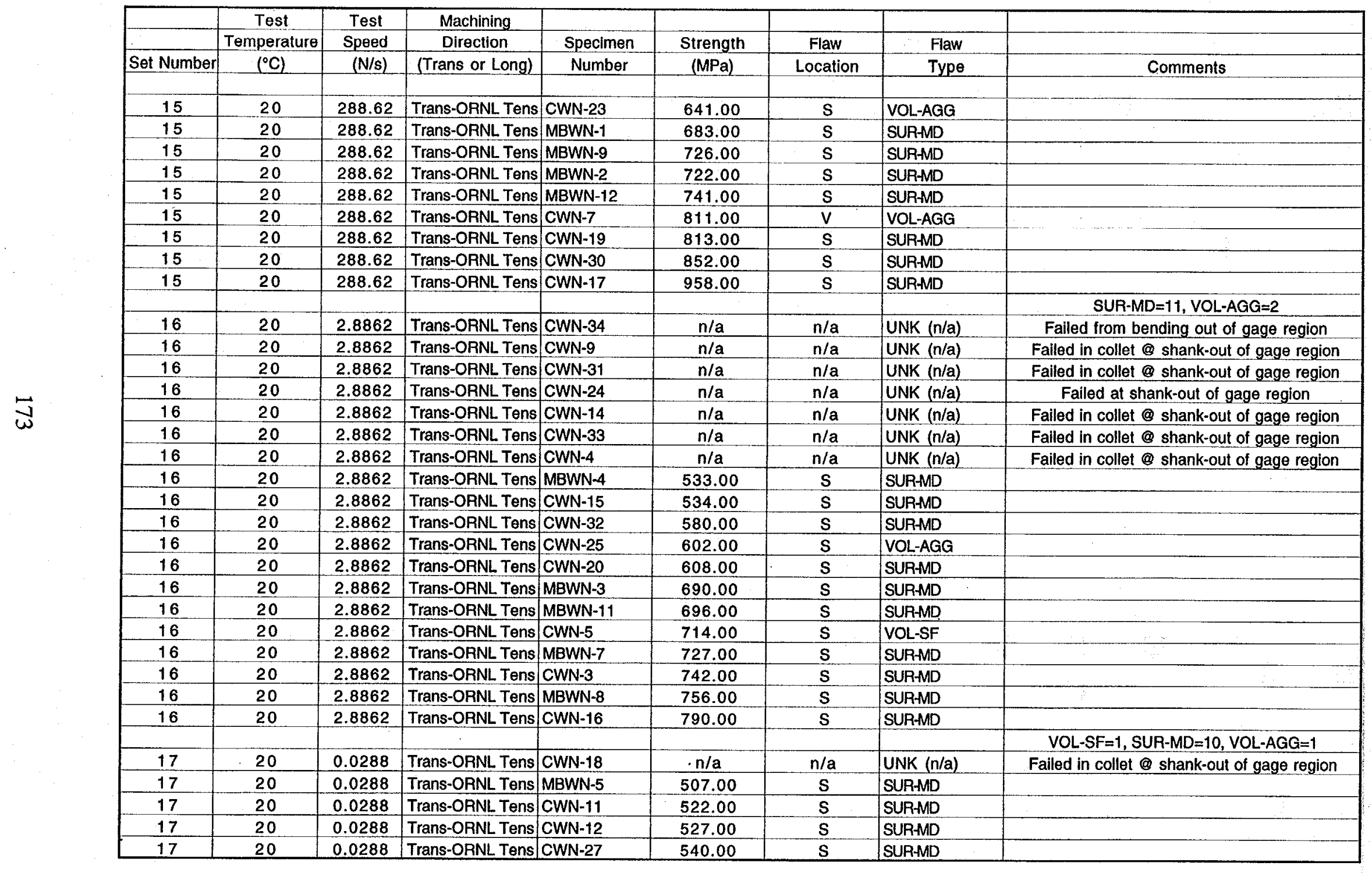




\begin{tabular}{|c|c|c|c|c|c|c|c|c|}
\hline & Test & Test & Machining & & & & & \\
\hline & Temperature & Speed & Direction & Specimen & Strength & Flaw & Flaw & \\
\hline Set Number & $\left({ }^{\circ} \mathrm{C}\right)$ & $(\mathrm{N} / \mathrm{s})$ & (Trans or Long) & Number & $(\mathrm{MPa})$ & Location & Type & Comments \\
\hline & & & & & & & & \\
\hline 17 & 20 & 0.0288 & Trans-ORNL Tens & CWN-1 & 560.00 & $\mathrm{~s}$ & SUR-MD & \\
\hline 17 & 20 & 0.0288 & Trans-ORNL Tens & CWN-2 & 571.00 & $\mathrm{~V}$ & VOL-AGG & \\
\hline 17 & 20 & 0.0288 & Trans-ORNL. Tens & CWN-26 & 588.00 & $\mathbf{s}$ & SUR-MD & \\
\hline 17 & 20 & 0.0288 & Trans-ORNL Tens & CWN-10 & 589.00 & $\mathrm{~S}$ & SUR-MD & \\
\hline 17 & 20 & 0.0288 & Trans-ORNL Tens & MBWN-10 & 619.00 & $\mathrm{~s}$ & SURAMD & \\
\hline 17 & 20 & 0.0288 & Trans-ORNL Tens & MBWN-13 & 634.00 & $S$ & VOL-SF & \\
\hline 17 & 20 & 0.0288 & Trans-ORNL Tens & MBWN- & 653.00 & $\mathrm{~s}$ & SUR-MD & \\
\hline 17 & 20 & 0.0288 & Trans-ORNL Tens & CWN-22 & 728.00 & S & SURMD & \\
\hline & & & & & & & & VOL-SF $=1, S U R-M D=10, V O L-A G G=1$ \\
\hline 18 & 20 & $36^{*}$ & Tran-new valve & $22-32$ & 464.41 & $s$ & VOL-AGG & Max tensile strength shown (see note) \\
\hline 18 & 20 & $36^{*}$ & Tran-new valve & $22-30$ & 515.39 & $\mathrm{~s}$ & SURF-MD & \\
\hline 18 & 20 & $36^{*}$ & Tran-new valve & $22-33$ & 560.69 & $s$ & SURF-MD & \\
\hline 18 & 20 & $36^{*}$ & Tran-new valve & $22-54-B$ & 600.34 & $\mathrm{~s}$ & SURF-MD & \\
\hline 18 & 20 & $36^{*}$ & Tran-new valve & $22 \cdot 37$ & 622.99 & $s$ & SURF-MD & \\
\hline 18 & 20 & $36^{*}$ & Tran-new vaive & $22-31$ & 634.32 & s & VOL-AGG & \\
\hline 18 & 20 & $36^{*}$ & Tran-new valve & $22-41$ & 645.65 & $\mathrm{~s}$ & VOL-SF & \\
\hline 18 & 20 & $36^{*}$ & Tran-new value & $22-67$ & 668.30 & $s$ & SURF-MD & \\
\hline 18 & 20 & $36^{*}$ & Tran-new valve & $22-51$ & 679.63 & S & VOL-SF & \\
\hline 18 & 20 & $36^{*}$ & Tran-new valve & $22-54-A$ & 685.29 & $s$ & VOL-AGG & \\
\hline 18 & 20 & $36^{*}$ & Tran-new valve & $22-62$ & 685.29 & $\mathrm{~s}$ & SURF-MD & \\
\hline 18 & 20 & $36^{*}$ & Tran-new valve & $22-69$ & 690.96 & $\mathrm{~s}$ & SURF-MD & \\
\hline 18 & 20 & $36^{*}$ & Tran-new valve & $22-55$ & 702.28 & $\mathrm{~s}$ & SURF-MD & 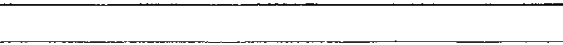 \\
\hline 18 & 20 & $36 *$ & Tran-new valve & $22-39$ & 781.57 & S & SUAF-MD & \\
\hline 18 & 20 & $36^{*}$ & Tran-new valve & $22-36$ & 815.56 & $\mathbf{s}$ & VOL-SF & \\
\hline & & & & & & & & VOL-SF $=3$, SUR-MD $=9$, VOL-AGG $=3$ \\
\hline 19 & 20 & $36^{*}$ & Tran-1000 hrs & 191313397 & 407.78 & V & VOL-SF & Max tensile strength shown (see note) \\
\hline 19 & 20 & $36^{*}$ & Tran-1000 hrs & 191413397 & 413.44 & $\mathrm{~V}$ & VOL-SF & \\
\hline 19 & 20 & $36^{*}$ & Tran-1000 hrs & $19 \mathrm{~B} 13397$ & 458.75 & $\mathrm{~V}$ & VOL-SF & \\
\hline 19 & 20 & $36^{*}$ & Tran-1000 hrs & 191513397 & 492.73 & $\mathrm{~s}$ & VOL-SF & \\
\hline 19 & 20 & $36^{*}$ & Tran-1000 hrs & $19 C 13397$ & 594.68 & v & VOL-SF & . \\
\hline 19 & 20 & $36^{*}$ & Tran-1000 hrs & 19713397 & 634.32 & $\mathrm{~V}$ & VOL-AGG & \\
\hline 19 & 20 & $36^{*}$ & Tran-1000 hrs & $19 \mathrm{E} 13397$ & 713.61 & $s$ & SUPF-MD & \\
\hline 19 & 20 & $36^{*}$ & Tran-1000 hrs & $19 \mathrm{G} 13357$ & 889.18 & $u$ & UNK & Fracture origin mot identified / found \\
\hline & & & & & & & & VOL-SF $=5, S U R-M D=1, V O L-A G G=1, U N K=1$ \\
\hline
\end{tabular}




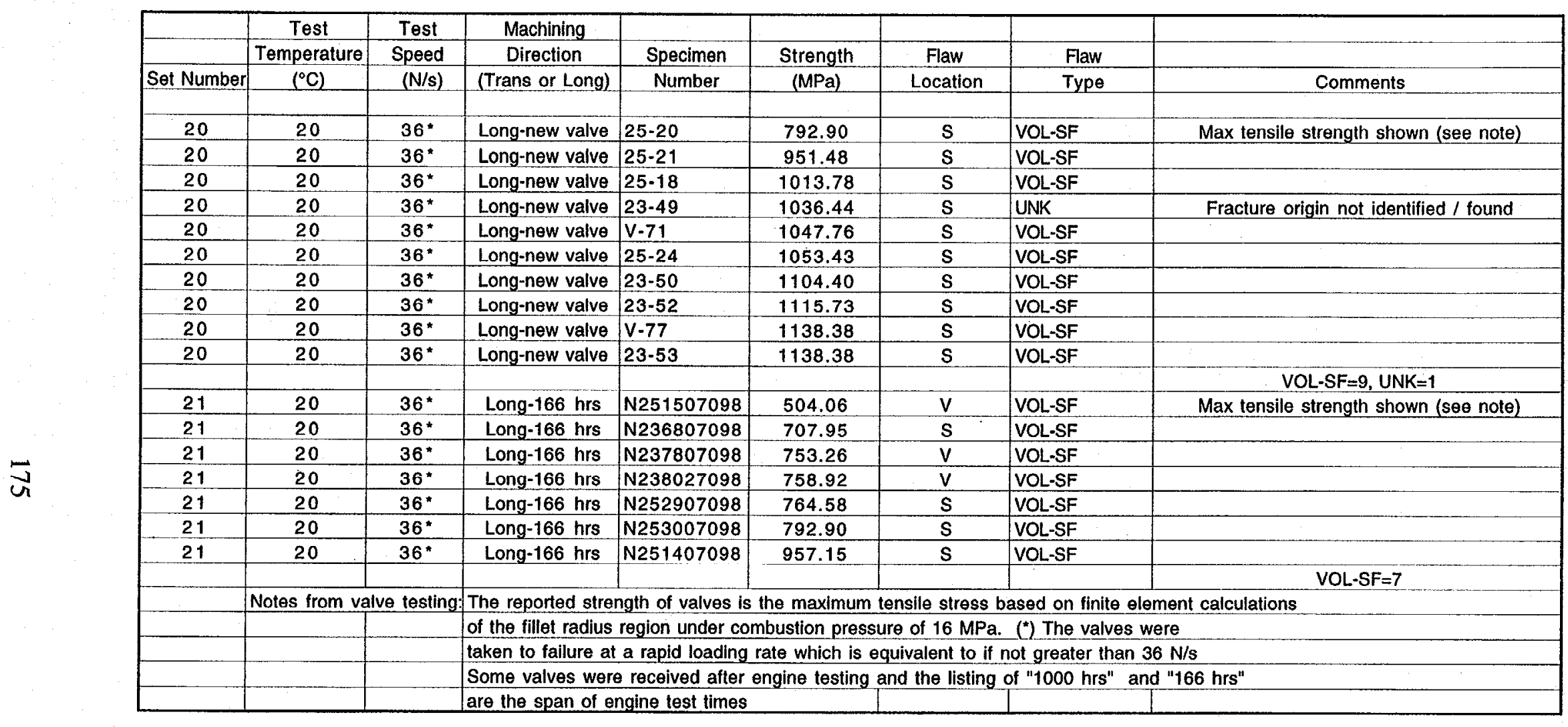




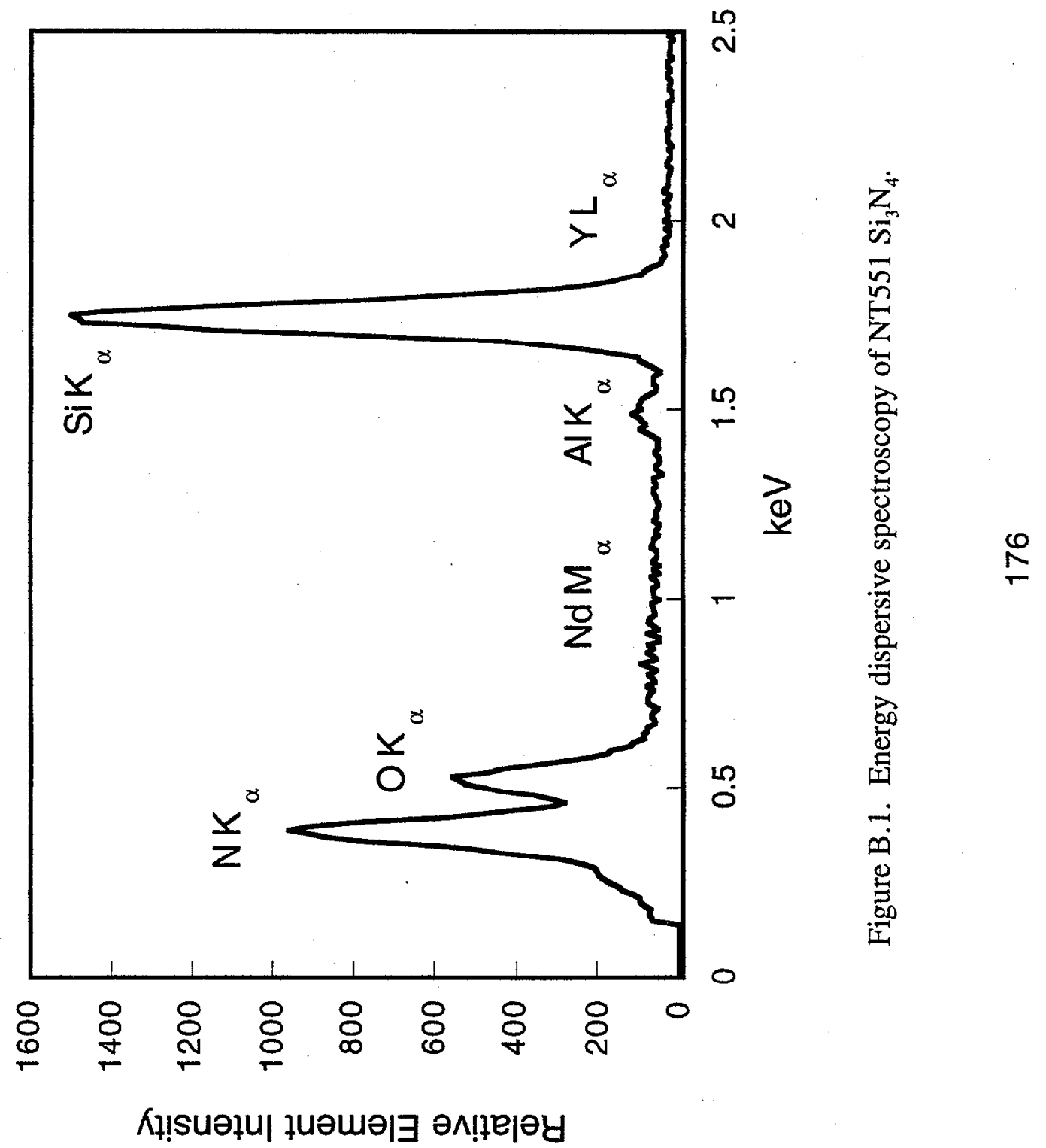




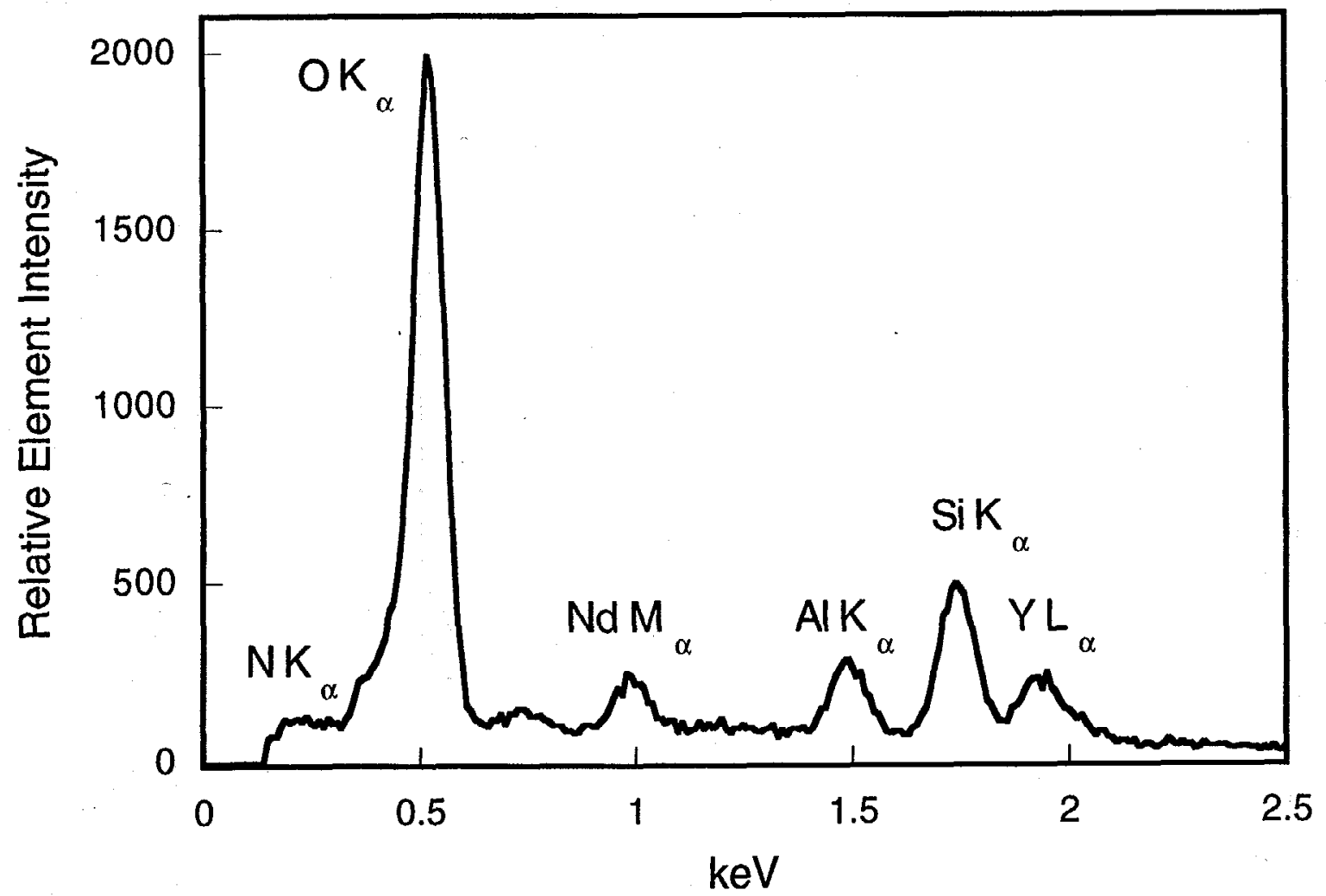

Figure B.2. Energy dispersive spectroscopy identifying $\mathrm{Al}_{2} \mathrm{O}_{3}, \mathrm{Nd}_{2} \mathrm{O}_{3}$, and $\mathrm{Y}_{2} \mathrm{O}_{3}$ compounds as the secondary phase in NT551. This spectrograph was taken from a "non-snowflake" region where no strength-limiting failure mechanisms were identified. 


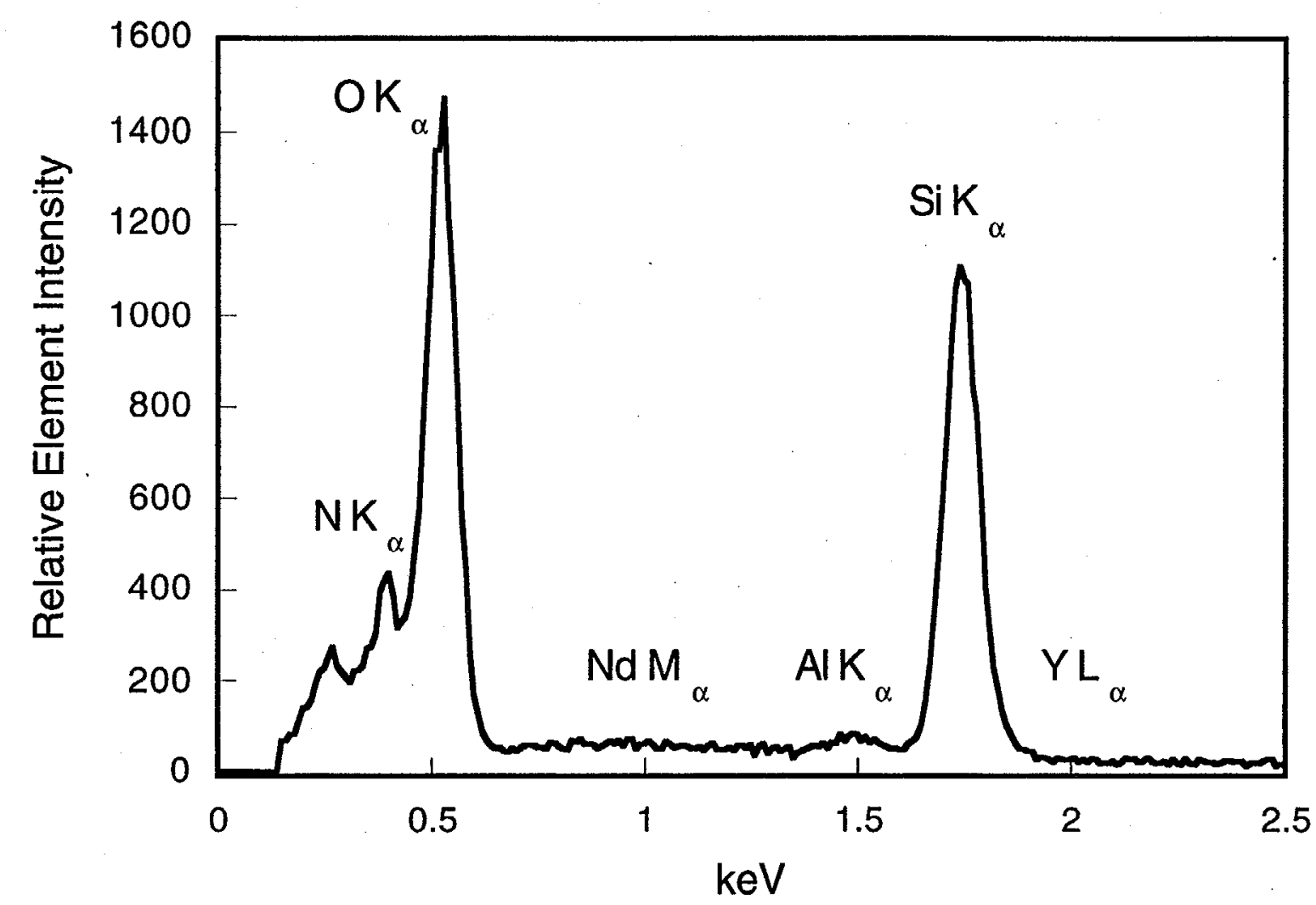

Figure B.3. Energy dispersive spectroscopy identifying $\mathrm{SiO}_{2}$ as the secondary phase found in NT551. This spectrograph was taken from a "snowflake" region and was identified as strength-limiting failure mechanism. 
P. Angelini

4515, MS-6065

R. Battiste

9204-1, MS-8051

P. Becher

4515, MS-6068

P. Blau

4515, MS-6063

E. Bloom

4500S, MS-6132

R. Bradley

4500S, MS-6161

C. Brinkman

4500-S, MS-6154

J. Corum

9204-1, MS-8051

W. Corwin

4500S, MS-6161

M. Ferber

4515, MS-6069

B. Gieseke

4500S, MS-6161

R. Graves

9108, MS-8087
R. Johnson

4515, MS-6066

R. Judkins

4508, MS-6084

M. Karnitz

4515, MS-6065

T. Kirkland

4515, MS-6069

E. Lara-Curzio

4515, MS-6069

H. -T. Lin

4515, MS-6068

S. McSpadden

4515, MS-6069

R. Ott

4515, MS-6063

A. Pasto

4515, MS-6062

M. Rawlins

4500N, MS-6269

J. Roberto

$4500 \mathrm{~N}, \mathrm{MS}-6240$

B. Russell

4515, MS-6062 
A. Schaffhauser

$4500 \mathrm{~N}$, MS-6186

D. Stinton

4515, MS-6063

A. Wereszczak (15)

4515, MS-6069
S. Winslow

4515, MS-6066

R. Ziegler

$4500 \mathrm{~N}, \mathrm{MS}-6188$

Laboratory Records, ORNL-RC (3)

$4500 \mathrm{~N}, \mathrm{MS}-6285$

\section{EXTERNAL DISTRIBUTION}

\section{J. Abboud}

US Advanced Ceramics Association 1600 Wilson Blvd., Suite 1008

Arlington, VA 22209

M. Andrews (5)

U.S. Department of Energy

Albuquerque Operations Office

SASD

P.O. Box 5400

Albuquerque, NM 87185-5400

T. Baker

Waukesha Engine

1000 W. St. Paul Avenue

Waukesha, WI 53188

\section{J. Beatty}

Army Research Laboratory

Attn: AMSRL-WM-M

Aberdeen Proving Ground, MD 21005
B. Boardman

Deere and Company, Technical Center 3300 River Drive

Moline, IL 61265-1792

J. Bougher

Caterpillar, Inc.

Technical Center, Bldg. E

PO Box 1875

Peoria, IL 61656-1875

K. Breder (4)

Norton Company

Higgins Grinding Technology Center

1 New Bond Street, MS 413-201

Worcester, MA 01615-0008

W. Bryzik

US Army Tank Automotive Command

R\&D Center, Propulsion Systems

Warren, MI 48397-5000 
O. Burchette

New Mexico State University

Department of Mechanical Engineering

Box 30001/Dept. 3450

Las Cruces, NM 88003-0001

J. Burnette

Fairbanks Morse Engine Division

701 White Avenue

Beloit, WI 53511-5492

D. Carruthers

Kyocera Industrial Ceramics Corporation 5713 E. Fourth Plain Blvd.

Vancouver, WA 98661

\section{R. Chand}

Morton International Advanced Materials 185 New Boston St.

Woburn, MA 01801

E. Chin

Army Research Laboratory

Attn: AMSRL-WM-M

Aberdeen Proving Ground, MD 21005

W. Chmura

Torrington Company

59 Field Street, PO Box 1008

Torrington, CT 06790-1008

W. Coblenz

DARPA

6 3701 N. Fairfax Drive

Arlington, VA 22203-1714
W. Collins

Saint-Gobain Industrial Ceramics

Norton Advanced Ceramics

Goddard Rd

Northboro, MA 01532-1545

S. Cooper

FEV Engine Technology

4554 Glenmeade Lane

Auburn Hills, MI 48326-1766

G. Crosbie

Ford Motor Company

PO Box 2053, 20000 Rotunda Drive

MD-3182, SRL Building

Dearborn, MI 48121-2053

S. Diamond

US Department of Energy

Office of Heavy Vehicle Technologies

EE-33 Forrestal Building 1000 Independence Avenue SW

Washington, DC 20585

S. Duffy

Cleveland State University

114 Stilwell Hall

Cleveland, $\mathrm{OH} 44115$

V. Duggal

Cummins Engine Company, Inc.

MC 50179, Box 3005

Columbus, IN 47202-3005 
J. Eberhardt

US Department of Energy

Office of Transportation Technologies

EE-33 Forrestal Building

1000 Independence Avenue SW

Washington, DC 20585

J. Edler

Eaton Corporation

26201 Northwestern Highway

PO Box 766

Southfield, MI 48037

G. Graves

University of Dayton Research Institute

Ceramic and Glass Laboratories

300 College Park

Dayton, OH 45469-0172

\section{T. Gross}

US Department of Energy

Office of Transportation Technologies

EE-30 Forrestal Building

1000 Independence Avenue, SW

Washington, DC 20585

D. Haught

US Department of Energy

Office of Industrial Crosscut Tech.

EE-23 Forrestal Building

1000 Independence Avenue, SW

Washington, DC 20585

N. Hakim

Detroit Diesel Corporation

13400 Outer Drive, West

Detroit, MI 48239-4001
P. Hoffman

US Department of Energy

Office of Industrial Technologies

EE-222 Forrestal Building

1000 Independence Avenue, SW

Washington, DC 20585

O. Jadaan

University of Wisconsin - Platteville

General Engineering Department

150 Ottensman Hall

1 University Plaza

Platteville, WI 53818-3099

Y. Kalish

Detroit Diesel Corporation

13400 Outer Drive, West

Detroit, MI 48239-4001

W. King

Mack Truck, Z-41

1999 Pennsylvania Ave

Hagerstown, MD 21740

A. Layne

US Department of Energy

Federal Energy Technology Center

3610 Collins Ferry Rd., P. O. BOX 880

Morgantown, WV 26507-0880

S. Lee

Caterpillar, Inc.

Technical Center, Bldg. E/854

PO Box 1875

Peoria, IL 61656-1875 
R. Licht

Saint-Gobain Industrial Ceramics

Northboro R\&D Center

Goddard Rd

Northboro, MA 01532-1545

J. McCauley

Army Research Laboratory

Attn: AMSRL-WM-M

Aberdeen Proving Ground, MD 21005

B. Mikijelj

Ceradyne, Inc.

3169 Red Hill Avenue

Costa Mesa, CA 92626

N. Nemeth

NASA-John Glenn Research Center

21000 Brookpark Rd., MS 6-1

Cleveland, $\mathrm{OH} 44135$

A. Peralta

Mechanical Engineering Department

SUNY @ Stony Brook

Stony Brook, NY 11794-2300

L. Powers

NASA-John Glenn Research Center

21000 Brookpark Rd., MS 49-7

Cleveland, $\mathrm{OH} 44135$

V. Pujari

Saint-Gobain Industrial Ceramics

( Norton Advanced Ceramics

Goddard Rd

Northboro, MA 01532-1545
G. Quinn

NIST

Bldg. 223, Rm. A-329

Gaithersburg, MD 20899

M. Readey

Caterpillar, Inc.

Technical Center, Bldg. E

PO Box 1875

Peoria, IL 61656-1875

M. Savitz

AlliedSignal Ceramic Components 2525 West $190^{\text {th }}$ St.

Torrance, CA 90509

B. Schenk

AlliedSignal Engines

111 S. $34^{\text {th }}$ St.

PO Box 52181

Phoenix, AZ 85072-2181

J. Swab

Army Research Laboratory

Attn: AMSRL-WM-MC

Aberdeen Proving Ground, MD 21005

J. Thiele

Caterpillar, Inc.

Technical Center, Bldg. E

PO Box 1875

Peoria, IL 61656-1875

R. Tucker

Cooper Energy Services

1401 Sheridan Ave.

Springfield, $\mathrm{OH}$ 45505-2255 
J. Wimmer

AlliedSignal Ceramic Components

2525 West $190^{\text {th }}$ St.

Torrance, CA 90504

E. Wong

Caterpillar Gas Engines

980 Ninth Street, Suite 2200

Sacramento, CA 95814

R. Yeckley

Kennametal Inc.

Corporate Technology Center

PO Box 231

Latrobe, PA 15650

T. Yonushonis

Cummins Engine Company, Inc.

Ceramic Engineering

4412 Mallard Point

Columbus, IN 47201 